S 679

. 88

Copy 1

Deffer

Farming with

Atlas Farm Powder THE SAFEST EXPLOSIVE The Original Farm Powder

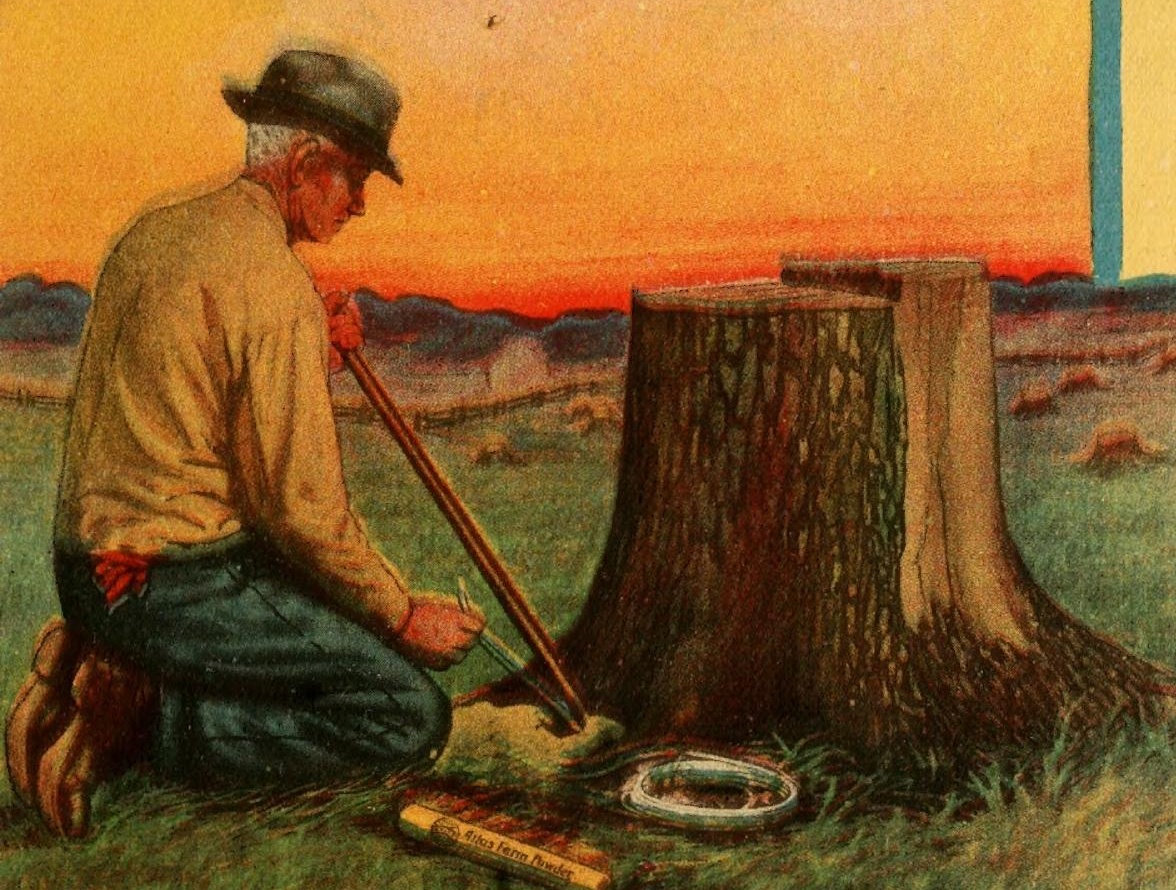


MAY 151919 


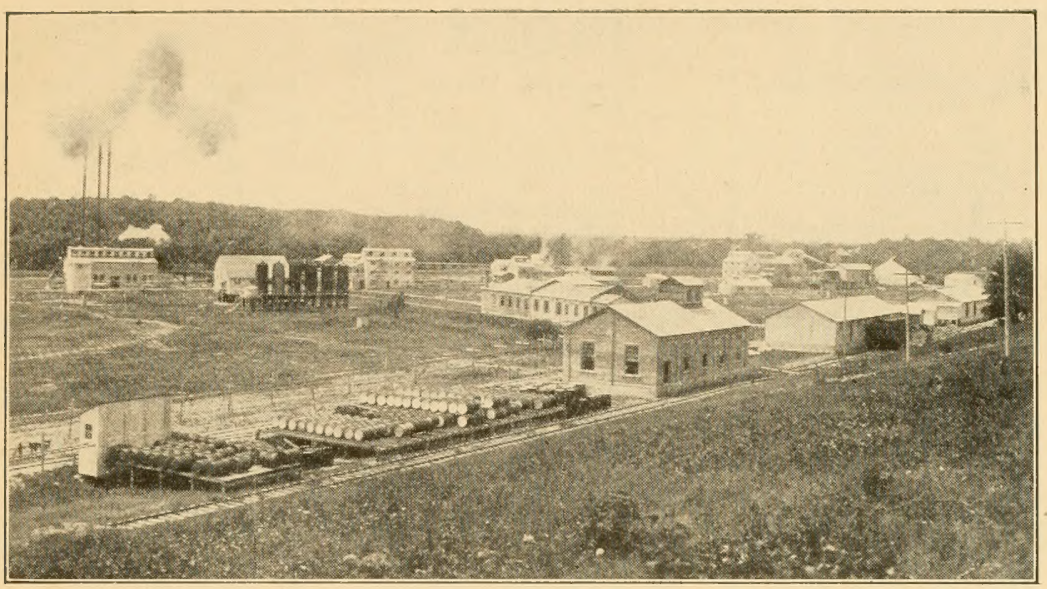

One of the Atlas Powder Company's Fourteen Plants

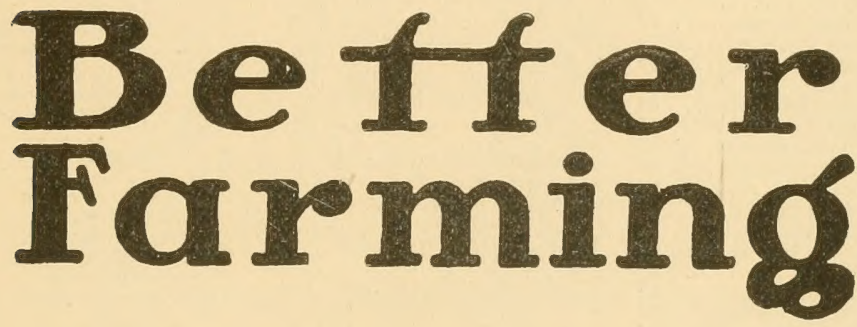

WITH

Atlas Farm Powder
THE SAFEST EXPLosive

The Original Farm Powder

\section{ATLAS POWDER COMPANY}

Home Office, Wilmington, Delaware

Allentown, $\mathrm{Pa}$.

Birmingham, Ala.

Boston, Mass.

Chicago, IIl

Des Moines, Ia.

Houghton, Mich.

Joplin, Mo.
Kansas City, Mo. Knoxville, Tenn.

McAlester, Okla.

Memphis, Tenn.

Nashville, Tenn.

New Orleans, La.

New York, N. Y.
Philadelphia, $\mathrm{Pa}$

Pittsburg, Kan.

Pittsburgh, $\mathrm{Pa}$.

Pottsville, $\mathrm{Pa}$.

St. Louis, Mo.

Wilkes-Barre, $\mathrm{Pa}$. 
ATLAS FARM POWDER, 5-7

ADAPTABILITY........ 6

Cost............... 6

FreEzing...........

HANDLING

HAULING.

PROPERTIES

QUICKNESS OR VIOLFNCE. 5

Sensitiveness........ 6

SHIPPING ........... 6

Stability.......... 6

STORING...........

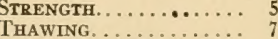

ATLAS BLASTING MA

TERIALS .......... 126

DESCRIPTIV E MATTER . . 126

ILLUSTRATIONS . . . . . . . 127

BLASTING AS A BUSI

NESS. . . . . . . 124

INFORMATION

124

NEED FOR EXPERIENCED

Blasters.......... 124

Profits in Blasting . . . . 124

OULDER REMOVING

BLASTING LEDGES 62-71

BLOCK-HOLING METHOD.. 69

Depth of Holes...... 69

Drilling Holes. ....... 69

Drills............ 69

Loading Charges. . . . . 69

Powder Required..... 70

Priming Charges..... 69

When to Use Block holing Method.

Mudcapping METhod... 65 Kinds of Stones. . . . . . 6 Locating Charges ..... 65 Mudcap, the........ 65 Powder Required ...... 66 Priming and Loading. . . 65 When to Use Mudcap Method

SAFETY FACTOR.

NDERMINING METHOD.. 67

Powder Required..... 68

Priming Charges. . . . . 68

Tamping. 68

When to Use Under-

mining Method.... 67

COST OF STUM P S

B O U L D E R S

SWAMPS........17-20

APPEARANCE........... 19

Clean Cultivation. . . . 17

Gullies............. 18

HaRdPan.............. 18

IDLE LAND... . . . . . . . . 19

INCREASE IN CROPS...... 18

Sale Value . . . . . . . . 19

STUMP LAND . . . . . . . . 19

WEEDS.............. 19

DITCH BLASTING. . . 21-36

ToOLS REQUIRED . . . . . . 21

ELECTRIC F IRING .......

Extra Wide and Deep Ditches.

Finishing

Laying Out Ditch.... 29

Loading and Firing... 28

Making Holes....... 23

Obstructions in Line.. 31

Powder Required..... 25

Spacing of Charges.... 26

Test Blasting......... 27

Wide Ditches........ 30

Cap and Fuse Firing... 31 Extra Wide and Deep

Ditches............. 34

Loading ............ 33

Powder Required..... 33

Spacing of Charges.... 32

Test Blasts......... 33

\section{INDEX}

Transmitted Detonation............ 31

Miscellaneous Points. 34

Comparison of Blasting and Other Methods.

Comparison of Electric and $\mathrm{Cap}$ and Fuse Method.

35

Ditches for Tile Drains 34

Effects of Wind....... 35

Loading Charges Off

Center Line....... 34

Speed Attained....... 3

Straightening Stream

Channels ......... 35

Subsoil Drainage..... 35

FERTILIZATION A N D

TILLAGE. . . . . 104-109

Food Used By Crops. . . 106

How SoIls Gain AvatL-

ABLE FOOD.........107

How SoILs Lose Avail-

ABLE FOOD........... 107

Micro-organismS, BaC-

TERIA . . . . . . . . 108

Nature of SoIL.......... 105

Plant Foods in Soil. . . 106

WATER IN SOIL. . . . . . . 108

FOUNDATIONS, EXCA-

VATING.......... 79

FUSE

126

GROUNDHOGS, KILL-

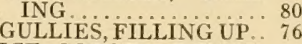

ICE GORGES, REMOV-

ING $\cdots \cdots \cdot \cdots$

LOADING

Ditch Blasting..... 26-33

Stump Blasting.... 47-48

Boulder Blasting... . 66-69

Soil Blasting 0

LOGS, COAL P I L S ,

LOOSENING. ....... 80

POST-HOLE BLASTING 76

PREPARING CHARGES

Cap and Fuse Method 8

Cutting Fuse.

Cutting Sticks of Pow-

der. 10

Fastening Caps......... 10

Materials and Tools... 9

Priming........... 11

Waterproofing......... 12

Electric Firing....... 13

Advantages......... 13

Cutting Sticks of Powder.

Electric Connections... 14

Equipment Required. . 15

Sources of Current.... 14 QUARRYING

ROAD MAKING ...... $72-; 5$

DITCHES AND STREAM

ChanNels

HILLSIDE Grading ..... 72

Loosening Material... 72

Removing Grades...... 73

SHARP CURVES ......... 74

SOIL BLASTING. . . . . 82-109

Blasting Under Trees AND CROPS........ 94

Drainage. .......... 95

Placing Charges....... 95

Condrtion of SoIL ..... 80

Firing Charges . . . . 89,99

LOADING CHARGES .... 89

Making Holes........... 91

Placing Charges....... 91

Powder Required..... 90

SoIL MAPS. ............ 85

SoIl, Why IT Should BE

BLAsted........... 101

Drainage........... 102

Erosion. . . . . . . . . . 101
Mellowing ......... 104 Moisture Supply...... 103 Plant Food .......... 103 Root Penetration.... 102 SoILs, What SoILs to BLAST . . 83 Bound Sand ............ 83 Cemented Gravel. . . . . . 83 Clay ............. 84 Hardpan...........8 83

Light Loams . . . . . . . . 84 Muck ....... 84 Ordinary Sand ....... 84

Spacing Charges...... 92

Field. . . . . . . . . . 93

Gardens........... 93

Home Grounds, Lawns 93 Orchards.......... 93

Tree Planting ......... 96

Cropping and Fertiliz-

ing........... 100

Effects of Blasting... 101

Laying-off Tree Positions........... 97

Pot-holes... . . . . .... 96

Reservoirs of Plant

Spacing of Trees and

Crops.............112

STUMP REMOVING . . 38-59

BORING MachINES...... 53

COMBINATION OF BLAST-

ING AND OTHER METH-

ODS............ 56

DEEP LOADING. . . . . . . . 52

EFFECT OF BLASTING ON

SOIL ..........41,58

Fuse, Lighting ....... 50

Hillside Blasting . . . . . 52

INVESTIGATING STUMPS. . 39

Frozen Ground....... 40

Nature of Ground... 40

Nature of Stumps.....4 42

LoAding Charges...... 48

LOCATING POWDER

Charges......... 43

Making Holes......46,53

Powder Required..... 47

Loose Sand and Gravel 52

Standing Trees, Blast-

ING

STUMP DisposaL...... 58

TAMPING....... 5

Test LoADING.

ToOLS REQUIRED ....... 38

VARIETIES OF STUMPS... 55

When BLASTING is Best 57

TILLAGE AND FERTIL-

ITY RULES. . . 105-124

Cover Crops .......... 114

Alfalfa............115

Clover, Crimson. . . . . . 115

Clover, Sweet. ....... 115

Peas, Cow . . . . . . . . . 115

Peas, Field.......... 115

Rye..............116

Soy Beans..........115

Value of Cover Crops 114

Vetch..............115

Fertilizer Facts. .....120

Adaptation to Crops . 121

Composition.........120

Commercial Fertilizers, Formulæ, etc......122

Lime Facts............. 117

Commercial Limes. ... 118

Necessity of Lime in

Soil Testing Soil for Lime. . . . 117

ManURE Facts......... 118

Amount Required .... 119

Composition..........118

Value of Manure. . . . . 119

Nitrogen Facts . . . . . . 114

Spacing of Crops.......112 


\section{INTRODUCTION}

THE publishers have tried to make this little book much more than a catalog of their commodities and an argument for them. They have tried to see agricultural problems through the eyes of farmers and fruit growers, and to discuss solutions that will work in the field, garden and orchard.

In the first part of the book will be found directions for blasting ditches, stumps, boulders and soil, and for miscellaneous blasting. For the beginner there are the a. b. c.'s of blasting practices; for the expert the latest developments, kinks and shortcuts; and for both beginners and experts, facts about the nature and action of explosives that they should know. Everyone who gets this book will do well to read this matter carefully before attempting to blast, so the work may be done to the best advantage.

In the remainder of the book will be found a discussion of soil treatment and fertilization, with special notes on the relation of soil blasting to each process and each fact brought out. Much material is included, however, which has no direct connection with the deep tillage of soil. It should be found useful by the man who must make the plans for the planting and care of crops of any kind.

We are indebted to the United States Department of Agriculture and to the Experiment Stations and Colleges of various states for information published in bulletins and elsewhere, the sum of which has helped toward a clearer understanding of deep tillage and other matters, as explained on the following pages. A list of publications which may be valuable to anyone interested in studying deeper into soil fertility and other subjects will be furnished on application. We are also indebted to the Institute of Makers of Eyplosives for some of the illustrations used herein.

Gasoline engines now are used successfully in every neighborhood in America. Gasoline operates an engine by means of explosions, and its power is suited to the purpose of an engine. The power or energy obtained in the explosions of Atlas Farm Powder can be used for other farm purposes just as well as that of a gasoline engine for belt and traction purposes.

The energy in farm explosives is always ready. It does not get weary. It does its work quickly and surely-in a fraction of the time required by other methods for doing the same work. The great needs on farms are cheaper power-to replace the men and horses so costly today-and cheaper plant food, as well as more abundant water during dry seasons. Intensive deep tillage is too costly by old methods - yet is a means by which farms may be made to yield heavy profits. The solution of some problems of labor, of tillage, and of fertility lie to a large extent in the intelligent use of explosives. 
Better Farming with Atlas Farm Powder

\section{THINGS THAT MAY BE ACCOMPLISHED WITH POWDER}

Boulder Disposal, including the rolling out of the ground and breaking up of boulders, the reduction of ledges of rock, etc. See page 62 .

Cellar and Wall Excavation, and many other jobs in which dirt must be moved by hand or with plows and scrapers ordinarily. See page 79 .

Deep Tillage, for purposes of improving drainage, increasing moisture storage, bettering root development and making plant food available. Page 82 .

Ditching of different kinds, including small drainage ditches later to be tiled, big permanent open ditches, drainage and boat canals, stream correction, and including help in making some other ditches not to be completed by blasting. See page 21 .

Erosion Prevention, including the prevention of gullying, the filling of gullies already formed, the stopping of ordinary surface washing, and the checking of the leaching away of plant food. See page 77 .

Hardpan Breaking, including the correction of bound or cemented soil or ground of any reasonable depth. Page 83 .

Miscellaneous Work, including loosening frozen coal and logs, ice-jams, killing ground hogs and many other jobs. See page 76 .

Post Hole Making, for fence and 'phone lines or any other purposes. See page 76 .

Road Work, including cutting down of grades, removal of stumps and rocks in the track, cutting down banks, shortening or eliminating curves and many other kinds of work. See page 72 .

Stump and Tree Removing, including complete removal, cracking to hasten decay, to help burning, or in co-operation with pulling, in all soils, North, South, East and West. See page 38 .

Tree Bed Preparation, to secure the benefits listed under deep tillage, together with a reduction in labor and time needed for planting trees right. See page 96. 


\section{POWDER FACTS}

\section{Properties and Appearances}

Atlas Farm Powder and other Atlas Powders are improved forms of dynamite made especially for farm conditions and purposes. They are high explosives, requiring a shock to detonate them, and bear no relation to black blasting powder.

All grades are put up in sticks, the standard size of which is $1 \frac{1}{4}$ inches in diameter and 8 inches long. On page 126 will be found specifications regarding size, weight and packing of Atlas Powders.

The chief qualities or properties which should be investigated by buyers and users of explosives are: Quickness or violence, strength or lifting power, sensitiveness, safety, freezing point, stability, cost, and general adaptability to the work in view.

Quickness or Violence. It will be observed that this quality ranks close to strength-but most users of explosives pay no attention to this important feature. What is meant is just this: An explosive must exert its strength in the manner suited to the material and breakage desired, or results will be poor and costs high. To illustrate, we may consider mudcapping of boulders. When a "slow" explosive is fired on a rock, the expanding gases are permitted to escape by the yielding air almost as fast as they form, hence no great pressure is exerted against the rock. But when a "fast" explosive is so fired, the air cannot yield quick enough, and the gases, accumulating pressure, shatter the stone by exerting immense force on a small area, as from the blow of a heavy sledge.

On the other hand, when a "fast" explosive is fired in soil it forces its way to the surface so quickly that it grinds and pulverizes for a short distance only. The result is usually a pot-hole where the charge laid, and surrounding this are walls of soil that were powdered, then solidly compacted, several inches thick, and beyond that little disturbance. When a "slow" explosive is fired in soil work, the gases accumulate pressure gradually, with the result that cracks are opened for long distances underground, and there is almost as much breakage and crumbling several feet away from the charge as close to it. Pot-holes seldom are formed.

In stump blasting the "fast" explosive (in ordinary heavy soil) tends to tear off roots close to the charge and to reduce them to splinters, while often leaving other roots, or the ends of broken roots, in the ground as tight as ever, and frequently not splitting the body or top of the stump. The "slow" explosive lifts the entire mass of earth containing the roots, shakes and loosens it, and throws upward the roots and trunk in pieces of about the right size for easy handling.

No further illustrations are necessary to bring out the point in question. The fact is, it is very difficult to do good and economical stump blasting in any soil with "fast" explosives, and only those explosives adapted to the purpose should be tried. To an even greater degree good soil blasting is impossible with incorrect explosives. Recognizing these points, we formulated and compounded Atlas Farm Powder, and gave it the exact action required for best and cheapest results under these conditions. Atlas Powder 40 per cent, on the other hand, is made for use where "fast" action is required for any reason, as in mudcapping rock, and sometimes for other work in dry sand.

Strength or Lifting Power. The lifting power or actual strength of an explosive is only a little more important than the quality of speed just described. The percentage figures included in the name and grade designation of an explosive are somewhat misleading. A 60 per cent. powder, although it contains twice as much of the principal explosive material, is NOT twice as strong as 30 per cent., because the 30 per cent. contains nearly twice as much of the other materials which form gases that produce pressure when the powder is exploded. In stump blasting no great amount of difference can be detected between the strength of 40 per cent. explosives and 50 per cent. ex- 
plosives; or between 40 per cent. and 60 per cent. the difference in strength is not as much as might be expected. Differences in violence can be noted plainly, however. If the quantity of high percentage explosives is cut down much below the quantity of the lower percentage powder required for the same work, the efficiency of the charge is lowered.

The strength of Atlas Powders is correct for the work intended. Atlas Farm Powder will lift its proper burden in a most satisfactory manner. No percentage figures are used to describe its speed and strength. It produces the results desired. That is enough.

Sensitiveness in a powder is necessary in order that it may be exploded or detonated. Atlas Farm Powder is made very insensitive in order that it may be safe under all sorts of farm conditions and in the hands of the average farm laborer not experienced in handling explosives. It must be fired with a No. 6 or stronger cap or electric fuze, as anything giving a weaker shock will not detonate it satisfactorily. Atlas Powder 50 per cent. is made more sensitive, and can be fired by transmitted detonation in ditching. Nothing weaker than No. 6 cap or electric fuze should be used to explode it.

Freezing Point of powder is important, since much farm work must be done during cold weather. Ordinary dynamites chill at temperatures of 50 and 55 degrees above zero, and when they are frozen they cannot be fired satisfactorily by any means. (See Thawing, page 7.) Atlas Farm Powder is composed of materials which rate it with the low freezing powders. The convenience, economy, and safety of this feature can hardly be overrated. Atlas Powder which is not of low freezing grade will chill at about 50 degrees. Low Freezing Atlas Powders of all percentages will stand considerable cold without having to be thawed.

Stability of powder in storage or in holes after loading is a quality often overlooked. Atlas Farm Powder will not stand long exposure when loaded under water, or when moisture is permitted to penetrate the cartridge wrappings. While these wrappings are made of a heavy paraffined paper and are further waterproofed, any charge that is loaded in wet work must be fired promptly. Atlas Powder 50 per cent. is also carefully waterproofed, and, in addition, will not be harmed as quickly if water penetrates the stick wrappings.

The Cost of explosives is an important item to consider, since high percentage and low percentage powders generally are used stick for stick. There is no economy in buying expensive powder for use where it is not needed. Atlas Powder 50 per cent. costs more than Atlas Farm Powder, but is necessary for a few special jobs. Atlas Farm Powder, however, can be obtained anywhere for as little money as the cheapest dynamite or ordinary high explosive.

Adaptability of the powder to the work to be done, it has been pointed out, is of great importance. If an explosive is used that is not suited for the purpose, it will fail to accomplish proper results, no matter how expensive it may be or how well it succeeds for some other purpose. This is the respect in which Atlas Farm Powder and Atlas Powder 50 per cent. excel. They are not makeshifts, borrowed from the mining or quarrying industries. They are the original farm powders.

Shipping, Hauling and Storing. The shipping of powder of any kind is governed strictly by Interstate Commerce Commission rules. Any farmer who makes a shipment should consult his freight agent beforehand as to the regulations concerning shipments.

Shipping. A notice of 24 hours is required before delivery of the explosives to the station. Boxes once used to pack explosives must not be used for shipping any commodity again, under penalty of law. Blasting caps or electric fuzes must not be hauled on the same car that carries powder. Shipments of powder, caps or fuzes must be removed from the receiving station within 48 hours after they arrive there. If the consignee fails to take them away, the railroad is forced by law to move or to destroy them.

Delays in iransit of ten are caused by the railroads not having available cars which conform with safety rules or by the necessity of their having to observe other precautions. Buyers of powder, therefore, should allow more time for 
shipments to come through than would be required for ordinary freight.

Hauling of Powder and Caps may be done in any ordinary wagon, though a spring wagon is best. They should not be hauled together, even though the caps are carried at one end of the wagon and the powder at the other. One should be hauled at a later trip. A little straw or a blanket or two in the bottom of a wooden bed will help to ease the jolts. The boxes should not rest on projecting bolt heads or other metal. The wagon should be strong, and in no danger of break-down, and the horses, or engine if truck or car is used, should be kept under perfect control. A runaway might be disastrous. If stops are necessary, the brake should be set firmly and if horses are used they should be held or tied at all times. Dangerous roads and especially railroad crossings should be avoided, or passed over with caution.

Storing of powder and blasting supplies on the farm or orchard often presents a problem, though it need not puzzle one long. A special magazine is desirable only where powder is to be kept on hand all the time. One can be built of brick or stone for a few dollars. We will be glad to furnish plans and specifications without charge.

The only vital requirements are that the explosives be kept from getting too warm, and from getting damp or wet. To keep them dry, the floor of the storage room should be elevated from the ground enough to permit free circulation of air, and of course the roof and sides should be rain- and snow-proof. To keep them cool, there should be a ceiling to shut off the heat from the roof, with provision for free circulation of air in the room with the powder, and free sweep of air between ceiling and roof. An attic or a cellar is a poor place to store them. An old hog pen, chicken pen, wood house or special outhouse built for the purpose is good. In emergencies they may be kept in a barn for a brief time, though we must record a warning against such practice. Even where the insurance policies do not prohibit it, danger from carelessness of children or other persons should do so. Some advantages of magazines are that they are fireproof and bullet-proof, as well as dry and cool.

Caps and electric fuzes may be stored together, but neither should be stored with powder. They should be kept in another room, or another building.

Cautions. A few faults are indulged in so naturally that they may be pointed out. If you find yourself doing any of the prohibited things mentioned below quit them at once. There is danger in them. If you find anyone else doing them, go away from him immediately.

Don't smoke near powder or detonators.

Keep detonators (caps and fuzes) away from powder.

Don't let caps or fuzes fall.

Don't expose powder, caps or fuzes to heat of sun or stove.

Don't expose powder directly to sun.

Don't drill or dig out a misfire.

Don't punch or grind anything against a cap.

Don't handle wet powder. (Water may cause exudation of free nitroglycerin or other explosive ingredients, causing headaches.)

Don't space charges too far apart in transmitted firing. It leads to dangers.

Don't try to fire charges with weak caps or weak fuzes, either those deteriorated from poor storage or that were not strong enough to begin with. Use nothing less than No. 6 strength.

\section{Thawing Explosives. The chilling of explosives is hard} to detect by any signs on the surface of the sticks. Freezing, however, usually can be detected by hardness, either in spots or all over the sticks. In cold weather press the sticks with the thumb. If there is a uniform springy feeling, the chances are that the powder is not frozen. Often the hardness of freezing is accompanied by whitish spots which help to show the frozen condition. The best plan is to be suspicious of any "high freezing" powder whenever the temperature is lower than 50 or 55 degrees, and to take measures to keep it warm or to thaw it in case it is frozen. 
Although frozen powder is generally very insensitive, scraping, cutting, punching or rubbing may set it off, though the same things happening when it was not frozen might have no effect. Therefore sticks that are frozen must be handled carefully, and as little as possible before thawing. On no account should they be broken, punched or cut.

Thawing may be done in the special thawing kettles which we can furnish, or in any of several home devices. The most convenient for small lots of powder is made of two buckets and a blanket. One bucket should be considerably larger than the other, though the small one should be big enough to hold the sticks of powder on their sides. Fill the larger bucket half full of water as warm as the hand can comfortably stand, but no hotter, then set the small bucket containing the powder in it, and cover both with the blanket.

Thawing may be done in a warm room, provided the heat that reaches the powder is absolutely under control, and at no time gets higher than is comfortable for the skin. More heat than this likely will cause deterioration of the powder, and may cause an explosion. The more slowly that powder is thawed, the less liability there is for deterioration. The ideal thawing temperature is between $70^{\circ}$ and $80^{\circ} \mathrm{F}$.

Another effective method of thawing, though a good deal of trouble, is the old-fashioned manure pile. This consist of a large box, with tight lid, buried in fresh horse manure that is heating. Into this larger box, the box of frozen powder should be laid. About 24 hours, at least, is required for thawing.

Freezing and thawing, when the thawing is done at a low temperature (slowly), should not damage powder appreciably. Quick thawing may damage it.

Danger. Powder, and the handling of powder, is not particularly dangerous. Intelligent following of directions is necessary. There is no room or excuse for experimenting, "to see if it will go off or not." Powder represents an enormous force confined in small bulk, and as such should be respected. If the directions in this book are followed, there will be no cause for regret.

Ninety per cent, of all accidents that ever happen in connection with powder are caused in just two ways-by improper thawing of frozen powder, and by failure to follow directions in the handling of misfired charges.
The above paragraph on thawing tells how the one class of accidents may be avoided. We warn repeatedly in this book against approaching misfires before many hours have elapsed. See page 59 for hints regarding misfires.

\section{Preparing Powder Charges (Priming)}

Charges for all kinds of blasting-ditch, stump, soil, boulder and miscellaneous - are prepared in the same way. Here we tell how the powder, caps and fuse, or fuzes (electric detonators), should be arranged, up to the point of loading. Directions for loading for every purpose will be found in each division under the proper subject.

\section{Priming With Cap and Fuse}

Fuse must be cut to the required length, one end must be inserted in a cap, the cap crimped on the fuse, and then inserted in a stick or part of a stick of powder, and the fuse tied to the powder. This primed powder may or may not be enough for the charge. If more is needed, it requires no priming. Detailed discussion of best practices in each operation follow. 
Collecting Materials and Tools. The first thing is to collect in a small box, easily carried, or in a basket, the following:

Blasting caps (keep in original box).

Roll of fuse.

Cap crimper.

Knife-must be sharp.

Twine or string.

Tallow or soap (only when charges go in damp or wet ground). later).

Small wooden punch (see description

Gloves for handling the powder.

These materials should be kept together at all times. If in a box, the box should have a bail or handle so it may be picked up quickly and carried easily. If a basket is used, it should have a piece of blanket or canvas bag in the bottom, or better still, oil cloth or rubber sheet, to keep out dampness from the ground. Another piece of waterproof material should be carried along to cover tha basket from sun and rain or dew. Carry nothing but matches in pockets.

In another basket or box carry along what powder may be required. It is best to keep the caps and the powder in different boxes. When a large number of sticks are needed in the job, carry the powder in its original box and do not disturb the sticks till the actual priming and loading is to be done.

Examine Powder, Fuse and Caps. Powders not made on the low freezing formula will chill or freeze at temperatures lower than $45^{\circ}$ or $50^{\circ} \mathrm{F}$., as noted fully on page 6 . In this condition they should not be handled unnecessarily, and the sticks must not be cut or broken. To do any of these things is dangerous. If cold powder shows hardness when pressed with the thumb, the indications are that it is frozen, and it must be thawed as directed

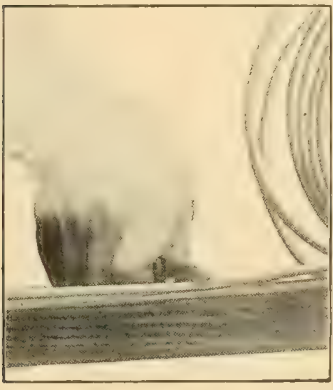

In cutting fuse from roll use a sharp knife.

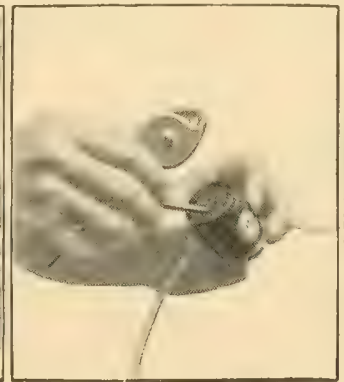

Taking ore cap carefully from box.

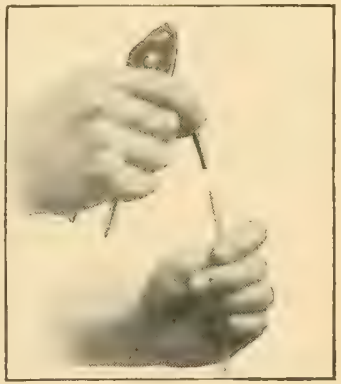

Inserting fresh end of fuse in cap.

on page 7 before anything more is done with it. Atlas Powder 50 per cent., of the straight nitroglycerin type used in transmitted ditch blasting, is an example of the kind which must be kept warmer than 50 degrees when fired. Atlas Farm Powder very seldom freezes.

Inspect the blasting caps. They should be tright and cle $\mathrm{n}$, and will be in first class condition if they have been stored in a dry place. If they have been in the damp, they may be weak. If the shells are corroded, or there is any reason to think that dampness has weakened them, it will save you time and money to secure a fresh stock.

Fuse also should be inspected. If it has been damaged by excessive heat or by dampness in storage, it will not carry the fire properly. Don't unroll fuse when cold. Warm it first. Cut off a foot or more and fire it without a cap. It should burn at the rate of 2 or 3 feet to the minute, though it may burn much slower than this and still be serviceable provided it burns regularly and surely. If the test shows that it will not carry the fire down reliably, a new fuse should be provided. 
Cutting Fuse. The shortest length needed for any charge is enough to reach to the mouth of the hole. If the hole is short it is necessary for the blaster to assure himself a sufficient time to reach a place of safety. Three feet of fuse, if it reaches to the mouth of the hole, is generally enough.

The end of the fuse which is to go in the cap must be cut off clean, with no dragging sides or threads.

A sharp knife does this best, with the fuse laid on the edge of box or on a

block of wood. For cutting only a few dozen fuses, a pocket knife is as good as anything; for hundreds, a sharp hatchet is better.

The cut should be made square.

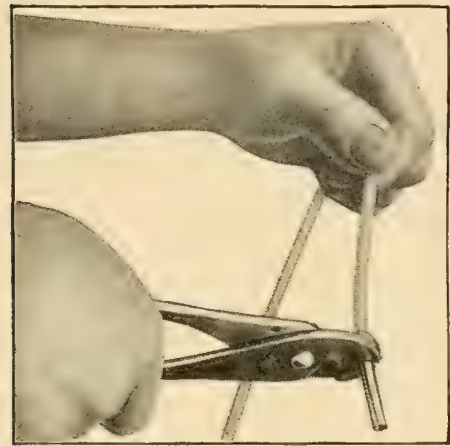

In fastening cap to fuse the best method is to use our special crimping tool. (See page 127.)

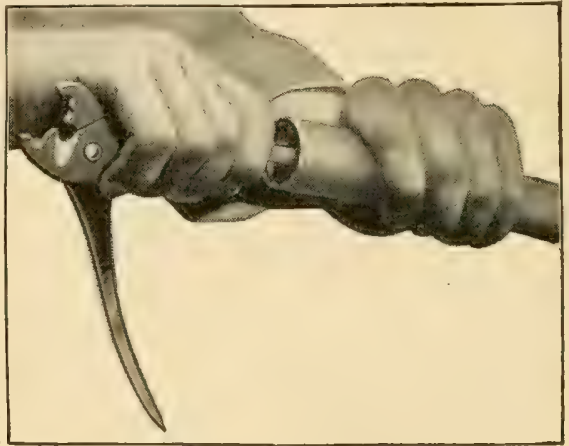

With a wooden pincer or the cap crimper punch a hole 2 inches deep straight down in the end of the cartridge.

Cutting Sticks of Powder. There is no danger in cutting unfrozen sticks of Atlas powders. 'The paper wrappings may be slit with a sharp knife with entire safety, and the sticks divided into as many pieces as required in order to get the right charge.

To cut a stick, apply the edge of a sharp knife to the paper and roll the stick under the knife, as a length of green twig or limb might be rolled in cutting the bark. It is not necessary to cut entirely through any of the powder. The stick then will break in two almost under its own weight. To cut the wrappings lengthways, in order to make the sticks swell to fill holes snugly, draw the knife from end to end. (See illustration page 48.)

Be sure, in cutting sticks of powder, that they are not frozen. There may be danger in cutting and there is in breaking frozen sticks of powder. After they are thawed they may be cut with the same degree of safety as before freezing.

Fastening on Cap. When the fuse is cut, hold it point up and slowly slip on a blasting cap. Be sure there is no dirt in the cap. Let the cap rest gently on the fuse, of its own weight, and be sure to avoid twisting or pressing the end of the fuse against the detonating material in the bottom of the cap. It is bad practice to stick the end of fuse or any other small object into a cap in order to get it out of the little tin box that caps are packed in. The box should be tilted on the hand till several caps slide partly out, then one can be picked up with the fingers.

When the fuse is fully inserted in the cap, it must be fastened there by crimping $\frac{1}{8}$ to $\frac{1}{4}$ inch from the open end of the cap; never near the end that contains the charge. The cap crimper we supply does this to perfection, making a joint that is almost water-tight, but still not gripping the fuse so tightly as to shut off the 
Powder Facts-Properties and Appearances

spark. Every job should have its cap crimper, and if there is much blasting to do, an extra one should be kept in reserve, in case the first is lost.

This is the only safe and secure way to attach a cap to the fuse. The practice of using a knife or the teeth for this purpose invites disaster, and is to be strictly condemned. The charge contained in a detonator is a very powerful high explosive, very sensitive to shock, heat or spark. Should a cap explode while you are holding it the loss of your hand might result.

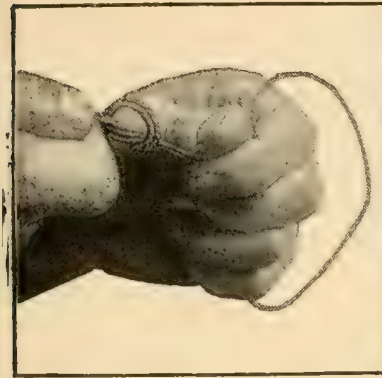

Tie together the ends of a piece Make a clove-hitch around of thin twine.

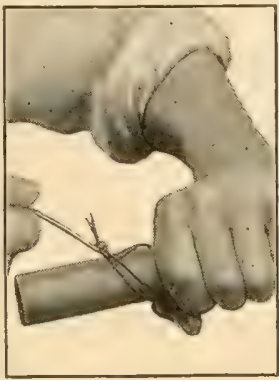

the cartridge with the twine.

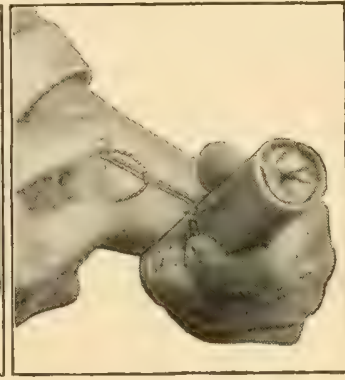

Put another clove-hitch in the other end of the twine.

\section{Putting Cap and Powder Together, Called "Prim-} ing." The cap, with the fuse crimped to it, may go in to the side of the stick of powder or into the end. We recommend the end method, as when properly done it eliminates the possibility of the

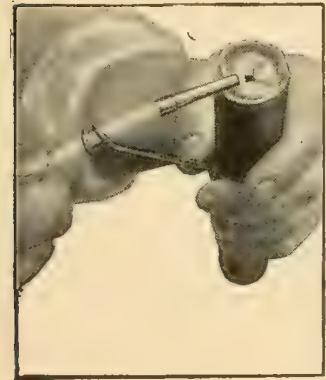

Put the cap and fuse through this hitch and into the bole in the cartridge.

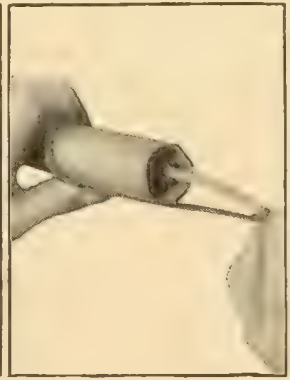

Then slide the hitch up until the cap is pushed down tight and the fuse is bent as in the illustration.

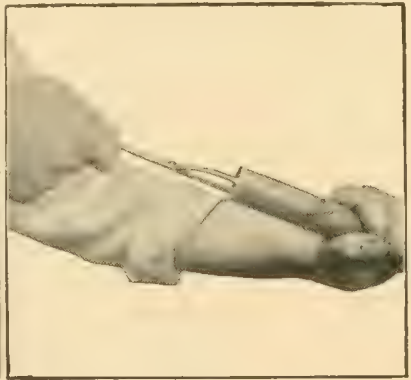

Pull everything tight; in wet work plaster a little Kapseal or tallow around the top of the cap after it has been crimped to the fuse and also around the fuse where it enters the cartridge.

cap being pulled or pushed out of the cartridge during loading or tamping.

This method of priming is shown clearly in the illustrations on this and the preceding page.

The hole in the cartridge should be made so that the cap may lie as near directly up and down in the charge as possible. If made slanting or across the stick the detonation may be poor on account of the way the cap points.

The hole should be no larger and not much deeper than the cap, but it must be large enough to let the cap in easily. Cap crimpers usually have one handle pointed so it can be used for punching these holes in sticks of powder, but we recommend that a wood punch be used instead. The chief reason is that the 
nitroglycerin which gets on the crimper handle may help to cause headache if later pressed against the skin of the hand. A punch can be whittled out of any piece of solid wood in a few minutes. It should be 5 or 6 inches long, to give a good hold.

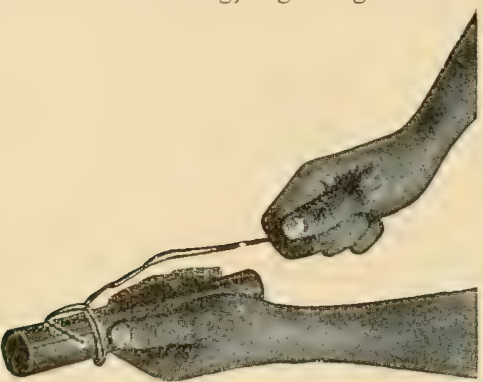

Bad method of fastening wires. It is better to tie them.

When the hole is made, insert the cap. It should go in until it is all covered, but not deep enough to let a part of the fuse touch the powder. (If fuse touches powder, the latter, instead of exploding, may catch fire and burn like oil, giving forth poisonous gases.)

Note carefully in the illustrations how the cap and fuse is secured to the powder by hitching a piece of strong twine around the cartridge and fastening it to the fuse.

The important point is to see that the pull upon the fuse comes against the cartridge and that the cap cannot be pulled out of its proper position.

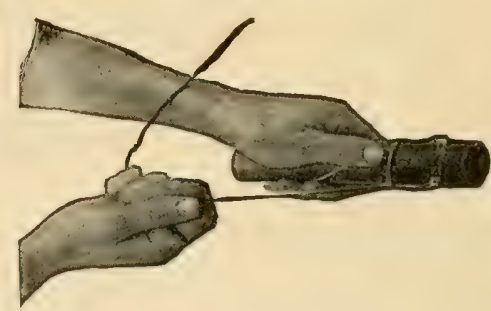

Bad position of cap in stick, and of cap

Under no circumstances pass the fuse through the stick, loop it about the stick or double it back from the lower end at the time of loading. Improper priming may shoot the charges, but there are sure to be misfires. Besides that, many charges which seem to go off alright in reality develop but part of their full strength owing to some of the powder burning.

Waterproofing. Whenever charges are to be loaded in wet ground or where water will cover them, the joint of cap and fuse must be made watertight. It is also well to waterproof the break in the paper wrapping of the stick where the cap is inserted.
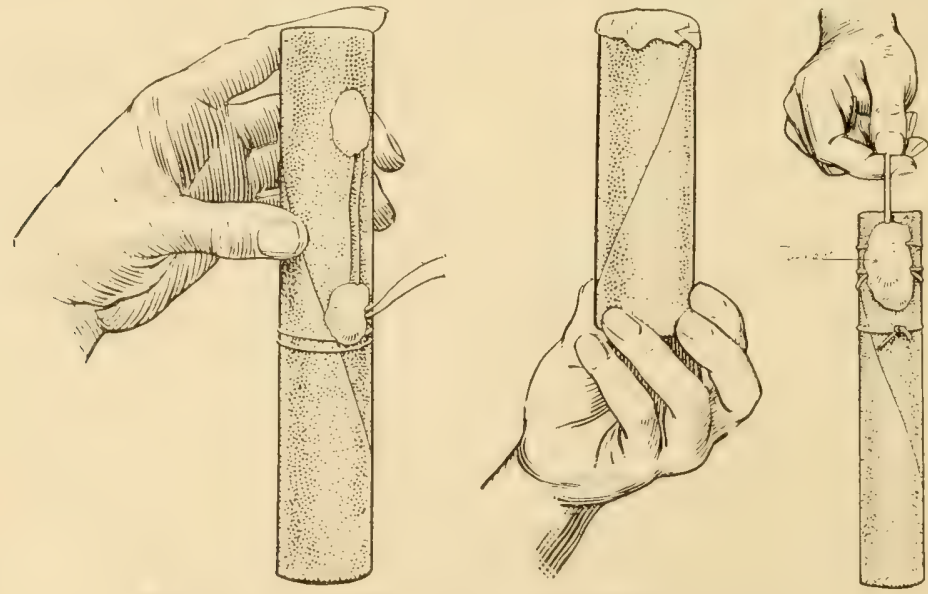

Waterproofed (tallowed) sticks ready for loading in wet holes.

'Tallow is an excellent material for the purpose. Where it is not to be had, or costs too much, soap or even stiff blue or yellow clay may be used. Axle grease and heavy lubricating greases and oils should not be used as they often soften the covering, ruining the powder train inside the fuse.

This primed powder is ready for loading, as described under the different headings. 


\title{
Electric Blasting
}

The firing of charges of powder by electricity is not a new practice. It has been in use for many years. Only of late years, however, have small, easily carried, reliable machines for making the current been on the market at low prices. Many blasters do not make use of electric firing for stump, boulder, ditch and other agricultural blasting, even though it often has many advantages.

\section{Priming Charges for Electric Firing}

\author{
(Priming with Fuzes or Electric Detonators)
}

The essential points in priming for electric firing are identical with the priming with cap and fuse. The fuze must be inserted in the stick of the powder in the same way, and the leading wires must be fastened to it.

A fuze is a cap with two insulated copper wires attached to it. Cap and wires cannot be separated. The wires, unlike fuse, may touch the powder without setting it on fire. To fasten them to sticks they may be tied with the clove hitch as fuse is tied, or they may be looped through and around sticks. The only precautions necessary are to see that no half-hitches are taken, and that no pull whatever comes on the cap, either endways or sideways. The pull should come on the stick directly from the wires at the point where they are tied.

A little slack between where they are tied and where they enter the cap is good. If the wires are half-hitched or crossed under pressure they may rub off their insulation and short circuit, causing a misfire.

\section{The Advantages of Electric Firing are (a) the in-} stantaneous exploding of the charges when the blasting machine is worked, and (b) the simultaneous exploding of two or more charges.

Blasts can be timed at will just as a gun is fired at the instant desired. The operator can save his own time as well as that of his helpers. They do not need to wait for many minutes after retiring to a safe distance. Along a road or near buildings there is no necessity for sending out guards or for holding up traffic or movement about the vicinity for an indefinite time. Fuse sometimes hangs fire, and when it does all workmen and others must stay away from the place for hours to be safe. We have seen instances where, on account of a misfire with fuse, it was necessary either for someone to assume grave risks or for work and traffic to be tied up for several hours at an expense of many dollars. When the firing is electric the blaster can order his helpers back, watch till the road is vacant for a few minutes, and then fire the blast in an instant. After he has pushed down the handle of the blasting machine and the charge has exploded all danger will be over. 
In case a damaged fuze does cause a misfire and the charge fails to explode when the handle of the machine is pushed down, the wires should be disconnected from the blasting machine, and after 15 minutes' wait an investigation to locate the trouble can be made. Traffic or movement in the vicinity can then be resumed. Perhaps half of all the accidents that occur with blasting materials are caused by carelessness in approaching unexploded blasts where fuse hangs fire. The probability of this kind of accident is eliminated after waiting 15 minutes when firing electrically. We cannot emphasize too strongly the convenience and safety of this method.

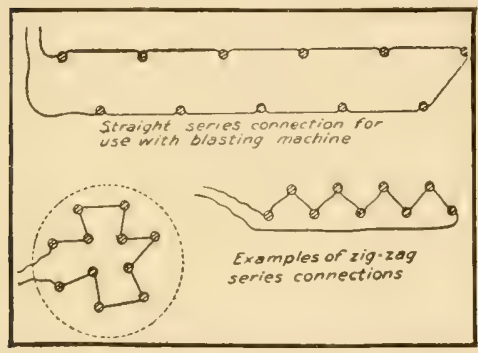

Ways of connecting charges for electric firing.

The total number of misfires is greatly reduced by electric firing, since most of the usual causes which prevail with cap and fuse firing, such as damp and damaged fuse or caps, are eliminated. The electric method should always be used when firing under water.

Aside from transmitted (propagated) firing in ditch blasting, the electric method is the only practicable way there is of securing simultaneous explosions of two or more charges of powder. Transmitted ditch blasting can be relied on only when the ground is warm and full of water, but electric ditch blasting is successful at all times. In most stump removing the firing of two or more charges together is a great help, since the blasts can be hitched short to the load. Instead of placing one big charge under the middle of the stump and irusting that the roots will hang together till all are pulled loose, a light charge can be placed under each main root to pull it loose, and another can be placed under the trunk to split it, then all can be fired together. Less powder is required, holes in the ground are smaller, roots are pulled out cleaner, and broken better.

The loading of these several small charges is easier than of one big charge because straight bar or auger holes usually are big enough without enlarging. When one big charge is used, there is difficulty in getting it concentrated at the right spot. The use of several light charges under the main roots is the only practicable way of getting out big longrooted stumps such as pine and some oaks, particularly if they are green and in loose soil.

In rock blasting the use of two or more charges on large boulders, and in ledges, often makes good work possible where single charges would fail to accomplish satisfactory results except at an extremely high cost. Thus two undermine blasts under a long rock often will break it well from end to end; or a mudcap and an undermine charge can be made to break thick boulders almost impossible to reduce in any other way at reasonable expense.

Electric firing saves work, saves time, saves powder, does away with most of the usual dangers and makes blasting more convenient. Finally, results are better than are possible with fuse and cap firing.

\section{Sources of Electric Current for Firing. Atlas electric} blasting machines are small enough to be carried anywhere, and cost so little that anyone who has blasting to do can afford one of a size suitable for his work. They are made to produce exactly the right voltage and amperage of current needed for firing the designated number of electric fuzes.

These machines are small wood or metal boxes containing generators and other necessary mechanism. The Altas Little Giant machine will fire up to 4 charges at once, measures $8 \frac{1}{4}$ by $5 \frac{3}{4}$ by $3 \frac{3}{4}$ inches and weighs $4 \frac{1}{2}$ pounds. The No. 2 United States Standard machine will fire up to 10 charges, measures $7 \frac{1}{2}$ by $8 \frac{3}{4}$ by 14 inches and weighs 15 pounds. The No. 3 machine will fire up to 30 charges, measures $7 \frac{1}{2}$ by $9 \frac{3}{4}$ by $18 \frac{3}{4}$ inches and weighs 25 pounds. Larger machines that will fire up to 150 charges can be furnished. Instructions for operating and caring for the machines are furnished with them. 
Dry batteries can be used to fire $a$ single charge at a time, provided the cells are fresh and full strength. Wet batteries and generators of automobiles can be used to fire single charges in emer- gencies. Electric light or power current can be made to fire almost any number of charges. IVrite us and our Service Division will give you full directions.

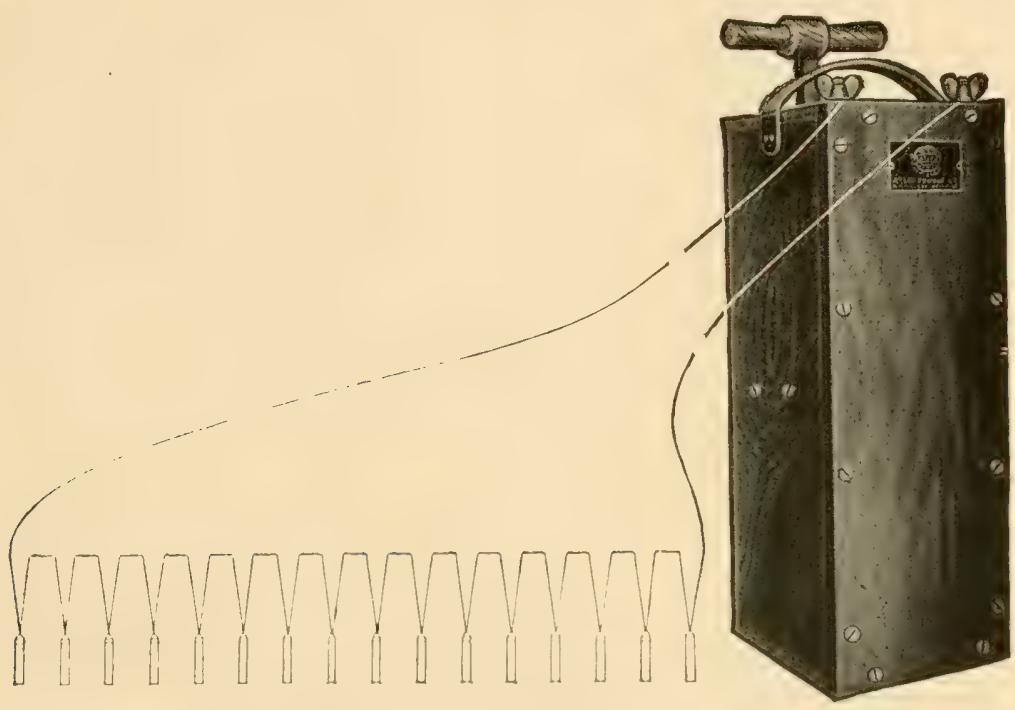

Connecting the wiring with blasting machine. The electric fuze wires are connected together in series and the outside wires of the end fuzes are connected to the leading wires and these to the blasting machine.

Equipment Required. Besides the electric blasting machine or connection from a power or light wire, electric firing requires fuzes, connecting wire and leading wire. The latter is heavy insulated copper wire intended for carrying the current from the machine to the blast, and should be long enough to permit the operator to stand in a safe place-usually 250 feet from blast is considered safe. Duplex leading wire, the most convenient form, has two insulated strands of wire wrapped together in a third insulating layer to form one big strand. Single leading wire must be doubled for use, hence must be twice as long as double wire.

Connecting wire is lighter copper wire than that just described, and has thinner insulation. It is intended for connecting in a series the different fuzes in the charges making up a blast.
Electric fuzes are copper shells or tubes, like blasting caps, made with two wires 4 feet long attached to them. The pictures on page 127 show all these articles plainly.

Wire Connections for Electric Firing. When a blasting machine is used, which will be for nine-tenths of all electric firing, the charges must be connected together in a series. That is, each charge must be connected to another one, and so on until all to be fired together are joined, with one fuze wire on each end free. These two free wires are then connected to the leading wires, and the other end of the leading wires to the blasting machine. 


\section{Better Farming with Atlas Farm Powder}

When light or power current is used, write us, giving its voltage and amperage and the number of charges to be fired. A rough sketch of the proposed blast will permit our experts to give the exact information you will find necessary.

To make a good electrical connection between wires, twist them together for an inch or two as shown in the pictures. Do not loop them. The right-angle twist made by holding the two ends of wires almost parallel, and then twisting them together with thumb and finger, probably is quicker accomplished.

Poor connections will cut down the amount of current that reaches the fuzes, and may cause misfires. All proper care should be used to secure firm contact between freshly scraped surfaces of wire ends. Dirt or corrosion on the wires, and loose twisting, will cause trouble. Bare places on wires must be kept off the ground. Breaks in the leading wire should be repaired by twisting together the ends, then soldering them, and finally wrapping with insulating tape.

The manner of preparing charges (priming) with fuzes is explained on pages 10 and 11 , and the loading for each different purpose is explained under the proper division.

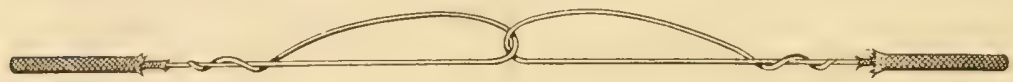

A very bad connection - a cause of misfires.

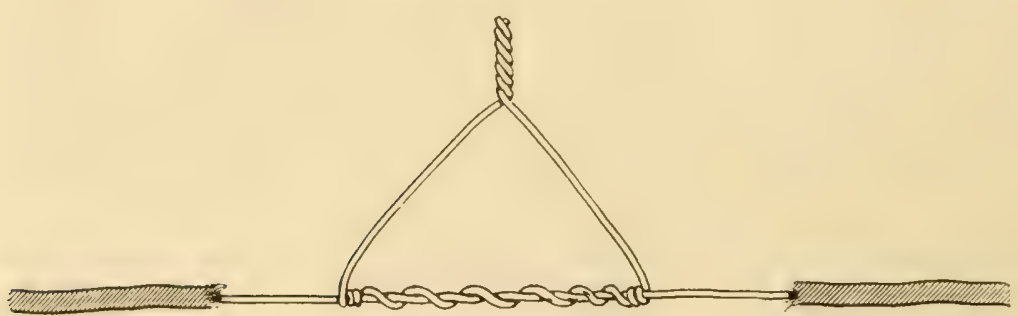

Good connection for electric fuze wires.

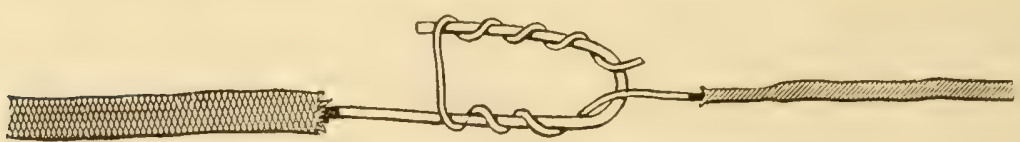

Good connection for small fuze wires and large leading wire. 


\section{THE COST OF STUMPS, BOULDERS AND SWAMPS}

Clean Cultivation. The gain in time, convenience and cconomy of cultivation perhaps is the greatest single factor in the cleaning up of obstructions from cultivated land. To understand its importance, it is necessary to contrast present farm conditions with those prevailing twenty to thirty years ago. At that time a man could be hired to do farm work for a dollar a day, and the time he lost dodging stumps and stones and turning out for swamps did not amount to so much. All these things are changed now. Wages of farm helpers average nearer three dollars a day than one dollar, and minutes wasted mean dollars in extra expense and loss by the end of the season.

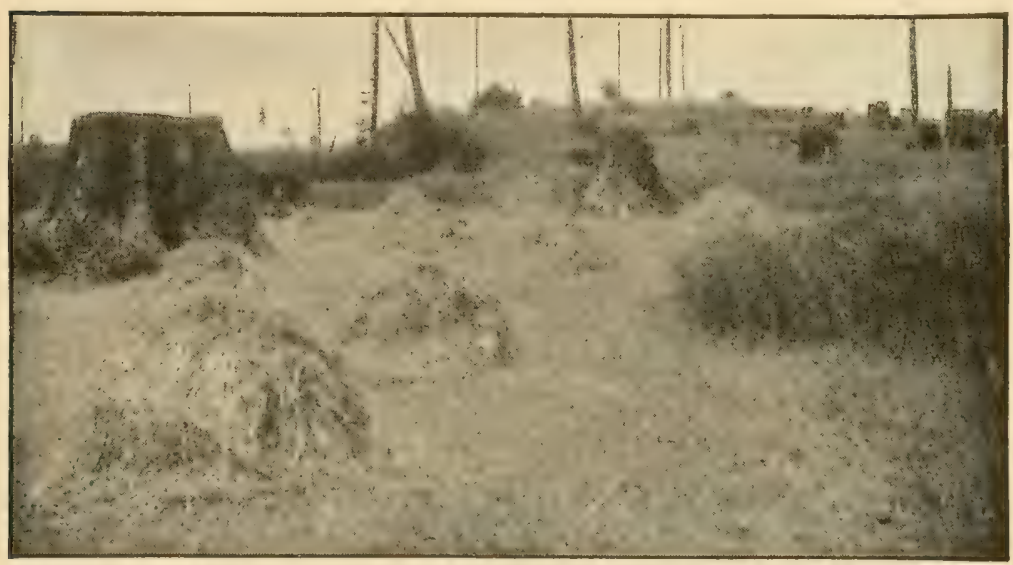

When the stumps are as thick as the hay piles or the shocks of wheat or oats or corn there is something the matter with the farm system. They are boarders who never pay bills.

Wide-cutting implements must be used in order to increase the amount of work that one man can accomplish, but they cannot be used with satisfaction where stumps and boulders interfere. Engine tools especially are helpless where there are obstructions. They cut wide tracks and cover big acreage in a day when every thing goes right, but they are delayed unreasonably and are in need of repairs continually where there are stumps and stones. Plowing with engines is impracticable when anything remains in the ground to catch the points. If shares do not break, beams will bend. Harrows get torn up in a short time if the teeth can catch any obstructions. Mowers and binders will stand no hard hauling when the guards are against obstructions. Something has to give way when an engine is checked, and it is the implement or machine more often than the root or rock.

Every farmer who thinks of hitching anything stronger than two horses to his implements must plan to take out every obstruction before he begins work. Only after that job is done can he realize the economies possible through speedy operation. It will not do to wait until the machinery strikes, with the idea of marking the place. To take that course usually means the buying of enough repairs to pay for the clearing.

Almost all engines are helpless in soft ground. Wet spots in fields can- 
not be tolerated when engine tools are used, for turning out is not always practicable. The machines must go straight through to be economical. If this reason is not enough for eliminating the excess moisture, another can be seen by looking over a cornfield for water on the surface. While they are naturally rich in plant food elements, they are in such a condition that none of their fertility is available.

Swamp Land nearly always is productive when the surplus water is drained off. Under present conditions in the agri-

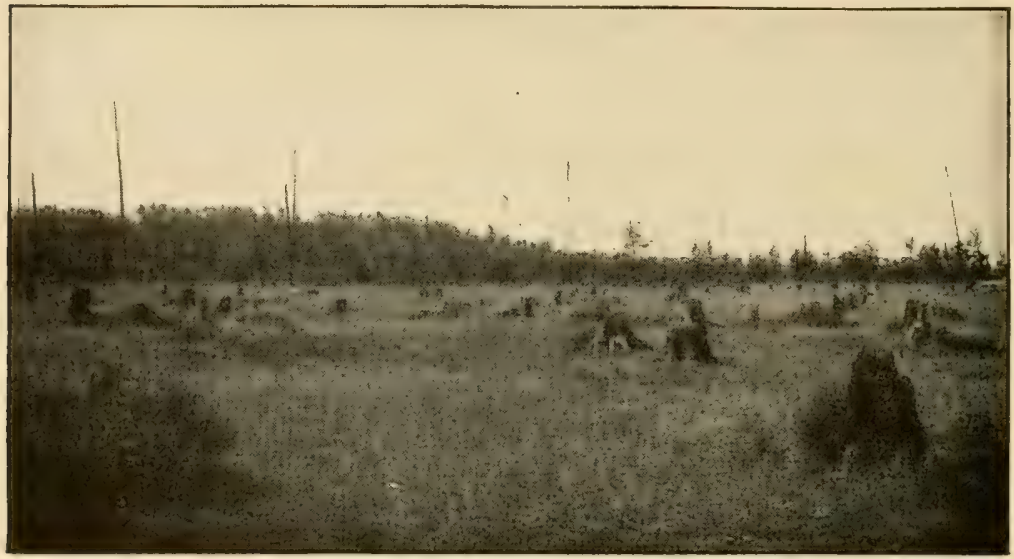

This is idle, tax-eating land. The use of Atlas Farm Powder will turn this into a fertile, cropproducing field.

instance, those parts that are not well drained. The plants may be 6 feet high on the dry parts of the field, dark green and thrifty, but on the wet areas they grow 2 or 3 feet high only, and are of a sickly yellow color.

Gullies are almost as bad as swamps to cut large fields into pieces that must be farmed separately. To turn teams or engines often is to lose time. Patch farming is poor business. Crop costs can be kept down only where the work can be done to the best possible advantage, which means on long, regular-shaped pieces of ground.

Gullies represent a loss from erosion as well as in the way just described. The most fertile of the surface soil from the ground adjoining the actual ditch is likely to be carried away in every gully, and this action continues as long as the gully remains. The loss of further soil and fertility can be stopped and economy and convenience of tillage of the entire fie'd can be secured by filling up the gullies and preventing their rewashing through proper blasting.

Hardpan and clay spots, like wet spots, can be located easily by observing crops any time after they have begun to grow. In dry weather they dry out so much as to stunt plants; in wet weather they hold cultural world, it will pay for the necessary ditching within two or three years at most. For the first ten years after draining, such land is like newly cleared ground-full of a store of fertility that will produce big crops with little cultivation and fertilizing. It does not need to be rested or rotated, and may be kept in money crops every season for some time.

The Net Increase in Crop Yield which the removal of obstructions will bring about is startling to anyone who has not investigated.

To bring out the point, it may be said that almost every stump and large stone will prevent crops from growing on almost a square rod of ground. In terms of corn, a stump displaces 8 to 15 hills. Ten stumps or stones to the acre, therefore, occupy about 6 per cent. of the total crop space and decrease the yield by that much. Since the net profit often is only about 10 per cent. of a crop, an increase of 6 per cent. produced by taking out these few obstructions is equal to an increase of 60 per cent. in the net profit. To carry the idea still further, if the crop income from the obstructed land has been $\$ 1000$ a year it just as easily should be $\$ 1600$ a year after the ground is cleaned up. 
The gain always should be compared to the net that is left after cost of cultivation and other items are deducted, for these costs are rather decreased than increased on the clean land. An extra profit of $\$ 5$ or $\$ 10$ an acre does not look like much when compared to the total sales price of a crop worth $\$ 40$ to $\$ 80$ an acre, but it has a different appearance and meaning when compared with the part of the $\$ 40$ or $\$ 80$ that stays in the bank after the costs are paid.

Idle Land of any kind owned in connection with productive land, whether it lies in the shape of a square rod here and there occupied by a stump or in blocks of many acres that are too wet to farm, makes a drain on the income from the whole property. The owner should not forget that such land is not self-supporting. To make this land productive results in a double gain - the expense is cut off and a profit added.

Weeds, Appearance, Sale Value Other ways in which stumps, boulders and swamps cost money are in the weeds they harbor, the ragged appearance of the farm which they are largely responsible for, and to a certain extent a general lowering of the level of farm life. Obstructed farms rent for less money than clean farms. They alwavs sell for less- and the decrease is out of all proportion to the cost of cleaning up the waste land.

A powerful factor in keeping farm boys satisfied is to make their homes and their working surroundings attractive and convenient. Boys seldom leave clean farms for town life; it is the stony, stumpy, swampy place that goes against boy nature. Stumps and swamps harbor all sorts of vermin, including the moles and mice that destroy an enormous volume of grain and grass the country over.

The cost of removing a stump is small compared to the cost of keeping it, and the same statement applies to stones and swamps. The damage these obstructions do can be measured in a dozen different ways. It is by no means confined to loss of time in cultivating and of crops that might grow on the ground occupied, though these items each year amount to enough to pay for the cleaning up in a great many cases. The gain must be a matter of personal experience to be appreciated. It can be illustrated by what one Missouri man said about the removal of some stumps on his farm. "It cost $\$ 80$ to take the stumps off my farm," he told us, "but I wouldn't take $\$ 500$ and have them back again."

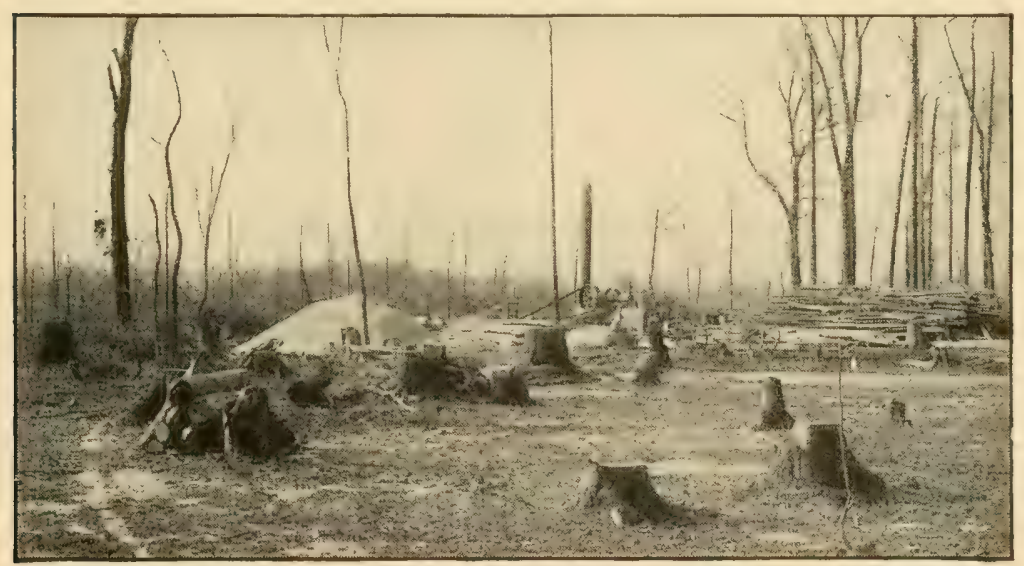

The next process is stump. removal. The quickest, cheapest method is blasting. The use of Atlas Farm Powder will also imorove the soil by deepening the top soil and permitting it to supply abundant plant food readily.

\section{Glearing and Draining Land This Year}

The present conditions have brought about changes in the business of farming which react particularly to the advantage of the owner of idle, cut-over and logged-off land which is capable of producing staple or special crops. The demand for food materials has so increased that prices have reached a very profitable level.

A few years ago the margin of profit in farming was slim and land clearing hardly paid. This is proven by the 


\section{Better Farming with Atlas Farm Powder}

census figures as shown by the average farm income. Today the difference between the cost and selling price of a bushel or ton of farm produce is in most lines two to twenty times what it used to be. There is money waiting for every body who has crops to sell.

Agricultural conditions the world over are such that this condition is going to continue for at least ten years. The world's surplus of foods and feeds has been consumed and destroyed. The owner of rich, new ground has a very great advantage, because he can secure yields, and big ones at that, with the application of less hours of labor to each acre. His cost therefore is low at a time when prices are high.

The sum of the matter is that considerable stump land and swamp land can be cleared and drained this year at a cost that will be returned by one or two vears' crops; then will follow many seasons in which just as high prices

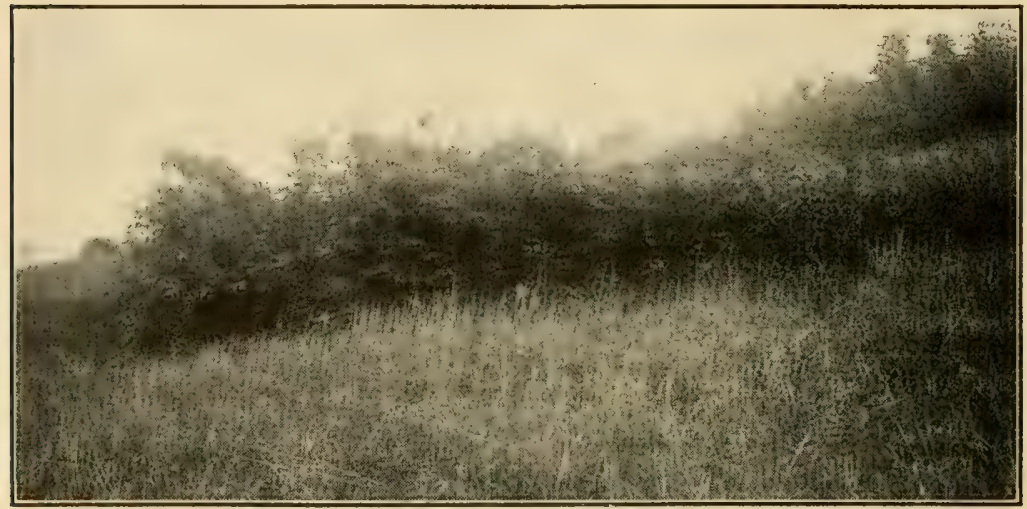

A stump in a field "kills' a square rod of ground, or more. The roots may not take up so much space, but the weeds and briars that grow about it do.

farming business of Europe has become disorganized to the extent that fifteen to twenty millions of people over there who formerly were fed with European home products must now depend on America for their daily bread. If American farmers do not produce the food, those people do not eat.

As it affects unimproved fertile land, this situation brings about an unusual opportunity. New ground has a store of fertility which makes it yield enormous crops with little cultivation and fertilization or rotation compared to the requirements of old land. As soon as the stumps are off, or the surplus water drained away, new ground can be planted to money crops, and for several seasons can be kept in them without rest or interruption. The virgin fertility can be capitalized at a high rate under the present conditions of the world markets. If leftidle for ten years it may not bring nearly so much.

Thelabor market is such that intensive tillage methods, the only economical methods of inducing heavy yields on old ground, are now too costly over a large part of the country. The should prevail, and during this period yields should be as high as at first. The clearing itself takes some extra labor and money, but by avoiding the use of many men, using instead labor-saving materials and methods, it can be accomplished before time to put out crops next spring. Money put into clearing is a sound and high paying investment at present.

Swamp and stump land is not salable nor will it pay its current expenses, let alone interest on the money invested in it. Its pasture value is a delusion as long as the obstructions remain. It cannot support many stumps or much swamp area, and many animals at the same time. The way to market such land, either by sale or in its products, is to clear it up. If $i t$ is worth $\$ 5$ an acre with the stumps on it, it should be worth $\$ 30$ to $\$ 100$ an acre without them. The clearing is not to be regarded as an expense or an item chargeable to upkeep, but as an investment to the same extent as the purchase of additional clean land would be.

The next ten years will see agricultural conditions the like of which have not been known for a long time. 


\section{BETTER BLASTING OF DITCHES}

The making of ditches by blasting is easier even than stump blasting. The details can be learned quickly by blaster or workmen, little equipment is required, and the results are very satisfactory. The advantages of the blasting method, and its place in comparison with other methods, will not be discussed at this point (see page 35 ), but we want briefly to describe the appearance of a blasted channel.

The ditches made with one line of holes usually measure about twice as wide at the extreme top or surface of the ground as they are deep. In gravelly and sandy ground the sides slope in-
A properly blasted ditch looks like a shovel or machine job without the piles of excavated dirt along the sides. Anyone who has not seen a blasted ditch can have no idea of the characteristic

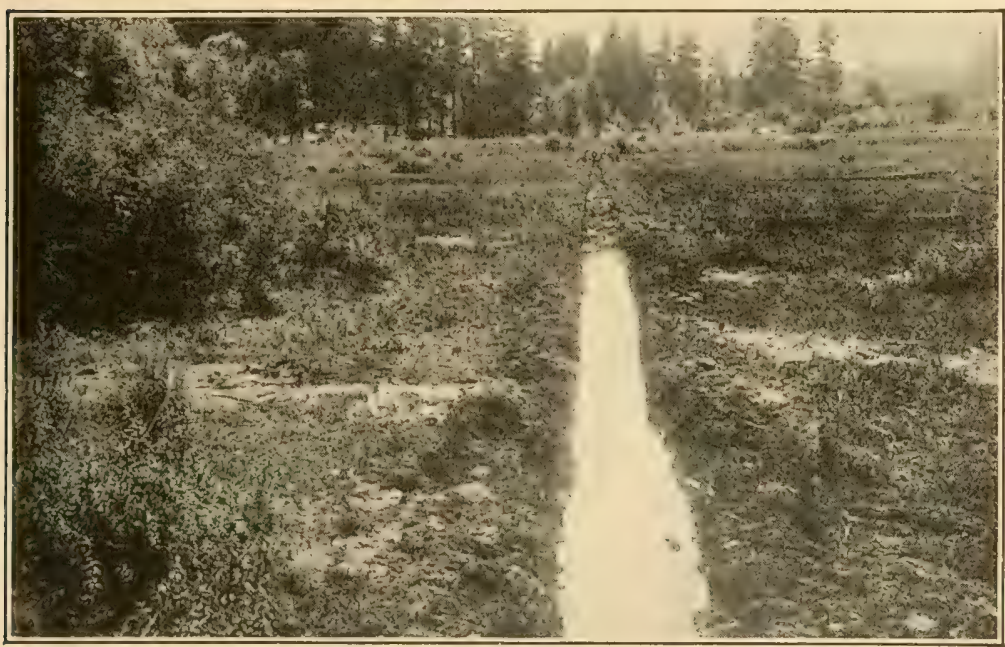

The result of cutting sod and roots along ditch sides before blasting. Shovel, axe or hayknife may be used. A man can cut a rod along one side in about two minutes. After the sides are cut a proper blast will scoop out the dirt clean, but leave the earth outside the cuts undisturbed and firm.

ward at the bottom to a point, or are within a foot of one another, making ditches of the shape of a low, flat $V$. In loams and clays the bottoms of blasted single-line channels usually are two or three feet wide, and somewhat rounded, and the sides are steep, making $\bigcup$. shaped ditches. The slope of the sides as left by the blasts usually is just about what it must be permanently in the particular soil.

The sides are clean cut and the bottoms are smooth. Usually there is some loose dirt on both bottoms and sides, but since this is even all along, with no ridges, the water flow is not obstructed. true lines or finished appearance. One or two properly loaded experimental ditch blasts should convince the man who hesitates to adopt this method.

Tools Required. The box or basket of small items necessary for priming charges, described on page 9, should be the first thing provided. In addition the following are needed:

A sharp-pointed crowbar 4 or 5 feet long, about $1 \frac{1}{2}$ inches in diameter, preferably round.

A wood tamping rod 5 or 6 feet long and $1 \frac{3}{8}$ or $1 \frac{1}{4}$ inches in diameter.

A soil auger, such as is described and pictured on page 39. 
A sledge is needed to drive and loosen the bar in dry or stony ground.

Two or more posts or stakes.

String, like mason's line, about 200 feet long.

Gloves, for handling the powder.
If the ground is clean, nothing more will be required.

Where there is a stiff sod, a longhandled shovel or spade, and perhaps a hay knife, will be needed. Where trees or brush grow on the ditch line an axe also may be useful.

\section{Two Methods of Firing Ditch Blasts}

One is the electrical system; the other the cap and fuse system in connection with transmitted firing. We will describe each separately.

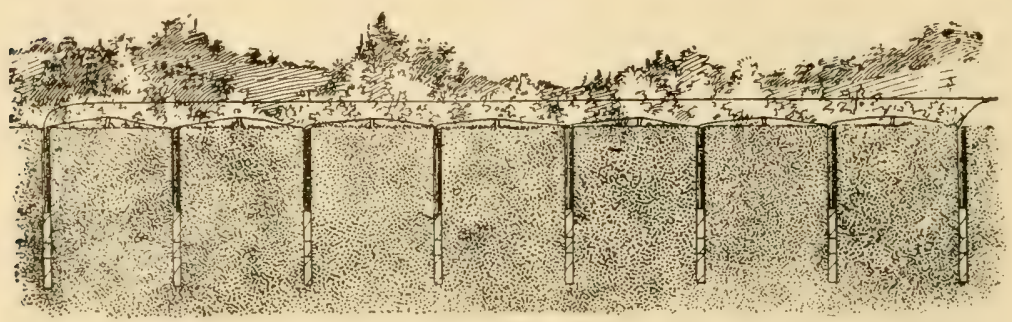

Typical loading of ditch blast for straight electrical firing of all charges for $3 \frac{1^{\prime}}{2} \mathbf{7}^{\prime}$ ditch.

\section{Ditching when Powder is Fired Electrically}

The conditions necessary to consider are the kind of powder to be used, the depth and spacing of the charges in the ground, the amount of powder to the charge, the nature of the soil, amount of water present, temperature of air and ground, and obstructions

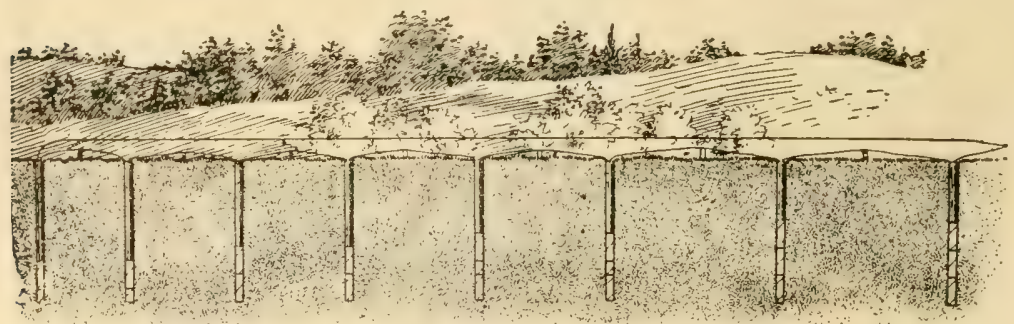

Typical lest loading to determine proper charges and placing of explosives for electrical firing. Note the variations in spacing between holes as well as in amount of explosives used. (See page 27.)

such as boulders, ledges of rock, stumps, sod and roots of trees and brush.

Under this method each charge is primed with an electric fuze. The work should proceed as follows:

Collect tools, powder and supplies, including an electric blasting machine and necessary wires.

Lay off ditch with stakes and line.

Cut sod and roots, if any, at ditch sides, with plow, hay knife, spade or axe.

Make holes in ground for test shot with bar or ainger at proper distances and to right depths. 
Load charges and connect wires.

See that people and animals are at a safe distance, then fire.

Inspect results, and throw out any big stones, roots or sods.

Make more holes after calculating best loading from test, and repeat other operations.

Soils. Ditches can be blasted through any kind and condition of ground except dry sand.

The most economical blasting can be done in ground full of water to the surface or to within a few inches of the surface, and of a heavy, tenacious nature, such as clay. Muck blasts out easily. The least economical blasting is done in sandy and other loose soils, particularly when they contain no standing water. Clay is a little harder to blast out when dry or only damp than when soaked. If convenient, it pays to wait for wet weather before ditch blasting is started. When ground is full of water the cost is less in several ways.

The nature of the soil from the standpoint of the possibility of making a ditch by blasting (except dry sand) is not important, though it is important from the standpoint of the manner of loading. Thus a blaster or farmer can proceed to almost any field (except a sandy one in dry condition), and, after determining the size and location of the charges required, will have no difficulty in shooting out the channel. But if the nature of the soil changes half way across the field, as, for instance, if one-half is watersoaked and the other is not, or if one part is clay and the other gravel, the manner of loading must be re-determined for the new conditions.

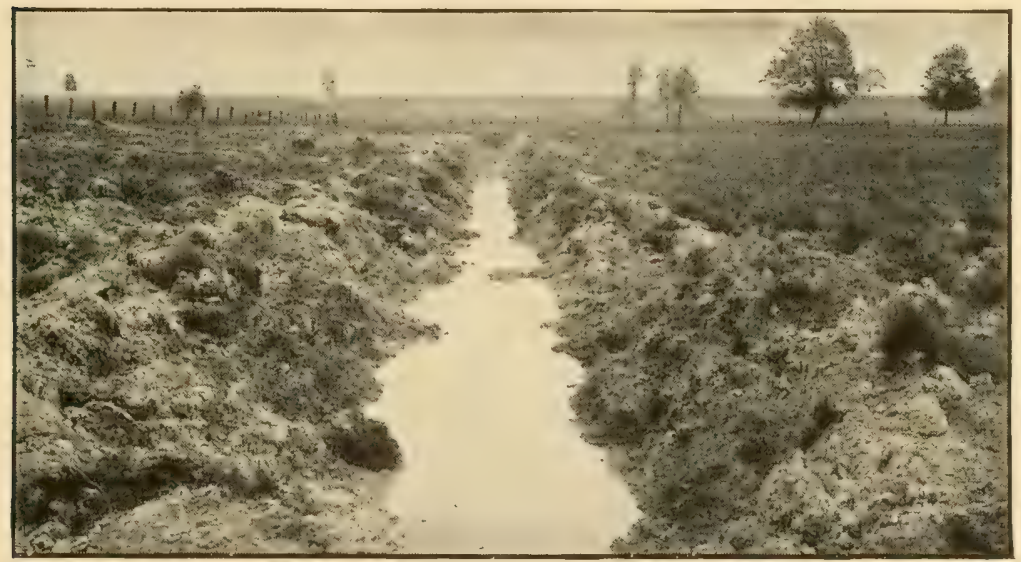

A 4-foot ditch opened out in fine shape through stiff clay in a meadow. Note the clean edges of the ditch, and how well the soil is scattered instead of banked up along the edges as it would be from plowing or shoveling.

Laying Out the Ditch and Making Holes. The line which the ditch must take should be determined with all proper care in respect to drainage requirements and other factors.

A blasted ditch should have a grade similar to a ditch made in any other way; it needs no more fall. The line as finally determined should be marked with stakes. A string should be used to guide the bar or auger. Without it time will be lost in sighting. A convenient length for such a string is about two hundred feet.

The nature of the soil must be taken in to consideration in selecting the manner of making the holes, for much time may be lost and much extra work caused by trying to do this work with inconvenient equipment. In soft, watersoaked ground, such as muck and clay free from stones, there is nothing better than a straight, round four- or five-foot bar. No sledge is needed. If there are stones, the sledge may be useful in breaking them. The hole should go down to within an inch or two of the right depth or level. If the line of holes is shifted to one side or the depth of the holes vary, the ditch will be crooked, or uneven in the bottom. 
Better Farming with Atlas Farm Powder

In all stony ground the bar and sledge combination is excellent. The bar usually can beloosened if it gets fastened, simply by hammering it from different sides. Another plan is to use an imple- withdrawn. The only satisfactory way of getting the charges loaded right in such ground is to use a tube or pipe big enough to fit over the bar. The hole may be made with the bar fitted in

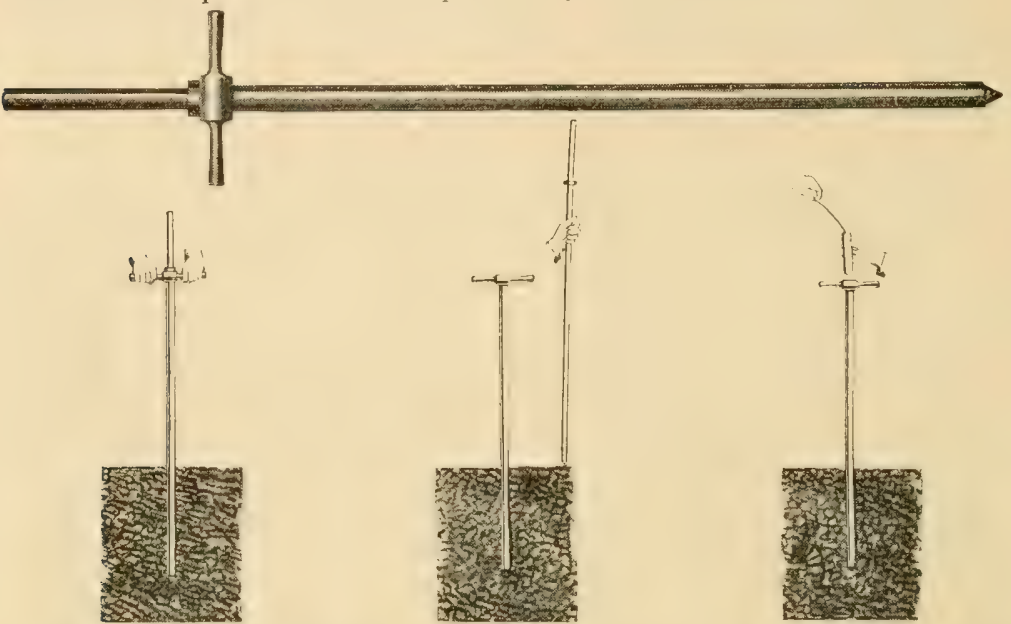

DUPLEX DITCHING DRILL, or BAR. (Pat. April 17, 1917.) Holes in loose gravel, sand and muck can be made and loaded with this drill without any trouble whatever from the usual caving in of the sides. The drill consists of two parts - a bar and a casing, as shown in the picture. The bar is solid, with a drop forged steel point. The casing is a steel tube into which the bar fits. The combination is pushed or sledged into the ground as though of one piece, the casing being carried along by a stop-ring welded on the bar near its top. When the drill is down far enough, the bar is pulled out of the casing. Then the powder is dropped to the bottom of the hole right through the casing, and is held down in place with the tamping rod while the casing is pulled up. Loading with this drill takes only about two minutes to the hole in muck. For further information write Atlas Powder Company, Wilmington, Del.

ment consisting of two wheels and an axle, with a "tongue" that extends about a foot over the axle at the short end. The other end may be as long as desired; 10 feet usually is satisfactory. A chain bolted to the short end can be half-hitched to the bar and the bar pulled with little effort. Other good implements are posts or tripods carrying a similar lever and chain, or just a second bar to run through a loop of the chain.

In hardpan and rock, regular rock drills are needed. They are described on page 69 , and may be bought ready to use, or may be made at home.

A measuring stick of the exact length of the proper distance between charges should be provided for each workman. Any less particular spacing will be costly in powder used, and may cause inferior work.

In clay and other heavy soil containing few stones, the holes will remain clear for several hours if desired, and no trouble will be experienced in getting the powder to the bottoms. In muck and other light soils, particularly in gravel and loose, soaked sand, the sides of the holes will cave in the second the bar is the tube, or with the bar first and then enlarged with the bar in the tube. After proper depth is reached, the bar can be withdrawn and the powder dropped down the tube, and held in place with the tamping rod while the tube is taken out.

A soil auger is useful chiefly for finishing holes in more or less dry ground such as heavy loam or clay free from large stones. Pebbles do not interfere with its use. The first foot or two usually can be punched with a bar, but deeper holes are hard to make without an auger.

Wherever there are sod, roots of trees or brush in the ground, it pays to cut along the line of the proposed ditch before blasting. Without cutting, especially in light ground, the sod tends to fall back into the excavated channel, even though all the dirt is blown out from beneath it. Pieces up to two feet wide of ten will fail to tear loose from the bank. Roots break somewhere in the channel width, usually near the middle, but fail to break at either or both sides.

The cutting can be done speedily with a hay knife where there are not too 
many stones. Spades or long handled shovels are good for the purpose, though slower. An axe is needed for cutting off roots larger than an inch or two. The cut should not be straight down, but at a slant such as you want the side of the finished ditch to have. The powder will clean out the ground to the cut, and will leave that beyond solid and unbroken.

Powder: Kind and Amount Required. For all electric ditch blasting except in very light soils, Atlas Farm Powder has advantages over any other grade of explosive.

To a considerable extent the superiority of the electric firing method is due to the possibility of using this comparatively low-cost powder, instead of the more expensive straight nitroglycerin powder of high percentage which has been recommended exclusively for ditching.

In very light soils, such as light loams with little moisture in them,

other grains. For such soils, Atlas Powder 50 per cent, is recommended.

This same 50 per cent. Powder is recommended where charges must be left more than half an hour under water before they are fired. Sticks of Atlas Farm Powder, as noted on page 6, are waterproofed with care, and will stand immersion in water for considerable periods of time. Yet prolonged soaking

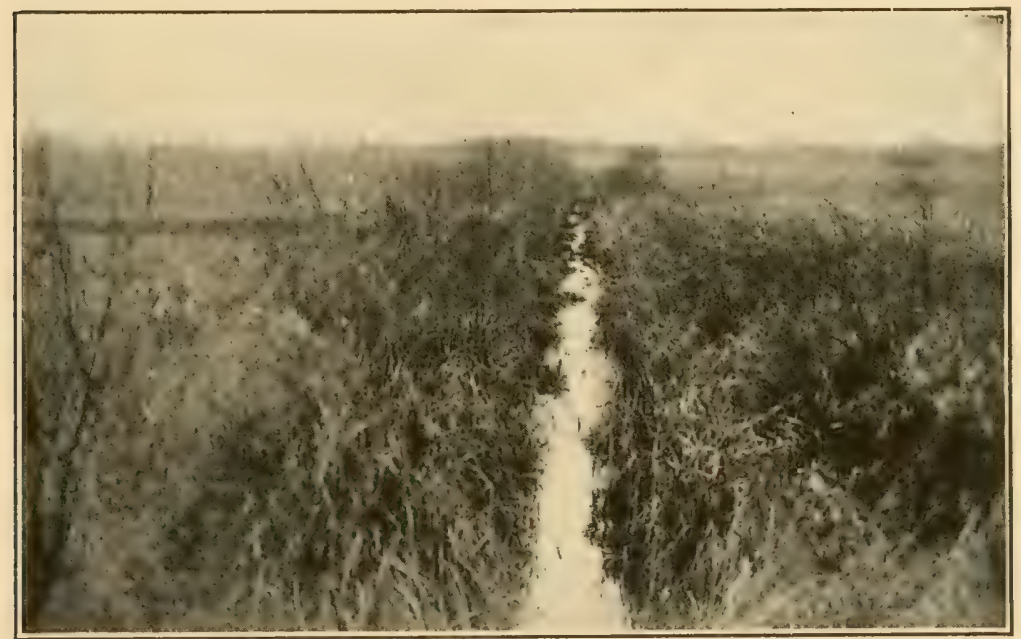

Proper blasting will open a channel through thick brush and grass, though such a ditch will not measure nearly so much in the clear as if the land were clean and free from roots. You can make channels for boats or for drainage through a marsh where the ground is under water. (Kentucky.)

and in wet, sandy land, a more violent powder will throw dirt out better than Atlas Farm Powder That is, owing to the poor resistance ofiered by these loose, open soils, Atlas Farm Powder, which applies its strength more slowly, is handicapired by the sand or fine dirt sifting back into the excavation. Heavier charges will overcome the trouble, but on big jobs it has been found that a cheaper way is to use ordinary charges of a powder which has a speedier action-which starts each grain of the sand or dirt so fast that it fies clear of the ditch independently of. may permit the water to leak through seams in the paper wrappings of the sticks, and once the powder inside gets wet, it will start to weaken immediately. For this reason, where the loading is done through swamps or brush, or on big jobs where long series of charges are fired together, with much time required for connecting the wires or completing the loading of each shot, the powder used should be of a nature not quickly damaged by water that may get inside the wrappings. Atlas Powder 50 per cent. will stand consider. able soaking without deterioration. 
Atlas Powder 50 per cent. must not be used, however, when the temperature of air or ground is lower than 50 degrees. In fact, a safer limit is 55 degrees.

A great many different explosives have been recommended for blasting ditches during past years, and others doubtless will continue to be recommended by people who have tried them in a few ditches. Sometimes the results compare favorably with the work done by Atlas Powders. In almost every instance, however, a slight change in the manner of loading, as recommended in the following pages, will permit Atlas Farm Powder to do its usual superior, more economical work.

The following table gives average figures for the amount of powder required per charge for making ditches of various widths and depths. It should be used for extra wide and extra deep ditches. See also the explanations on pages 27 and 29.

\section{Powder Required Per Charge and Depth of Loading}

Ditch Dimensions:

Width of Ditch, Feet........ $2 \quad 2 \frac{1}{2} \quad 3 \quad 4 \quad 456$

$\begin{array}{llllll}\text { Depth of Ditch, Feet......... } 3 & 3 & 5 & 7 & 9 & 12\end{array}$

Powder Charges:

Depth of Loading, Inches. .... 15-18 $\quad 24-26 \quad 30-33 \quad 36-42 \quad 48-52 \quad 60-70$

$\begin{array}{llllllll}\text { Space Between Charges, Inches.. } & 30 & 30 & 36 & 42 & 48 & 52\end{array}$

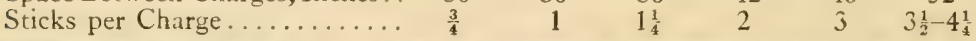

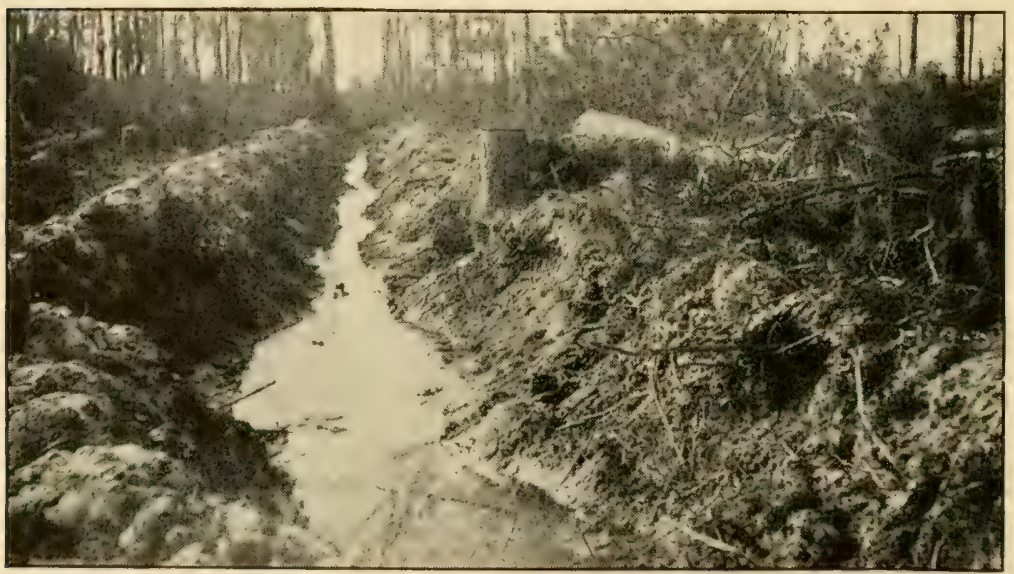

Ditch blown through sandy loam at Wilmington, N. C., with Atlas Powder, by Holly Shelter Land Co.

These figures apply to average wet should be in case the amount of powder clay and clay loam. The amount of per charge is increased for any reason. water in the ground, the texture and The longer the spacing, the less holes structure of the soil, the ground temper- there are to make, and the fewer fuzes ature and the kind of powder used all required. The spacing should be even have influence in modifying the amount and accurate. To guess may be expenof charge and the distance between sive. A measuring stick should be used. charges required for the best results. We have no intention of naming any In only a few instances will the exact "best" charges, or manner of loading, amounts and spacing given here be the since the exact number of ounces of best that can be used.

The figures for spacing of charges are about the minimum that will be required. In many instances they can be increased with economy, and usually powder and of inches between charges necessary in any circumstances can be determined only by test blasts. The table above can be used as a guide in loading the first trial shot.

Spacing Between Charges and depth of loading that is correct for any particular soil and time, should be determined experimentally on each joh. No matter how well the first trial shot seems to work, the next two or three should be loaded a little differ- 
ently, to see if still better excavation can be secured, or smaller charges or longer spacing can be used.

The depth at which the charge ditch, however, the charges must be should be placed in ordinary heavy placed at the full depth desired for the loam and clay is 6 to 12 inches less than ditch, or even a few inches deeper, as the desired depth of ditch. Proper the loose material causes a loss of force. ditch blasts will blow the dirt out 6 Where hardpan or rock lies under the to 12 inches deeper than the charges clay or heavy loam, the blasts will are placed. In case of an open layer clear out the dirt right down to the like gravel or quicksand under stiff rock whether loaded down against it or clay, near the bottom of the proposed somewhat higher in the soil.

Loading of Test Blasts must be relied on to determine the exact spacing if the greatest economy and the best excavation is to be secured. The blaster should put in 5 to 10 charges along his ditch line, according to the tables and other directions. Depth, spacing and amount of powder per charge should be so balanced that the excavation will be complete, the sides and bottom of the ditch even and true, without holes under the charges or ridges between them, and the material thrown high enough to scatter it well.

Too much powder will throw stones and dirt unnecessarily far, which will increase costs. Too little will toss the material a few feet in the air and let it fall back into the ditch again. Too deep loading will do the same, leaving an excessive amount of broken ground in the ditch (6 to 10 inches is not too much). . Too wide spacing will leave uneven sides and bottom of channel, and ridges across the bottom.

The blaster should repeat the test blasts and vary the amount of powder, the depth and the spacing of charges till the right results are secured. $\mathrm{He}$

should bear in mind that careful loading of the right powder will make straight, even, deep channels, and should not be satisfied with anything short of these results.

Changes of nature and conditions of soil as the work progresses should be watched for with care. Frequently clay gives way to gravel, or more and less water is encountered. Any change must be met with a corresponding variation in the loading, for any one manner of loading positively will not do equally good work under other soil conditions.

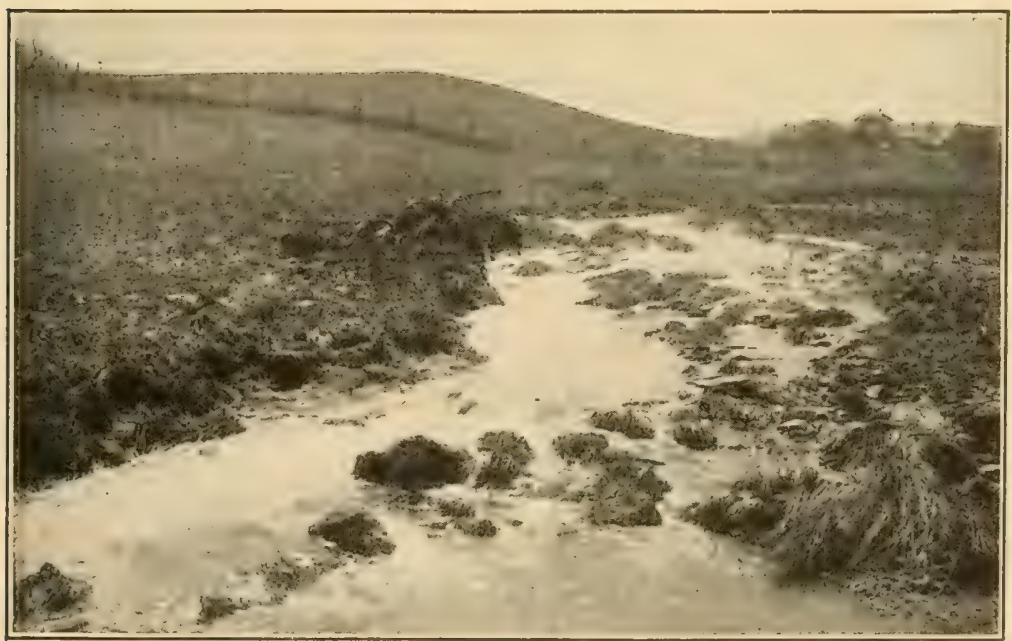

A picture that tells a story of swamp grass damming up a stream, which backs up and floods a field, ruining the hay or corn or any other crop which may happen to be there. To dig by hand or plow out such a clogged stream-bed is difficult and expensive, but to blast it out is the work of one man for an hour or so, at a comparatively small cost. (Mud Lick Farm, Julian, Center $\mathrm{Co}_{0}, \mathrm{~Pa}$.) 


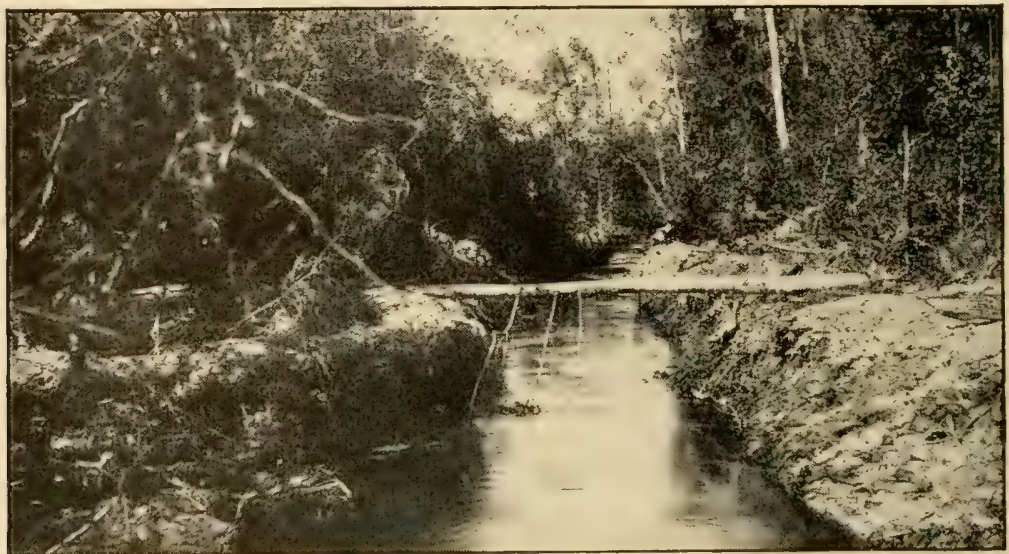

Ditch blown through wet soil with Atlas Powder, by The Co-operative Homestead Company. Crystal Springs, Florida.

Loading and Firing Details. Each charge must be primed with an electric fuze. It is presumed that the blaster will prepare his charges according to the directions on pages 13 and 14 . Where two or more men are on the job, it is well for one or more to go ahead making the holes, after the line of the ditch has been staked and lined off, while another brings the powder and blasting supplies in the boxes or baskets, and prepares and loads charges. Connecting wire is needed for making the return circuit in each series of shots.

Where there is water in the holes, which is the usual ditching condition, any sticks of powder that are cut or have the wrappings broken should be made waterproof with tallow, soap or clay, as directed on page 12 . This is particularly important with Atlas Farm Powder. If the sticks are waterproofed carefully, they should not leak to any serious or damaging extent for half an hour, which is plenty of time for loading and firing a large or long blast.

A tamping rod a trifle thicker than a stick of powder is convenient, as with it the loader can test each hole with certainty before he drops in the powder. If the rod will go down freely, the powder ought to. Unless a loader is careful to test each hole, and to remove the tamping rod gently, as well as to lower the powder in the hole without shoving it against the sides, considerable trouble will be experienced in getting charges down to the bottoms of the holes on account of caving in of stones and muck. Any charges loaded at less than full depth will leave high spots in the ditch bottom. The loading tube mentioned on page 24 should be used wherever there is any trouble at all from this source. It may seem unhandy and

slow, but it is almost sure to save time in the end, as well as be the means of producing better work.

The amount of tamping material required depends on the amount of water in the holes and on how wide you want

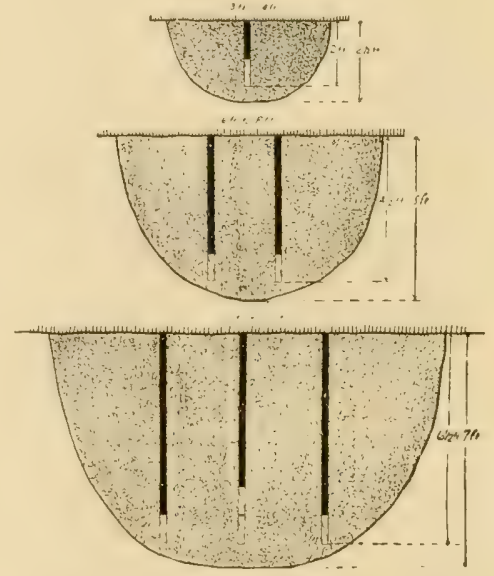

How the charges should be placed for blasting ditches of different widths and depths. 
the ditch. The more tamping there is, the wider the ditch will be in proportion to its depth. If a narrow, deep ditch is desired, the less tamping there is the better, though it is well to tramp shut the tops of the holes as they are loaded. Where water rises to the surface of the ground, no tamping is needed in any case. Even 8 or 10 inches of water over the charges will act almost the same as proper tamping. on till all the charges are connected, then the free ends of the first and of the last charges are connected with extra wire to the leading wire and thence to the blasting machine. Connections in parallel cannot be used satisfactorily with a blasting machine as the source of current.

Where the ditch is within easy reach of electric current from a power or light station, that source of current some-

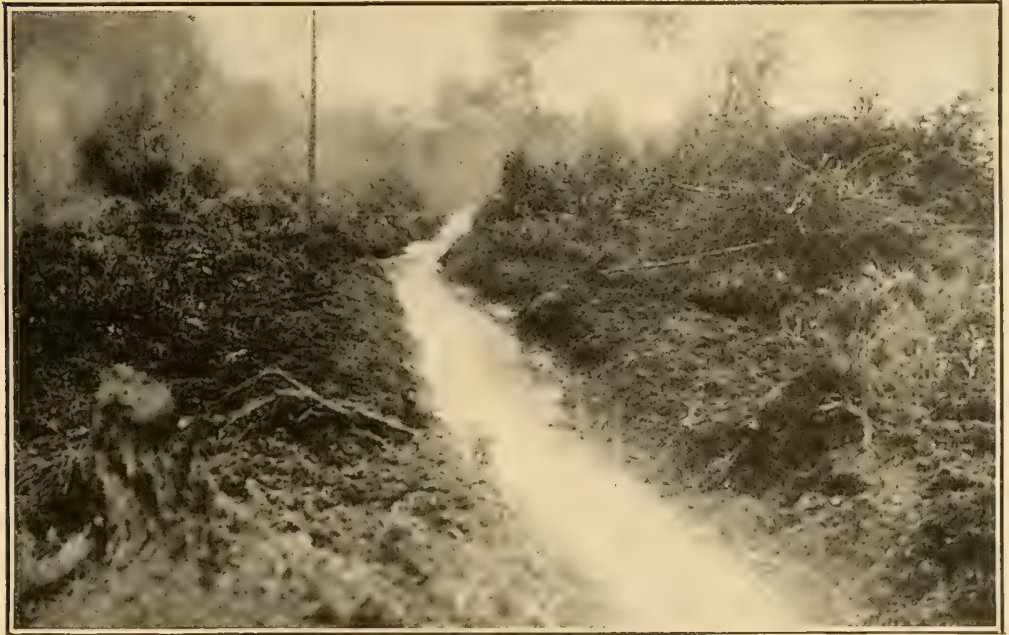

This ditch is a good instance of the speed and efficiency of the blasting of ditches. Three men made it complete, as the picture shows- 1000 feet long-in five days. About 400 pounds of explosive was used. Much cutting of roots and sod was required. (The Hart E. Hutchens Co., New Britain, Conn.)

When the loading is started, it is well to finish putting all the charges for that shot into the ground with as little delay as possible. The wires should be connected as directed in the chapter on electric firing, pages 13 to 14 , the vicinity cleared of people and animals, and the shot fired. - The blasting machine or other current should be manipulated the same as in stump blasting.

Connections in series are correct for all ordinary ditches - that is, one charge is connected with the next one, and so

times can be used to advantage instead of a blasting machine, particularly for making large, long ditches and when workmen are numerous. The connections in that case likely will have to be in parallel (see page 14), though the exact handling of such current in each case must be figured out by an electrical expert who is informed of its voltage and amperage. We shall be glad to take up the matter with anyone who has such current available on a ditching job.

The Finishing of a blasted ditch usually consists only in throwing out an occasional big stone, root or sod that happens to fall straight down instead of off to one side at the time of the blast. There will be a few inches of loose dirt in the ditch, but it will wash out or compact within a few days after the water starts through. In case the channel is not deep enough, however, this dirt can be shoveled out, though proper calculations in the first place will insure adequate depth being secured by the blast.

In case the sides have not been cut before the blasting, some roots and sods may be found projecting into the sides of the channel. These should be cut loose and removed, as they may fall down later and cause the bottom to fill 
with sed ment.

Where the new ditch cuts through to straighten an old channel, there may be places where the sides of the new channel are low enough to permit water to flow out into the old channel. At such places banks should be built up of large stones, poles, logs or other material that will turn flood water.

The first flood after the ditch is blasted will clean out the channel in an excellent manner provided the water is forced to flow through it exclusively, and the outlet is kept free. There will be a large quantity of silt and gravel carried down to the mouth of the ditch, and, if necessary, provision should be made for this in order to prevent its checking the free flow of water in the ditch.

Wide Ditches. The table on page 26 specifies 12 feet as the widest ditch that may be blasted with a single row of charges. Wider ditches up to 20 feet may be blasted out by using two or three lines of charges, and under favorable conditions it is possible to excavate even 30 -foot channels.

The second line of holes should be a duplicate of the first in almost every instance. The charges, however, in the two lines should not be located directly opposite one another, but should be staggered or alternated. Spacing between the lines should be 30 to 60 inches, -usually should be about the same number of inches as the depth of loading. Some blasters prefer to put the rows 6 to 12 inches farther apart. A double line blast will excavate a ditch as wide as a single line blast of the same depth of loading, plus the spacing between lines and one to two feet more.

Triple line ditches should be loaded the same as single or double line ones, The charges should be staggered, the

spacing should follow the rules in the preceding paragraph, and other details should be the same. Some blasters prefer to use heavier charges in the middle row under certain soil conditions. For instance, if the charges in the outside rows consist of 2 sticks of powder each (16 ounces) they use $2 \frac{1}{2}$ sticks (20 ounces) or 3 sticks (24 ounces) in the middle row.

There is no way of determining in advance just what the best loading will be. Test blasts, as mentioned on page 27 , will establish the facts on each job. All the lines of charges should be fired together, of course. A large blasting machine is needed to fire charges in multipie row ditch blasting.

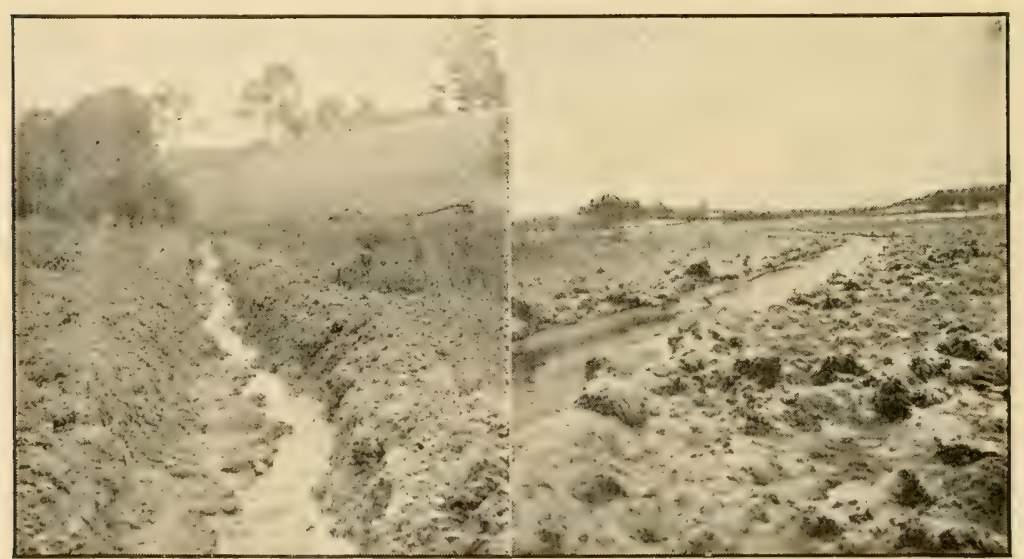

Two ditches made with Atlas Powder without the use of shovels or scrapers.

Extra Deep Ditches. Depths of 5 to 6 feet can be secured without trouble with ordinary heavy loading. When greater depth is desired, double-deck blasting should be practised. This consists in blasting out a wide ditch of about half the desired depth, then blasting again in the bottom of this one to take out the remaining earth. 
The number of double depth ditches that have been made is not great, as depths of more than 6 feet seldom are required. The usual practice, however, is to blast a 2 or 3 line ditch 3 to 6 feet deep. Then a one- or two-line blast is loaded in the bottom of this. The result is a channel with sides sloping evenly at the proper angle from bottom to top.

Experimental shots again are the best means of determining the exact manner of loading that is best. The blasting out of deep channels such as are mentioned is not particularly difficult. The loading should be the same and all features of the work should be carried out the same as for the single-depth ditches. The dirt of all correct ditch blasts is lifted 100 to 200 feet into the air, hence the comparatively slight 5 to 6 foot banks of the excavation made by the first blast interferes little with the work of the second blast.

In deepening old ditches and stream channels the loading should follow the same rule of locating the charges and determining their depth and size so that the new excavation in the bottom will be slightly narrower than the walls of the old channel above.

Such blasts are governed by the same principles governing ordinary blasts loaded from the surface to make new channels.

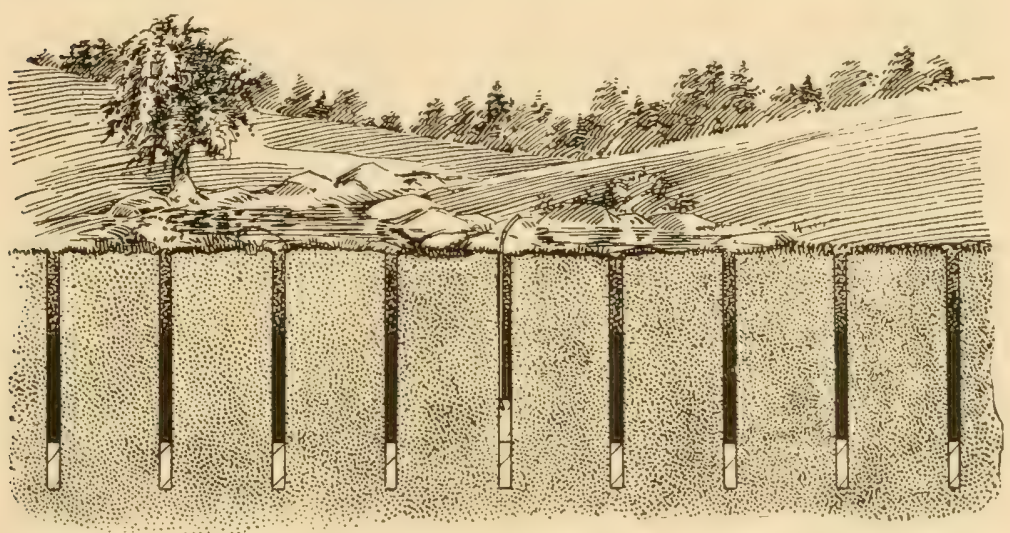

Showing typical loading of transmitted detonation ditch blast-fuse firing-for 3 ?' $\times 7^{\prime}$ ditch.

Obstructions in the Ditch Line, such as stumps, clumps of brush, trees, boulders, and ledges of rock, should be blown out at the same time the ditch blast is fired, but require separate loading.

A boulder is heavier than the ground it lies in, hence requires more powder to lift it. If it is to be broken up at the same time it is thrown out, still heavier loading is essential. (See page 62 for discussion of boulder charges.) Roots and stumps bind the soil, and addi- tional force is required to loosen and split them. (Page 47, in the stump section, gives the information on charges.) Ledges of rock in the bottoms of ditches must be drilled as directed on page 70 , and may be shot out very satisfactorily.

\section{Ditching When Powder is Fired With Cap and Fuse in Connection With Transmitted Detonation}

This method, formerly called "propagated ditch blasting " requires no electric blasting machine. Its advantages and disadvantages are discussed on page 34 . One charge only in each blast is primed with cap and fuse, and all the others of each blast are loaded without priming of any kind. 
Since simultaneous firing of all charges making up a shot or blast is necessary for the success in ditching, this method depends on the shock from the explosion of each charge to put off or explode the next charge in the line. The usual length of such a blast is 50 to 100 feet, though under favorable conditions blasts 400 feet long are fired. Shorter sections than 50 feet, of course, are fired equally well.

The work includes the following:

Collecting tools and supplies.

Laying off ditch with stakes and line.

Making holes at proper depth and at proper distance for first test shot.

Cutting sod and roots, if any, along sides of ditch.

Preparing one charge by priming with cap and fuse, as directed on page 8 .

Loading holes with proper charges, then loading center hole with primed stick in addition to regular charge.

Lighting fuse in any ordinary manner, after vicinity is cleared of people.

Inspecting result and making calculations for correct loading.

Making more holes and repeating later operations on sections of ditch 10 to 400 feet long at a time.

The conditions necessary to consider are the same as those influencing ditch blasting by the electrical method, though greater emphasis must be placed on the amount of water present and on temperature of the ground.
Temperature. Since the powder that must be used in transmitted detonation ditch blasting in order to secure sufficient sensitiveness, will freeze or chill at temperatures lower than 50 degrees, this method of blasting ought not to be attempted when the thermometer registers lower than 55 degrees either in the air or in the ground.

Water in Ground. Air is elastic. Water is not. Ground that contains much air - that is, ground free from water-has a good deal of "give" and in consequence deadens or absorbs shock from one explosion before it has had a chance to reach the next charge. But ground containing water transmits the shock with little loss in its force.

These principles govern both the selection of ground where transmitted ditch blasting is possible, and the spacing of the charges. It is impossible to secure successful transmitted detonation where the water does not at least cover the charges. Water should rise well up in the holes for best results. In clay and other finely divided soils the water level may be lower than in sand and other coarse soils, in which economy demands that it rise in the holes almost to the surface of the ground. No harm is done by a reasonable amount of water over the surface of the ground, provided the amount of powder in the charges is determined by measuring the total depth of loading from the top of the water.

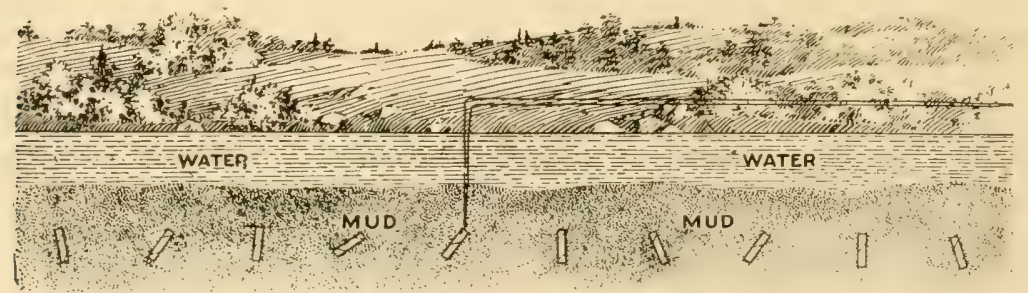

Typical loading for deepening ditch with bottom of mud-electrical firing of center charge for transmitted detonation.

The Spacing of the Charges is governed by the distance the wave of detonation will carry in the ground, which can be determined by test. Roughly it is half the spacing used when charges are fired electrically.

The table on following page will serve as a basis for making the first trial blast, but we wish to emphasize that the condition and nature of the ground in each case is of the greatest importance. For example, charges of one stick of powder sometimes will detonate successfully when as far as 24 inches apart, or even farther, but in another soil, even in the same ditch at a point where there is less water, they may fail to detonate when spaced 15 inches apart. For reasons of economy it is important to space the charges as far apart as full and complete detonation will permit. 


\section{Powder Required Per Charge, and Loading Details}

Ditch Dimensions:

\begin{tabular}{|l|l|l|l|l|l|l} 
Depth of Ditch, Feet......... $1 \frac{1}{2}$ & 2 & $2 \frac{1}{2}$ & 3 & 4 & 5 & 6
\end{tabular}

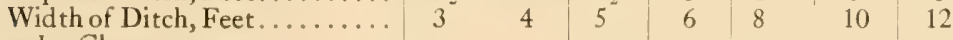

Powder Charges:

Sticks per Charge.......... $\frac{1}{4} \quad \frac{3}{4} \quad 1 \quad 1 \frac{1}{4} \quad 1 \frac{1}{2} \quad 2-3 \quad 3 \frac{1}{2}-5$

Space Between Charges, Inches . 14-16 14-18 $14-20 \quad 15-20 \quad 16-24$ 18-28 $18-30$

Depth of Loading, Inches...... $16 \quad 20-22|24-26 \quad 30-33 \quad 36-42| 48-52$ 60-70

\section{The Amount of Powder Per Charge is noted in the} table, but this is another factor which can be determined with accuracy only through trial in the ground to be blasted.

It will be noted that the amounts given as the average are only slightly smaller than those given in the table on page 26, for electrically fired ditch blasts. Our figures here are derived from

records of much actual field work. They should meet unfavorable conditions. Where the ground is heavy, hangs together, and is full of water, less powder often will do the work.

Kind of Powder. Atlas Powder 50 per cent. straight is recom. mended for ditch blasting when charges are fired with cap and fuse, by means of transmitted detonation. No less sensitive explosive can be depended upon to detonate when this method is used.

Test Blasts, such as are described on page 27, are important with transmitted ditch blasting.

A test blast should include 8 to 10 charges. The spacing should vary, and careful observation of the blast and inspection of the result should be made to note any charges that fail to explode or that explode with less than full force or throw dirt too high and far. Depth of loading and amount of powder per charge should be changed till the excavation is judged to be perfect and the amount of powder and work reduced down to a minimum.

Watch for change of soil nature and conditions as the work progresses, and vary loading accordingly.

The Loading is easier than for electrical firing. One charge must be primed with cap and fuse as directed on page 8 and should be well waterproofed. Any cut sticks also should be waterproofed. The holes all should be made before loading is started, as only a few minutes are required to put the powder in the ground and to prepare for firing. All holes must be clear of fallen dirt and stones, and the loading tube mentioned on page 24 should be used where material tends to cave in.

It usually is best to begin loading the unprimed charges of powder at one or both ends of the section of the ditch to be shot in that blast. All the holes but one near the middle of the blast should be loaded in this way, then the primed charge should be loaded in it, on top of an extra stick of powder. Some blasters also place an extra stick in each of the two adjoining holes.

As water must cover the charges, tamping is not important unless the widest possible ditch is required, when the holes may be tamped tight and solid to the top. When no tamping is used, the top of the hole should be tramped shut immediately after the charge of powder is seated at the bottom, in order to prevent double loading of some holes.

Firing of Transmitled Blasts is done by lighting the fuse of the center charge. Great care should be taken to clear the vicinity of people and animals, and to put guards on roads that pass near the blast. Stones of considerable size often are thrown a hundred feet or more into the air. The man who lights the fuse and his helpers should 
watch upward as the dirt rises, so that they may be able to dodge stones coming down toward them.

A blasting machine and fuzes can be used to fire these center charges electrically if desired. They have the advantage of timing the blast to the second, and resist water better.
Other details, including cutting the sides of the ditch when there is sod or roots, finishing the channel as mentioned on page 29, making the holes with bar and sledge, suil auger or other methods as mentioned on page 23, should be done just the same as when the charges are fired electrically.

\section{Extra Wide and Deep Ditches can be blasted by the} transmitted detonation method when ground conditions are right, the same as single line ditches.

The two or three rows of charges should be spaced as directed on page 30 . To fire them together, however (which must be done), extra charges must be loaded between the rows at the middle point where the primed charge should be placed. These serve to carry the wave of detonation from one row to another. The extra charges should contain one more stick than the regular ones in the line, and it is well to put an extra stick in each one of three charges in every row or line.

Where an electric blasting machine can be secured it is well to fire the two or more rows with it by priming the center charge of each with a fuze, and firing them together in ordinary series. See page 13 .

Obstructions, such as boulders, stumps, logs or other solid objects or materials, will stop the wave of detonation. It is necessary, therefore, in addition to loading extra powder under the obstructions as directed on page 31 , to handle the line on both sides of each obstruction in separate blasts; or, in other words, to load one primed charge after each obstruction.

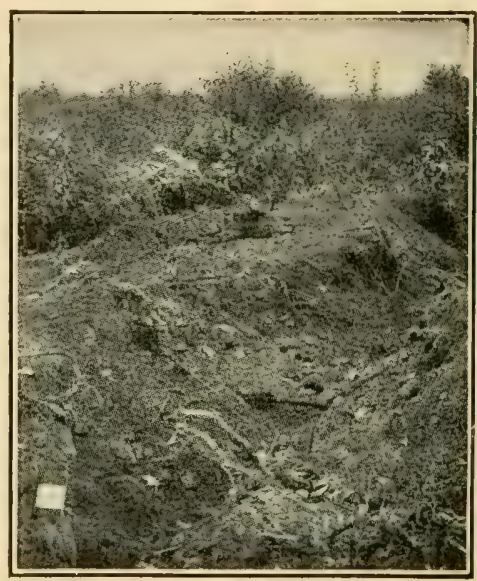

What happens when dry sand is blastedpoor excavation.

\section{Miscellaneous Points on Ditch Blasting by Both Methods}

Loading Charges Off Center Line of * Ditch. Sometimes the ground on one side of a ditch line will be higher than the other side, or one side may be more solid and heavier than the other. Such conditions are found often in cutting through old stream channels. To blast straight through such places, the line of charges must be shifted a few inches toward the high or firm ground, as that side will present a greater burden.

Speed of Ditch Blasting. 'Those not familiar with the work required to blast ditches will be interested in the speed that may be made by one or more men. We usually estimate that two men working together, blasting by the electrical method, in wet soil requiring a bar and sledge for making holes, but containing no stones that make punching difficult or that cave in, will make a ditch 3 feet deep and 6 feet wide at the rate of about 600 feet a day. In muck the work will go faster, because the making of holes, which is the big end of the job, requires little effort and time. In rock ground and in ground too dry to be penetrated easily by the bar, as well as in sands and gravels where the loading tube is needed, the work will go slower. Double-line ditches require twice as long and triple-line three times as long.

Blasting Ditches for Tile Drains. Blasting is not a practical method of 


\section{Better Blasting of Ditches}

making trenches for laying tile. It leaves the bottom of the channel too loose, makes it unnecessarily wide, and scatters the dirt too much for easy filling in.

This statement by no means implies that blasting is not of considerable value in the tiling of land, however, for there are several ways in which it will help. Light charges may be used to loosen hard ground without throwing it out, after which the excavating may be done with shovel entirely, without any digging being required. See the Subsoiling Division, pages 82 and 89 , for details of proper loading to accomplish this.

Another plan where tile is to be put down 3 or 4 feet or more, is to blast shallow, narrow ditches along the line, leaving about a foot in the bottom to be shoveled out. The tile then can be laid in the narrow shoveled trench, and to fill, the dirt can be scraped from several feet on each side with a road drag, road machine or land grader.

Where the tile will not be laid for a year or more, the ditch should be blasted out as usual. During the months following blasting the bottom will compact in excellent ondition, and the pipe can be laid satisfactorily later on.

Subsoil Drainage. In this connection it is proper to mention that both tile drains and open ditches can be made more effective in heavy, soggy ground by subsoil blasting the ground between drains. Breaking it up in this manner permits the surplus water to find its way more easily and quickly to the drains. See page 77 .

The depth of any drainage ditch should bear a well-understood relation to the height of standing water desirable in the particular soil. Thus in clay the water table may be lowered to 6 feet or more below the surface, and still the moisture will rise properly in dry weather, but in muck the water table should be lowered only $1 \frac{1}{2}$ to 2 feet below the depth of the majority of feeding roots.

To Correct Streams ditches need not be blasted out very large, even for creeks of same size and for small rivers. The water will wash loose and carry away the dirt and gravel in the sides and bottom of a ditch once it has a free flow with fair fall. A ditch 6 to 12 feet wide, and deep enough to catch a foot of water from above usually is big enough.

It is well to watch the sides or the banks of newly made stream channels. Stumps, big boulders, stony banks and clumps of bushes may deflect the flow of water against a soft bank with the result that after a time the channel gets crooked. A little work in removing obstructions now and then will prevent uneven side cutting.

The Wind may be made to help spread dirt thrown up by a ditch blast. If it is blowing across the line it will carry to one side considerable of the material. Such action is desirable when most of the dirt is wanted on one side only. The wind influence also may carry over some dirt that ordinarily might fall back into the channel, hence may secure a few inches more depth of excavation.

Comparison of the Two Methods. At the present time, owing to conditions prevailing in the markets for practically all materials, electric ditch blasting is almost always cheaper for the same job than transmitted firing, because lower priced powder can be used. Many considerations enter into a choice of methods, however, and we shall name them in order that everyone can decide for himself which is best.

For electric firing the holes are spaced about twice as far apart as for transmitted firing, which means that only half the number of holes need be made. When holes are hard to make, as in dry or stony ground, or where gravel caves in, the saving in labor is a big item, amounting to a third or more of the entire job. Against this saving, however, must be charged the extra time needed to prime each charge with fuze and to connect the wires, for it must be remembered that transmitted firing requires only one primed charge for each shot.

Convenience as to when the job may be done, and certainty of its being done well, are all on the side of electric blasting. When electric firing is depended on, the work can be done at almost any time men are available or when the ground is not frozen hard.

To compute the comparative costs of both methods, it is necessary to consider differences in the price of Atlas Farm Powder and Atlas Powder 50 per cent., the cost of a fuze for each hole as against a comparatively few blasting caps and a few feet of fuse, the varying amounts of each powder that may berequired, the labor time required to prime charges, and the labor time required to make holes. The cost of an electric blasting machine cannot all be charged rightly to any one job, because it depreciates very little, and can be used for other ditches, for stump and boulder 
Better Farming; with Atias Farm Powder

blasting, or it often can be sold for nearly as much as it cost.

Choice of a method sometimes is determined by the nature of the ground. When the ditch runs through extremely soft swamps or through badly tangled brush and briars, the connecting of wires sometimes takes sufficient extra time to justify the use of the other method, which requires only one wading through. On the other hand, conditions much more often are found where transmitted firing is impossible owing to the light nature of the ground and the impossibility of doing the work when it is wet enough. Electric blasting always is sure to yield the desired results.

Blasting Compared to Other Methods. The blasting method of ditching has numerous advantages, which entitle it to a place on most farms. It is not, however, recommended to do all kinds of ditching under all kinds of conditions, or to do away with other reliable and economical methods.

The making of trenches for immediate laying of tile drains already has been cited as one job for which blasting is not best suited. Another is the digging of miles of large ditch through unobstructed ground where such a machine as a floating dredge can be purchased and used to advantage. What a "large" ditch is, from this viewpoint, will vary with the circumstances. It can be said, however, that the cost of blasting increases out of proportion to the increase in the size of the excavation when the depth is greater than 5 or 6 feet and the width greater than 16 or 18 feet.

Note table on page 26. An experienced blaster can blast a ditch as small as 18 inches deep and $2 \frac{1}{2}$ feet wide. The maximum should be fixed at 8 or 10 feet deep and about 20 feet wide, though wider excavations of short length (such as ponds) have been blastcd out frequently by taking advantage of a high wind which carries the high-flung dirt to one side.

The Michigan Experiment Station found that in a certain representative soil two men could dig by hand a rod and a half a day of ditch of a certain size which we know could be blasted out by the same two men at the rate of 30 to 35 rods a day. The blasting method gets the job done, instead of the draining being postponed. It gets it done with the labor at hand, without the trouble of hunting up extra men (they cannot be found in many localities). In fact, blasting makes possible the digging of ditches now that otherwise might not be dug for a gencration. The work can be done in spare.time on farms, when planting, cultivating, harvesting and other operations are not pressing, simply because it can be completed in a few hours or days.

In general the worse the ground conditions, the greater the advantages of the blasting method. Soft ground where horses or machines cannot be taken is thrown out to the very best advantage by powder. Trees, brush, briars, stumps, boulders and ledges of rock which make excavating machinery

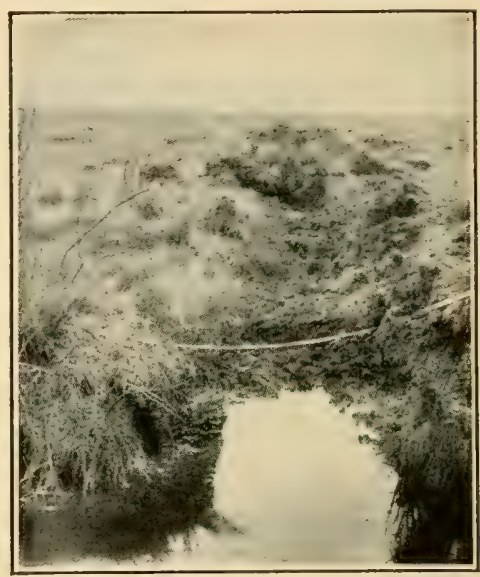

A typical instance of what results from an attempt to blast a ditch through heavy sod without first cutting the sides. The sod breaks loose in the middle of the ditch and either folds back without tearing loose or falls into the ditch after the dirt beneath it has been swept away. Such ground should be thoroughly watersoaked and the edges of the ditch cut with shovels or hay-knife, or at least by plowing furrows. (Virginia.)

and plows helpless can be thrown out by blasting.

The cost of a blasting machine and its equipment is small compared to the cost of ditching machinery, even of the simplest character. Unless the length of the ditch to be dug is great, the investment in such machinery increases the overhead on the job to a prohibitive extent. Not so, however, with blasting, for which just the required amount of supplies, and no more, may be bought. When the job is ended, the equipment on hand need not inventory more than $\$ 25$, and on small jobs can be kept to half of even this small figure. 


\section{EVIDENCE}

"The cost in digging ordinary ditches with dynamite is less than hilf the cost of hand digging."

\section{MICHIGAN EXPERIMENT STATION.}

"The quickest way to dig a ditch, no matter what the kind of soil, is to use explosives. The dirt is nearly all thrown out and scattered over the land, if desired, leaving no ridges or heaped-up stuff along the sides."

UNIVERSITY OF SOUTHERN CALIFORNIA, Los Angeles.

"I have made almost a mile of open ditches 5 feet wide by $31 / 2$ feet deep with Atlas Powder. It is easier and quicker than hand digging. My longest ditch is $1 / 2$ mile long, and does its work perfectly."

\section{W. A. SCHOCK, Falls City, Neb.}

"During the past few months we have used several tons of Atlas explosives in making ditches, blowing out stumps and subsoiling. Among other things we have made some three miles of ditch. We have found Atlas explosives thoroughly satisfactory."

THE CO-OPERATIVE HOMESTEAD CO., Crystal Springs, Florida.

"We have used Atlas Powder to dig about thirteen hundred feet of ditch this spring. The price of digging by hand would have been prohibitive, had we been able to secure labor. The ditch was left in such a condition that we have had to do nothing more with it."

\section{RENOUF RUSSELL, Mondamin Farm, Keene, N. H.}

"Last August we blasted nearly 100 rods of ditch, some 3 to 4 feet deep and 4 to 8 feet wide, and a few stumps, using 500 pounds of your Atlas Powder. 'The ditch blasting was a perfect success, also the stump work. I shall be pleased at any time to say a word of praise both for your explosives and your treatment of me."

ZENAS W. P. FARRAND, Essex Junction, Vt.

"'The ditching work done by us recently with your Atlas Powder was a great success and really surpassed our expectations. We blew out a ditch 225 feet long, four feet wide and three feet deep with only 60 sticks. This work was done in about two hours from start to finish. A prettier and more even ditch could not be made with a shovel."

\section{W. D. WEBSTER and S. C. WEBSTER, Nevada, Mo.}

"We have used Atlas Powder with extremely good results in draining the Holly Shelter swamp. We have blasted one canal about a mile long, averaging eight feet deep and ten feet wide, and are now blasting another canal in which Atlas Powder is working even better than in the first. This canal is fifteen feet wide and ten feet deep. We shall also use Atlas Powder for a good many smaller ditches."

ROYAL C. REMICK, Manager, Holly Shelter Land Co., Wilmington, N. C.

"A ditch blown on my place with Atlas Powder 60 per cent. has been very satisfactory. It was run about 2600 feet in meadow bottom which before redemption was a swamp of cedars, maples, etc. Below the surface were many stumps and roots. The work was about as difficult as can be found in ditching. To have run this same ditch by hand would have entailed such enormous expense as to be practically prohibitive."

\section{H. B. WEAVER, Burlington, N. I.}

"On my farm October 15 th one man with three helpers blasted a 600 -foot ditch about 4 feet wide at the top and $2 \pi / 2$ feet deep in about five hours, with Atlas Powder. We got a perfect ditch. I have about 600 feet more to dig, which $\mathrm{I}$ am going to do in the Spring, using Atlas Powder. When we get the other 600 feet dug the job will be worth at least $\$ 1000$ to me. I certainly would recommend that any land owner use Powder in ditch digging.

$$
\text { V.S. DARLING, Auburn, Maine. }
$$




\section{BETTER STUMPREMOVING}

The removal of stumps and the clearing of land by blasting is a simple, speedy process, which anyone can accomplish easily. One or more charges of powder must be placed in the ground under the roots, tamped tight and fired, and the pieces disposed of.

Such a brief statement of the operation would be enough, were it not that roots may be left in the ground or other imperfect work result from careless or unwise loading, and this is found to be expensive in money, time and labor. Skill and knowledge bring clean, complete work, and also economy. Few farmers who use explosives avail them-

selves of all the best blasting practices.

There is meat in a study of this mat. ter by contractors and employers, for they can save powder and time by making clear to their workmen all the factors which go to make perfect blasts. There is almost equal advantage in a full un. derstanding to the men who do the work, for knowledge will cut down the labor.

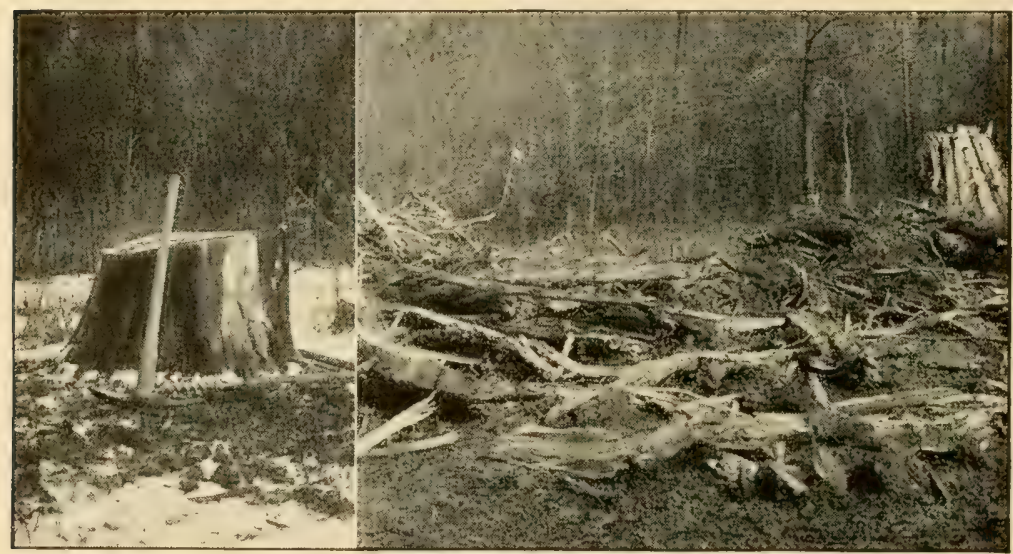

By using Atlas Farm Powder you can break the largest stumps into pieces ready for the fire the same as the stump shown above.

The Tools Required. It pays to get the right tools before the work is started, as much time may be lost and a great deal of effort expended uselessly in trying to place charges under stumps with poor tools. This does not mean that a costly outfit is needed; rather it means that the few tools required should be of the right type and size.

On page 10 we have pointed out the necessity for a Cap Crimper (when blasting caps and fuse are used), for a small wood punch to make cap holes in sticks of powder, for tallow or other waterproofing material when the charges are to be loaded under water or in very wet ground, and for a box or basket in which to carry caps and fuse or fuzes and other small supplies. All the light equipment and materials should be kept together to prevent them getting lost and to avoid any danger that might come from them getting tramped. The

powder itself had better be carried to the field in its original box or boxes, ex. cept that where only a few sticks are needed they should be carried in another box or basket. To follow these rules requires little or no extra work, and almost always saves trouble and expense.

For Making Holes in the ground perhaps the most useful tool is a crowbar, but with the soil auger a close second. The bar usually had better be sledged in to the ground after the hole is started. A 10-lb. sledge is about the right weight. The bar should be made of steel, 
and should be $1 \frac{1}{2}$ inches in diameter. It may be either round or octagonpreferably round, as that shape comes loose the easier. The point should be only a couple of inches long, though it should be sharp. (See illustration below, Fig. 2.) Unless the steel is good, the end hit with a sledge will chip off badly.
A Scraper can be made from a $\frac{1}{4}$ - or $\frac{3}{8}$-inch iron rod, 5 or 6 feet long, with a handle ring turned on one end and the other fastened and bent at right angles. (See illustration, next page.)

A Long-handled Shovel is useful in cleaning off the ground where the holes are to be made, and in getting

Fig. 1.-Pipe shaft soil auger.

The Soil Auger, as illustrated in Fig. 1, should be $1 \frac{1}{2}$ inches in diameter, though where very large stumps only are encountered, a 2 inch or even a $2 \frac{1}{2}$ inch auger may be more convenient. A soil auger differs from a wood auger in having a point 2 to 4 inches long instead of $\frac{1}{2}$ inch and in having a steeper pitch. damp clay or other soil for tamping purposes. Good tamping may be impossible if no shovel is available. (See illustration, next page.) A grub hoe and axe are desirable on some jobs. Where the holes are to be made in loose ground, sand or thin muck, a loading tube may be useful. I.ast, but by no means least, a

\section{PUEH}

Fig. 2.-Punch bar.

An old wood auger with a long shank welded on will do in an emergency. The standard tool is the one best suited for this work. We can either ship direct or give you a nearby address where you can secure this tool. probing rod is needed. This is a straight piece of steel about 5 feet long, with a $T$ or ring handle on one end and the other end sharp. It may be $\frac{1}{4}$ or $\frac{3}{8}$ inch in diameter, and had better be of spring steel. An old hay-rake tooth straight-

Fig. 3.-Pipe shaft wood auger.

The Tamping Rod must be of wood. A metal one is objectionable, and may be a source of danger or at least trouble. An old broom stick or hoe handle makes a good one. All that is required is a piece of straight wood 4 or 5 feet long, an inch or $1 \frac{1}{4}$ inches in diameter, with one end cut off square. ened out makes a good one except that it is a little heavv.

The tools may be carried where only a few stumps are to be blasted, but when there is a half day's work or more to do, it pays to load everything in a buggy or at least a cart or wheelbarrow, and haul them to the field.

\section{Investigating Stumps. The first thing to be done in every} instance is to learn the nature of the stump above and below ground, and the nature and condition of the ground it stands in.

The variety of tree is important; also whether the stump is green or decaved, sound or rotten, and if rotten, whether it is in one or more pieces and if hollow. Jarring the top with sledge or foot will tell something of the underground situation. Knowledge of woods and stumps will tell more. The probing rod, how. ever, is the real telltale, and should be used on every stump. By probing in the ground a blaster can find where the roots lie, and something about their condition, and can locate the best open-

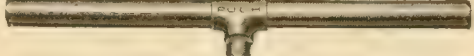

Fig. 4. - T pipe-handle for wood and soil augers.

ings between roots for the holes. This importance of the use of the probing rod as an economy measure can hardly be over-emphasized. Those blasters who do not use one, thinking it not worth carrying along, should try it regularly for a day or two. 
Nature and Condition of Ground. When powder explodes, the gases escape the easiest way they can. When one side of the space or pocket they are in is solid and firm and the other side more or less open or insecure, they blow out the weak side and disturb the firm side very little. To put it another way, they push out through the ground or roots in the direction and by the path that offers the least resistance.

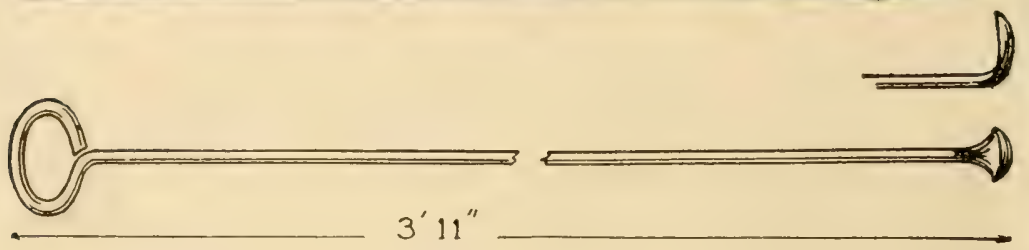

The upper picture shows a spoon shovel. Lower pictures show a scraper of iron from enlarging bottoms of blast-holes. Courtesy of The Sandpoint Experimental Station, University of Idaho.

To loosen roots embedded in the ground, therefore, gases must be confined under the burden to be lifted with sufficient weight and strength so that they will push against or strike the wood with the required power, or in the case of long, deeply buried roots, so they will lift the whole area of earth contain-

tically as much resistance to the gases as the roots themselves, hence the charges need not be any deeper than required to place them under the roots. In clay that is dry (which is easier penetrated by gases, hence in which the confinement is not quite so strong and close) slightly deeper loading is advis-

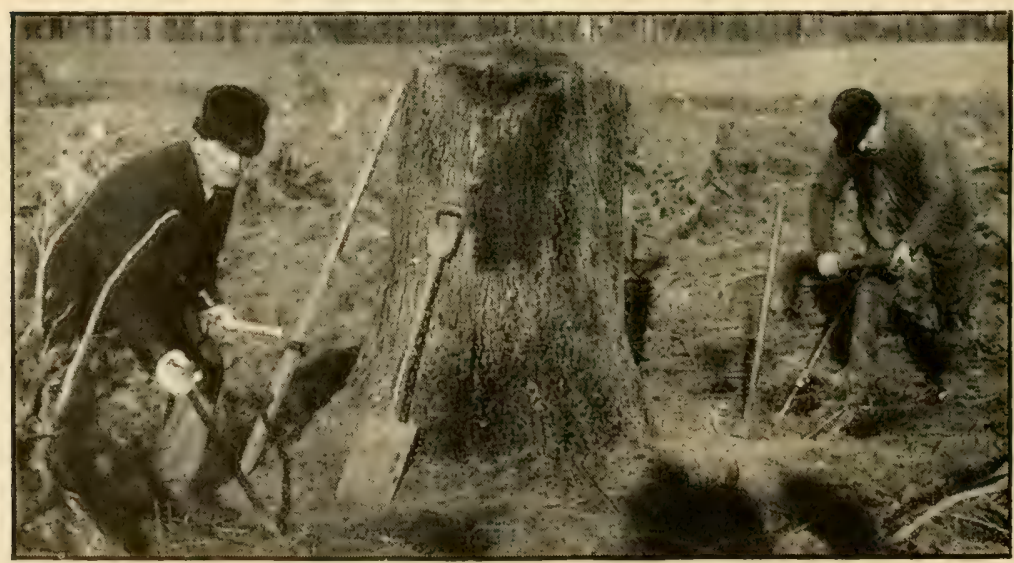

Placing several charges under a big green stump (for firing with an electric blasting machine). Notice primed stick of powder, sledge, bar, shovel, and tamping stick; also blaster pulling out auger to clean hole.

ing the roots and shake them loose. Some kinds of ground hold the gases better than others. For instance, clay is not penetrated easily, while sand is. Water helps to close the pores of the ground and to confine the gases.

In stiff, damp or wet clay, therefore, the charges need not be placed very deep. In fact, such ground offers prac40 able. In sand the charges must be deep enough so that depth of covering will make up for lack of confinement. Watersoaked sand is not so bad in this respect, but dry sand calls for careful, deep loading. Other soils range between clay and sand.

Frozen Ground. The blasting of stumps may proceed when the ground is 
frozen so long as the crust is not too thick for easy making of holes. Two or 3 inches does not greatly hinder operations. The roots seem to come free from the ground and the stumps break up better under such conditions than in summer. Atlas Farm Powder is par- ticularly satisfactory for this cold weather blasting, since it requires little or no thawing. Since fall and winter. or early spring, often are the times when there is least other farm work to do, stump removing in many instances can be done then to advantage.

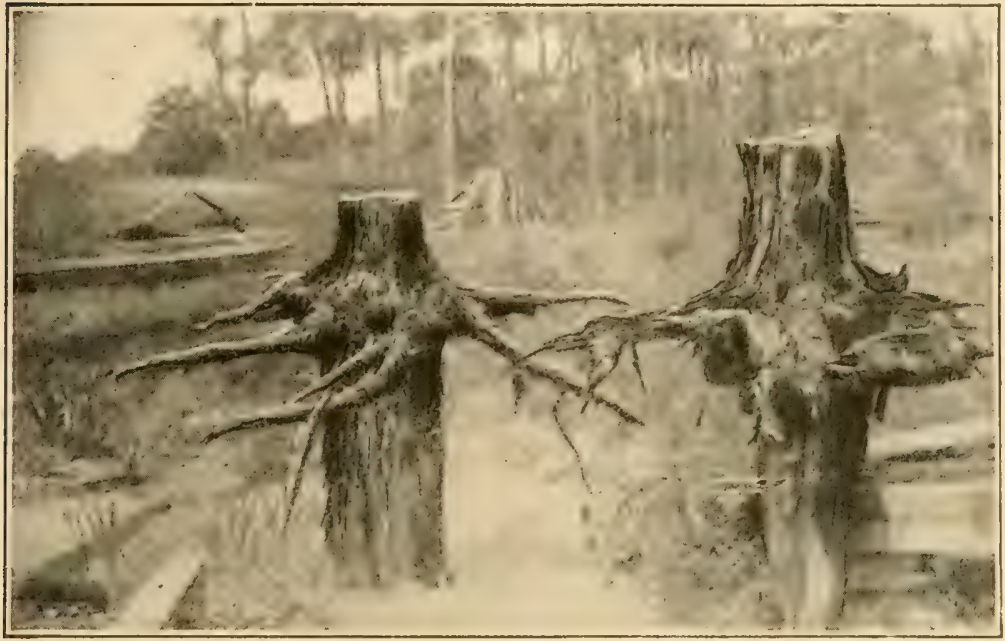

Typical tap-root stumps, with the dirt washed away. To blast them out the charge must be located against the big root, four or five feet below the surface of the ground. Two charges to each root are better than one, though either loading will cut off the root.

When Blasting Benefits Soil. An explosion in soil, like plowing it, may benefit it from a tillage standpoint when dry, and harm it when wet, though this is not true of all soils in equal clegree. The explanation lies in the fact that wot soil packs under the pressure of the gases, but dry soil crumbles and breaks apart.

The pot hole or cavity underground, familiar to anyone who has blasted in wet soil, is largely due to the wet condition. The earth surrounding the charge for at least half a foot is driven into the

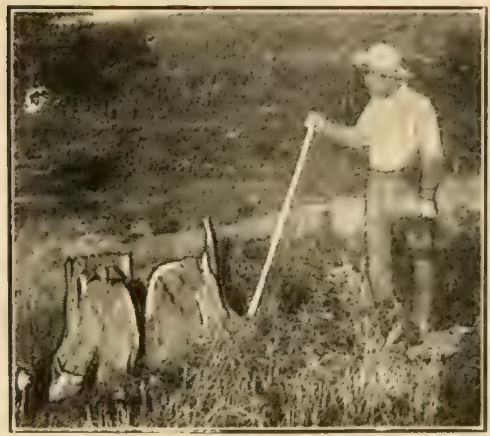

surrounding earth, with the result that a hollow is made, surrounded by compacted, hard walls like those of a jug.

The test for condition is explained on page 83. Soil moist enough to be plastic is too wet to blast if the tillage factor is important. A clay soil must be

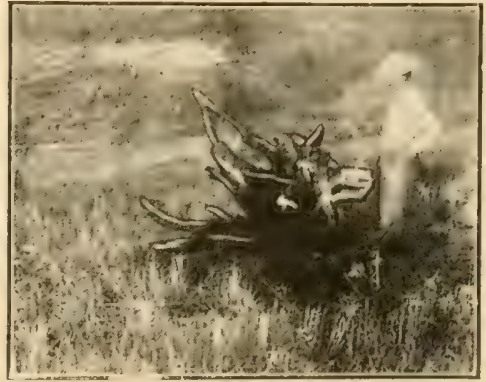

This stump had been obstructing the plow for fifty years, but was taken out in half an hour. 
very dry before it fails to stick together. Sand, however, may not stick even when watersoaked. Damp loam soils may or may not be worked, depending on how much humus or organic matter they contain.

In heavy soils, therefore, it is well to avoid blasting out stumps till the ground gets dry. In sandy soils, usually, the work may be done without injury even when water rises in the bar holes.
There are many other considerations which enter into the matter-for instance, it may be necessary to go ahead with new ground clearing without much regard to the soil conditions, trusting to later cultivation to counteract any compacting that may be caused in heavy ground by blasting it when wet. Blasting or any other handling of the soil when it is wet should be avoided just as plowing is avoided then.

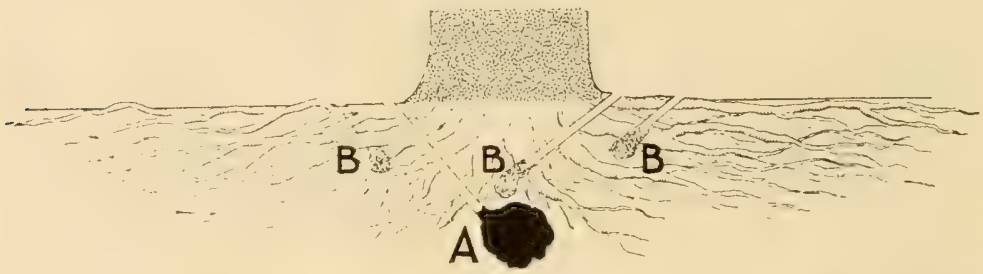

How to place charges under lateral rooted stump. "A" shows how to place charge when the cap and fuse are used and one charge is relied upon to remove the stump. "B" shows how to place three small charges under main roots when stump is to be removed with several charges fired by electric blasting machine. Use either method " $A$ " or " $B$ " - never both.

Nature of Stumps. The three main types of root growthtap root, semi-tap root, and lateral root-are shown plainly in the cuts on this and the next page. If the man who does the blasting has a mental picture of these general classes of root growth, he will know what to probe for and to expect when he investigates a stump. Hemlock and sassafras are examples of the laterals, white pine and most oaks are of the semi-tap root type, and southern pine and hickory of the tap root.

A particular variety of tree seldom grows true to one type of root in all soils and locations, however, hence the judgment of the blaster and what his probing rod tells are doubly important. Hemlock, for instance, when it grows in the wet places it prefers, seldom sends roots down more than a foot or two. But hemlock trees that grow on hills, particularly in loose soil or among stones, will develop roots which very much resemble those of a normal white pine. The true tap root trees, which in soft, loose soil send down main roots almost as big as the trunk several feet, in harsher or poorer soil often develop roots split up and running out sideways like white pine trees do in open soil. It is well for every blaster to understand the kind of roots his stumps are likely to have, taking into consideration the variety of the tree and the nature of the soil. Hard ground and high level of standing water force more shallow root growth; open ground and dry ground permits deeper penetration.

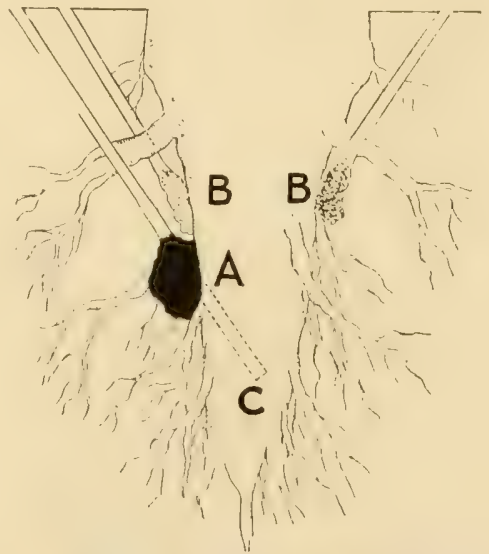

How to place charges for blasting out taprooted stump. Three methods are shown. "A" shows how to do it with one charge. "B" shows how to place two charges when electric blasting machine is available. "C" shows by dotted lines position of auger hole in wood where one charge could be placed to cut off the root and throw out the stump. 


\section{Better Stump Removing}

The length of the roots is an important factor, but should be considered in connection with the age of the stump since the tree was cut, and on the liability of that kind of wood to rot. A white pine stump, for instance, grows roots which even 10 or 15 feet away may measure several inches in diameter - which at least are big enough to interfere with cultivation, if close to the surface, or that give much resistance to the blast if deeper. 'These pine roots do not decay in an ordinary generation. As an instance of another type, a walnut tree and an oak (except white oak) have roots which become small rapidly as they leave the tree, and which decay in a few years, particularly where less than 3 inches in diameter. A stump of this sort, therefore, is easier to remove even while green, because its anchor roots rot off and leave nothing but a bulk of trunk wood on which few short root stubs remain.

Locating Charges of Powder. Reviewing briefly the foregoing considerations of ground and stump, the charges must be placed deep in light, porous or open ground, and may be placed nearer the surface in heavier ground.

The amount of water in the soil has considerable to do with the depth necessary to give proper confinement to the gases. In soil that is dry the charges should be placed at least a foot deeper than in the same soil when water-soaked. For some varieties of small stumps in clay, charges sometimes may be loaded only a foot or so under the surface; for the same kinds and sizes of stumps in sand the charges should be placed at least 2 to $2 \frac{1}{2}$ feet deep. Ordinarily it is best to make the holes for average sized stumps between 3 and 4 feet deep. If all roots above such depth are removed, any left will not interfere with cultivation.

One rule much used among professional land clearers is to place the charges as many inches down from the normal surface of the ground as the stump is inches in diameter at the surface. For instance, if the stump is 2 feet thick, place the charge 2 feet deep.

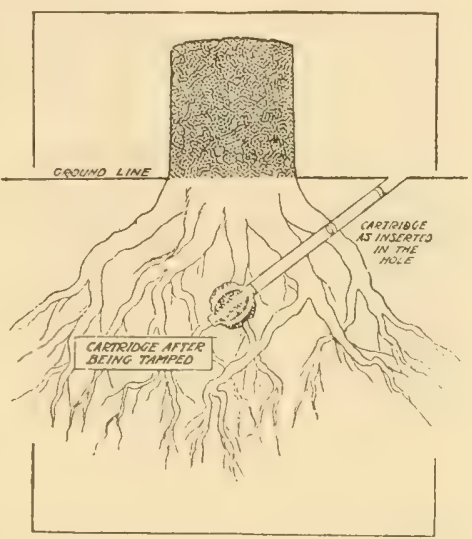

How cartridges of powder swell and fill the hole when they are split and pressed with tamping stick. See illustration page 51 .

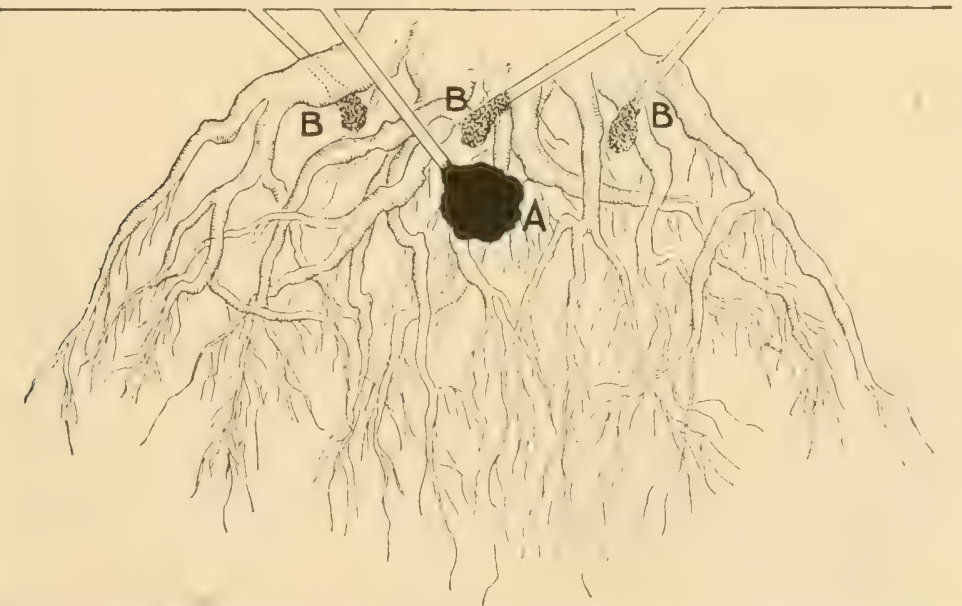

How to place the charges under semi-tap-rooted stumps. "A" shows proper position where one charge and cap and fuse are used. "B" shows proper positions of several small charges when electric blasting machine is used. Use one or the other method illustrated-never both. 
Variations in soil of course must modify this rule.

Charges placed too near the surface tend to blow off or to split the tops of the stumps without pulling cut or even loosening the roots. On the other hand, those placed too deep exhaust their is relied upon ought not to be located as deep as the heavy charges used when the firing is done with blasting caps and fuse. The charge cannot lift an equal weight of earth, nor is there any need for trying to make it do so, as the charge can be placed close under

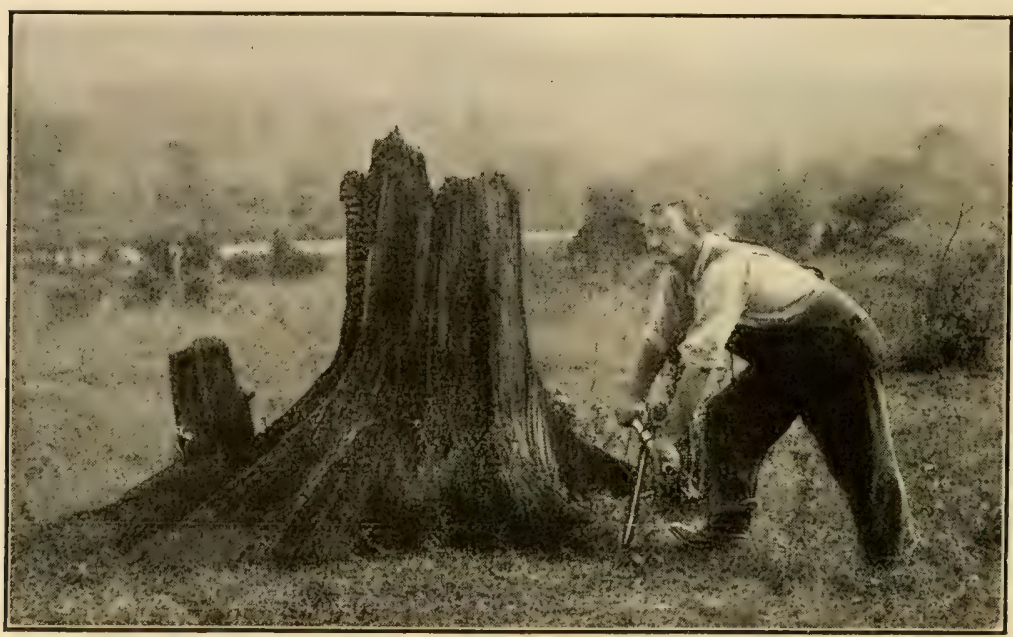

Two close stumps were taken out together. Note the depth of charge hole to get below roots. Before-

energy and force uselessly in lifting large masses of earth, and likewise do not loosen the roots, or loosen them enough to permit of their easy removal.

The method of firing and the spread of roots has much to do with the depth of loading. The light charges generally used when the electric method the roots it is intended to throw out. It is said that a well-balanced blast will normally blow out a crater as wide at the top as it is deep. This is not always true, but the idea serves as an illustration of the need for placing single charges that are intended to take out whole stumps, deep enough

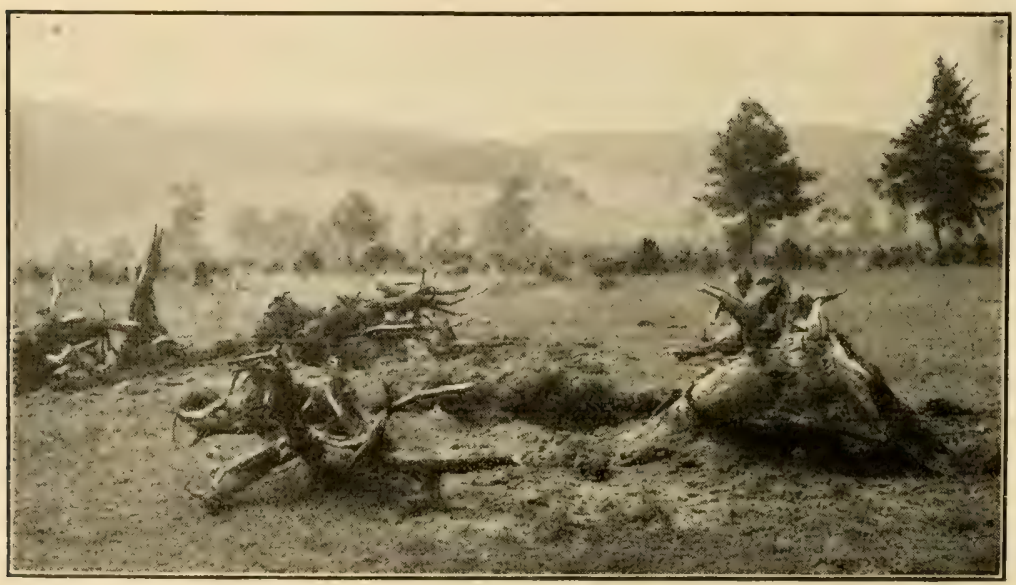

-and after. (Picture taken from opposite side to show roots where they fell.) 
so that the blast will reach sideways to the main roots. If placed nearer the surface, the pull of the body of the stump on the roots is the only force exerted on them, and they usually split off before they come loose from the ground.

The number of charges or holes which any certain stump demands when

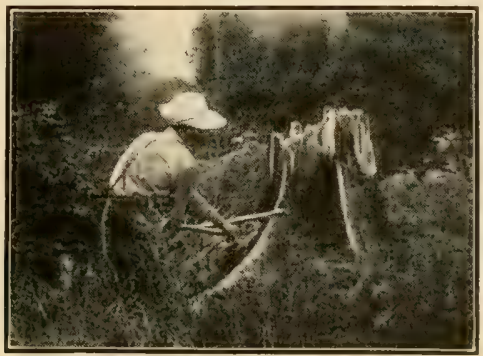

Before blasting-

electric firing is used depends on the number of main or anchor roots. Some blasters arbitrarily limit the number to $2,3,4$, and 5 for certain sizes of stumps, with roots equally solid all round, this means under the center of the stump. On sloping ground it means slightly uphill. Seldom, I owever, are roots equally strong on all sides. If one charge only is to be used, place it nearest the firmest anchorage; if more than one charge, locate under roots.

Tap root stumps to be taken out with one charge should have that one loaded 3 to 4 feet down against the main root or in the root itself. To secure the latter loading, which is very effective, dig the dirt away from one side to a point 2 feet below the surface of the ground. Then bore a hole in the wood with a longshanked wood auger. The hole should be bored about two-thirds of the way through the tap root-never entirely through. Two charges used and fired together is another effective way of loading true tap root stumps. They may be loaded on opposite sides and at a foot or two less depth than the single charge-just deep enough so the pieces of roots left in the ground will be below the level of cultivation tools.

Wide-spreading roots of all kinds offer more complicated problems. Big

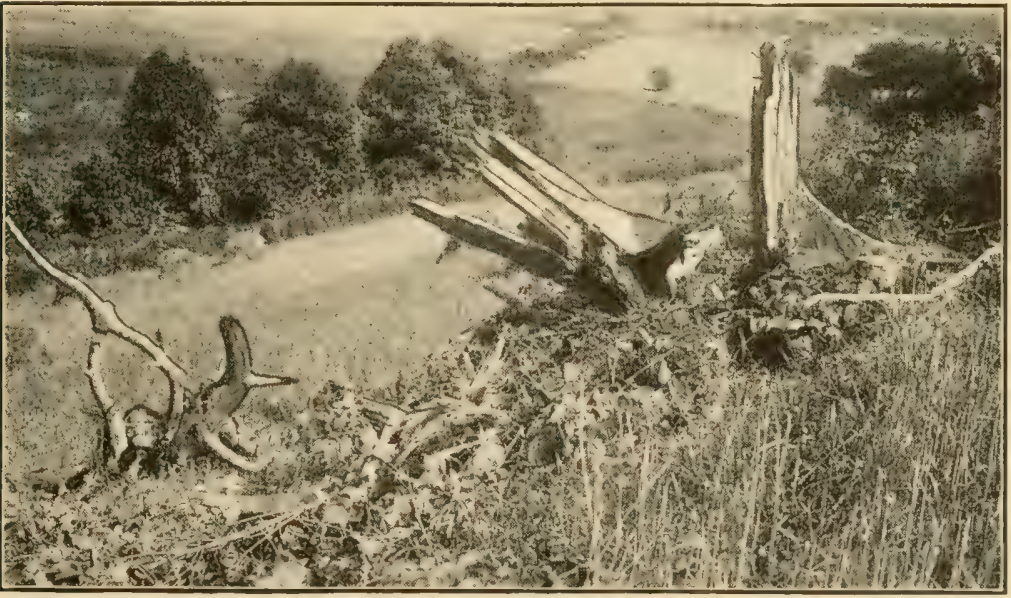

and after. Big stumps, even though not very tight in the ground, should be split with light charges before attempt is made to handle them. Picture taken from different angle to include roots as they fell after shooting.

but this is not an intelligent rule. To place a charge wherever one is needed is a better plan. The cost of electric fuzes is an item to consider in this connection.

Lateral location of charges can be summed up in a few words: Place the powder as near as possible under the center of resistance. On level ground, stumps of this type are hard to take out with single blasts fired with cap and fuse. The electric method of firing all the charges simultaneously does away with considerable trouble and expense. Time is a very expensive item at present. The use of a blasting machine places you where you know just when the blast will occur. You can 
fire numerous charges together, the men having to leave for safety only once, and if the work is near a public road traffic will not be interfered with to any extent.

The average blaster pays entirely too little attention to the apparently unimportant points of difference in soil and in roots. He fails to realize and to act on the knowledge that for some stumps charges should be placed twice as deep as for other stumps that look the same on the surface. The placing of charges out well from the trunk, under the roots, or close under the center of the stump, is another matter too often left to chance. It should be gauged strictly by the conditions found through examination. A free use of all the variations in loading to suit each particular stump will cut down the cost and labor, and make for better results than are possible from any set method of loading. The danger is that a blaster who succeeds in getting out one stump well, will use the same manner of loading for others, relying on that experience rather than on judgment based on observation.

No other element goes so far toward economical land clearing as good judgment in locating charges.

Making Holes in the Ground. Wherever the ground is soft, the bar and sledge will make holes easier than anything else. They also are necessary in dry ground that contains many stones. In dry ground of a heavy nature that is free from stones, however, the soil auger of ten can be used to advantage, as in such work the bar goes down very slowly.

Frequently the holes can be started to a depth of two or more feet with the bar and then finished with the auger. The bar should be on hand at every job to break through stones. In sandy soils of the South, bars can be used to make holes straight down along the tap roots of pine stumps. A wood auger with

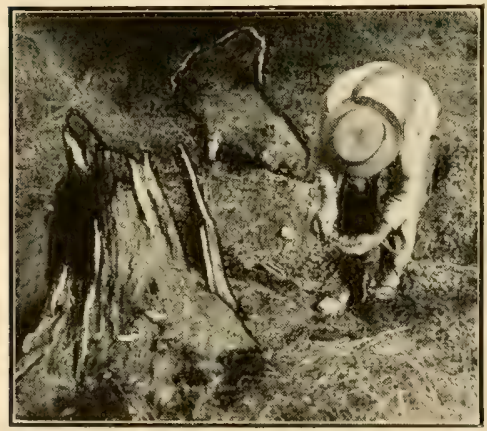

Before blasting. Connecting the wires of several charges under one stump.

a long shank is necessary when blasting tap root stumps by placing the charges in the roots. This method is economical in blasting out Southern pine stumps, and is much used throughout the turpentine industry. In dry ground the making of holes can be hastened by pouring in along the bar or auger from time to time a little water. In case roots are struck in the path decided upon, and they cannot be broken through with the bar, the wood auger again becomes useful.
To make the cavity at the bottom of the hole large enough to hold the required amount of powder is an easy matter when the charges are to be fired electrically, since two or three sticks at the most constitute a charge. When cap and fuse are used, however, the amount of powder needed often is seven or eight sticks or even more, and so many strung along end to end make too long a charge. The hole must be

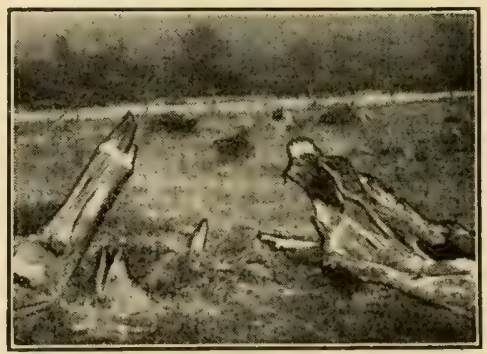

And after. Showing the wide spread of roots heaved out by a multiple charge blast, fired electrically.

enlarged to permit the compression of the powder into a round bulk.

In the Northwest, where stumps often are several feet in diameter, blasters sometimes use a narrow-bladed,longhandled shovel, and tunnel under the stumps in order to get a cavity large enough. This plan is objectionable, however, on account of the difficulty of getting the tamping in tight, as well 
as on account of the time required to do the work. A better plan usually is to scrape out the bottom of a bored or punched hole with the little scraper described on page 39, or even to "spring" the bottom with a small charge of powder, fired without tamping. "Springing" is effective in enlarging the hole- but often forms cracks which interfere with the confinement of the main charge. The method therefore is to be considered in emergencies only. When "springing" is done, no powder must be loaded into the hole until the ground cools. This is very important.

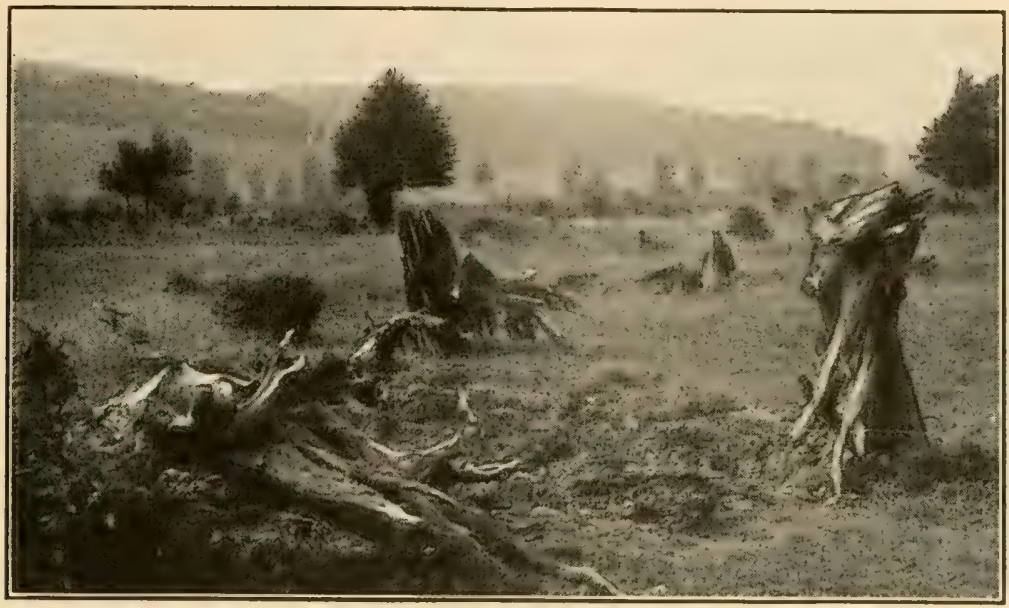

Good blasting - pieces all out, and not too big to handle.

The Kind and Amount of Powder. Atlas Farm Powder, as explained on pages 5 and 6 , is particularly designed for blasting in average soil. Time has fully established everywhere over the country our original claim that it would take the roots of stumps out cleaner, pull them from deeper in the ground, and make smaller holes than the ordinary dynamite so much used for the purpose. If the work is done with any higher percentage explosive it will not be done so well, or for so little money.

The only conditions under which Atlas Farm Powder is not the most effective explosive are those of loose, porous soils such as sand, with practically no water in them. For blasting stumps from such ground, use Atlas Extra Powder of 50 per cent. strength, or Atlas Straight Powder, 50 per cent. These powders are not as economical as Atlas Farm Powder, and tend to break and tear the roots off close to the level of the charge rather than to pull them out. But their action is so violent and quick that they do their work before the yielding sand can give way.

The amount of powder required per stump cannot be stated in any set way. Each stump, with its particular root system and its own kind and conditions of soil, is a problem in itself. Experience is the best teacher, and the blaster who takes careful note of what happens when he shoots a stump will know best how to load the next one. Keep a note-book record as work proceeds.

It is well to know in advance what to expect of the blasting, in order that good results will be secured. A proper stump blast will not have a loud report. If it does there is a waste of explosive or poor loading in some way. The dead, muffled report is the effect to work for. The blast should lift all or nearly all of the roots out, but should not throw them far, and should not throw much dirt or make big holes. Big holes and high-flying roots and dirt are signs of too much powder, or perhaps too shallow loading if the blast leaves some roots tight in the ground. The amount of powder must be balanced against the weight and resistance of the stump 
and the ground anchoring it. Carefully balanced charges will make wonderfully clean jobs while laying the broken pieces of the stump close beside the blast or only a few feet away.

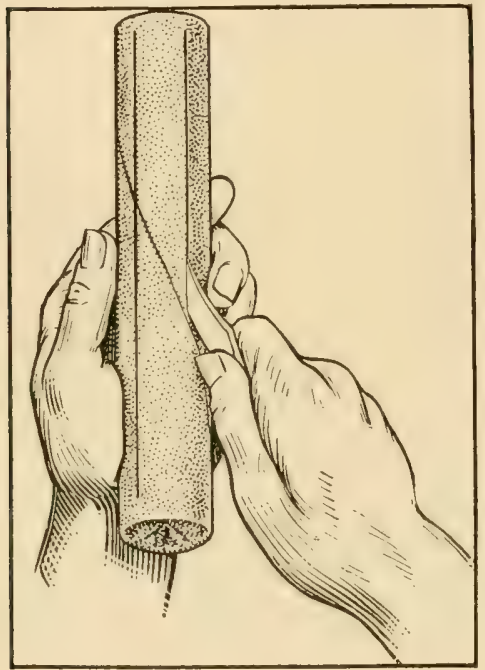

Slitting the paper wrapping of stick to secure compact charge for dry hole.

Some authorities say that a pound of explosive should be used for each foot of diameter of stump. For those up to 30 or 40 inches in diameter this rule will work. For larger stumps $1 \frac{1}{2}$ to 2 pounds are required for each foot of diameter. A rule for the enormous stumps of the Northwest is to square the diameter of the stump in feet and to use this figure for the number of pounds of powder.

Finally, we give a table below which shows the charges that gave perfect results in actual field work. These figures are taken from records made by the Kentucky Experiment Station and by our own men. In using them as a guide, it must be remembered that identically the same results can be secured only under the identical conditions of stump and soil.

Amount of Powder used for Blasting Stumps

$\begin{array}{ll}\text { Kind of Stump } & \text { Diam. } \\ \text { Inches } & \text { Sticks } \\ \text { Used }\end{array}$

Dead Oak............... 12

" $\ldots \ldots \ldots, 16$

Dead Pine......... 16

Dead Oak.......... 8

" $\quad . . . . .30$

"

"

"

“ 34

Dead Pine. ........... 14

Green Oak......... 16

Dead Oak......... 24

" $\quad \ldots \ldots \ldots .38$

"

“ 30

Dead Snag........ 20

Dead Oak......... 27

Green Black Gum... 16

Dead Gum......... 24

Green Sugar Maple.. 16

Dead Oak............. 26

Green Gum........ $15 \quad 3 \frac{1}{2}$

Dead Walnut...... 10

Dead Hemlock...... $15 \quad 2$

Dead Pine......... $40 \quad 7$

$\begin{array}{lllr}\text { " } & \ldots \ldots \ldots \ldots & 24 & 5 \\ \text { " } & \ldots \ldots \ldots \ldots & 20 & 4 \\ & & & \end{array}$

Loading Charges of Powder Under Stumps. It is well to delay the preparing of primers (putting cap and fuse together and inserting cap or electric fuze in stick of powder), till after the holes are ready to receive the charges. In big stump blasting operations, as in sections where cut-over and logged-off land is cleared, and in the turpentine sections of the South, the hole-making crews and the loading crews work independently, the former often days ahead of the latter. In ordinary farm stump blasting, the priming may well be done in the field just before the loading. Another good plan is to prime enough sticks at the beginning of each day or half day for that time, and to carry them along in a basket or box separate from other explosives.

Run the tamping rod down each hole to see that it is clear of stones, fallen 48 dirt and projecting roots, and measure it for comparison with the charge. 
Estimate the amount of powder required as explained on page 47 . If the amount is more than a couple of sticks, the charge likely will be too long when the sticks are placed end to end in the hole-that is, the powder will not be directly under the spot it ought to be. The remedy is to make sure the hole is enlarged at that point (which should be directly under the main resistance of the stump or root, as the case may be) and to compress the sticks endways till they swell and fill the space. To make them do this, slit the paper wrappings of the sticks with a sharp knife. There is no danger in this operation. When water rises in the hole, however, the wrappings of the sticks should not be broken, as a rule.

It is presumed that the blaster has prepared his charge by this time (primed it) according to the directions on pages 8-13. He should have, therefore, if he expects to do the firing with blasting caps, a stick of powder to which is tied a piece of fuse cut 3 or 4 feet long and crimped fast to a blasting cap inserted in the powder. If the firing is to be done electrically, the stick of powder will be primed with an electric fuze. bulk, the first stick should be placed in the hole and pushed home with the tamping rod. There is no danger in pushing on the powder. Press it gently but firmly to the bottom.

Each of the remaining unprimed

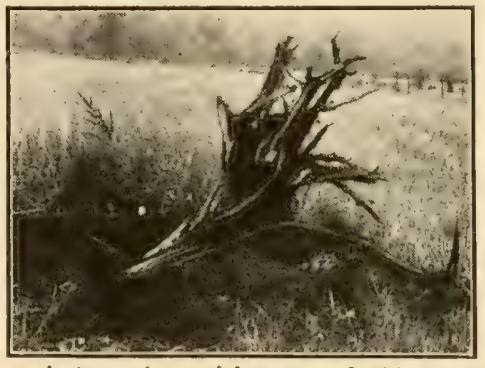

A ten minute job removed this root, which broke a binder platform and caused a loss of $\$ 25$.

sticks of the charge should be pushed home and compacted separately, and the stick containing the primer should be put in last. It should not have the wrappings slit, or at least not over the upper half containing the cap. Be careful to see that no dirt or stones get be-

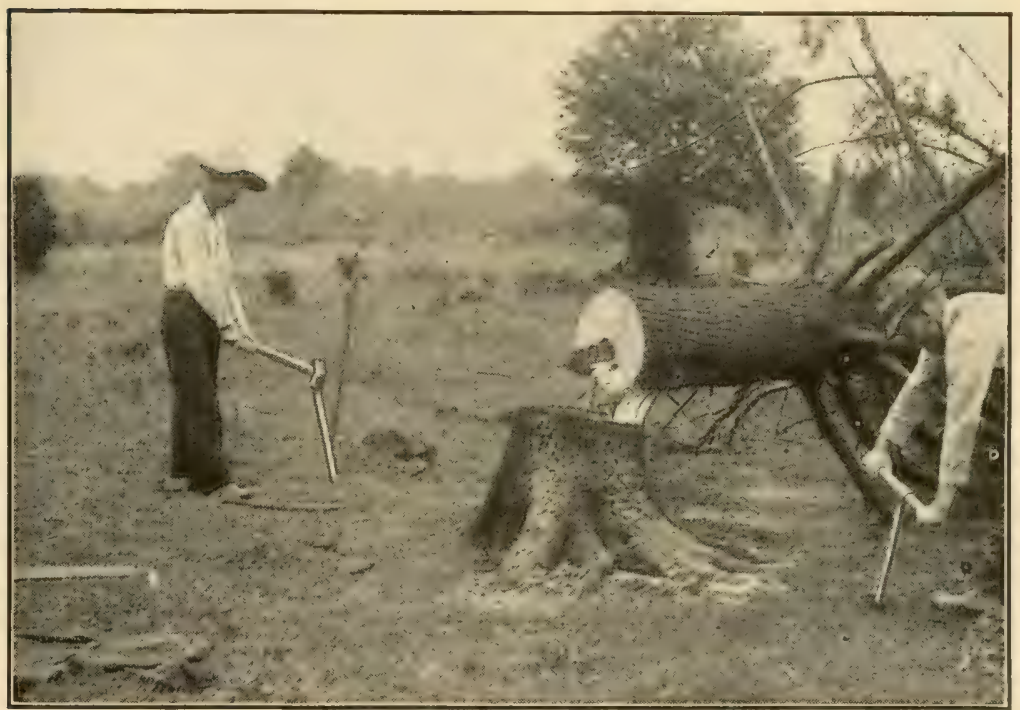

Green stumps come out better when several charges, fired all together electrically, are used under each one. See photo. on following page.

When the hole is known by test to be large enough to hold the powder at the right place in a more or less compact tween the sticks of powder in the hole, and that they all are forced into firm contact with one another. Obstructions 
or air spaces may prevent part of the charge from exploding.

When all the powder is in place, tamping should begin. The material should be damp, and the more like pure clay it is, the better. Have a shovel to dig and to carry tamping material if necessary. Lack of a shovel may tempt a blaster to use poor tamping material. It must be packed solid. Begin by rolling in a handful of damp ground and shoving it down as the sticks of powder were shoved. Press it, but do not hammer or pound it. After there is a few inches over the end of the charge, however, you can tamp it as solidly as you like. Be careful that the fuse or wires are not broken or sharply bent. Hold them to one side with one hand while the other hand works the tamping rod. Fill the hole.

In case there is a depression at the hole, particularly if it is on the downhill side of the stump, a small pile of dirt should be placed over the spot. It is well to investigate any hollows be- with an oil, gasoline or other torch, or with a red-hot iron. The latter is good when many fuses must be lit in quick succession, though no better than a blow torch using gasoline for fuel, such as machinists, painters, and plumbers have

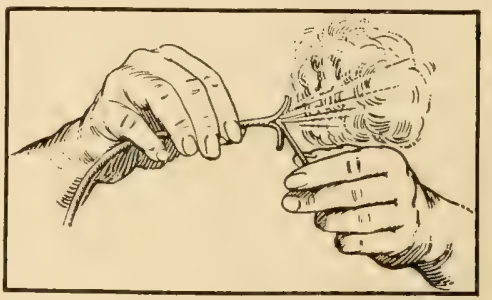

Stick the burning head of a match against the powder to light fuse surely.

for soldering. In the hands of a man who knows how, however, matches are about as fast and are more convenient and less troublesome. The way to use them is to split the end of the fuse back far enough

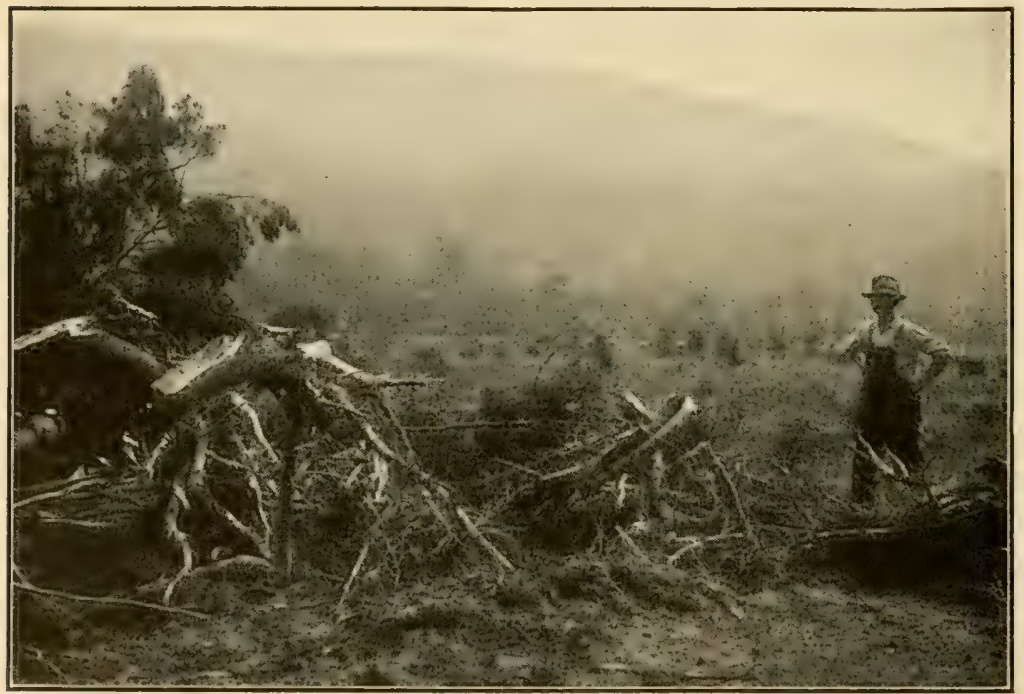

The green stump shown on preceding page-blown out complete. Note how all roots came free from the dirt.

tween roots, and to fill them with dirt solidly if they need it. Groundhog, skunk and even squirrel and gopher holes permit the escape of the gases and interfere seriously with the effectiveness of the blast. They should be filled and tamped. Avoid placing any stones in the tamping or over the top. They are likely to fly like bullets.

Fuse may be lighted with matches, 50 to expose some fresh powder, or to slice off a chip from the outside of a bend. Then scratch a match and stick the burning head instantly-before it flares -against the powder. The whole thing takes only a second, and no amount of wind will prevent the success of the operation when it is done quickly.

Electric firing is explained at length on pages 13 to 16 . 
Test Loading. The suggestions and directions for placing charges and for determining the amount of powder required for any particular stump, as given on preceding pages, must not be regarded as hard and fast rules. The observe and experiment more widely than he usually does.

The Location of holes, number of holes, amount of powder to use, all can be learned by test. A few shots will tell the story under any conditions. If the

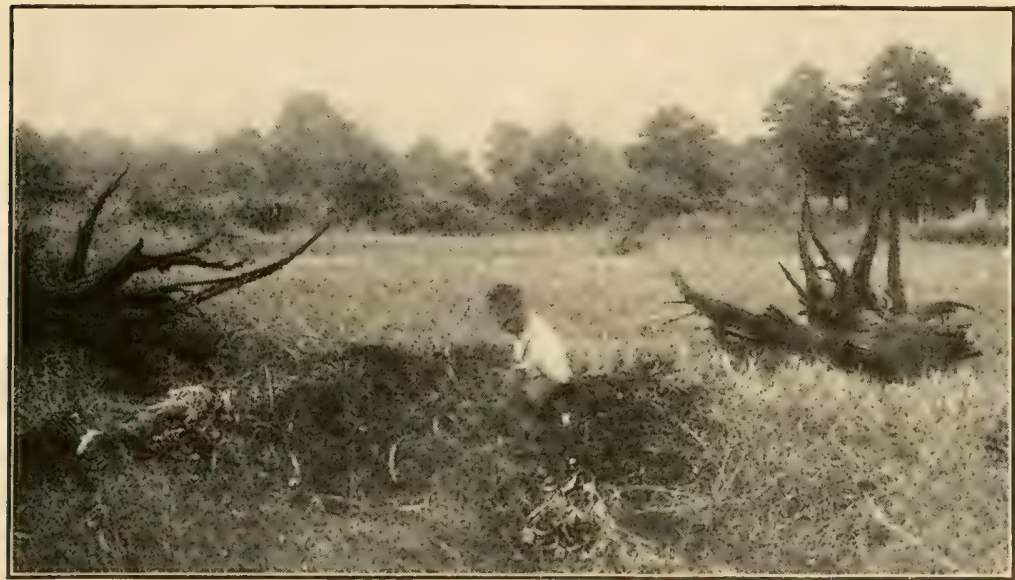

Complete removal, but big chunks and a big hole. Atlas Farm Powder would have broken up the stump better and thrown out less dirt.

main reliance at all times must be placed on experience and observation of results. The beginner should blast one stump at a time, note the effect he secures with the loading used, and vary it as seems to be required. The old hand at the work, who is prone to follow his own special ruts to his own loss in time and ease, and to the loss of money in excess powder used, should first few shots are made one at a time and each next one loaded a little differently, the result is bound to be better than without the test blasts.

Fuse. Be careful to prime charges according to directions. Powder is easily set on fire, and may burn without exploding, or may explode with little force if set on fire before the blasting cap goes off. Then you not only lose time

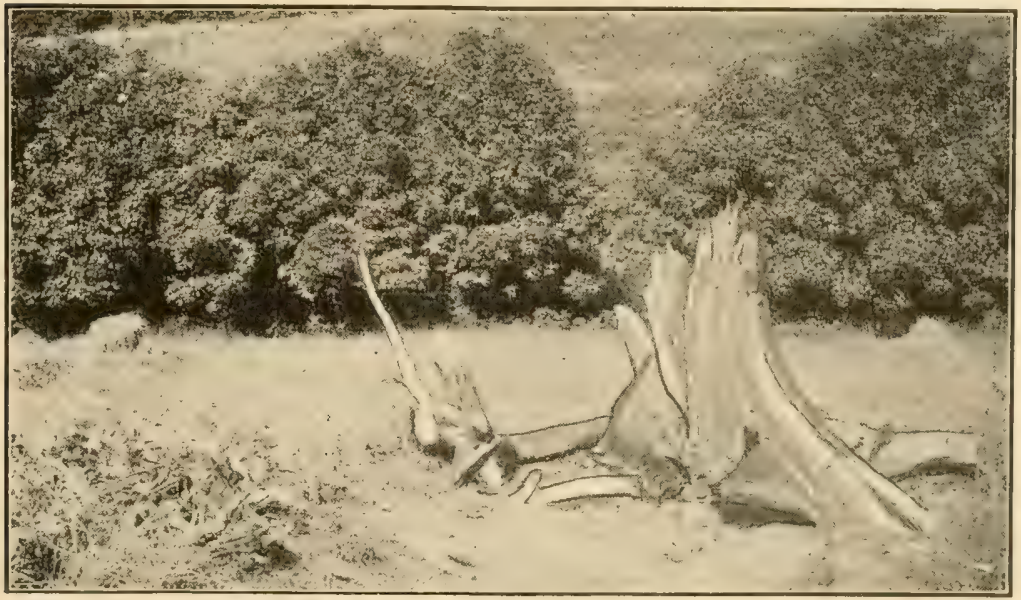

Partial blasting with light charges, roots to be pulled by horses. 
Better Farming with Atlas Farm Powder

and money, but expose yourself to the poisonous gases from burning explosive. Be careful in loading the primer not to kink the fuse.

Keep the ends of fuse dry. Fuse takes up moisture and water like a blotter. A few minutes only are required to dampen many inches, and to cause a misfire.

Deep Loading. The average man is inclined to load charges too near the surface. It takes work to put holes down more than 3 feet. In some places even 2 feet seems pretty far down to the man at the upper end of the bar or auger. When in doubt, go down. More under the center of the stump or root. To load between the stump and the hill, or under the upper side of a stump, often is good practice.

Loose Gravel and Sand. 'To load charges in loose ground that caves into the bar or auger holes, making it hard to get the powder to the bottom, provide one of the Atlas tube-bars, described on page 24. This consists of a pipe, with a bar inside that are driven into the ground together. Then the bar is withdrawn and the powder loaded through the tube.

Hollow Stumps. Whenever stumps are completely hollow or have centers

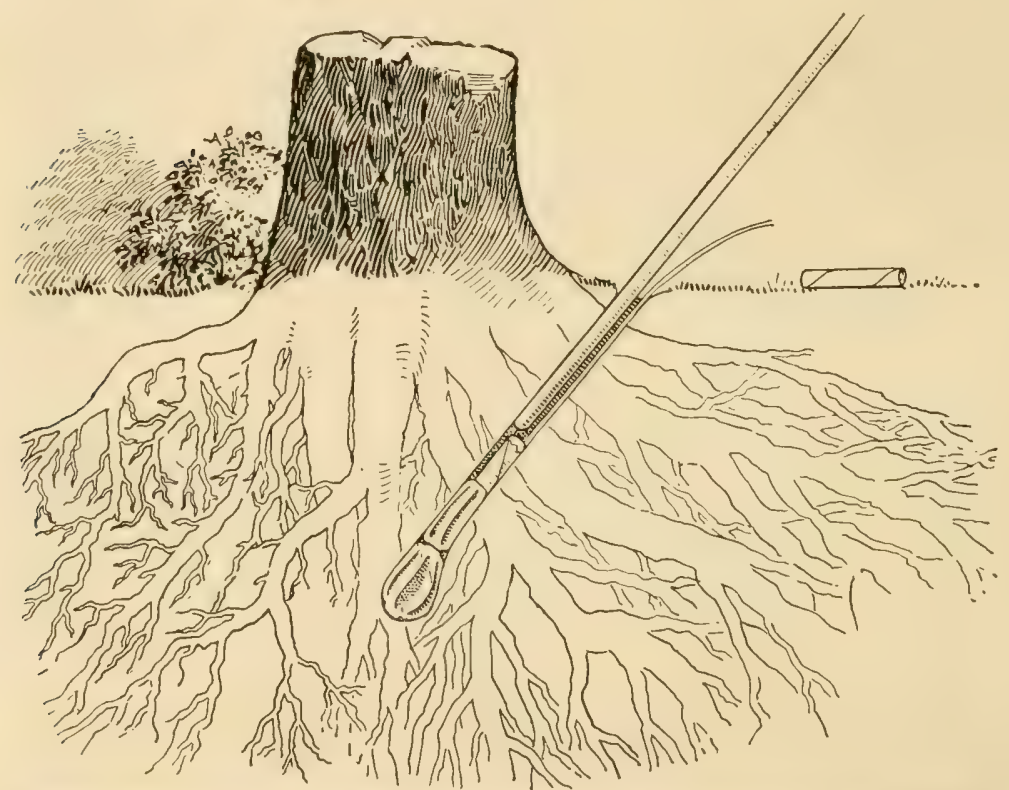

To show sticks of explosives expanded, as permitted by splitting of stick wrappings, in bıg hole.

powder is required to blow out roots with deep loading (whether it is necessary or not), which means that charges too deeply placed are wasteful. But they are not so wasteful as the shallow charge that fails to dislodge the roots, and which must be followed by second or third blasts, or, worse yet, by expensive digging or pulling.

Hillside Blasting. The placing of charges under the point of greatest weight and resistance is a primary principle of blasting. To carry it out, whenever there is a bank of earth that is higher on one side of a stump or root than on the other, the charge must be located toward that side rather than filled with soft, decayed wood, they are hard to blast out with fuse. Matters can be helped somewhat by filling the hollow part with earth well tamped. The best method is to use an electric blasting machine for firing and to load several small charges out under the roots.

Number of Holes Under a Stump. The Idaho Experiment Station, dealing with the large stumps found on its logged-off land, says that "One hole was found sufficient for removing stumps up to 18 inches in diameter, while two holes were sufficient for removing stumps up to 30 inches in diameter, and three holes for 40 -inch stumps. Four 
holes were generally found ample for removing larger stumps, though for the largest, five holes were sometimes found necessary."

This experience is with electric firing. Our own tests have forced the conclusion that two or more charges should be placed under 18-inch stumps, unless

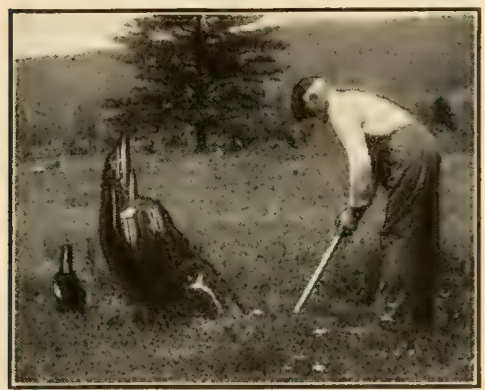

A pine root that didn't seem to be very big. Before blasting.

they are of hardwood well decayed. A pine stump, for instance, will come free from the ground with as many charges as there are main anchor roots much easier than with fewer charges. That is our rule, therefore-put a hole under each main root. To state the matter another way, hitch the blast short to ing is of more importance than determining upon the position, number and depth of holes to be made under large stumps. The exercise of judgment on these points will do more than anything else to reduce the amount of powder used and to secure the highest possible efficiency."

Tamping. Damp clay makes the best tamping material not only because it is of a heavy nature, but because it contains moisture.

The stump blaster can assist matters when the ground is dry, and when it is light, like sand, by supplying the missing factor-the moisture. A bucket of water in the hole with the tamping helps greatly to make a blast successful. So great is the effect of wetting the ground that the supplying of water makes all the difference between failure and effective results when stumps like live oak must be removed from dry sand.

Beginners. It is not well to begin operations on the largest or toughest stumps. Skilled blasters almost always shoot out some of the easy ones to begin with, in order to see the exact effect in the ground at the particular place. Beginners should take the smallest and oldest stumps first.

Making Holes. The tendency is to start holes too close to the bodies of

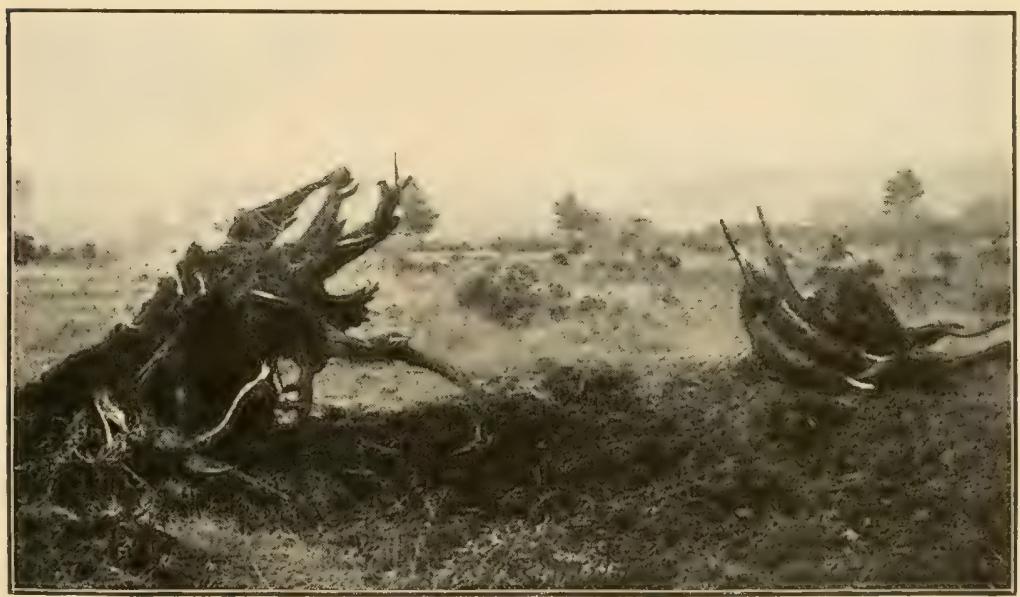

After the old piece was blown out, the original root system was found undecayed

the load. The loading takes less time, the stump is fully cleaned out and well broken, while the hole left in the ground is small.

The Idaho Station says further: "One should have a good knowledge of the root system before undertaking this part of the work (locating holes). Noth- stumps. The slant takes the bottoms of the holes under the trunk, and in some cases holes from opposite sides will almost meet. If the holes are started well out from the trunk better distribution of the charges will be secured.

Boring Machines. Hand boring of holes is almost as cheap as power boring, 
except on large jobs, but it is much slower and requires many more hours of labor to accomplish the same result. Boring machines therefore are economical and desirable wherever the job comprises many acres or the number of stumps runs into the thousands.

Probably the most satisfactory machines are electric ones, consisting of 6 to 10 horse gasoline engine, electric generator and drill or motor heads, to which the augers are attached. Two drill heads usually are used to each ma-

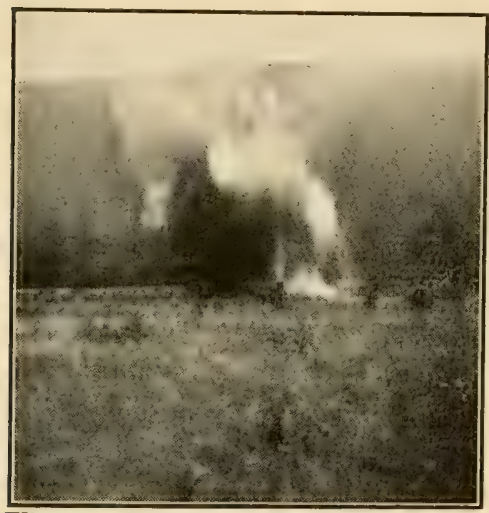

What a big stump blast looks like from the end of a 250-foot leading wire.

chine. We recommend this type of boring machine.

Other types, however, are in use and give satisfaction. Among them are the compressed air machine, the steam machine and the direct geared machine.

We shall be glad to advise anyone interested in the possible use and purchase of one of these machines of any type.
Southern Pine Stump Blasting. A typical stump blasting operation in Georgia works as follows, where the roots are used for distillation (pine).

The workmen are divided into crews -one for boring, one for blasting and others for gathering the roots, hauling and loading on cars. The blasting crew consists of a foreman-engineer, four men handling two augers (electric), and one man to handle the cables. This

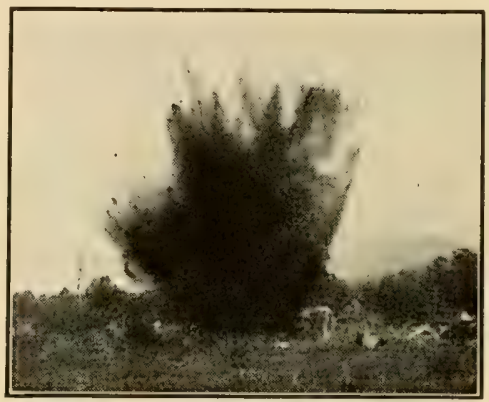

Too much dirt and smoke in the air - a waste of explosive.

crew is able to bore 500 to 700 holes a day (into the wood).

They should load and blast 200 to 250 stumps a day. The powder is distributed to convenient points over the job in a cart, the proper number of sticks being primed at the camp beforehand. Sticks of powder are almost always slit to make them fill the holes. The aim is to remove the stump from the ground completely, and to bring along the "fat" lateral roots, and it is important that they be broken just right for handling.

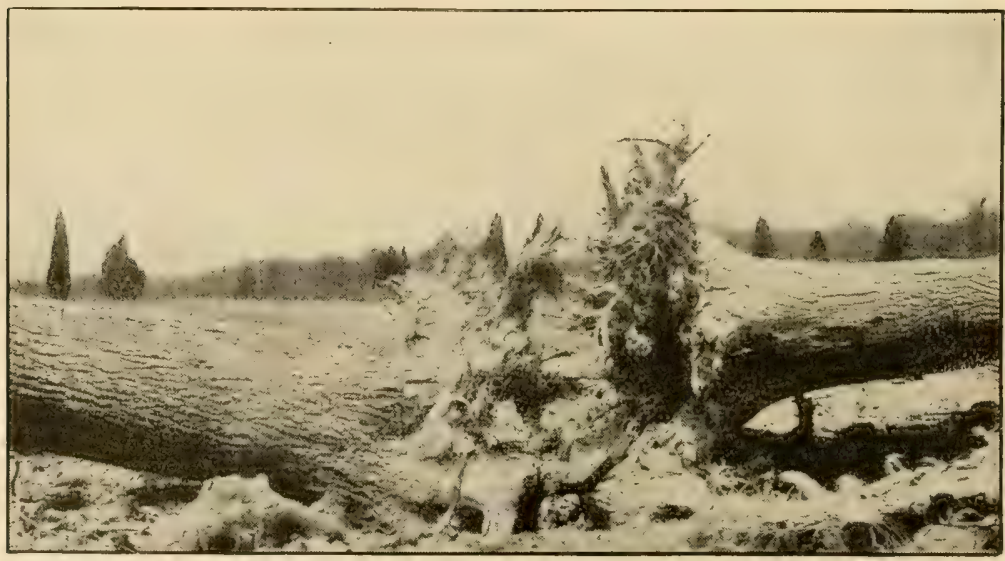

Two gum trees, the larger four feet in diameter, blown out with Atlas Powder. Both afterwards were split up with the powder. Ground left clear of roots, and the roots clean. 57 
Varieties of Stumps. Difference in rate of decay and in root development make necessary corresponding differences in loading. Some of the typical varieties encountered, with suggestions for blasting each, are as follows:

White Pine is a true semi-tap root tree in most soils. The roots not only go down, but spread widely in all direc. tions near the surface. Place one charge directly under the center of the stump on level land, and others 2 to 5 feet out under the anchor roots. It is no use to try to blast out big white pine stumps with single charges, even when fuse firing only is available.

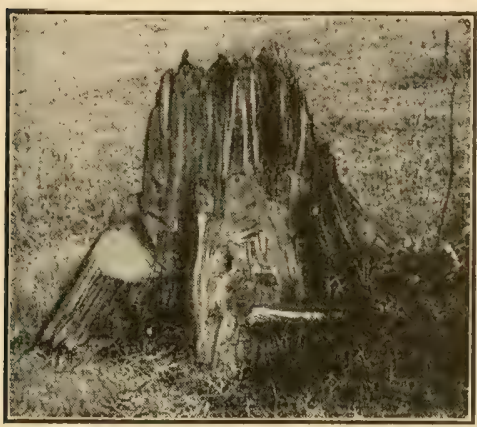

Before blasting. A stump that was loaded with a single charge, placed too shallow at that.

Oaks have the same general type of root development as white pine. The roots, however, are slimmer and hardly so long. To take out green stumps a heavy charge should be placed under the center and lighter charges out under the main roots. The most important fact about most oak stumps, however, is that the roots rot in a few seasons. After 5 to 10 years about all there is left of an oak stump is a bulk of trunk wood with short stubs. In this condition they can be blasted out and broken up with single charges very satisfactorily. White oak decays slowly. Oaks have a tendency to sprout.

Chestnut is another semi-tap root variety with much the same characteristics as oaks, except that the roots decay more slowly, and sprouting is more marked. When chestnut stumps are left alone the centers rot out of the trunks, but the sprouts keep the roots alive, and the net result is that the whole thing is harder to remove after ten years than within a year after the original tree is cut. In some places oaks present the same condition. Maple is a great sprouter. These woods, however, are soft and more easily broken, hence come out with lighter charges as a usual thing. When the stumps are small the blasting may be very light, and any roots left sticking in the ground will be torn out or cut off by the plow.

Clumps of Brush, often removed by grubbing alone, will come out with far less work and with less expense if they are blasted lightly. Wages are too high now to permit the use of men when their time can be saved by the use of powder.

Locust, Sassafras and other strictly lateral root stumps should be blasted by locating charges 2 to 3 feet under the surface of the ground. Most of the roots are in the top foot or so, but the deeper loading will cause wider breaking, and likely will result in the removal of all roots large enough to interfere seriously with cultivation.

Tap-root Stumps such as Southern pine have been discussed on page 41 . Hickory usually develops tap-roots and should be blasted the same way, which consists in loading proper powder

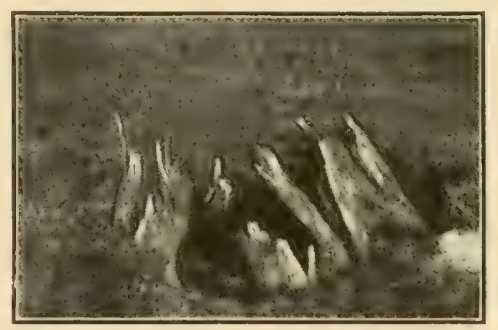

After the blast. Center of stump was blown out and roots left in the ground.

charges 3 to 4 feet underground against the roots, or at somewhat less depth in the roots. Taking into consideration the time and labor required, farmers usually will find that to put the charges in the ground against the roots is the most satisfactory plan.

Standing Trees. Green or dead trees may be blasted out, roots and all, without first cutting them down. The tops, in falling, help to pull the roots out and help to make a cleaner job of the removal of the stump than otherwise might be made. After the 
tree is down it can be sawed, chopped or blasted into pieces for removal or burning in less time than it could be cut down and afterward the trunk and stump handled separately.

As a rule, slightly heavier charges are needed for trees than for stumps of the same diameter. This is owing partly to the weight of the tree and partly to the fact that the tree usually has a stronger root system. Loading, however, should be done as directed on pages 43 and 47 . Electric firing is better than fuse and cap firing, because trees nearly

always require a distribution of the force. In case the firing must be done with fuse and caps under large trees, it is well to load and fire one or two relatively small charges under one side of the root system, to break off the roots and to loosen the ground, and then to throw the tree over with a heavier charge fired afterward under the other side.

\section{Removing Green Stumps or Waiting. Green stumps} without question are harder to remove than they will be five to ten or more years later. Everyone who has fertile cut-over land faces the problem of whether it will pay best to proceed with the clearing at once or allow the stumps to decay somewhat first.

As a general rule it does not pay to wait more than a few months, nor even that short period when there is a good market waiting for new ground crops. The loss of time itself is a serious factor. Farmers and land owners will find themselves growing older at a rate which ex-

ceeds the rate of decay of the stumps. Then there is the loss of money that may be made from the crops grown on the new, rich ground. If money is not available, usually it should be borrowed, and the land worked to pay it back. There is profit in such a transaction.

\section{Combination of Blasting and Other Methods.} The amount of powder required may be cut down greatly by only splitting the trunks of the stumps and somewhat loosening the roots, instead of blasting them entirely out. When this is done

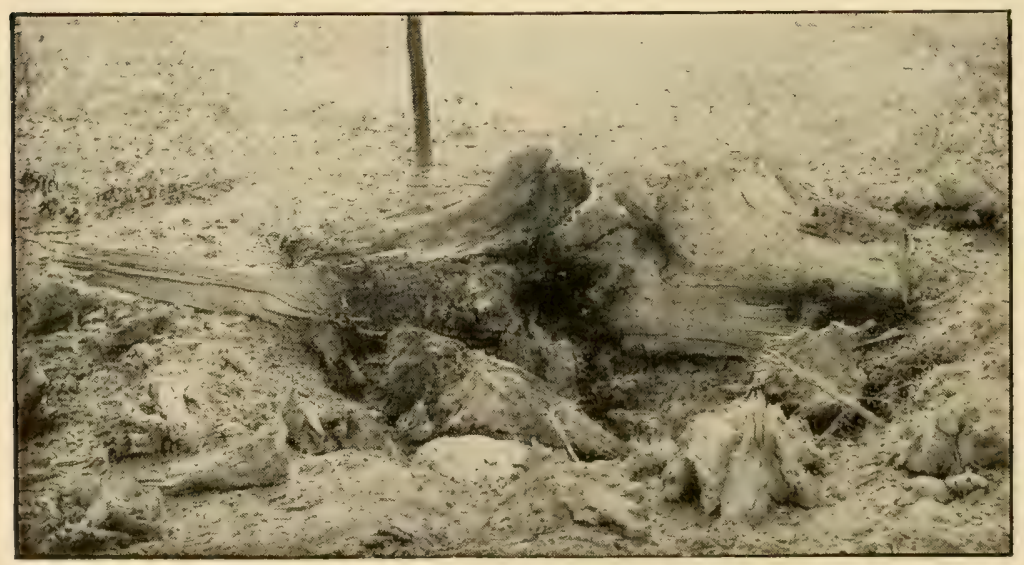

Result of a good stump blast. Note how the dirt is cleaned off the roots, and how they are split up small enough for easy handling and burning.

the pieces will have to be pulled out with a heavy team, stump puller, or burned out.

If the split stumps are burned without pulling, the roots can be made to burn deep into the ground, provided they are dry, by making use of the charpit system. To accomplish this, watch the fire in order to note when the top is consumed. Before the coals 
lose their intense heat, heap them over the root ends, and over that place $t$ to 6 inches of clay. The covering should be almost. though not quite, air-tight.

Light blasting to split stumps, followed by pulling of the pieces with a team or a stump puller, is justified when money is scarce and labor is plentiful at low cost. This practice is not best when labor is scarce or high priced, nor when the job must be completed in a short time. In fact, the comparison of the pulling and blasting combination with complete blasting serves to establish one of the main advantages of blasting, which is to get the job done

Large Green Semi-tap Root stumps perhaps can be handled by a combina-

tion of methods to greater advantage than any other class of stump. They are too large to be pulled whole with any satisfaction, but the pieces can be pulled out one by one easily. If it is not desirable for any reason to blast them out completely, either with one shot or several, the combination should be the next thing considered. In the Northwest this light blasting is called cracking. It is a serviceable method of clearing newly cut-over oak lands of the East and North, where the stumps are a foot in diameter, or a little larger.

When Blasting is of Advantage. It is by no means claimed that blasting is the only good way of removing stumps, or that it is the "best" method under all circumstances. There are times and places when other methods are better suited, just as there are times and places when blasting is the only method that a sensible man would use. To make the matter clear, a brief consideration of the advantages of blasting is necessary.

The one great outstanding advantage under present conditions is that one or two men can accomplish by blasting in a few days what would require a crew of men weeks to do by other meth-

speedily, cheaply and easily. If the roots are to be used for kindling or other fuel they are ready for hauling; if for distillation, no chopping or sawing is required; if they are to be burned on

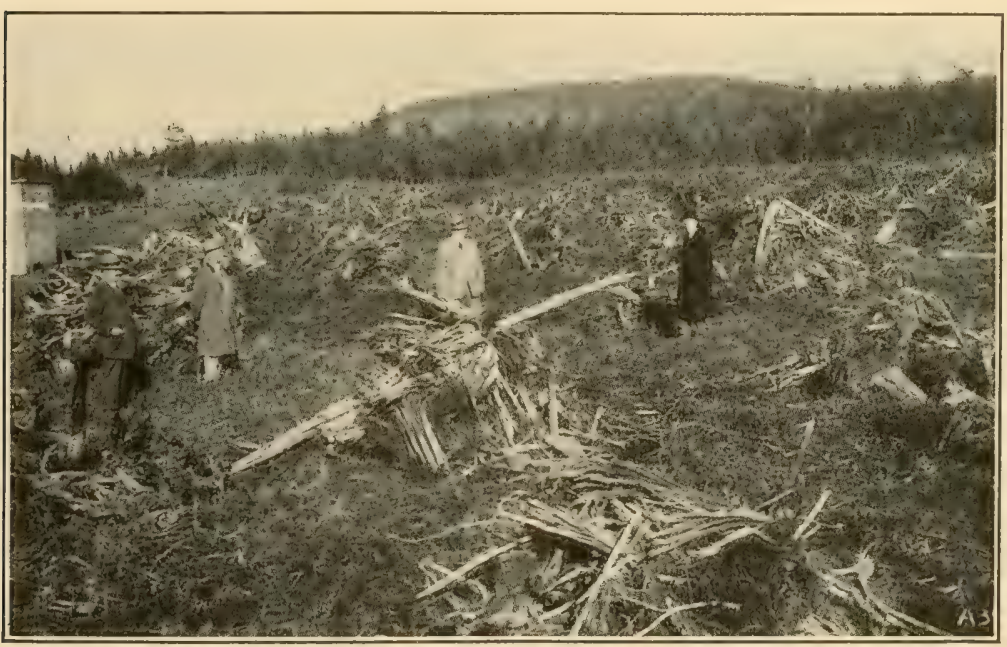

The sort of wreckage perfect stump blasting should give. The pieces are shattered so they are easy to handle and so they burn well.

ods. Men are scarce and wages are high, while powder can be bought and used by almost anyone.

The second point in importance is that blasting breaks and splits the stumps into pieces that can be handled the ground they can be gathered up by hand and hauled on sleds to small piles, instead of requiring heavy machinery for piling. When stumps are not broken up in process of removal from ground, their disposal costs as much as 
Better Farming with Atlas Farm Powder

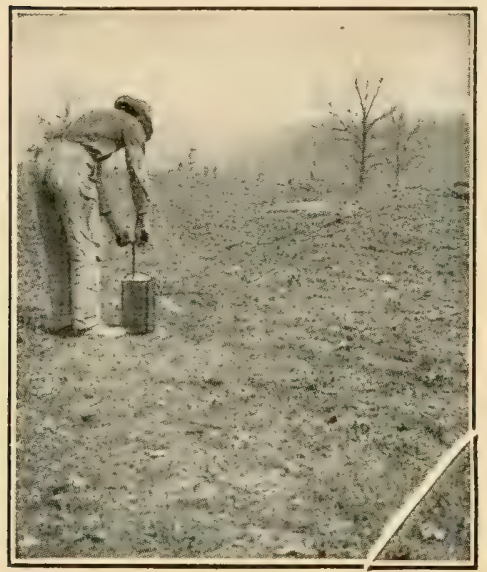

The charges are placed and the wires connected, the stock has be $\mathrm{n}$ chased away and the helpers warned bact- - now the blaster is ready to shove the har, dle of his machine down and to fire the exp;osive.

their pulling as prrsved by government figures. When they are broken, the disposal cost is much lower. When stumps are pu!'ied whole, it is necessary to use a pick to remove the mass of dirt which comes with the stump. Blasting not only breaks up the stump but brings it out clean.

The actual cost of blasting as compared with other methods may be lower or higher, depending on local conditions of s,round, stumps, labor and the like. In many instances it is lower. Blasting calls for no purchase of expensive machinery or equipment. There is no big investment for tools, which is a point in its favor in the case of small jobs. What little outfit is required costs only a few dollars, and more than that, is small and light enough to be carried by hand from place to place if need be. There is no reason for maintaining motive power for hauling it.

As respects the Size of the Stump which should be pulled and which should be blasted, the line should be drawn at the point where a stump gets too heavy to be lifted readily by one man after it is free from its anchorage. In oak clearing this will mean that stumps less than 5 or 6 inches in diameter should be pulled, and those larger should be blasted. When a few dozen stumps are to be removed, as from a pasture or from cultivated fields, blasting alone is the sensible method. When many acres are to be cleared, the small stumps may be pulled, and the large ones blasted out clean or blasted enough to split them, then the pieces pulled.

The Effect of the Blasting on the Soil is a factor to be considered. When the blasting is done in dry weather it is decidedly beneficial from a tillage standpoint. New rround, while rich and productive, rearly always is in need of aëration ar,d drainage, particularly the latter. Fundreds of instances have been naced where wet spots have been dried by the loosening of the under soil, this ioosening obtained sometimes when blasting out stumps. The size of the 'soles made has little to do with this, but the shallow holes give the greatest benefit to soil drainage. The amount of filling that is necessary is little if any greater with proper blasting than with other forms of stump removal.

The Nature and Condition of the land enters into the matter to the extent that blasting is more effective in heavy ground, and is decidedly the most convenient method, if not the only one practicable, where the ground is swampy. Nearly all other methods are at their best in light, dry ground that does not anchor roots so strongly, and where the footing for men, horses and machinery is solid. Blasting is just as effective on hillsides, no matter how steep, as on level land, while many other methods will not do satisfactory work on very much of a grade.

Stump Disposal. There are few sections of the United States east of the Rockies where stumns and roots now do not have or in the near future will have a fair market value. Kindling

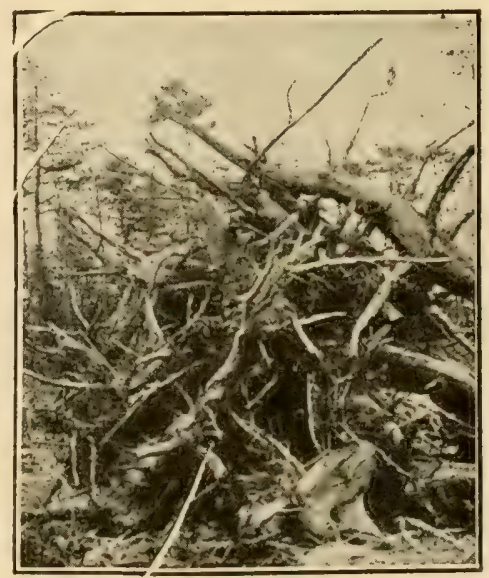

The id eal size and kind of pile for burning stumys and roots. These piles can be built by "nand, in unloading the stumps from a low wagon or sled. The fires can be started and wore roots fed to keep them going. 
wood is needed by every family in America. In most towns it sells at $\$ 3$ to $\$ 20$ a cord. A farmer should be justified in storing five to ten years' supply when he has the wood ready cut and must handle it anyhow to get rid of it.

The use of stumps and roots for distillation purposes unfortunately is restricted to limited sections of the South. Other markets of a similar nature are the lime kilns in limestone sections, and the ever-present boiler in factory, mill, school, office and home. Wood for fireplaces is a field which every farmer who has stumps to sell should investigate. There are mineral elements in roots which make them sparkle and give off a brilliant flame without snapping brands in to the room, just as the salt does in driftwood - the fireplace wood so much prized. Town owners of fireplaces to whom this is explained will buy a great many roots.

Failing a Market, however, the pieces must be disposed of on the ground before the land can be cultivated. In many sections enormous piles are built up by means of a derrick operated with engine or horses, or by hitching a block and rope or cable high on a tree or gin pole erected for the purpose. 'The derrick, of course, is re- moved before the pile of stumps is burned, but the gin pole is left to burn too. This method is speedy and effective, but is expensive, as a considerable crew is required to operate the equipment properly. Small derricks that can be moved easily have considerable merit and are open to fewer obiections.

$A$ Better Plan all round, when the stumps have been blasted properly and are well broken up for easy handling, is to hitch a team or one horse to a large stone boat, and to haul the roots into small piles made here and there whereever required and wherever convenient. The fires can be started at once and can be fed with additional roots and thus kept going till the field is clear. This method is speedier than the making of large piles by any means.

Misfires. Should misfires occur in stump blasting, after the wires are disconnected in the case of electric firing, or after waiting several hours in the case of fuse and cap firing, put down another hole within 3 to 6 inches of the original one, and duplicate the charge and loading. Do not pull at the fuse or wires, and do not attempt to dig out the old charge. Many accidents occur every year through failure to observe this caution.

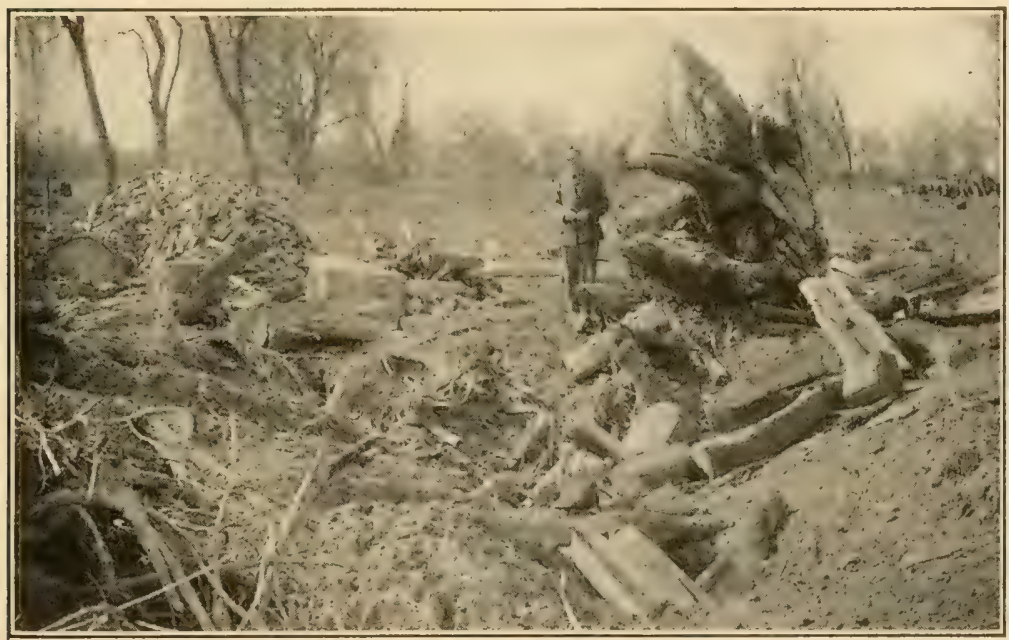

Wood is a very expensive commodity in many parts of this country to-day. It never will get cheaper. Utilization of all parts of the trees that are cut down in land clearing is the thing to do whenever it is possible. 


\section{EVIDENCE}

"One point seems clear, and that is that when stumps are to be removed, the cheapest method is by the use of dynamite."

\section{KENTUCKY AGRICULTURAL EXPERIMENT STATION,} Bulletin 154 on "Blowing Stumps with Dynamite."

"Powder plays an important part in the clearing of logged-off land, as a powerful agent is required to dislodge large stumps. All of the devices for pulling large stumps are dependent on powder to split and loosen the stump before it is pulled."

UNITED STATES DEPARTMENT OF AGRICULTURE,

Bulletin 239, on "Cost and Methods of Clearing Land in Western Washington."

"At the present time few undertake to clear even a small tract of land without the use of powder, and in the hands of an experienced man powder can be made to do a large amount of work at comparatively small expense."

UNITED STATES DEPARTMENT OF AGRICULTURE,

Bulletin 25 on "The Cost of Clearing Logged-Off Land for Farming in the Pacific-Northwest."

"The advantage of using explosives in clearing new land is that a big investment is not necessary as in case of stump machinery. Explosives can be used in some way by almost every settler. The stumps and boulders are left in such form as to be handled and disposed of easily. The roots are freed from soil and the large parts broken up so they can be used for fuel, as is the practice in many sections at present."

UNIVERSITY OF WISCONSIN AGRICULTURAL EXP. STATION, Bulletin 216, on "The Use of Explosives in Clearing Land."

"Where stumps from twelve to thirty inches across have been cut for some time, and the soil is not very sandy or loose, the use of dynamite alone has been found, in practice, to be the most satisfactory method. The advantage of dynamite is that it will not only blow stumps entirely out of the ground, but it will remove the dirt from the roots at the same time, and break up the stumps so that they can be easily handled and burned."

UNIVERSITY OF MINNESOTA AGRICULTURAL FXP. STATION,

\section{Bulletin 134 on "Land Clearing."}

"Explosives have the advantages of thoroughly breaking up the stumps, of not requiring a large force of men for clearing operations or a large cash outlay at one time, and of enabling the work to be done quickly. Where medium-sized stumps have been well blasted the problem of stump disposal is relatively simple. Where the stumps have been pulled by a stump puller without the use of powder, the problem of disposal is more difficult. The general opinion throughout this region is that the cost of disposal practically equals the expense of pulling."

UNITED STATES DEPARTMENT OF AGRICULTURE,

Bulletin 91 on "Costs and Methods of Clearing Land in the Lake States."

"In the removal of large stumps dynamite is serviceable and economical.

"There are many different makes of stump-pulling machinery upon the market. The promoters of these various grubbing devices claim great merits for their respective machines, but catalogue claims should be accepted with great caution.

"In the neighborhood of the writer, and doubtless in many other neighborhoods, can be found such machinery in idleness because it was tested and found wanting. The difficulty with most stump-pulling machines is that if they are strong enough for the work desired of them they are too expensive, cumbersome and unwieldy.

"When these machines are once properly adjusted, their work, provided nothing breaks, will be satisfactory. But the labor of moving and the care of adjusting, together with the liability of breakage, more than outweighs the virtues of any stump-pulling machine known to the writer."

UNITED STATES DEPARTMENT OF AGRICULTURE, Bulletin 150 on "Clearing New Land." 


\section{EVIDENCE}

"Thanks for 'Better Farming.' I just blasted out 15 big boulders. It more farmers would get your book there would be fewer stumps and stones in their way." F.. E. CROSBY, R. F, 1). 6, Iockport, N. Y.

"I blasted the stumps on 160 acres with Atlas Powder. The largest stumps were shot hard enough to split them to pieces. Atlas Powder gave the most satisfactory results, and did its work at an extremely low cost."

FRED LAUGHLIN, Foster, Mo.

"Within ten minutes from the time I started work on the first stump I had it out in pieces that I could handle easily, although I had never done any blasting before. It is easy to use Atlas Farm Powder."

DEAN JOHNSON, St. Louis, Mo.

"We had never seen stump blasting done, but the directions in your book made the way to do it perfectly plain. We blasted 218 stumps with Atlas Farm Powder and got fine results."

\section{GARACOVE FARM, North East, Md.}

"Atlas Farm Powder has proven so satisfactory in clearing my land of stumps and boulders that I am sending you another order, and have decided to clear all of $\mathrm{my}$ land in this manner. It is a great time and labor saver."

IV. F. WINK, Allentown, Pa.

"I have never used anything to beat Atlas Farm Powder for removing stumps. I used one stick to a stump on the dead ones and two on the green ones. I would recommend Atlas Farm Powder to anyone who has land to clear."

LEO G. BARNHART, Zolfo, Florida.

"This morning I tried my hand at blasting stumps for the first time. I had no trouble removing the stumps with Atlas Farm Powder after seeing just how to do it in the book 'Better Farming.' A 12-year-old boy can remove the shattered stumps."

VICTOR M. SHAIV, Cranbury, N. J.

"I have used Atlas Farm Powder on one of my farms near Allentown and find it to be a great labor saver, and a quick way of removing stumps and boulders. The results obtained have been so satisfactory that I expect to clear all of my land in this manner."

\section{JOSEPH C. SLOUGH, Allentown, $\mathrm{Pa}$.}

"It was no trouble at all to get rid of the stumps by blasting. I had never used an explosive before and had never seen the work done. It is easy to blast stumps with Atlas Farm Powder. I shall use your Powder hereafter instead of a stump puller."

R. C. ENGLISH, Port Matilda, Pa.

"Perhaps you would be interested in the results of my first experiences with the Atlas Powder for blasting stumps. It takes the pine stumps out beautifully and takes out the white oak stumps very well. It certainly does make the work of clearing land far less arduous."

\section{MRS. F. J. HANCHETT", Chicago, Ill.}

"In laying out my golf course I had to clear 10 acres of woodland, and I used hundreds of pounds of Atlas Powder for clearing up trees, stumps and ditches. I wish to say that it saved a great deal of time and labor and fully one-third of the cost of clearing."

\section{HUGO STEARNS, Freeport, L. I.}

"I have completed taking out the stumps on my place here, using your $40 \%$ powder with great success. There were 980 stumps, of which 684 were green pine, the trees having been cut the week before blasting. The other stumps were dead lighter. The tap roots of the green stumps averaged 11 inches in diameter. I used 572 pounds of Atlas Powder and it required two men helpers for 19 dars. I had one man one day trying to dig out the stumps but he stopped work as he could not make any progress and wished twenty-five cents per stump. The cost of removing the stumps averaged $\$ 0.148$ per stump."

\section{F. A. RULLMANN, Hawthorne, Florida.}




\section{BETTER BOULDER REMOVING}

To break boulders, powder may be loaded in three different ways-for mudcap blast, for undermine blast or for blockhole blast. The man who is doing the work should decide first of all which method he will use for each boulder, bearing in mind the shape, position in ground, and hardness of the stones, the total number to be broken, the amount of help he may have, the time available for the work and the cost in money. Then he should gather the powder and supplies in boxes or baskets, as directed on page 9, and such tools as may be required, including rock drills if the blockhole method is to be used.

For blockholing, a hole $\frac{3}{4}$ to $1 \frac{1}{4}$ inches in diameter should be drilled through each boulder to the center. The proper amount of powder should be loaded in the bottom (hav-

the rock as possible. The proper amount of powder should be loaded in a round bulk, the hole tamped well, and the charge fired.

For mudcapping, the proper amount

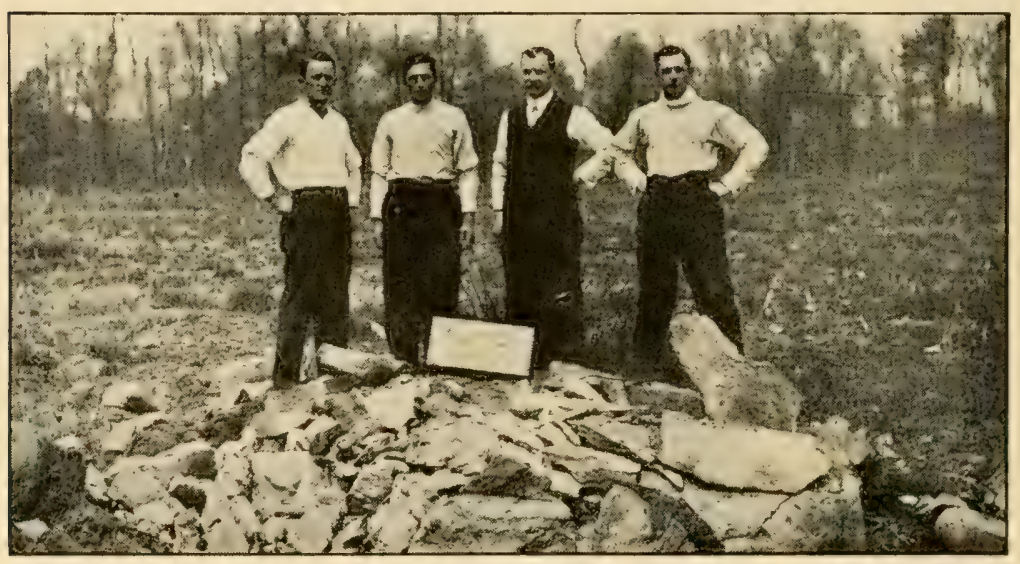

How large boulders are broken up by properly placed charges of Atlas Powder.

ing first prepared a primer as directed on pages 9 and 12), and the hole tamped well with damp clay or other heavy soil. Firing should be done as usual. Electric firing is safer than fuse firing, and more convenient. The extra expense required for electric fuzes usually is more than offset by the saving in time by not having to wait for the blast after a fuse is lighted.

For undermining, a hole should be punched or bored in the ground under the rock, with the bottom end as close to of powder should be piled on the rock where there is a flat side or depression near the center if possible. Priming should be done as usual. Then the powder should be covered with stiff clay or other very damp or wet mud to a depth of 6 inches at all points. Firing should be done as suggested above.

Each of the methods are described in detail in the following pages, which should be read carefully before work is attempted.

General Facts. Mudcapping is the handiest of the three methods of loading.

It requires the least labor and usually the least time. It is effective on all rocks not extremely difficult to break by

reason of their shape, or not extremely hard and tough, and even such rocks can be mudcapped successfully when not too 
large. It requires several times the amount of powder needed for blockholing. For economical mudcapping rocks should have one flat side at least, and if they are broad or long, or both, and thin, they break all the better by this method. Round boulders can be mudcapped, but it must be understood that the rounded sides act as an arch to resist the force of the blast, and an excessive amount of powder is required to produce the extra force demanded, hence the powder cost is high. The size also is important, for stones up to 2 or 3 feet thick often break very well, but those 5 feet thick or thicker sometimes fail to break even when the powder charges are increased out of proportion to the increase in the size. To be broken by this method, boulders should lie on the surface of the ground. If they are buried, ing is preferable to mudcapping or undermining. It requires only a fraction of the amount of powder needed for mudcapping. Where labor is scarce, however, and where it is important to get the work completed with as little loss of time as possible, and particularly where the boulders to be broken are too few to warrant the purchase of any special tools like drills, mudcapping and undermining should be the methods of loading selected.

All three methods may be required in the same field, owing to the varying nature, shape, position, and sizes of boulders. For instance, small flat rocks on the surface ought to be mudcapped, even when drilling crews are working on others of different shape. Or, as another instance, if round boulders of very hard, tough nature and more than 3

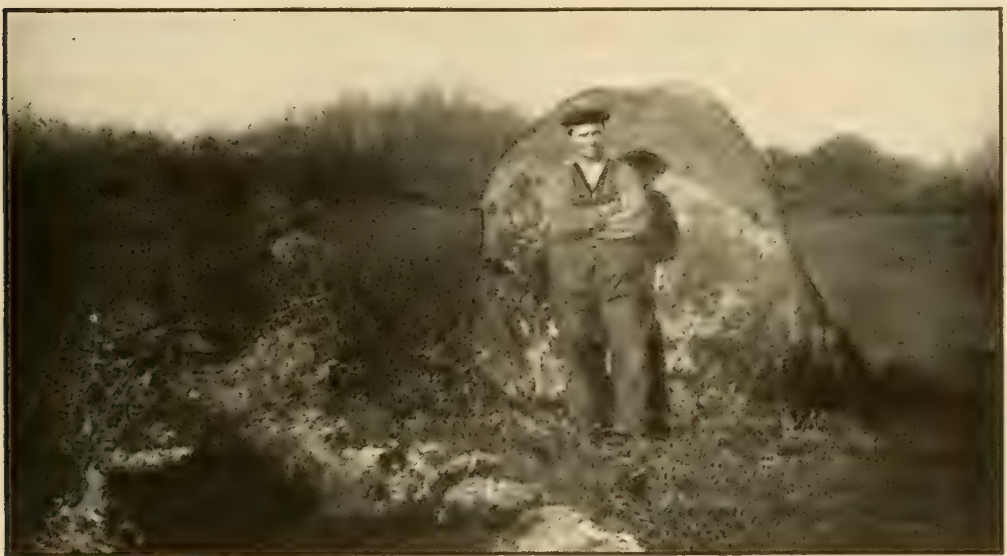

Boulder rolled out of ground by small charge of Atlas Farm Powder. It is now ready for mudcapping or drilling.

they should be rolled out first with light blasts.

From the above facts it will be seen that mudcapping is a quick and easy method where it is practicable. It is, however, somewhat more expensive than blockholding, where plenty of time and labor is available for drilling holes and where tools are available as well as facilities for sharpening drills. Undermine blasting costs a little less than mudcapping in powder used, but more in labor of making holes under the rocks. It requires no tools except bar and sledge and perhaps a soil auger and scraper.

When the money cost is to be kept down without regard to the amount of hard work required, and when the number of boulders to be broken warrants the purchase of the necessary drills, blockhol- feet in diameter are found, it often pays better to buy drills and make holes in them in order to break them, than to use the excessive amounts of powder they would require by mudcapping.

Between undermining and mudcapping there need be no hesitation. Mudcapping is desirable when rocks lie tree on the surface, or can be rolled out easily. Undermining is desirable when they lie somewhat buried in the ground in such a way that holes can be made under them easily to the proper point with bar or auger. In fact, undermining is just a modification of mudcapping in which the earth under the stone is used to back the charge instead of a covering of mud. It requires about the same amount of powder. The chief disadvantage of undermining is the difficulty of getting the powder charge at exactly the 
right spot, and of getting the powder into a round bulk against the stone or close to it. Experience shows that under- mining is a very effective way of loading a boulder blast, and we recommend it for more general use.

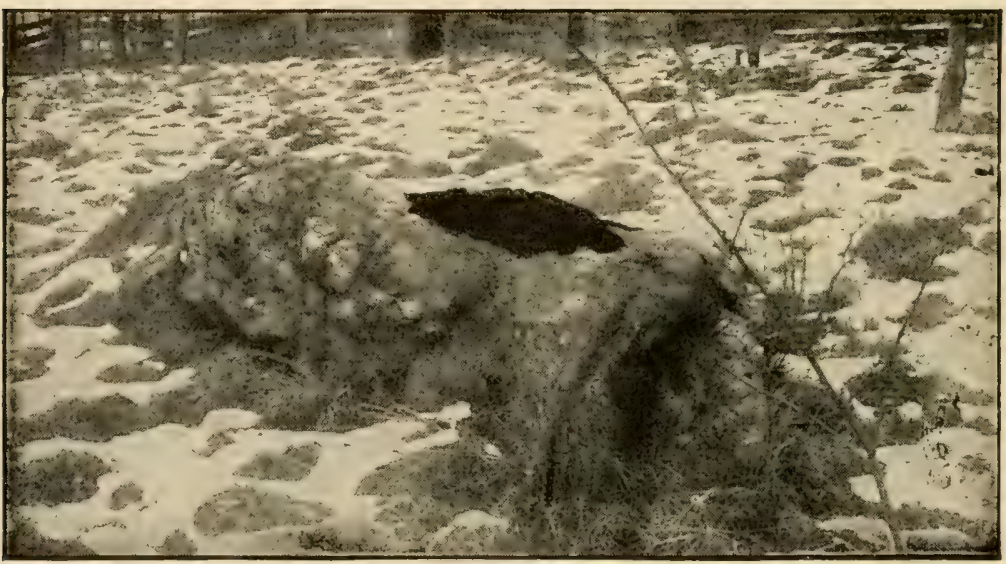

How to mudcap large stones to break them up. Put the Atlas Powder in a depression on a flat side of the rock and cover it with six inches of wet clay.

Kinds of Stones. The physical characteristics of boulders make considerable difference in the amount of powder required, as noted in the preceding paragraphs. Each boulder must be considered when loading. Size, shape and kind determines the location of the charge.

First, there is Hardness. Marble, granite, porphyry, and trap boulders are very hard, while sandstone is composed of hard particles more or less

Limestone, for instance, is tough, but not particularly hard, while marble and trap are both hard and tough. Shale often is tough, though usually very soft.

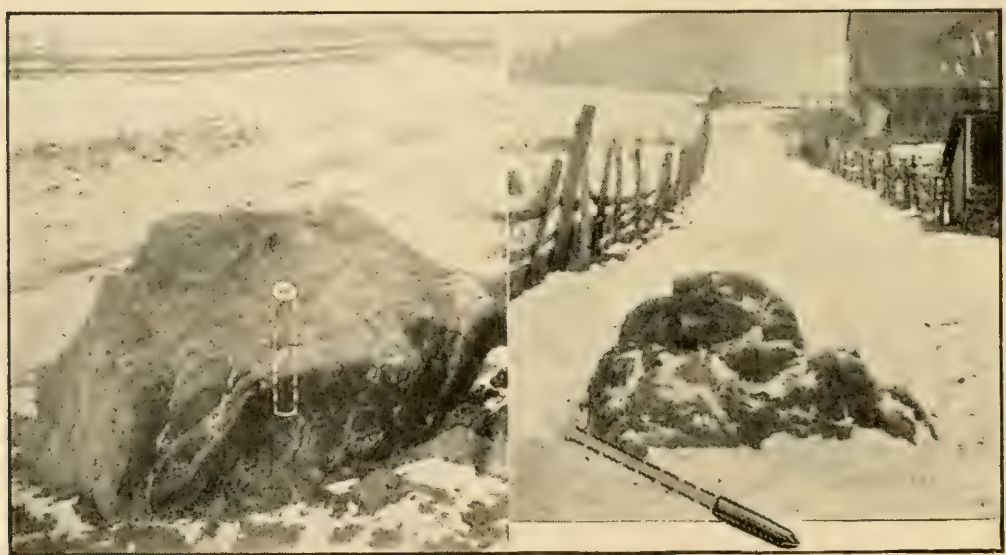

Left: How to drill a hole in a large stone to break it up with Atlas Powder. Right: How to place charge under tight stones to blow them out and break them up. Don't permit a road to be blocked up with a big stone.

loosely cemented together. Second only to hardness is toughness. Many boulders are tough which are not hard, and a few are both hard and tough. 64
Slate may be described as similar to shale.

Through all stones of every kind are Lines of Weakness. Sometimes they 
are marked enough to be seen plainly as seams; again they are almost invisible. Rocks break much easier, however, along these lines than through the flawless sections or blocks. And it is by taking advantage of these seams in the locating of the charges that good breakage is secured with economical powder charges

The Seams of most stones run in at least two directions. In some rocks, such as slate, they may be only $\frac{1}{4}$ inch apart, but usually they are 6 to 20 inches or evelı farther apart. The powder charge should be centered over a seam. To get it there the exact center of the boulder sometimes must be left to one side or another The blaster of boulders should examine each one carefully to find its seams before proceeding with any drilling or with the placing of the powder charges.

Mudcapping. The tools required for mudcapping are practically no others than those needed for preparing the charges and carrying the powder and supplies, as listed on page 9. A shallow box or a dishpan, however, often is a help, and in some cases a hammer and stone chisel can be used to advantage.

Locating. The charge should be located on a flat face of the boulder, or a seam, as directed above, and as near the center as possible. If the stone is to be broken without regard to the size or shape of pieces, the powder should be piled in a low cone. Where

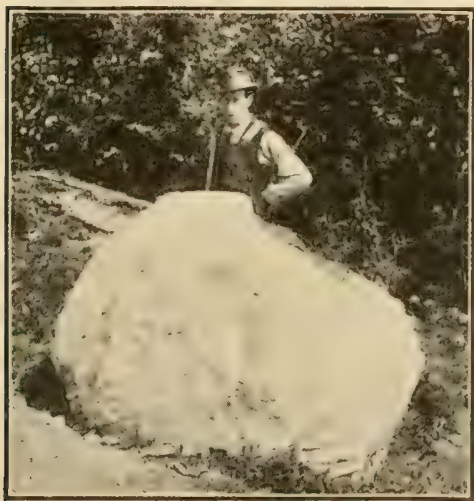

Study the stone to determine the best method of blasting it.

blocks of certain dimensions are wanted, for building or other purposes, the powder should be piled in lengthened heaps extending most of the way across the face, along the lines of breakage desired. Dimension breakage is made more certain by the cutting of shallow channels along the lines, and piling the powder into and over these.

Priming and Loading. In order to get the powder in a low cone, or in piles or ridges of other shapes, most of the charge should be taken out of the stick wrappings. Half a stick at least should be kept intact for priming (as directed on page 8), and this half stick should be bedded in the loose powder. If more than half a stick can be bedided in com. pletely, it is well to keep more intact. The edges of the pile should be thick and straight up. When the charge is packed in the shape desired, the paper taken from the sticks should be laid over it, after which the mud covering should be put on.

When the primer is tied to a half stick of powder correctly, there will be little danger of the cap being pulled back out of the charge during the placing of the mudcap. Should it be desirable or necessary for any reason to insert a cap in a pile of loose powder, the hole should be made near the top, in the direction of the center of the stone and the fuse (or wires) should be tied to a knob of the stone, or otherwise secured so that a. accidental jerk or pull will not displace the cap or fuze.

The Mudcap. The mud covering should be at least 6 inches thick, and

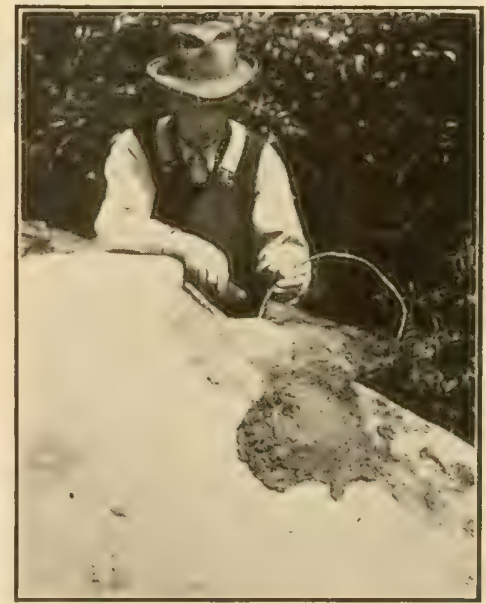

Place the mudcap charge in a depression ratber than on rounded point. 
Better Farming with Atlas Farm Powder

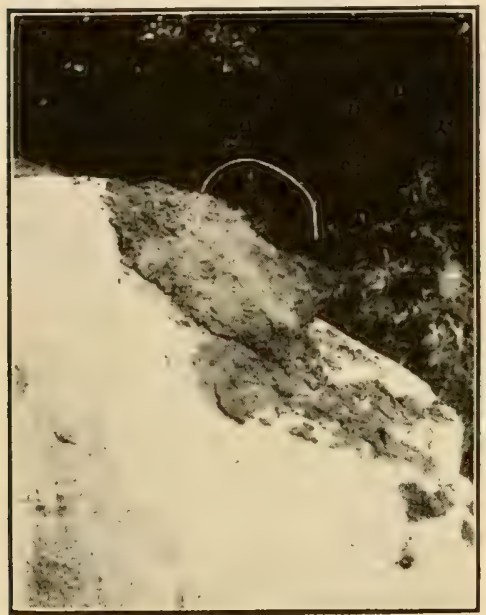

The cap of mud should be 6 inches thick, and should extend 6 inches or more beyond the powder all round.

should be of mud, not dry dirt. It should extend at least 6 inches over the rock in all directions from the edges of the powder, hence usually will have to be 18 or 20 inches wide. Clay makes the best mudcap, though other earth will answer. To get it of the proper consistency, dry dirt may be mixed with water in a dishpan or box. The pan or box saves some trouble in getting the mud in place, as it may be inverted and emptied over the powder charge. The blaster should make sure that there is at least 6 inches over the powder.
More will be even better, while less will cut down the effectiveness of the blast. Once in place, the mud should be packed well with a shovel. No stones should be permitted to get into the mudcap, for they will fly like bullets.

Powder. The powder to use for mudcapping is Atlas Powder 50 per cent. The violence of this explosive is suited for the purpose, and will accomplish the maximum of breakage with the minimum of charge. Atlas Farm Powder may be used, but excessive charges are required owing to the fact that its force is applied more slowly and escapes by lifting the mudcap before the rock breaks. When there is opportunity to buy powder especially for mudcapping, the more violent grade should be insisted on.

The amount of powder per charge is indicated in the table following:

Minimum Thickness

$$
\begin{aligned}
& \text { of Stone. } \\
& 18 \text { inches............. } \\
& 2 \text { feet............... } 3 \\
& 2 \frac{1}{2} \text { feet............ } 5 \\
& 3 \text { feet.............. } 7 \\
& 4 \text { feet.............. } 12 \\
& 5 \text { feet............. } 18
\end{aligned}
$$

Regarding this table, however, we hasten to remark that the charge in each case must depend on the stone. A boulder of trap rock, for instance, will require about three times the charge a boulder of sandstone takes. The kind of breakage desired also has a bearing, since a lighter charge will crack it into three or four large pieces, while

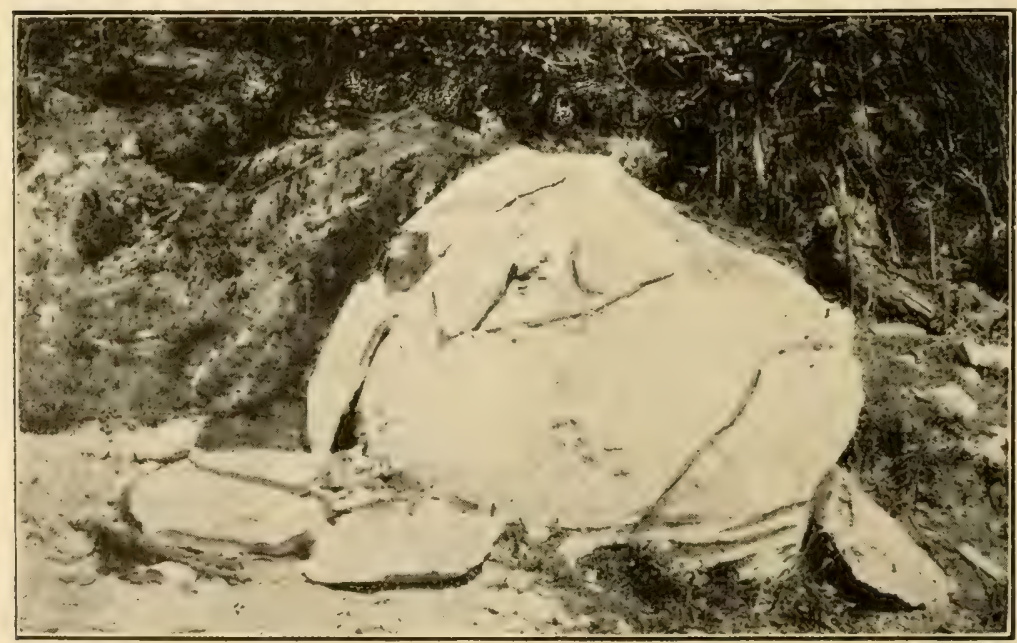

Sometimes the rock is well shattered but fails to fall apart. A little prying with crowbar and(See next page.) 
a heavier one may almost pulverize the larger part of it. Experience will show more exactly than a table can how much powder is needed for any particular kind or lot of boulders. One or two trial shots will demonstrate the matter in detail. Small boulders should be shot first. The charges for larger charge of powder ( $\frac{1}{2}$ to 2 sticks of powder), placed under it as directed for undermine blasting, except that the charge should be located under one side instead of under the center. Atlas Farm Powder will give best results for this work. Another plan is to dig a trench about the boulder, but since this takes

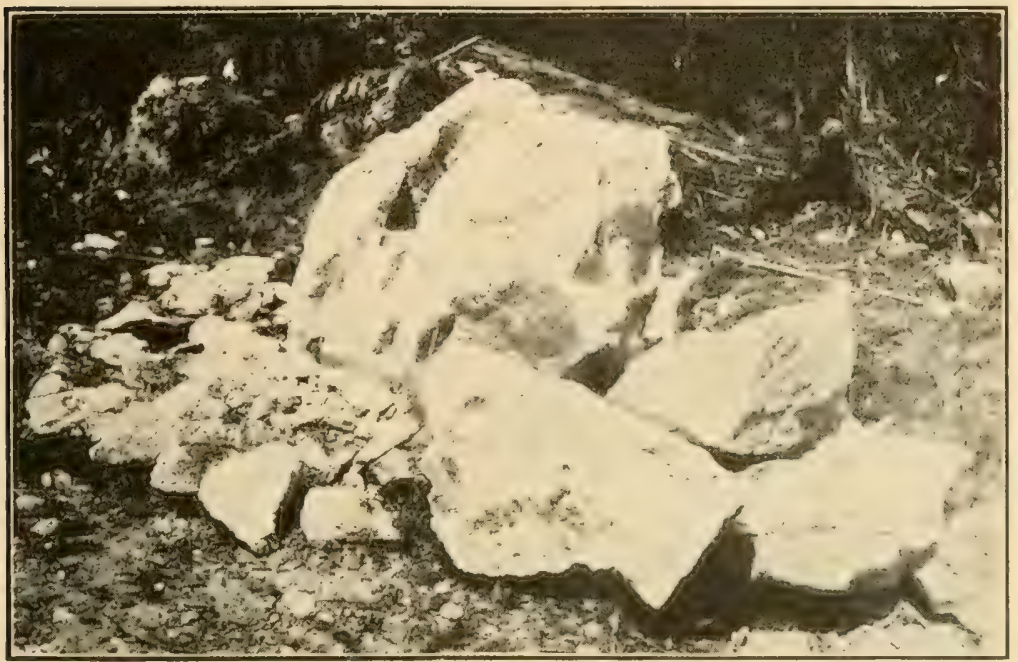

What looked like a solid stone proved to be a pile of easily handled pieces (see preceding page).

ones will be in proportion to the squares of the diameters.

Firing may be done with fuse and cap, or electrically. The latter method is more convenient and usually safer.

To be broken properly with a mudcap blast, a stone should lie free of binding earth. If it is buried, therefore, it should be rolled out with a light time and labor that often cannot well be spared from other work, the former plan usually is best.

Double Mudcap Blasts, and Combinations of mudcapping with other methods of loading, often are desirable where the charges are fired electrically and boulders are large. They are described on page 71 .

Undermining. This method of loading consists in locating charges in the ground under boulders. The tools required are the same as for stump blasting (described on pages 38 and 39), and include bar and sledge (perhaps a soil auger), tamping rod, and shovel and usual equipment of small tools for preparing and loading charges.

The boulder to be broken by this method should have a flat face down. It has been explained that in reality this method is just modified mudcapping. Therefore anything said on mudcapping applies to undermining, and to nothing else does it apply more than to the careful locating of the seams in the rock. Charges should be placed over seams rather than between them. They should go as near under the center of the weight of the boulders as the above consideration will permit.

The charge, in an ideal undermine blast, should be in a low cone directly against the stone, as in a mudcap blast. The difficulties of getting it so, however, are so great that such ideal loading seldom is accomplished. What can be done, however, is to see that the charge is close 
Better Farming with Atlas Farm Powder

to the stone and not some distance down in the ground, and that the powder is not strung out in the hole.

In many cases holes made with bar or auger should be enlarged at the bottom so the powder can be compressed into a more or less round bulk. This can be done with a scraper such as is shown on page 40 , or in cases where the charge is very large, by springing the hole as suggested on page 47. Springing, however, opens cracks in the ground which are detrimental to the confinement of the main powder charge, hence is recommended only for emergency use. Several sticks of powder strung out end to end in a long hole will not give good breakage unless they are under a long stone, and lie parallel to its length.

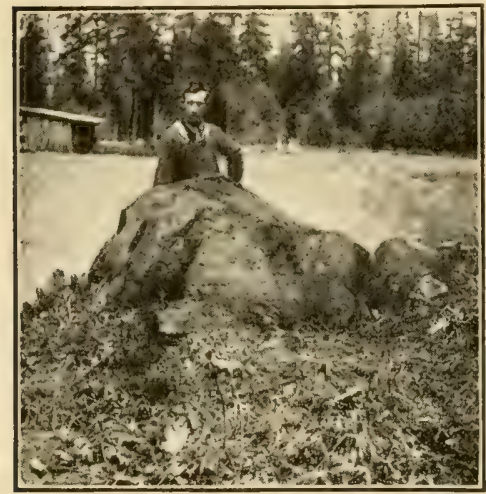

Half-buried rocks often can be "blockholed" to good advantage.

Unless the hole contains water at the time the loading is done, the paper wrappings of the sticks should be slit so that a little pressure from the tamping rod will make the powder break out and take the shape of the hole. It then should be tamped gently but firmly-pressed rather than pounded-and so that no air spaces remain.

Priming should be done as usual (see page 8). The cap or electric fuze should be inserted in at least half a stick of powder and tied to it. This primed powder should go into the hole laston top of the rest of the powder.

Tamping should be done carefully. The hole should be filled to the top with solidly packed dirt. Dry, light earth or dust makes poor tamping material. The best is stiff damp clay. Other soil may be used, however, when clay is not handy A shovel is not necessary when loose dirt for tamping can be found close to the holes.
The Powder to use for undermine blasting of boulders is the same as that for mudcapping-Atlas Powder 50 per cent. Any less violent powder will not give as good results. Atlas Farm Powder is not designed for such work as this. It will, however, break stones when so loaded, and give more satisfaction than when used in a mudcap blast owing to the firmer backing it has. It requires considerable more Atlas Farm Powder for breaking, though for rolling them out there is no better explosive. Atlas 50 per cent. also will roll out rocks.

The Charges required are generally the same as would be required for mudcapping, as indicated in the table and its following paragraph, on page 66. Smaller charges usually will do equally good work, though they cannot be very much smaller.

Firing may be done as in mudcapping.

Miscellaneous. Boulders may be undermined when free on the surface of the ground or when buried deeply. All that is required is a hole under them, with the end close under the center of the stone. Digging away the dirt, as required for mudcapping, does not help the blast, but rather hinders it.

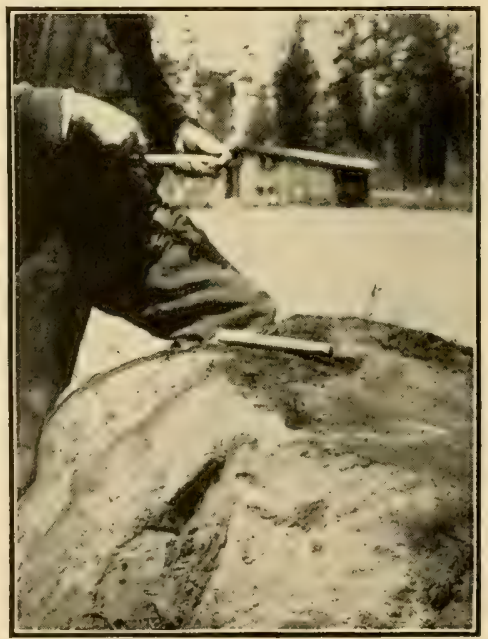

The paper wrappings of sticks of powder should be slit before they are pressed into a hole in a rock.

Two or more undermine blasts, or combinations of undermining with mudcapping, often are of advantage for breaking big rocks when electric firing is available. Their loading is discussed in detail on page 13 . 
Blockholing. This method of loading consists in placing the powder in the rock. Holes must be drilled about half-way through the center, the powder loaded in the bottoms of the holes, tamped in solidly, and fired as usual. Holes must be big enough to contain the proper powder charge, but no larger.

Any kind of boulders can be broken by blockhole blastinghard or soft, large or small. Usually blockholing is economical in breaking very hard and tough rocks, particularly when they are round and of large size. Ledges of rock underground can be broken by this method. In fact, when applied to ledges it amounts to simple quarrying.

Drilling Holes. Usually $\frac{3}{4}$-inch holes are about right for blockhole blasting work. Drills of this size cost little money, are easily sharpened, and the drilling proceeds at a satisfactory rate of speed. Where larger holes are required, 1 - or $1 \frac{1}{4}$-inch drills may be used. The progress of the hole making with them necessarily is slower.

Drills may be purchased at any hardware store. Drill steel, in bars desired, may be bought and the drills made at home. Any blacksmith can sharpen them. The new drills should be observed carefully as to bevel and curve of bit edges. For sandstone and very hard rock the bevel

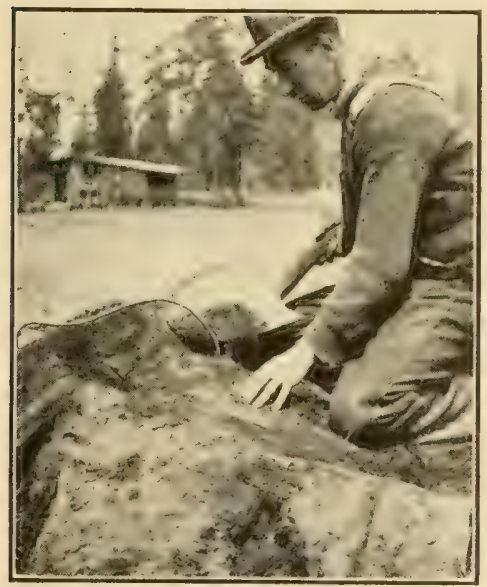

Good tamping material may have to be brought some distance, and a shovel is desirable.

should be very short-say 65 degrees or even shorter. For soft rock it can be longer-say 45 degrees-with satisfaction. Where a blacksmith shop is not near, drills may be sharpened on a grindstone or emery wheel, though this is not very satisfactory where there is much sharpening to do.
Machine or power drills should be used wherever the number of boulders is large enough to justify their purchase. They materially cut down the time and labor required and when wisely bought and used, they cut down costs.

The Holes should extend a little more than half-way through the boulders. If they can be drilled down through a seam, all the better.

The Charges of powder required will depend on the size of the rock, of course, but are more particularly governed by the size of the drill hole. Nearly always it is best to load the hole full of powder up to the point where tamping should begin. The tamping should be well packed to the mouth of the hole. It will not do to load the hole full or nearly full of powder, with little or no tamping. Less powder and more tamping will give better results. One rule is to allow for tamping to a depth at least six times the diameter of the hole. Sometimes it is necessary to drill holes deeper than otherwise might be necessary, just to provide tamping space.

Priming and Loading. Priming should be done as usual (see pages 9 to 16). The powder, blasting supplies, and tools should be carried to the field only after the holes are drilled, since drilling rock by hand is a slow job.

Any water in the holes should be removed. The wrappings then should be taken from the sticks of powder, and the loose powder packed in the bottoms of the holes firmly. The wooden tamping rod with which your work is done should be almost as big as the holes. The powder must not be struck or punched, but may be pressed to the extent of a few pounds, in safety.

When a small amount of tamping is needed, the material should be of good quality-heavy like clay, and damp enough to be stiff. Such material gives impervious, strong confinement.

The Powder best to use for blockhole blasting depends on the nature of 
the breakage desired. Atlas Farm Powder will break rocks into large pieces about the size for one man to handle. Atlas Powder 50 per cent. will break them into smaller pieces.

Ledges. The breaking up of outcropping rock in cultivated land and roads, and even of rock that lies under two or more feet of soil often is as important as the breaking of boulders. Many fine fields are so underlaid with such rock that plowing and other deep tillage is interfered with, and deep root penetration is impossible.

Often the rock is of slate, shale, or hardpan, though limestone, granite and other formations occur. The nature of the rock regulates the spacing between charges, but not the method of loading.

To blast out ledges, locate the front edge, or the point at which the rock dips far enough below the surface so as not to interfere with cultivation. Begin back of this a distance equal to the depth of the holes for charges That is, if the charges are $2 \frac{1}{2}$ feet down in the rock, place the row of holes an equal distance from the front edge. The spacing between charges may be a little more than this distance, but should be governed on that basis.

Amount of Powder per Charge required should be ascertained experimentally. Some soft slates and shales loaded with half stick charges wil be broken to a depth of one or two feet. Usually, however, it is well to apply the rule for blockhole blast charges (page 69), which consists largely in filling the hole with powder to the point where tamping must begin for good results.

The charges should be loaded and fired exactly the same as blockhole blasts. It is worth remembering, however, that electric firing will permit the exploding of two or more charges simultaneously, with consequent greater execution from both.

The depth at which charges are to be placed should usually be governed by the depth to which the rock should be broken. Sometimes one foot of additional depth is enough; again 2 or 4 feet are needed. The cost is directly in proportion to the depth of rock broken, both in drilling expense and in powder.

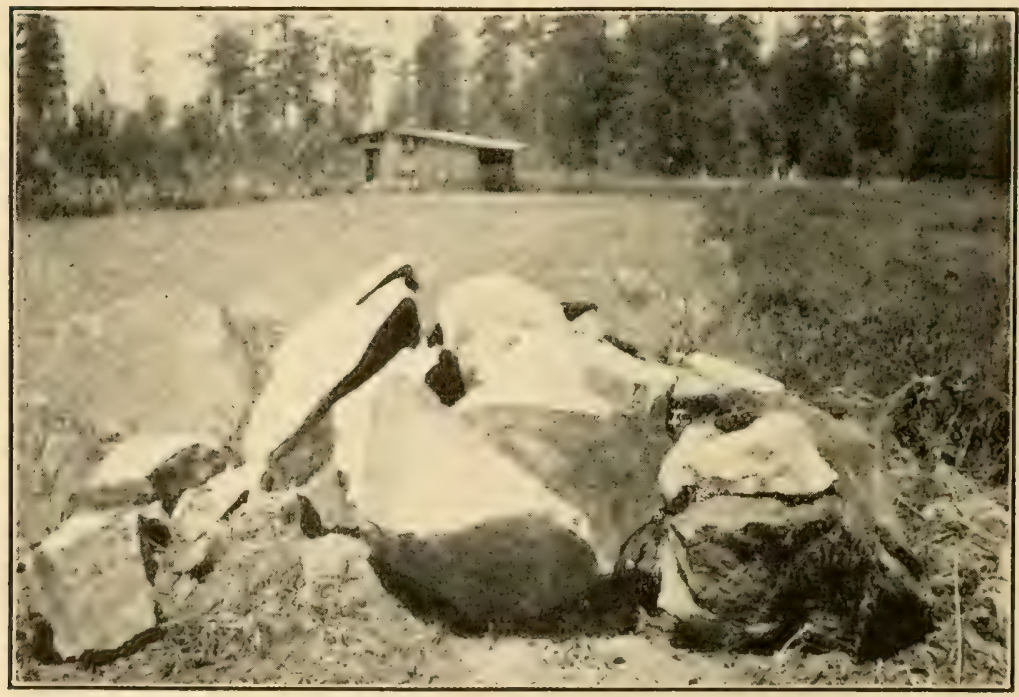

Perfect breakage reduces the rock to pieces easily handled, without throwing any very far.

Miscellaneous Features. The shape of rocks largely governs the method by which they can be best broken. A skilled blaster usually will determine in a few glances what had best be done-making up his mind to mudcap, to undermine or to drill, as the case may be. He mentally measures the length and thickness of the stone, and notes whether it has flat or round sides.

The amount of powder required to break rocks varies. One T) 
stick, or two sticks, on a soft red sandstone or slate boulder often will reduce it to pieces so small that they need not be hauled away. A marble or trap boulder of the same shape and size might not be broken small enough for easy handling with three times the amount of powder.

The safety factor in boulder and ledge blasting requires more judgment and caution than in stump or ditch blasting, and considerably more than in soil blasting. Big pieces of rock sometimes are thrown considerable distances. Ninety-nine per cent. of the rock, in the form of broken pieces, may not fly more than a few yards at most, but the remaining one per cent. may strike with force enough to break an inch board at 100 yards or farther away. The safe thing to do, therefore, is to make certain before every blast that there are no people or animals within reach of flying pieces of stones.

Along roads and near buildings we urge strongly the use of electric firing exclusively. The convenience of being able to time the blasts to the second is worth any slight extra cost. In ledge work electric firing usually results in ultimate economy. Fuse may be used where it does not matter if there is a

delay in the explosion after the field is cleared.

In blasting out banks of rock along roads or anywhere that the face is steep, the burden of rock above any line of charges should not measure more than one and a quarter times the depth of the holes. If it does, a second line of holes should be made at the proper distance above the first line.

The use of 2 or more charges on one boulder is strongly recommended whenever the rock is thicker than a couple of feet or longer than 2 or 3 feet. The combination may be two mudcap blasts a few feet apart on top of the rock, or one on top and one beneath, or on opposite sides. It may be two or more under. mine blasts for long or broad stones. Such loading is both easier and more effective than single blasts for breaking difficult rocks. It is an important feature of the advantages of electric firing.

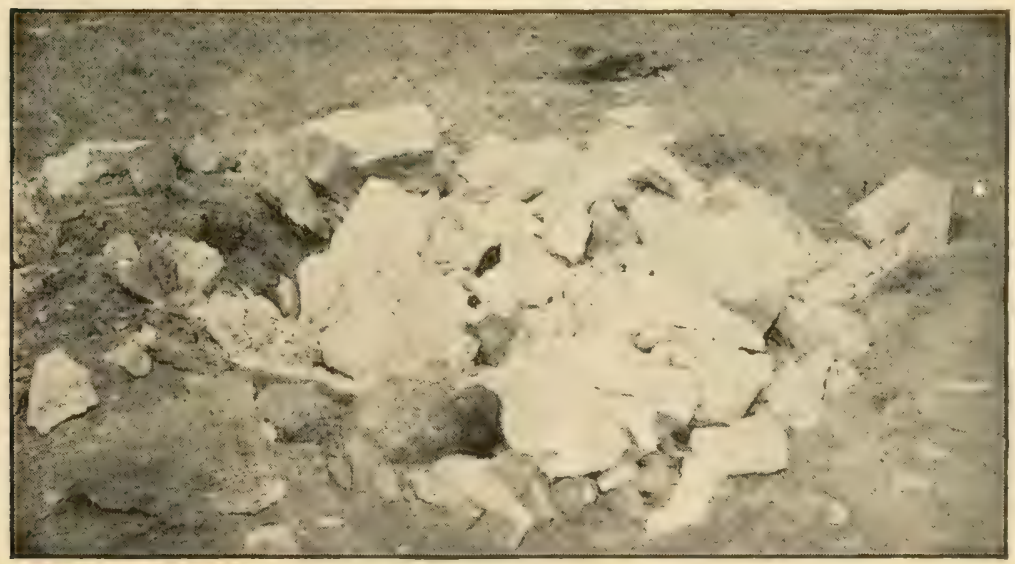

What can be done when a big boulder is blasted properly. Why permit them to obstruct your fields when they can be removed so effectively with the proper explosives? 


\section{BETTER ROAD MAKING}

We will make no attempt here to explain the principles of road building. We take it that farmers and road officials who read Better Farming, and who have these problems to deal with, will understand what drainage, grading and widening of the track is necessary.

Yet we know that labor problems, and those of expense, are preventing or delaying the accomplishment of many pieces of road building and improvement. It is to make the road man's work easier that we give the following suggestions. The methods here advised will get the work done with few men, in quick time, and at least cost in money.

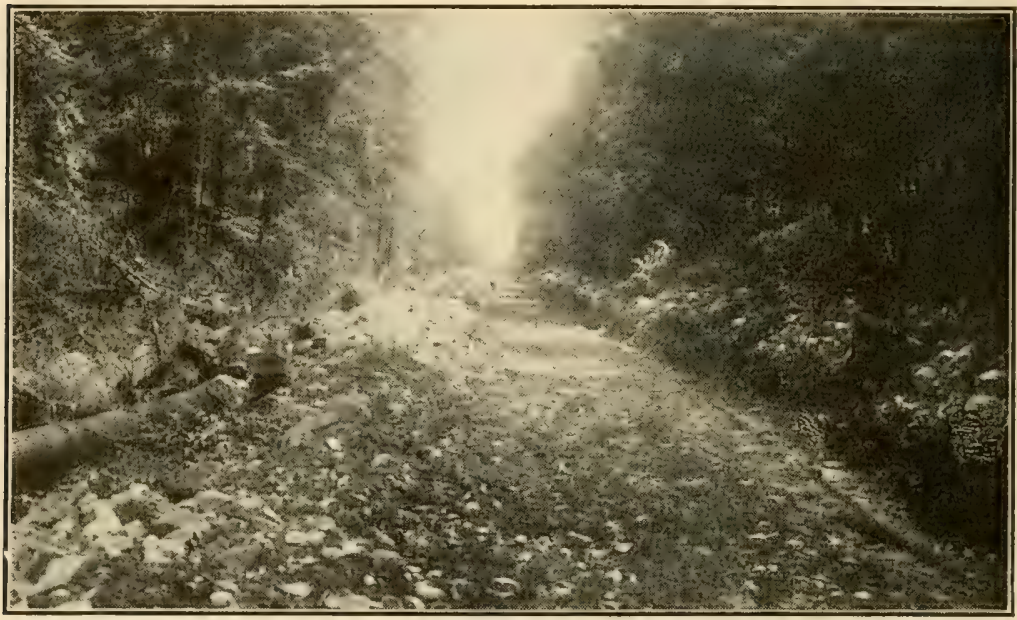

Whenever hard earth or rocks are encountered in road grading, blasting will cheapen and quicken the work.

Loosening Material. The demand is always for a good solid road-bed. Mudholes must be filled. Ruts must be filled. Soft spots must be given a bottom. The best material to do this with usually is gravel, shale or slate, which is hard to dig loose. In fact, the digging takes more labor and time than the shoveling and hauling.

Enormous quantities of this material can be shot loose with a small quantity of Atlas Farm Powder. It is safe to say that every stick of powder will loosen a load or more. If the powder costs 10 cents, the loosening costs half or a quarter of what it would cost if done by hand.
The greater emphasis must be placed on this use of powder for loosening any material that is to be moved. Blasting leaves it ready for the shovel, or if charges are heavy enough and the material is not to be hauled, most of it can be blown out of the way at once.

Ditches and Stream Channels. Ditches for draining roads seldom should be less than 2 or 3 feet deep and 3 or 4 
feet wide. Larger ones often are better. They can be blasted out cheaper, quicker and easier than by plowing. The chapter on ditching will give full directions for placing the charges, and for the kind of powder to use. See page 26.

Where ditches have to be made across a road hardened by use, slightly heavier charges are needed than usual. By increasing the charges, nearly all the dirt can be thrown clear of the road, particularly if the wind is blowing across the road toward the ditch you are making.

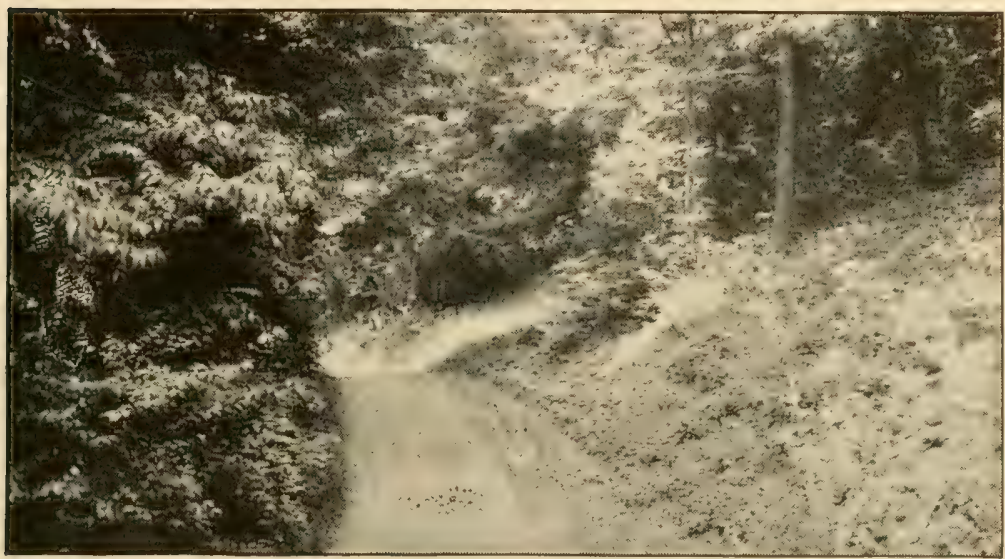

A grade we would all like to dodge, especially in bad weather. It would take only a few pounds of Atlas Farm Powder to level and make the necessary side ditches.

In the bottoms of many existing ditches are ledges of rock and boulders, which obstruct the flow of water, and cause it either to dam up or fill up culverts with mud, or to flood back and soften the ground under the road. There is no other way than by blasting to remove these stones. Atlas Farm Powder or Atlas Powder 50 per cent. should be used either in drilled holes or in mudcap charges. See pages 65 and 67.

In many instances, where a road follows along a large ditch or a creek, the bed of the stream can be moved or deepened by the use of Atlas Powder as in ditching. Serious flooding and washing away of the road can be avoided. This is particularly a good practice where the stream is crooked. Put the charges in a straight line, cutting across land round which the water now runs.

At the turns of the present stream course may be found big boulders, ledges of rock, stumps, trees or other objects which deflect the water and cause curves in the stream. All these can be blasted out and a new channel made.

It is not necessary to blast the new channels very deep and wide. If the water can get through it freely, it soon will cut and score out the bottom and sides till the space is big enough to hold the stream at flood.

Ditch and channel cutting can be done with Atlas Powders just as well through ground matted with roots and full of stones as through open ground. When the charges are handled right the work can be done under water with entire satisfaction.

Steep Grades on any road are an abomination. They are expensive. Not only because they cause frequent breakage and serious accidents, but because they delay traffic. Everyone who uses roads has an interest in seeing grades cut down. The best way to remove them is to blast out the earth or rock down to 
a point where the bottom of the grade is fairly level with the adjoining road.

Begin at one end and put a row of charges across the road. When these are exploded (they should be placed shallow and should be light) a shelf will be found back toward the hill. Place another row of charges several feet behind the edge of this shelf, and continue until the desired result is accomplished. It usually is best to place the charges about as tar back from the face as the depth of the holes. It will be found that up to 6 feet depth of earth can be taken out in this way in one layer. If more than 6 feet should be removed, go over the ground with a second series of blasts after all the material loosened by the first series has been removed.

Sometimes a road-bed can be lowered by blasting as for a wide ditch with several rows of charges running lengthwise. See page 28 for details of loading.

Usually it pays to charge the holes heavy enough to blow most of the earth and rock entirely out of the road so it need not be handled. Where this is not practicable the material at least should be loosened by blasting rather than by slow and expensive digging. Atlas Farm Powder is the best explosive you can get for these purposes in earth, slate, shale and soft rock. For hard rock Atlas Powder 40 per cent. may be used. In practically all cases electric firing is best for road work.

Sharp Curves, which are perhaps the most fruitful cause of wrecks, nearly always are associated with narrow places in the roads. The remedy is to widen the road by cutting down the bank, which at the same time lengthens the curve. In some cases, where the road makes almost a half-circle around the point of a hill, it pays to cut through the point and make the road straight.

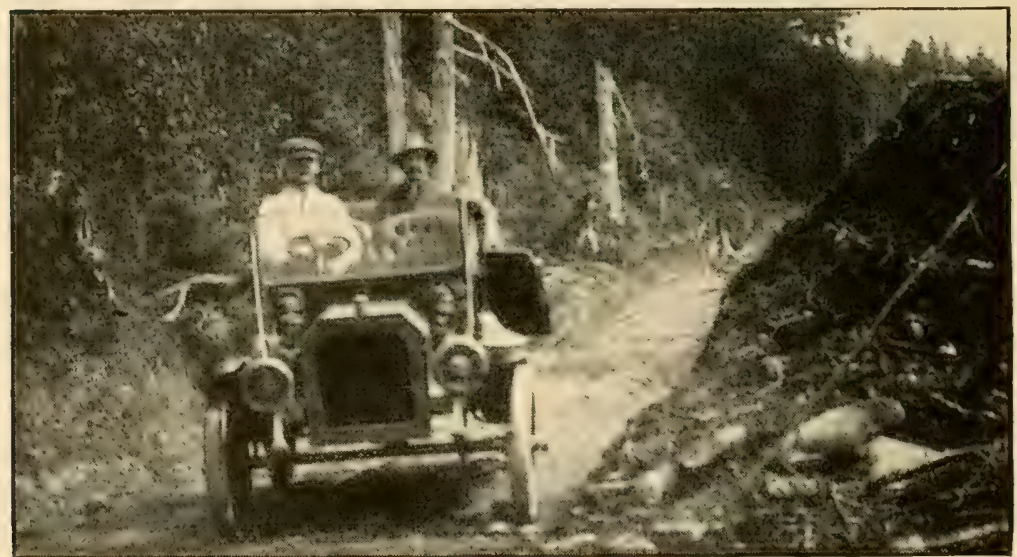

A 10 -foot cut which removed an ugly grade in a road. This work was practically all done with explosives and cost only a few dollars. This cut should have been made wider, and ditches blown along the sides.

Blasting out the cut either through the hill or the side of the hill is governed by the same principles as are explained in the foregoing paragraphs on grading. It consists of blasting by shelves. Nearly always the material can be thrown clear of the road by a properly placed blast, though many times the material is of such a nature that it should be used for surfacing the road at other points.

$$
7 t
$$

When blasting out a bank for any purpose, the charges should not be overburdened. When the bank is only 9 feet high, or less, one row of charges is enough. Should it be higher, two or more rows should be used. The holes should be drilled 4 to 8 feet deep, and an equal distance apart in both directions. A 20-foot bank, for instance, should have three to five rows of charges, one above the other. 
Nowhere else does the need for electric firing make itself felt so much as in blasting anything on public highways. Traffic must be stopped Should a misfire result, the loss and inconveni- ence is great. The safety factor alone is enough to require the use of this method. It pays from a standpoint of amount of material loosened, to fire as many charges together as possible.

Hillside Grading. Many roads are built along hills. New construction of this nature is quick and easy when the material is thrown down the hill from the upper side of the road with Atlas Farm Powder. One or two rows of charges will do the work. No plowing will be needed; a scraper will complete the work.

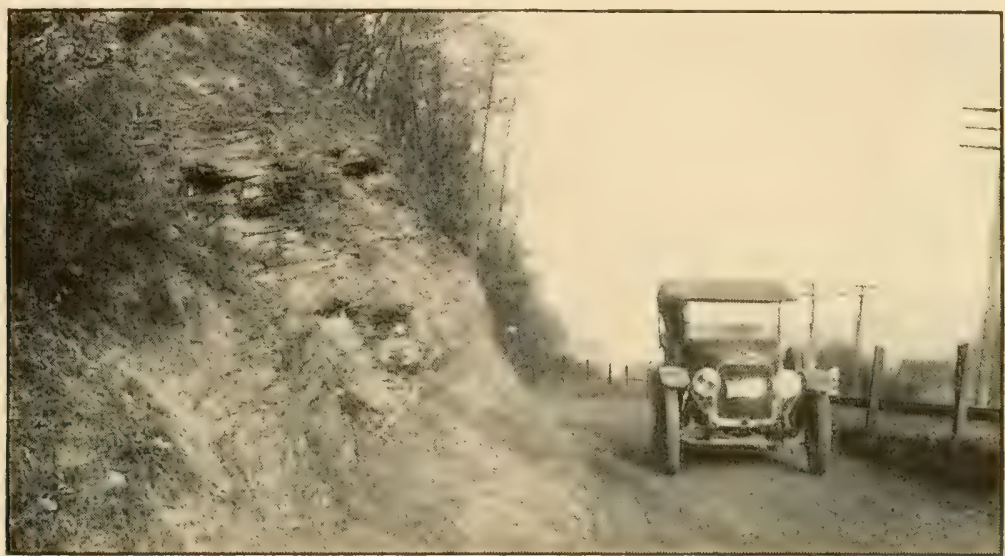

Three wrecks occurred at this narrow place in the road. Such dangerous places usually can be done away with quickly, easily and cheaply with a few pounds of Atlas Powder, blowing the dirt entirely away so little shoveling or hauling is needed. In the case pictured, however, the slate bank provides the very best road making material, which should be used at points elsewhere on the road.

Where hill roads have high sides, they should be removed with Atlas Farm Powder. Usually they cannot be taken off as cheaply by any other means. Narrow hill roads may be widened quickly and easily by blasting away the hill side. Where stumps are removed from the new road, roots should be taken out to at least a foot below the surface. If they are not they will make an uneven surface within a year or two, because frost will lift them up. Small boulders will be lifted the same way. The stumps, roots, boulders, as well as ledges of rock that outcrop, should be blasted away to depths at which they will give no trouble in the future.

Hand augers or drills are good where only a little work is to be done, but the use of a power drill of the hammer type, driven by electricity, steam or compressed air, is advisable if there is much blasting to do.

The cost per cubic yard of material moved is hard to estimate, because it depends to some extent on the skill of the blaster and to a greater extent on the kind of material. But in ordinary solid earth you can depend on loosening and throwing down the material so hand dump scrapers can get it, for less than half of the hand digging cost. If you have any work of the kinds named that ought to be done on your roads, we urge you to write our Information Division for specific estimate and instructions. 


\section{MISCELLANEOUS WORK}

\section{Better Post-hole Blasting}

It is entirely practicable to blast deep, narrow holes in hard or wet ground. What can be done with powder in this respect, when the loading is proper, will surprise anyone who never has seen it. The holes can be made nearly as wide at the bottom as at the top, and little wider than is required for the proper setting of fence posts or telephone poles.

The advantages of blasting are that the slow digging is done away with. The blast will throw out much of the dirt, and will loosen all the rest that ought to come out so it can be shoveled easily and quickly.

There is no advantage in blasting post-holes in ground so soft and loose that it may be shoveled without loosening. There is considerable advantage when the ground is ordinarily compact and there is more or less hard subsoil. Blasting is a very great advantage when the lower ground is hardpan, bound gravel or slate, shale or other rock.

How to Blast Post Holes. The powder must be distributed evenly along at different depths from the bottom of the hole to within 1 foot to 18 inches of the top of the ground, using no tamping.

Locating Charges. To make the idea clear, it may be stated that perhaps the ideal post-hole charge would consist of an ounce or two of powder every 3 inches from bottom of hole to top. But since such charges would be hard to load, small pieces of ordinary $1 \frac{1}{4}$-inch sticks must be distributed at intervals of 3 to 12 inches in a bar hole made at the center of where the post-hole is desired.

Boring Holes. Holes should be made with ordinary bar or auger, as noted on page 39. If rock is encountered, rock drills will be needed. See page 69 . The holes should be as deep as the post hole is wanted.

Spacing Charges. The exact spacing between pieces of powder should be determined by experimenting with different spacings on each job, as every soil and condition of soil requires somewhat different treatment. Usually it will be found that pieces of powder weighing about 2 ounces spaced 6 inches apart, will give good results. Sometimes this spacing may be lengthened without increasing the amount of powder in a piece. Again, the piece should be increased to
3 ounces, or even 4 ounces, and the spacing increased to $6,8,10$ or 12 inches. Once in a while it is best to use 2-ounce pieces with 3- or 4-inch spacing.

Some blasters prefer to place a 4 ounce piece of powder in the bottom of the hole, and smaller pieces above it. Others prefer to use small pieces below, and nearest the surface a 4-ounco or even bigger piece containing the cap. They claim that better detonation is obtained in this way.

The spacing determined on may be obtained in several ways. The best is to make cylinders of paper just big enough to admit the pieces of powder, which may be fastened at the required points with small nails or long tacks. Another good way is to tie the pieces of powder to slim sticks, at required intervals. A third way, not so good because it leads to uneven spacing and sometimes to misfires, is to drop pieces of large weed stalks into the hole after each piece of powder is dropped down. The pieces of stalk or sticks must not be more than $\frac{1}{2}$ inch in diameter, or they may interfere with detonation. 
Whatever the plan, wadding or tamping material must not be used between the pieces of powder. The hole must be left free.

Firing of the charges is done by priming the top piece of powder and firing by cap and fuse.

The other pieces then explode by transmitted detonation, as in ditch blasting. (See page 31.) Ordinary cap and fuse usually is best for firing these charges, because it is cheaper, and there is no greater execution gained by firing several charges together. Along roads or anywhere else that it is important to time blasts to the second, and to avoid all misfires, electric firing, as described on page 13 , is preferable.

The Powder best to use for blasting post-holes is Atlas Powder, Low Freezing 50 per cent. This is a sensitive powder and detonated by transmitted shock in a thoroughly satisfactory manner. It will not freeze till the thermometer goes many degrees below the freezing-point of water. Atlas Farm Powder is not recommended for posthole blasting. Yet it has been used with success, and when it is on hand it may be used with good results.

\section{Filling Up Gullies by Blasting}

More space is given in this book to other uses of explosives on farms, but not even stump blasting has such possibilities for the average farmer as the almost entire prevention of erosion and gullying, by means of blasting the ground.

If proper blasting is done land will not wash. More than this, gullies already formed will fill up. The red shale and other medium

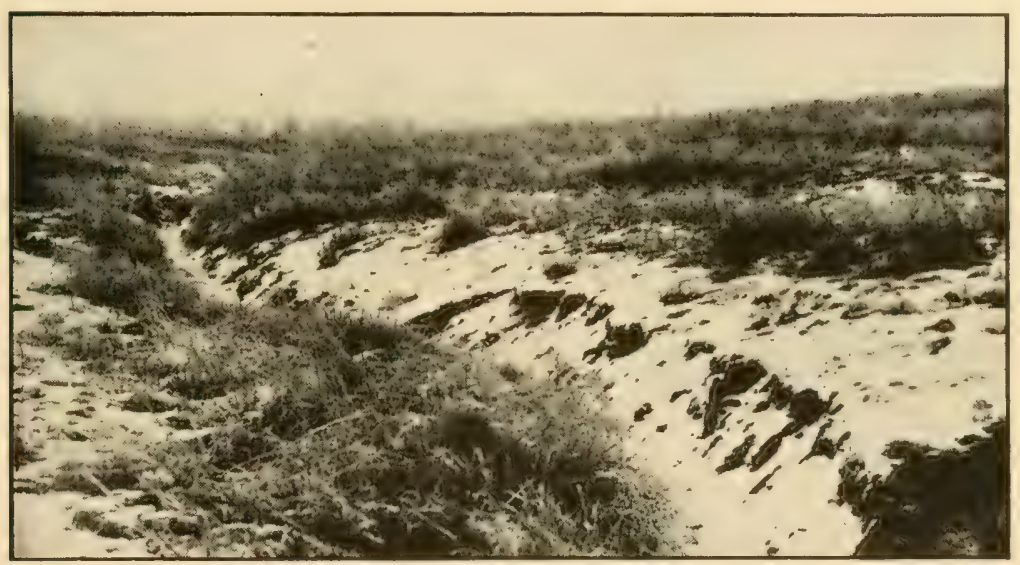

Natural gulley caused by washing. No use to fill it up with soil.

and light lands which wash so badly now, can be cultivated atter blasting the same as level land.

Ordinary subsoil blasting usually is enough to stop or to prevent the washing. See pages 89 and 90 for details of loading and page 101 for further discussion of erosion.

If deep gullies have already been formed, put half-stick charges every 10 feet along in the bottom, 2 or 3 feet under ground. A bout every 60 feet put in whole stick charges and blow out craters. These craters and the entire gullies will fill up after a few heavy rains, to a level with the surrounding surface, with sediment leached from the soil at higher levels. Within a year or so, if the work is done properly, you will not be able to tell where the gullies 
were located. The blasting should be done in late May, or in June, July or August, when the ground is dry and will crumble.

(See photograph below of gulley filled up, and note carefully how proper blasting will accomplish the desired result.)

Immediately after the blasting a heavy cover crop should be sown. This is to take advantage of the condition brought about by the blasting and to fill the soil with roots that will help increase fertility and help hold the soil together, when threatened with future washing. The roots will keep the soil open and porous for many seasons.

Before the blasting rain-water runs off the surface of unplowed ground in streams. When ground is plowed rain water soon soaks the 6 inches of loose top-soil. In both cases the surface of the ground is badly washed away. In plowed ground the water

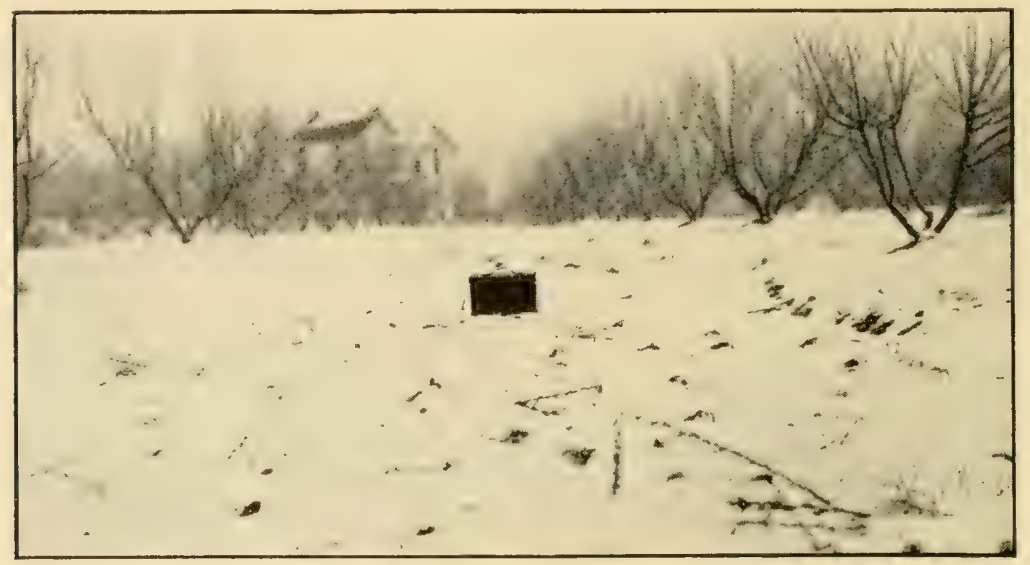

Two years before this spot was photographed a gulley as deep as the one shown on Page 77 cut through the place where the camera case stands. Blasting in the bottom of the gulley caused natural filling till the middle is now higher than the sides.

soon follows down hill above the plow-sole, carrying into the ditches or out of the fields considerable of the valuable plant food and quantities of the very best of the surface soil.

After the blasting the rain-water promptly sinks into the ground, not 6 inches but 2 and 3 and 4 feet. The blasting ioosens the ground for several feet down. In filtering through this loose earth the surplus water is freed of any plant food which may be leaching away, yet the escape of the excess water is helped instead of hindered, because no water-tight hardpan or plow-sole or layer of clay holds it.

\section{Draining Swamps with Atlas Powder}

In many swamps and ponds the water is held only by underlying layers of clay or hardpan. Below this water-tight material is an open layer of earth which will carry away the water.

Such places may be drained by blasting openings through the hardpan or clay down to the open ground underneath. Put down 
one or more test holes through the bottom of the pond until you strike loose ground. You may have to go down as much as 30 feet to do this, or you may strike it within a few feet. A pond or swamp of half an acre usually may be drained with one blast.

An extension dirt auger is best for making the holes. Put the hole down to the depth previously determined upon by the test holes, then "spring" it at the bottom with one stick of Powder. This will close the hole up slightly, but it can be opened easily. Fire this charge the same as you do the main charge.

After giving the hole a few minutes to cool, lower the sticks of the main charge and press each one to the bottom of the hole. The primer should be a whole stick of Powder fitted with waterproof electric fuze. If water fills the hole you need no tamping. If it does not, tamp the hole solidly.

The amount of explosive to use depends upon the depth of the hole and the thickness of the hardpan. If the hole is 6 feet (leep, a charge of 4 sticks of Atlas Farm Powder is enough; an 8-foot hole should have 6 sticks; a 10 -foot hole, 8 sticks; a 15-foot hole, 10 sticks; a 20-foot hole, 15 sticks; and a 30-foot hole, 20 sticks.

Use Atlas Powder 50\% or Atlas Farm Powder. The latter, which costs less, shoukd be fired more promptly after loaling. See "stability," page 6.

If your pond or swamp fills with water only during the wet season do the blasting in the dry season. If water stands too deep to permit you to wade do the work from a raft. Make the raft with a hole through the centre and run a 3-or 4-inch pipe down through this to the bottom. Do your drilling through this pipe. When the hole is loaded remove the pipe and raft.

\section{Excavating for Foundations}

In excavating, proper blasting with Atlas Farm Powder or Atlas Powder will save much work. You can take out a layer of dirt 4 feet deep with Atlas Farm Powder by putting charges of ? sticks about $3 \frac{1}{2}$ feet deep and every 3 or $t$ feet over the cellar area.

Keep the charges 2 or 3 feet from the sides. If the excavation is to be made deeper than 4 feet, go over the same ground with a second series of blasts put down 3 or 4 feet in the new bottom.

If nearby buildings prevent you from using heavy charges, use light charges to loosen the ground, as in subsoiling. If you find rock, blast the centre of the cellar out first. Then drill holes where you want the edges of the excavation to be and these blasts will throw the dirt and stones to the centre while keeping the side walls straight.

\section{Breaking Up Ice Gorges with Atlas Farm Powder}

Ice often dams back the water so that it covers fields, destroys fences, and floods buildings. A few pounds of explosive will remove any ordinary gorge and save trouble and loss.

If the gorge is small, only one blast need be made; if 30 feet wide and of considerable length, more than one blast will be needed. Use charges of 3 to 20 sticks tied together. A proper blast will shatter the ice for about 20 feet. 
Place the explosive as low as possible between the cakes of ice without putting it too deeply in the water. If the gorge is narrow and short, the charge may be placed near the centre toward the front or down-stream end. Remember that somewhere down in front and along the sides are certain key-cakes which lock the whole jam.
Place the powder so that these cakes will be shattered, then the main gorge will break up. An electric blasting machine is the best means of firing the charges, but the firing may be done with fuse and caps satisfactorily if fuses of all the charges needed are lit quickly, so that little time elapses between the different blasts.

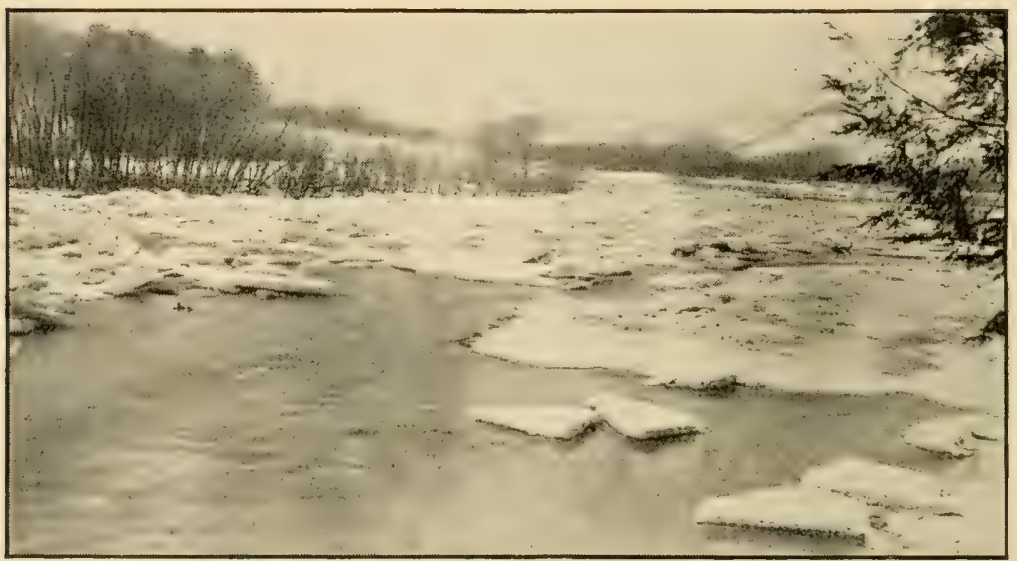

Ice gorges frequently cause serious flooding by damming back streams. They may be remored in five minutes with a few pounds of Atlas Farm Powder.

\section{A Quick Way to Kill Groundhogs}

Groundhogs (woodchucks) often cause much damage by eating and knocking down clover, wheat and corn and burrowing holes which cause injury to stock. They may be exterminated or driven away with Atlas Farm Powder.

When the groundhog is in his burrow explode a stick of powder 4 or 5 feet back from the entrance. Prepare the charge in the usual way, with a cap

and fuse. Stop up the mouth of the hole before firing. The force and fumes of the explosion will kill the animal.

\section{Loosening Logs and Coal with Explosives}

Log piles, post piles, wood piles, coal in cars and piles and other material often freeze so tight that they cannot be loosened by hand without excessive labor. Atlas Farm Powder will shake them loose without damaging the material or throwing it about.

Place a light charge near the bottom of the pile next to or underneath the "key"-that is, the log, post or place under the pile which when pulled out would bring the material down. Fire with fuse and cap or blasting machine. 


\section{BETTER BLASTING OF SOIL}

The governing principles of the actual blasting of soil are stated briefly in the next 15 pages for those who desire to know at once how to proceed. If you want to know why you should blast your soil turn to page 101. Here we tell how to do the work. 'Tests and field experience on a good many thousands of orchards, farms and gardens have shown what is required and what is not right. To tell how the work should be done is a comparatively short and easy matter.

To make clear all the finer points of advantage that may be gained by blasting soil, and to explain how these, as well as the more obvious advantages, are brought about, requires more lengthy discussion. The blaster who loads and fires the powder may be satisfied with nothing more than direction for the actual process. The owner of the land, or buyer of the powder, however, should be interested more in results of the blasting than in the blasting itself, and for him we include further along a memor-

andum of most of the factors that bear on the matter.

For a consideration of the place of blasting in connection with other forms of tillage, and with general matters of soil fertility and crop improvement in orchards and on farms, the reader is referred to the beginning of the second section, on page 95 . It is not possible from a briefer story to gain an idea of how soil blasting fits in the agricultural scheme, nor to acquire an understanding of what it will and will not accomplish.

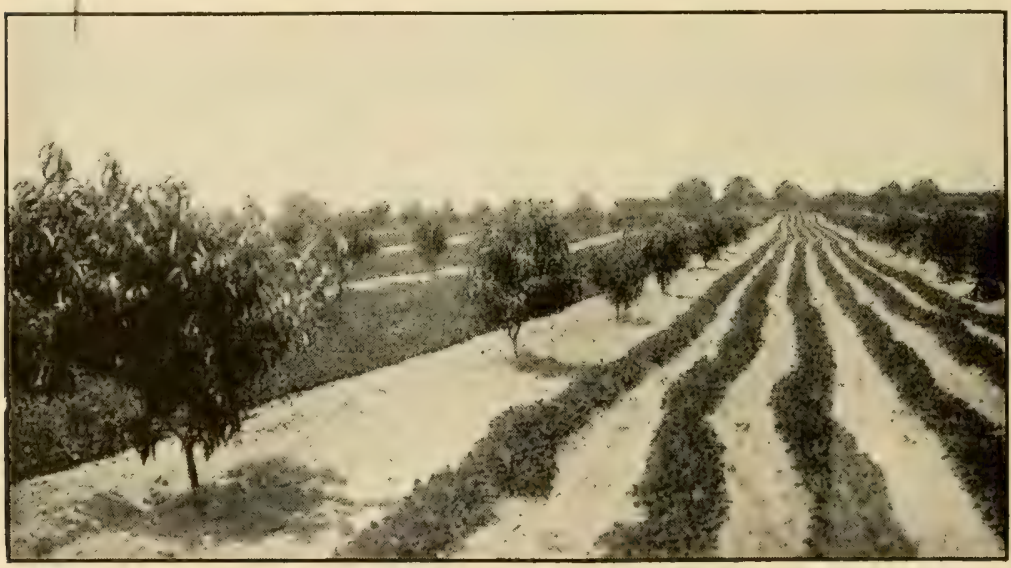

To get the heaviest crops of either large or small fruit it is necessary to subsoil the land with explosives.

\section{How to Blast Soil}

In the following pages we discuss the blasting of soil-not the blasting of tree "holes," or of garden plots or of corn land or any other special interest, except incidentally. Soil blasting for tillage purposes is the same whether trees or turnips are to be grown. The same reasons for doing it exist, the same results may be expected, and the actual blasting must be done the same. But, most important of all, whatever the crop to be grown, the principles that govern soil blasting should be understood fully. 
What Soils to Blast. The fact that most land is benefited by being broken up deeply with explosives for one reason or another, does not mean that all land should receive this treatment or that the blasting should be done the same everywhere. In every case it is desirable that the soil be examined carefully before decision to blast is made.

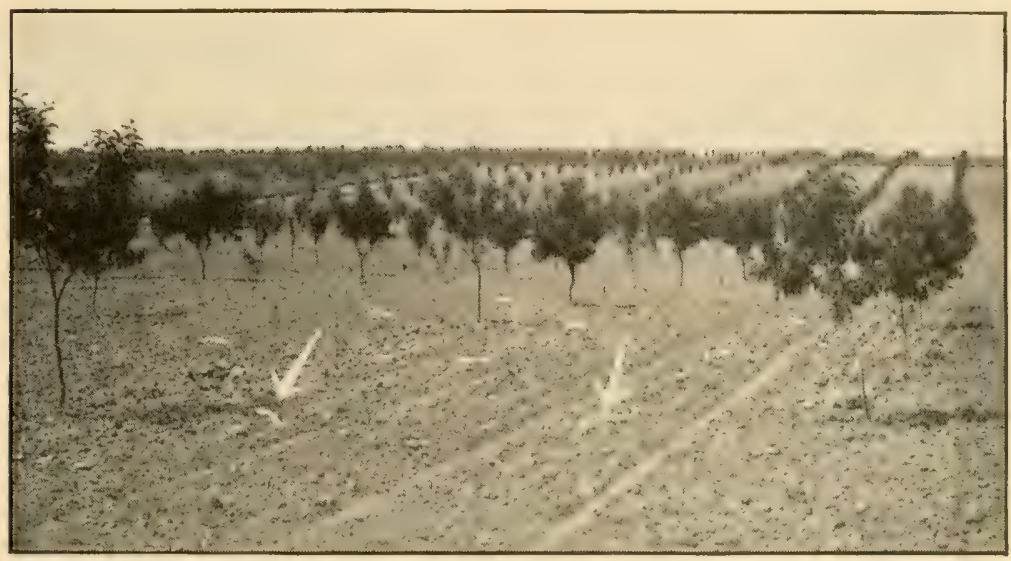

Young trees not planted in holes blasted with explosives should be subsoiled in the manner indicated here. Place a very light charge within 3 to 8 feet of trees.

Hardpan. The hardpan condition haturally presents itself as the one most obviously demanding blasting; though, in fact, hardpan may not be causing any more actual limitation of crops than heavy clay or other adverse conditions mentioned farther along. Hardpan is caused by a light cementing together of soil composed of fairly fine particles and is not unlike clay in nature, except for the binding material carried. It is so compacted that water will not drain or gravitate through it, or even penetrate it to any useful extent by capillary movement. Roots cannot penetrate it.

The layer of hardpan may be found within 6 inches of the surface, or perhaps not within 4 to 6 feet. It is harmful to crops, particularly to trees and such deep-rooting plants as alfalfa, if existing anywhere within 10 to 20 feet of the surface, as it practically shuts off ground water from the useful soils. The layer may be of any thickness from 6 inches to 30 feet, though perhaps the most usual hardpan is 2 to 4 feet thick.

An important point to remember is that hardpan (or other soil conditions) may exist on one acre or a part of one, and not on an adjoining one. An orchardist or farmer usually is familiar with the surface indications of every part of his place, but seldom realizes what is underneath. Examination should be made at numerous points to detect changes in soil structure.

Cemented Gravel is a condition that exists more often than is supposed by land owners. The coarser particles are bound together as hardpan particles are bound. During wet weather such soil often can be pener rated easily with a bar or auger, and is penetrated by water. As soon as the free water drains away, however, the soil becomes bound to such an extent that moisture will no longer move about in it, and roots, of course, cannot grow in it. Other bound gravels like hardpan are impervious to water and roots at all times.

Bound gravel usually occurs in beds of one to many feet in thickness, and may lie on the surface or deeper, between layers of clay, muck or silt. It usually is found in streaks along creek bottoms. The soil auger is the thing that tells the tale. This type of soil is usually productive after it is broken up, though it is worth very little without the deep tillage.

Bound Sand is another soil which presents the cemented condition period. 
ically. In wet weather it may appear to be as mellow as any other sand, but when dried it becomes brick-like. The surface indications, if the type of sand extends to the surface, are extremely hard lumps with sharp edges. Abundance of organic matter in the top-soil may prevent the surface indications from showing, though the condition of the lower soil may be bad.

Bound sand is more likely to occur over whole farms than any other of the hardpan conditions, since it is found mostly in those sections where the prevailing soil types are of sandy nature. The condition nearly always extends down many feet, though a clay subsoil sometimes underlays the sand at a depth of 3 or 4 feet. Such sand is productive to a certain extent with ordinary tillage, but responds wonderfully well to subsoiling followed by proper aftertreatment. There should be no hesitation about blasting this type of soil.

Ordinary Sands, for the purpose of this book, include all sandy soils which do not get lumpy and which do not contain big proportions of silt or clay. Blasting usually damages them, owing to the coarseness of the particles. come "exhausted" by continued cropping, or they compact and in that condition resemble modified clay, and should be blasted.

Light Loams containing no plow-sole and with subsoil light and open enough to permit free drainage and root penetration, should not be blasted. An exception would be in gardens where the most intensive of tillage is desired, and tree beds, where every possible advantage must be secured before planting on account of the years when thorough tillage will be impossible.

Clay. This type of soil nearly always is improved by blasting except where the layer is thin and near the surface, and is filled with abundance of organic matter. Whenever there is a lack of organic matter, deep breaking will be of decided benefit.

Clay may be in a solid layer many feet deep, or may be only 6 inches thick. It may start at the surface, or at any point below the surface. Frequently it occurs in layers in different colors and consistencies, above and below loam, gravel, sand or other soil. As with hardpan, it is damaging to growth in its original pure, unbroken condition when

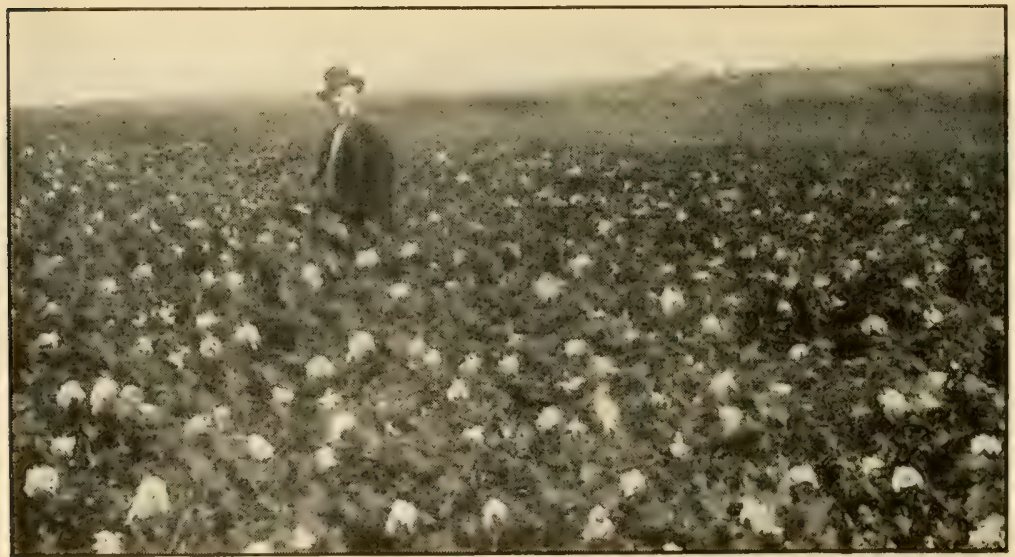

This cotton field, owned by Lee L. Galt, Ardmore, Okla., was subsoiled with explosives. It yielded 1775 pounds of seed cotton to the acre.

Moisture storage and capillary movement is decreased rather than improved. For consideration of clay subsoil, see below.

Muck Soils within five to fifteen years of their original draining from the swamp condition are by nature full of organic matter, hence are loose and light. They are not benefited by blast. ing. Often, however, they have be84 ever it occurs within 10 to 20 feet of the surface. The clay formation is found throughout the entire country in almost every section, and often forms the subsoil of lighter surface ground, including sand.

Often good farm land is underlaid within 3 or 4 feet with slate, shale or other rock. Sometimes this rock comes so close to the surface that it interferes 
with the plow. It may be broken up by blasting, and makes the best of soil, holding moisture well, and producing big crops. A 6-inch soil can be made a 4-foot one.

We wish it were possible to point out the soils needing blasting by their usual classification, such as limestone, red shale and others, but each of these classes of soils is a series containing nearly everything from sand to clay. Whether they are cemented into hard. pan or not seems to be an accident of nature; whether compacted to the point where they need loosening deeply, an incident of the care they have received. Soils of all kinds except those loose, light sands, mucks and loams mentioned (which have been abused, as on abandoned and "worn out" farms) usually can be built up faster and made to yield bigger crops by intelligent blasting in connection with the ether proper culture methods as explained in this book.

Soil Maps. It helps to know the general nature of the soil and subsoil throughout the entire locality, county or larger sections.

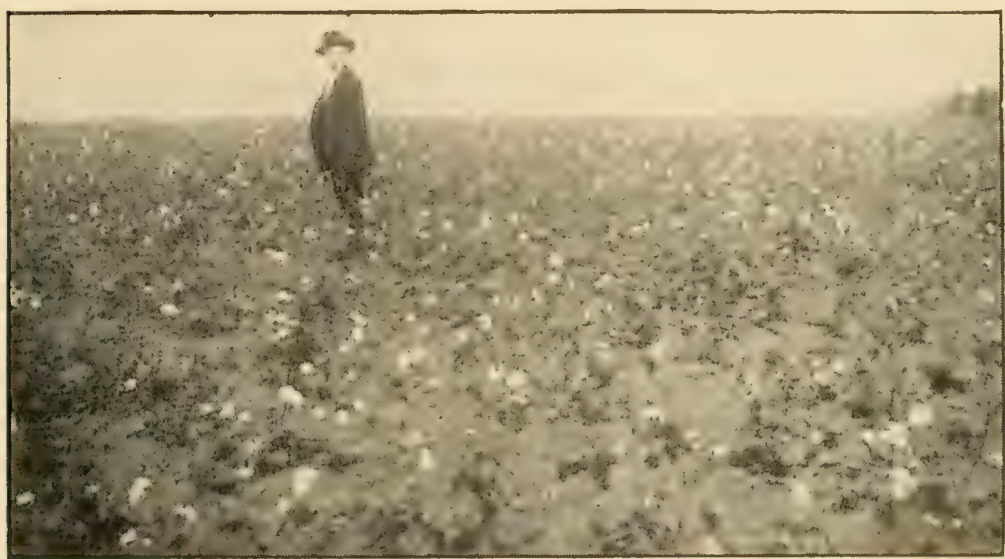

This field was not subsoiled with explosives. It has the same soil as the one shown on page 84 and yielded only 624 pounds to the acre.

For about half of the cultivated area east of the Rockies there are Government soil maps which describe the soils very much in detail, giving the facts about areas of clay, sand, gravel, hardpan and other soils that occur. These maps are published in three series. One set covers a large section of a state in each map, and is called a "Reconnoissance survey." Another covers a county to each sheet. These two kinds of maps are issued by the Bureau of Soils at Washington. Another series, issued by the Geological Survey, cover pirts of three different counties. All the maps are sold by the Superintendent of Documents, Washington, D. C.

An interesting relation apparently exists between the size of the soil particle and the possibility of securing benefit from deep subsoiling, or the extent of that benefit. Clay, for one instance, and hardpan, as another, have exceed. ingly fine particles.

The soil with the fine particles is benefited; the one with coarse particles is not benefited. An exception is cemented gravel.

Any soil that holds water on the surface for more than an hour needs deep breaking.

Viewing Soils from the angle of the use to which they are put, or the manner of their handling, they should be blasted (except the loose sands, mucks and loams). Blasting should be used when soil is used for gardens, when it is irrigated, traveled (rcads or paths) or pastured. Blast on hillsides to prevent gullying or washing, or where the soil holds up the water which causes drowned spots. The beds of trees, including both orchard trees and ornamental and fruit trees on home grounds, and the ground for all manner of small fruit and truck almost always should be 
broken deeply-excepting the coarse, open soils mentioned.

The Soil Auger described in the stump blasting chapter, page 39 , is an excellent means of investigating the under soil. Bore two or more holes on each acre, being careful to watch the borings or core from the auger. But it is well also to dig a hole down

\section{Condition of Soil Necessary for Blasting. Soil} must be dry when it is blasted, or the results will not only fail to be beneficial, but may be harmful. Years ago, when soil blasting first was extensively talked about, this rule had not been laid down. As a consequence there remains to this day tales of trouble and bad effect caused by blasting.

The degree of dryness necessary may be placed at the point where a soil has lost all its plasticity or stickiness. It should crumble when pressed, instead of packing, and this statement applies not only to the surface, but to a depth of 2 feet or more. If dry enough to plow it still may be too damp to blast properly. 'The amount of moisture that may be present without causing trouble varies with each particular soil. Gravelly or slightly sandy soils will hold a good deal without compacting under pressure; stiff clays hold little. The amount of organic matter has much influence.

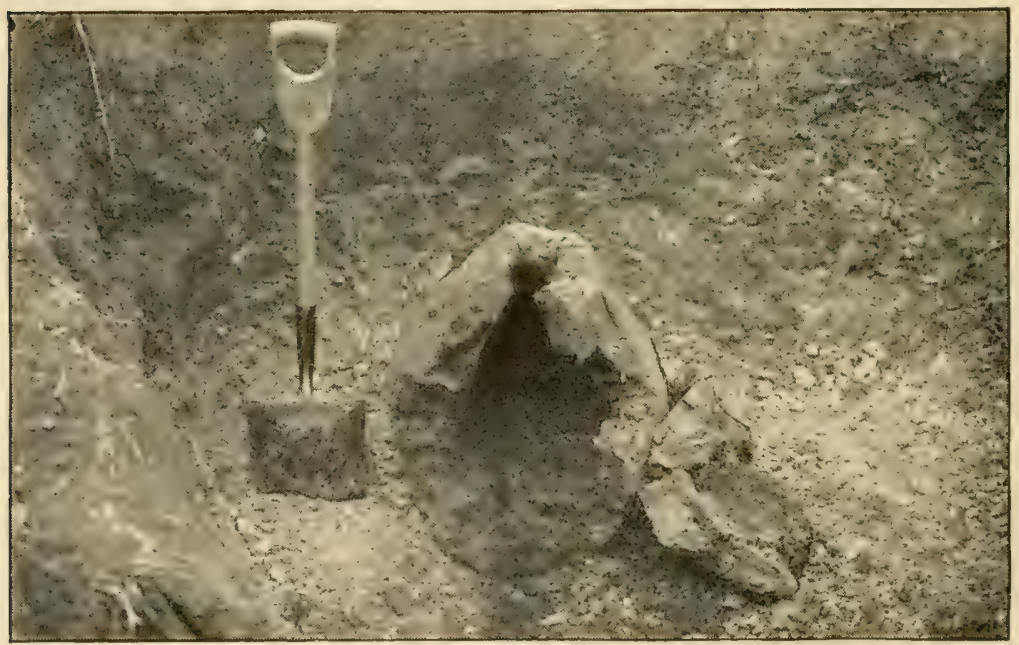

Result of blasting ground when wet. One "pot-hole" that was dug out. The walls were tightly compacted, making a jug that would hold water.

A blast in the ground exerts pressure against the earth surrounding the charge in almost the same manner as the pressure of a heavy blow with a sledge is exerted, could it be distributed as the blow of the gases is. In damp or wet ground the effect of the pressure is to drive some of the earth in a mass away from the chargé, and to pack it into other earth a foot or more away. A hollow or cavity is formed, with hard walls. This is the familiar "pot hole." A fact not so well known is that one of these "holes" can be dug out of clay and in many instances wili be found to have walls so thoroughly bricked as to hold water like a jug. Usually, though not universally, pot holes are indications of too much moisture for proper blasting. And, needless 
to emphasize, the compacting of the soil is very harmful.

In dry soil no such effects occur. The pressure causes a crumbling and breaking apart of the earth surrounding the charges. A slight cavity may be formed, but nearly always the dry, broken ground above and about it caves in and fills it in an instant. There is absolutely no compacting.
Some men say that ground can be too dry to be worked by blasting or in any other way, claiming that very dry soil powders and therefore looses its granular structure. We, however, advise everyone to get soil as dry as. possible. If it is dust dry do not hesitate. The next day may bring rain, and then a whole year may elapse before the proper condition is brought about again.

The test for condition should be to take a sample of the soil in the hand and squeeze it. If it molds to the palm and fingers, it contains too much moisture for blasting. It should crumble under the pressure, and tend to run between the fingers. The sample should come from a depth of two or more feet or even deeper.

When the ground is dry beneath the surface a heavy and prolonged rain is required to wet it more than a few inches. Light rains, such as ordinary thunder storms, need not stop subsoil blasting operations if the ground was in the proper condition before the shower. The surface wetting makes no difference so long as the under soil is in the right condition.

The Time of Year. The season best to do soil blasting is governed entirely by the amount of moisture in the soil. If the weather is very dry throughout April and May, as it once and a while happens to be, blasting may be done late in May or in June.

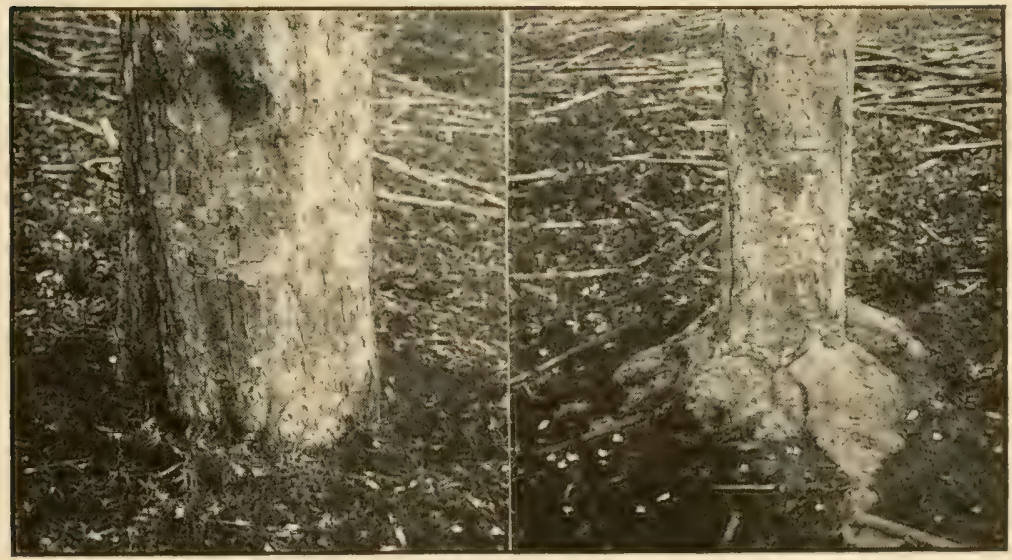

One tree grew 18 years in blasted bed, other same period in unblasted bed. Both tree s in same orchard. Hardpan beneath the latter has forced roots to surface. This unblasted tree also shows the effect of lack of enough food, which is because the roots have no room to spread as they should.

Nine years out of ten, however, in most localities, soil will not get dry enough before August or September. The fall months are more often dry than those of spring. October, November or even December may see dry weather for weeks, with consequent possibility of subsoil blasting. In practice, July, August and September are the months when the condition required will first 
be found-and the work should be done then. No delay should be permitted once the right conditions are established, as rain may come any day and cause an indefinite wait. It is im. portant to note that whole seasons pass perhaps a little lime applied, the amount of puddling and compacting that takes place will be less. The action of frost over winter may help to mellow broken subsoil.

Tree planters in Northern sections

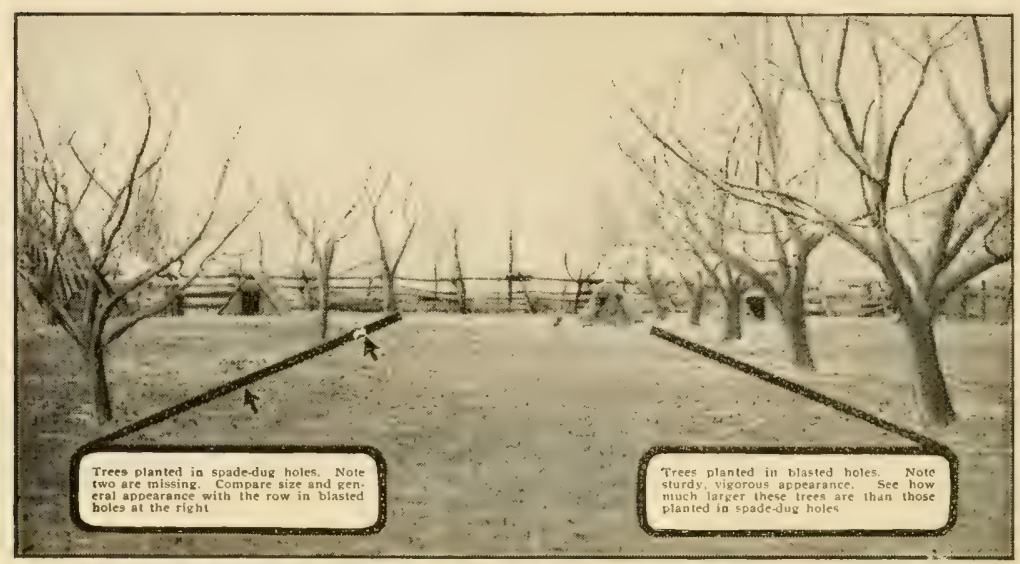

This is part of the orchard of George W. Brown, Mt. Cory, Ohio. The trees on the right were set in blasted beds eighteen years ago. Those on the left were set at the same time in unblasted holes. Note the difference in size.

sometimes without the soil once getting dry enough to blast. At such times it is best to wait for another year, except possibly in the case of subsoiling for preventing gullying, which usually is required in more or less gravelly or sandy soil that will stand handling while fairly damp.

Ground blasted in the fall for spring tree planting will puddle and compact somewhat over winter, but in most places the fall blasting is recognized as good practice. We recommend that anyone who desires to plant trees in the spring go ahead with his blasting the fall before. If cow-peas or other cover crops can be sowed over the blasted ground as soon as it is blasted (see page 114), and will ask whether they cannot blast their ground in the spring in time for setting the trees. As noted in the previous paragraph, there are a few years during which April and May are dry enough to permit this. Generally, however: those who wait for dry weather then will be disappointed, and will be compelled to blast their ground when it is too wet, or to plant their trees without blasting. Of the two evils, the latter is the less unless the ground is only a little damper than it should be (differences in soil, especially in organic matter present, should be considered--see page 86), because trees planted without blasting may have their beds blasted the next year or later on. See page 94.

\section{Adaptation of Atlas Farm Powder to Subsoiling.}

As noted on pages 5 and 6 , there are wide differences in the action of different explosives. Some tend to strike violently the material about the charges, and to grind to powder everything within 1 or 2 feet, while hardly disturbing the section beyond that distance. This action proves to be very poor for soil blasting or subsoiling. High percentage powders will do this, and will cause pot-holes and compacting of their walls even in ground dry enough to be blasted successfully with a proper explosive. The use of 40 per cent. and 60 per cent. nitroglycerin dynamite for soil blasting years ago was responsible for much poor work. 
Atlas Farm Powder was designed for soil blasting and stump removing (which is only another form of soil blasting). The errors of other explosives were avoided in it, and it was given an action particularly suited to lifting, crumbling and breaking apart the earth about the charges for long distances. It will give the minimum of pot-hole effect, the maximum of crumbling and breaking without powdering and pulverizing, and will reach out to distances beyond comparison with the work of many other explosives. The chances are that if soil is blasted with another explosive it will not be blasted as well.

\section{Loading and Firing Soil Blasts}

To blast soil, first determine the nature of the underlying ground to a depth of 4 feet or more. Then bore or punch holes $1 \frac{1}{2}$ inches in diameter to the proper depth, using auger or bar and sledge. Collect the powder and supplies, as directed on page 9, and load these holes with enough powder to break to the surface, but not enough to blow out a crater or to throw

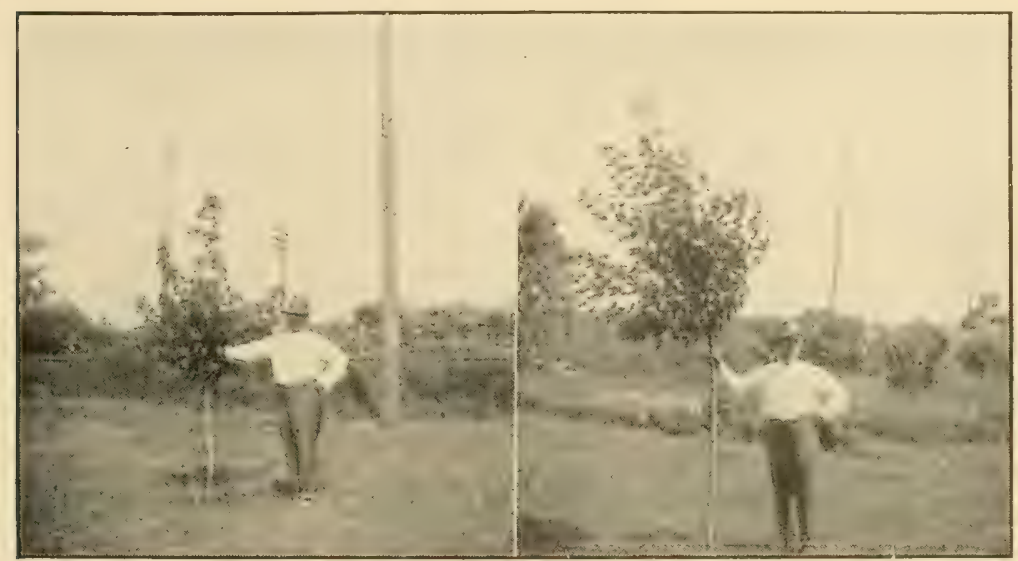

Two maples, one planted in the usual way and the other in blasted bed. The difference in size speaks for itself.

the dirt into the air. Prime charges as directed on pages 9 to 12 with caps and fuse. Space charges so they will overlap breakage of ground slightly, unless it is beds for young trees that are blasted, when charges should go where trees stand. This is the process in general. On the following pages it is taken up point by point in detail.

The depth at which to place the charges is the first consideration. It should be governed in every instance by the nature and condition of the soil. Referring to the notes on different soils, pages 83 and 84 , it is seen that in most places there are distinct layers of clay, hardpan or other compacted earth that are to be broken. The charges of powder should be placed in these layers, provided they are not thicker than 3 or 4 feet and are not more than 5 or 6 feet under the surface at their bottoms or lowest parts. The exact point in the layer that is best depends on the thickness of soil over the layer to be broken, and on the nature of the earth underneath it.

For instance, if a 3-foot layer of clay or hardpan is to be broken, which lies under 18 inches of sandy topsoil, the powder charges ought to go one-half to two-thirds the way down through the clay or hardpan, or at a total depth of 36 to 42 inches, provided the earth under the clay or hardpan is loose and open (such as sand or gravel). Should the underlying support be solid and im. 
pervious (as slate or shale), the charges should go deeper. In fact, they well may be loaded right down on the hard material.

In case the clay or hardpan layer is thicker than 4 or 5 feet, or in case it lies deeper at the bottom than 5 or 6 feet, to break it through is impracticable on a commercial or economical basis. The aim under such conditions should be to shatter and crumble the top 4 or 5 feet only. Charges therefore should be loaded to within 10 to 12 inches of the depth of breaking desired.

Sometimes the impervious layer is less than 18 inches thick, and lies near the surface-just under the plow depth, perhaps. When it is less than 6 inches thick it often can be broken to advantage with subsoil plows and other deep tillage machines. To blast such thin lavers the charges must be located just at their bottoms, or within 6 inches underneath them.

The depth must be such that, if pos- sible, the blasts will break through to the bottoms of the impervious layers. If the loading is too deep and the underlying material soft and open the force of the blasts may be wasted to a large extent in the soft material. Only a little breakage of the firmer layer may result. On the other hand, if the loading is not deep enough the blasts may blow out to the surface without breaking downward entirely through the impervious layer, or downward to the depth desired.

In every instance the proper depth for loading can be determined intelligently only by examination of the soil.

The kind of tree or plant and whether it is growing or yet to be planted have little influence on the depth for charges. An apple tree sends its rootsdown farther than a strawberry or wheat plant, it is true, but both must have moisture from far beneath the surface during dry weather. Subsoiling will accomplish many other things just as important as providing easy root penetration.

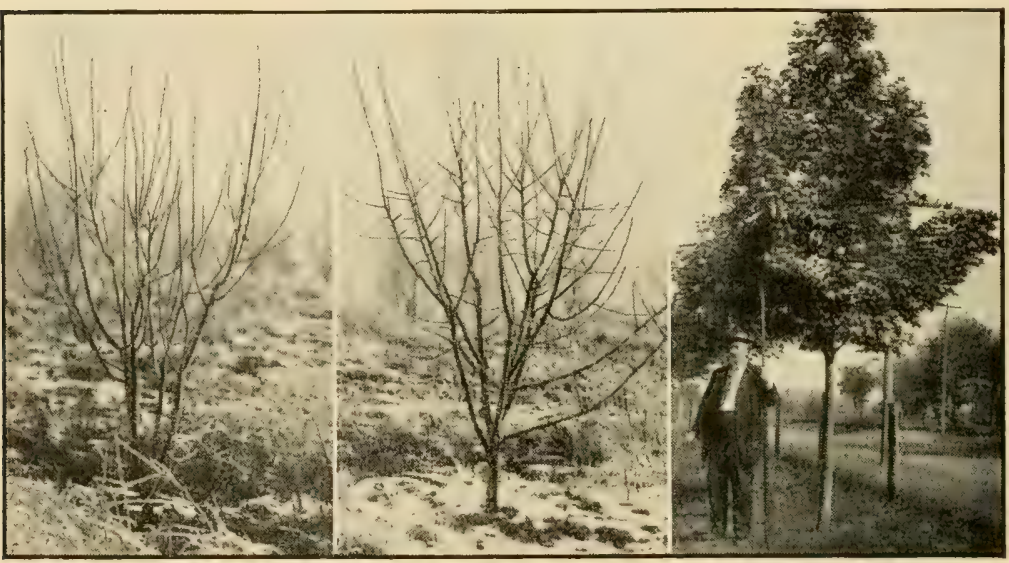

Two apple trees, left and center, one blasted and the other not. No need to say which is which. At right a shade tree making a remarkable growth because of blasting.

Amount of Powder Per Charge. There is one rule for determining the amount of powder to use which works infallibly in every kind of soil. The blast should not blow out a crater, yet should break the ground to the surface thoroughly-and the powder charge should be just enough to insure this effect.

A proper soil blast should throw a little dust into the air, or may throw a little loose dirt to a height of 2 to 3 feet. It should throw dirt no higher. After the blast the surface for 2 to 4 feet over the charge should be heaved or bulged upward 3 to 6 inches above unbroken surrounding surface, and should be somewhat soft under foot. The blowing out of a crater even 6 inches deep is exceedingly bad practice. That is why the term "tree-hole" blasting is misleading. It is the ground where the tree stands or is to stand that should be broken by blasting.

The matter of powder charge there- 
fore can be determined definitely only by test in each particular soil. 'The blaster first must investigate the soil, to learn its nature, as directed on pages 83 and 84 . When that is done he should load one or more test shots at the proper depth for the soil condition found. 'The amount of powder used for subsequent shots should be increased or decreased till exactly the right effect is secured.

In an average clay soil the following charges usually will give proper breakage at the depths specified:

$$
\text { Depth. Charge. }
$$

$1 \frac{1}{2} \mathrm{ft} . \ldots \ldots \frac{1}{4}$ stick (2 ounces)

2 ft...... $\frac{1}{3}$ stick ( $2 \frac{1}{3}$ ounces)

$2 \frac{1}{2} \mathrm{ft} . . . .2 \frac{2}{5}$ stick ( $3 \frac{1}{5}$ ounces)

3 ft...... $\frac{1}{2}$ stick (4 ounces)

$3 \frac{1}{2} \mathrm{ft} . . . . .3 \frac{3}{3}$ stick (5 ounces, about)

4 ft...... $\frac{3}{4}$ stick (6 ounces)

These figures of necessity are approximate only. They can be used for a ruide in loading the first test holes. They bring out the important fact that the proper amount of powder requires careful determination. Not only economical work but successful and satisfactory breaking and crumbling of soil depend on exactness of loading. It will not do to "guess" at the amount required or to vary the charges 2 or 3 ounces either way.

Hardpan often requires more powder than is indicated above. When it is flint-like, double charges may be needed to break the soil to the surface. Lighter soils than clay may show proper surface effects with less powder. The final gauge is the slightly rounded mound of broken soil over the position of the blast, and this rule applies alike in fields, gardens and orchards.

Few fields or orchards have exactly the same soil formation in all parts. Those who subsoil must test the soil often and with intelligent care, to detect any changes that require different loading. It may not do to let it proceed across a field without changing depth or loading.

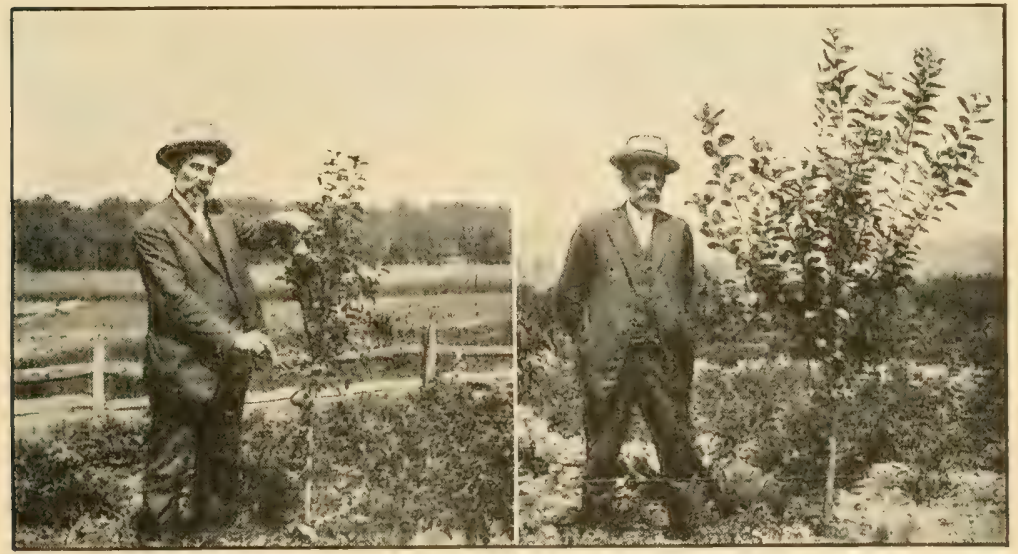

Pear tree on left and apple tree, both two years old, in blasted beds, and bearing fruit.

Making Holes and Placing Charges. It is supposed that the blaster has previously prepared his charges for loading and firing as directed on pages 8 to 16 .

Usually the most convenient practice is to prime as many pieces of sticks of powder as the job will require or as may be used in a half-day or a day, before coming to the field. These primed charges may be carried in baskets or boxes, and should be well protected from possible rain or wet grass, and from the hot sun.

Since the charges almost always will be fractions of sticks, it is important to determine before cutting up the powder and priming, just how much of a load will be needed. For the test shots the powder and supplies should be carried to the field and there prepared. In subsoil blasting the fuse (or electric wires if fuzes are used) had better be tied to the pieces of powder with string. Experience shows that no other arrangement 
will give as satisfactory results.

A $1 \frac{1}{2}$-inch subsoil bar usually is the best tool for making holes, though there are few jobs on which a soil auger of the same diameter does not come in handy for deepening holes well started with the bar. The sledge for driving the bar should not be too heavy. A man will strike more blows with a light one, which is what counts in soil.

An apparatus to pull a bar when it gets tight in the ground will save considerable hard work and time.
Power outfits for making holes for charges similar to those described on page 54 are of advantage on big jobs where there are no stones in the ground. Anyone interested should write us.

The powder should be dropped to the bottoms of the holes rather than lowered by the fuse. When charges are small pieces of sticks the best of tying of the fuse is none too secure. Caps may be pulled out of the powder very easily.

Tamping should be done thoroughly, as on it depends to some extent the dis-

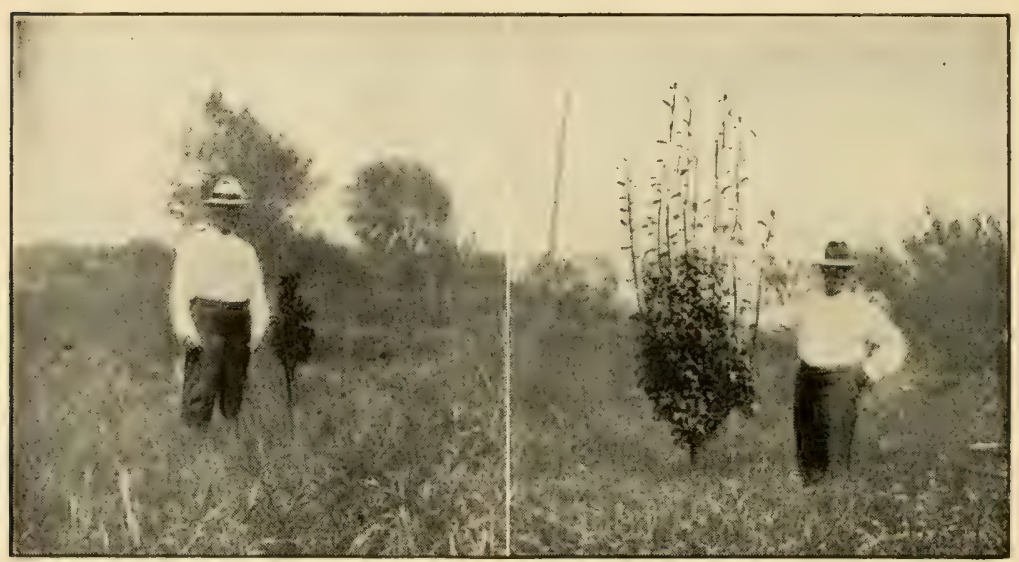

It is easy to see which tree is growing in a blasted bed and which is not. Both the same age and variety.

A special subsoil bar usually is about 4 feet long, though any crow-bar can be used. Other tools that are needed are a wood tamping rod and the usual basket or box containing small blasting equipment, as described on page 9. No waterproofing material is required, since the soil must be dry when the work is done. Don't forget the gloves for handling powder. tance the blast will break the ground sideways. Dirt should be solidly tamped to the top of the hole. If tamping is neglected the blast will tend to blow out a crater. Compare, for illustration, the method of blasting post-holes, described on page 76 , in which no tamping is used.

The fuse (or wires) should be held to one side, or the rod may damage it.

Spacing of Charges. Up to this point we have not distinguished between blasting soil for ORCHARD, GARDEN, FIELD OR OTHER PURPOSES, as the governing principles are the same. Spacing of charges, however, usually is different for each purpose, and may or may not depend on the actual distance sideways to which the blasts break the ground.

The breaking distance easily can be determined by observation of where trickles of dust and smoke arise from cracks in the ground at the time of the explosion, and by use of the probing rod (described on page 39). Usually the ground will be more or less crumbled for a distance nearly twice as far in all di-

92 rections from the point of the charge as the depth of loading. Beyond that, cracks will be formed for several feet, diminishing in depth and number the farther out they go. A 20-foot circle often is broken satisfactorily for field purposes by charges located 3 to 4 feet deep. In heavy clay and hardpan simi- 
lar charges, however, may break no more than 12 or 15 feet. Shallower charges extend to less distances. At what point in its extension the breakage is insufficient and unsatisfactory is a matter for personal judgment in each job, and the judgment should be based on the needs of the soil and the purpose.

For Orchard purposes it often is enough to blast the bed for each tree with a single charge. "This is the standard recognized practice throughout most fruit-growing sections. The spacing therefore coincides with the spacing of the trees, which for apples usually is 30 to 40 feet where filler trees are not used, and 18 to 20 feet with fillers. The table on page 88 gives the amount for the charge. Other tables on page 112 give the number of trees and charges required per acre at each spacing. The amount of powder and other supplies required can be easily figured from these tables.

Of late years there has been a considerable movement among some progressive fruit growers toward the use of more than one charge for each tree. In some instances where clay, hardpan or rock were encountered, three or five charges were used in each tree bed, to secure more thorough crumbling and wider range of it. These multiple charges usually are kept as light as possible for the soil, and are spaced within 4 to 6 feet of one another.

Another practice which is rapidly gaining in popularity is that of blasting not only in the beds of the trees, but along the lines of the rows one or both ways. For ground that washes easily this blasting is of special benefit. When the soil layers are too thick to be broken through, the blasting will relieve the drainage by lowering the water table. It does away with the dangerous condition of a reservoir of broken ground under and about each tree, into which water drains and is held, in time perhaps killing or at least stunting the trees. Blasting has been condemned in the past for having caused the death of newly planted trees, when single charges were used in heavy clay extending many feet deep. Orchardists readily will see the cause of the trouble, however, and will be able to judge of their own conditions. The charges should be close enough together along the lines so that good shattering is assured, with no unbroken sections to act as dams.

It is entirely practicable to blast the entire soil of an orchard. When the ground between the trees is shattered, as well as that immediately under them, the growth of cover crops is helped, and by the time the trees have reached bearing age and have grown big root systems, the soil can be developed into a high state of fertility and tilth.

For Garden purposes the blasting should be specially thorough. What is needed is the crumbling and churning effect secured only within a few feet of the charges. In this hurrying day and age there is little of the old-fashioned trenching done in gardens. Blasting of soil can be made to duplicate its effects, except that the ground is not turned over - the topsoil is not buried and the lower soil not brought up.

Charges ought to be close enough to one another so that the explosions will communicate at the full depth of loading. With very light charges the spacing may be as little as 3 or 4 feet. With heavy charges 6 to 8 feet ought to be satisfactory. Judgment of the operator (and on use of the probing rod) must determine the spacing.

For Field purposes the spacing usually should be the maximum at which satisfactory cracking is secured by the charges necessary to use. There is need for economy in field operations which is not present in garden work. The acreage is larger and the crops of less relative value. Twelve, fifteen, eighteen, twenty feet are usual distances. Observation and investigation, however, form the only real basis for establishing the spacing, as has been pointed out on page 91 .

For Home Grounds, Lawns, Parks and other ornamental plantings, the spacing should be such as to give thorough work. As with gardens, economy is not as important in this blasting as the greatest possible good effect. The beds for trees and shrubs usually should be broken with more than one charge each, and the operator should pay strict attention to the nature of the soil. If it appears to be impervious, and is of such a depth that he cannot easily break through to porous layers beneath, drainage lines should be blasted as in orchard planting. Flower beds should be broken up with light charges placed within 2 or 3 feet of one another. The planter of ornamentals must bear in mind that his trees and shrubs likely will have to grow under adverse conditions of sod and neglect, horticulturally speaking. The preparation at planting time therefore should be especially thorough. 
Firing Charges. In most instances soil blasting charges had better be fired with blasting caps and fuse. This method consists of crimping a blasting cap to the end of a piece of fuse cut to the right length, and inserting the cap in the stick or piece cf stick of powder, after which the fuse is tied to the powder with string.

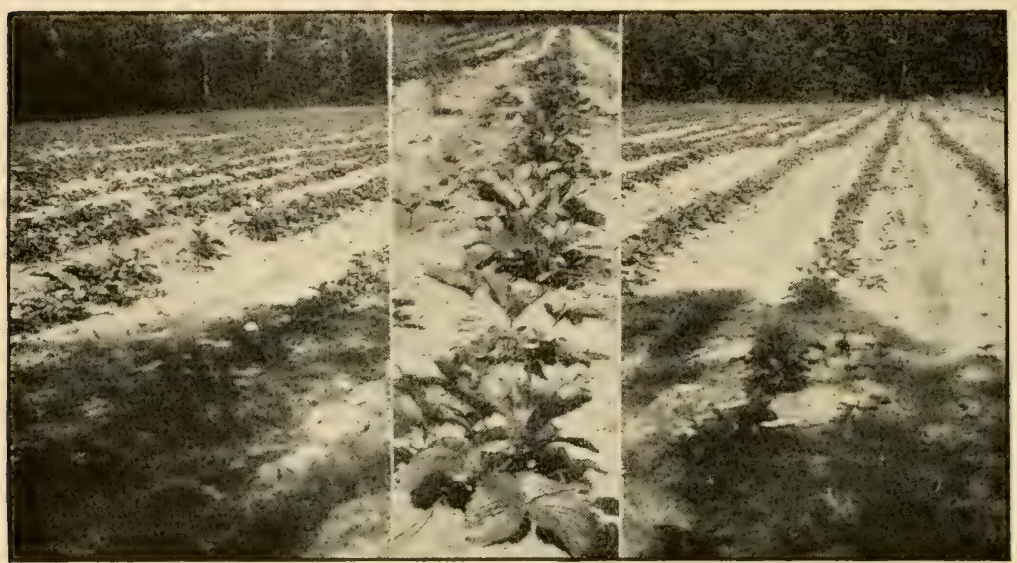

The finest strawberry patch in Delaware, fall 1915. Set spring 1915, on land subsoiled with explosives.

The preparation of the charges is fully described on pages' 8 to 12 , and the lighting of fuse is discussed at length in the stump blasting section, page 50 . Matches are the best means of lighting fuse when only a few dozen charges are to be fired; when hundreds must be handled, a torch is best. Soil blasting permits of more leisure in fuse lighting, since the blasts are not particularly dangerous.

The only instances in which simultaneous firing of two or more soil charges is desirable or of advantage are those where the charges are placed close enough together to communicate, as, for instance, multiple charges for one tree bed, or thorough garden blasting. Simultaneous blasts close together make each individual explosion more effective. The cost of electric fuzes is more than of blasting caps and fuse, however, hence electric firing adds expense. In small jobs, with a comparatively small number of charges, the extra cost does not make much of a total, but where the acreage is large it amounts up enough to make electric firing too expensive.

\section{Blasting Soil Under Living Trees and Crops}

Seldom is it convenient or profitable to have land bare of all crops when it is dry enough for proper blasting. To do so means the missing of a full season in gardens and fields, and often the delaying of a cover crop in orchards. In addition to this, there are some millions of orchard and ornamental trees already in the ground which have been planted without deep breaking of their beds.

It is fortunate, therefore, that proper blasting of soil under living trees and plants does them little or no damage, even temporarily. Incorrect blasting, particularly blasting done when the ground is too damp or wet, or done with charges too heavy for the depth of loading, easily can cause damage, but we take 94 it that anyone who subsoils his ground will study the suggestions and instructions in this book and will use care in carrying them out, even as he does in handling the powder. In that case there will be no cause for regret.

Blasting in fields of grass and grain may proceed without regard to the crop. 
Better Blasting of Soll.

In cultivated fields where the crops are in rows (as potatoes and corn), the charges, of course, should go between the rows, as they can be loaded there with least tramping.

Under standing trees the blasting may be done at any time the ground is dry, as discussed on pages 83 and 84 , except possibly in the case of fruit trees of early ripening varieties that are heav. ily loaded, when the blasting may be delayed till after the harvest. It is under such trees that the greatest care must be used to get the charges right and the loading correct. Some slight disturbance of the summer growth of the blasted trees may be noticed (as from summer pruning), and the fruit of late ripening varieties may be slowed up for two or three weeks in its development, though not in coloring.

When fruit trees are small these disturbances are of no account. With Jarger trees, however, in order to minimize the effect on the crops, it often is wise to blast only one side of the root srstem in any one year, or even only a third or a fourth of it. When part only is blasted, there need be no hesitation about doing the work under the largest trees at any time the ground is in condition.

The blasting of the ground under evergreen, shade and other ornamental trees, shrubs, vines and flowers is subject to the same governing principles. They are not harmed by summer blasting, if any. Very large trees, particularly those very tall and old, should be handled as large fruit trees are handled-part of their beds blasted one year, and the remainder the next one, two or more years. The chief reason is that the roots of old trees have to sustain enormous strains during wind storms, and if all the ground about them is loosened, their roots may pull loose if severely tested.

Placing Charges. The depth at which charges should be placed, and the amounts of powder to use are exactly the same as though the trees were not there. These matters are governed by the nature and condition of the soil as found on investigation. The discussion of this matter on pages 86 and 87 applies equally well here. The only point of difference might be that lighter charges would be permissible should the blaster be in doubt. To use less powder is the safe course. Proper charges, which do not blow out craters, should break few roots. For instance, roots $\frac{1}{2}$ inch thick should escape damage except a battering of bark. Smaller roots may be broken, but larger ones should not be. Years ago it used to be the practice to place heavy charges 12 or 15 feet directly under the trunks of trees. When the explosions occurred, the entire trees were lifted a few inches. Such practice may not cause excessive harm in some instances, but is likely to, and we advise against it.

The distance away from the trees at which charges should be placed is a matter of judgment in every case. To place them under the tips of the limbs is not a bad rule for wide-spreading trees. For very young trees the charges may be placed close enough so their crumbling effect will just reach the outer edge of the main root system, and their cracking effect, which extends much farther, will penetrate under the trunk. Four feet away from trees that have been planted one year, and 5 feet from trees in the ground two years are good general rules.

For older trees the charges should be placed just out from the points where the larger roots break into feeders. The difficulty is to learn where such points are. So far as fruit trees are concerned, the height of the tree may be some indication when considered in connection with its spread of limbs. Shade and ornamental trees should be judged carefully, and the doubt, if there is any, be given to the tree-that is, if the blaster is undecided as to the distance, he should locate the charges at the farthest outward point he thinks ad. visable rather than closer in.

Drainage through impervious clays and hardpan is just as important in the blasting of standing trees as in the preparation of beds for young trees. Wherever the clay cannot be broken through to something more open beneath that will carry away the water the blasting should be complete from tree to tree and round each tree. Otherwise water will stand in the blasted ground, as mentioned on page 102. Standing water is of no use whatever to roots of ordinary trees. In fact it is harmful to them.

Test Shots. Whatever the depth of loading indicated by the soil, the amount of powder that seems to be required from a study of the directions, or the distance away from the tree trunks decided on, the final authority should be the test shots. Observe carefully how far the ground is broken. Probe and shovel about in the broken ground for roots. Make any changes in the loading that seem necessary. 


\section{Planting Trees}

A blasted bed is cracked in all directions. The one particular difference between planting in a blasted bed and in a dug hole is that the ground should be tramped tight against the roots in the blasted bed. When the blasting is done in the spring in time for planting there seldom will be entire absence of underground cavity left by the blast, owing to too much moisture. (Blasting MUST NOT be done when there is enough moisture to cause pronounced pot holing and compacting of walls.) When the work is done in the summer or fall the ground may be dry enough so that cavities will not form.

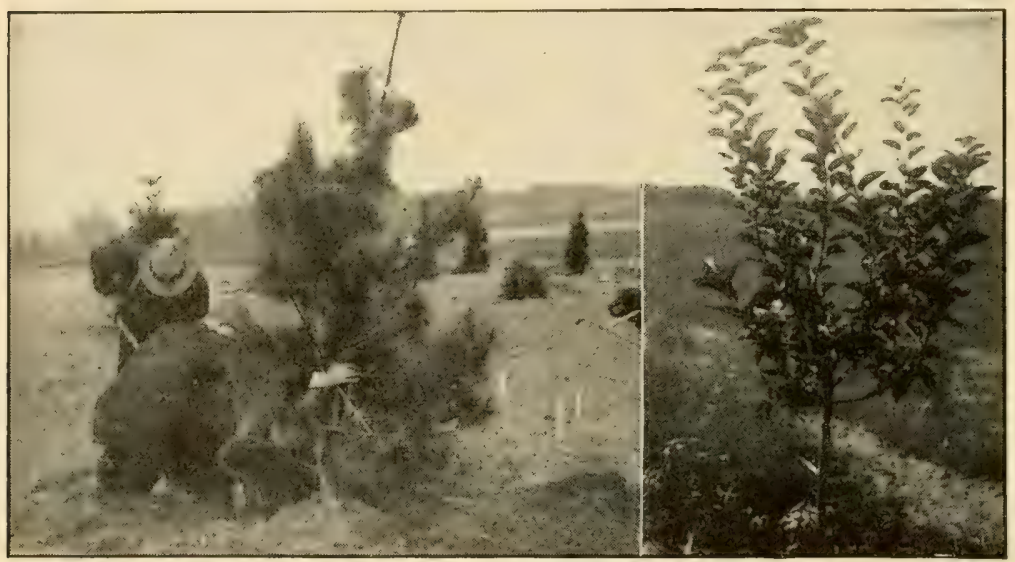

Evergreens respond to blasting of their beds as well as fruit trees, particularly since the soil of the average home grounds is very hard. The right-hand picture shows an apple tree on the Garacove Farm, Northeast, Md. Two thousand of these made an average growth of 18 inches, season of 1915-all in blasted beds.

At the time of planting the trees, the workmen should make sure that not only actual cavities but loosened ground at the points where charges were located are punched and tamped until no settling will take place after planting. A long handled shovel is a convenient tool for locating hollow places. The user should bear in mind that the shovel should be pushed down to a depth 6 inches lower than the depth of loading.

When the blasting has been correct, the surface soil will have to be shoveled out. The shoveling is a quick and easy matter, however, as the ground is as loose as grain in a bin. When the

shoveled hole is 12 to 18 inches deep, the bottom should be probed, as directed above. Any cavities should be found and filled, and the bottom of the hole afterward should be filled up to the proper depth for the roots with top-soil. The expression "Dig out the smoke" has been used for this exploring of the under soil for hollow or loose spaces immediately after a blast. The term is a good one as it explains its own meaning. Blasted ground left over the winter will be somewhat settled by freezing, thawing and water, but not enough to make further filling unnecessary when the trees are planted the following spring.

Pot-holes which have been caused by wrong blasting, together with the compact walls, may be broken and corrected by proper summer blasting, even though the trees have been planted. Large pot-holes are caused by soil blasts only when the ground is too 
wet for the work, or when the wrong kind of explosive is used. The characteristic compacting of the walls of these underground cavities is illustrated on page 86. Charges should be located within 3 to 5 feet of the trouble. Usually it is better to use three light charges for each tree or position.

Reservoirs of Plant Food. In some old orchards where the soil is very poor it is of advantage to establish reservoirs to which the trees may send their roots for easily obtained food. To accomplish this a large cavity should be blasted out in the middle of the space between trees. The hole then should be filled with a mixture of organic matter, and fertilizers, manures and sand or other light soil, and a covering of a foot of ordinary soil placed on the surface. Due attention must be paid to providing drainage in case the subsoil is impervious.

Laying Off the Tree Positions is assisted materially by the use of wire guides or measures, and stakes. The blasting should be done accurately at the points the trees are to stand, not 5 or 6 feet away. To get it so requires careful measuring.

When blasting is to be done in the spring immediately before the trees are planted two stakes may be placed at tree bed. They should be located with care by the use of a planting board. The board, about 10 feet long, has a hole near each end and a notch in the middle. It is used by putting the notch on a stake (previously set) that marks the exact position for the tree trunk, then driving pins through the end holes to mark the points in the ground for the two stakes.

When the blasting is clone in the fall, unless the planting is so small as to require no great number of stakes, the best plan usually is to stake off the ground for blasting and again for planting.

To obtain the positions for the trunk stakes we advise your choice of two methods of measuring. The first, and perhaps the most accurate in the hands of ordinary workmen, is for the triangular system of planting, and consists of a triangle of wire each side of which is exactly, to within $\frac{1}{4}$ inch, the desired distance between trees. A small iron ring should be used at each corner for fastening the wire. Start the planting by setting two trees where they should go along any side. Stretch the wires up, with two corners at trees or stakes already in place, and the third corner of the triangle always will mark the proper position for another stake or tree.

A speedier method of measuring is to use a wire about 250 feet long, with rings on the ends, and to these rings other pieces of wire just long enough to reach across the proposed rows. The main wire should be marked with lumps of solder, to which are wrapped bits of red string or ribbon, at the exact distances the trees are desired in the rows. The method of using is to stretch the short end pieces across at right angles from the first row of stakes or trees. 'The "rear" end of the main wire then should be fitted with care at the proper point opposite the first tree in the previous row.

Blasting of the tree beds can be done with the wire in place, and the planters can follow immediately after the blasting. Or the end positions of the wire can be staked with care, the blasting proceeded with, and the planting done later by replacing the wire at the stakes.

The trees should be fresh and moist. It does not pay to plant trees in a dry or shriveled condition. Unless the roots and tops are plump, moist of bark and healthy looking, it is best to soak them in water-roots, tops and all-for some hours or days. roots.

Pack the soil solidly about the tree 


\section{EVIDENGE}

"I have a prosperous growing young orchard which will attest the superiority of trees planted in dynamited holes over those planted otherwise."

\section{J. T. KELLY, Timberville, Va.}

"Powder shipped to Clark Brothers, Stuart, Va., arrived O. K., and it did a good job for my tree planting. Will always use it for that purpose."

E. A. RAINOUS, Stuart, Va.

"Two years ago I found that trees planted in holes blasted with Atlas Farm Powder did nearly twice as well in growing as those on which no powder was used, and will use Atlas Farm Powder to plant every tree on my suburban place."

J. J. FUNK, Webb City, Mo.

"In blasting for cherry trees, I would not at all have believed what it would do to the ground. It was tough ground, with clay underneath, and the way it broke the dirt to pulverized ashes was a wonder. It is the only way to plant trees."

L. W. BYRAM, 610 Kansas City Life Bldg.,

Kansas City, Mo.

"Having used some Atlas Powder last year in tree planting and subsoiling I can say it is the greatest labor saver, and gives the best results of anything I swer heard. Whenever I wish to plant any trees, the holes will be prepared with Aria H.rm Powder every time." $\quad$ R. 1.. K.ARCHER, Haysville, Pa.

"The trees were planted two years ago and were one-year-old whips when planted. They were Stayman Winesap trees. There is strong indication of fruit on the tree that was planted with Atlas Farm Powder, for this year. If my indications are correct, I will be more than pleased as they will be only 3 years old. There is nc indications of fruit on the trees that were planted in spade-dug holes."

PIPPIN HILL, FRUIT FARM, Blairstown, N. J.

"I set out 264 trees last year. While crops were ruined for want of rain, every tree lived and thrived vigorously, much to the surprise of neighbors, who said I would lose every tree. One thing is settled in my mind. Planting fruit rees without dynamite is obsolete, wasteful of time and money. I cannot afford w plant. without blasting. I am using it again this year."

\section{J. IRWIN, M. D., Springfield, Mass.}

"I have used great quantities of dynamite for blasting tree holes. The land here in Dade County. Florida, is extremely rocky. My method is to place a bavy charge at the bottom of a hole about 2 feet deep. I leave the broken rcck in the hole. Dynamiting is a great advantage in our rocky soils. The larger part of the citrus groves set by me have had dynamite used where the trees were set."

E. V. BLACKMAN, Miami, Florida.

"In April, 1912, I slanted with dynamite 225 apple trees and the same time 1 ianted with a space 20 apple trees. The difference between the trees where drramite was used ard rhose where dynamite was not used is almost beyond de ription. I only los: sue sut of 225 planted with dynamite and I lost 4 out of nade-planted. The difference in growth from April to October the same year . six _. eight inches." J. A. McLAIN, Fredericktown, Pa.

"Some wh vars ago I used some of your Farm Powder in tree planting. The $1: \leqslant$ ults have been more than sat ${ }^{+}$- tory. I used it in setting sugar maple and asso soft maple and peach trees. We have a large number of customers who have examined the trees mentio :ad above, and who are now using dynamite for setting their own orchards. We are a. so selling it for stumps and boulder work, with good results."

J. F. BURGE, St. James, Mo.

"Without the use of dynamite it is necessary to dig the holes at least three fiet in diameter and two feet deep. Ii the hole thus prepared is filled with new scil and the tree planted in it, the tree !nay thrive for a year or two, but the roots soon meet with the smooth and compacted sides of the hole, through which they have great difficulty in penetrating. The iree is in about the same situation as if it had been planted in a large tub. When dynamite is used, however, the cracks are formed in the soils to greater denths than wo.ld be reached by hand diggingto distances of five or sometimes six feet on all sides. This makes the very best conditions for the continued growth of the tree. "or tree planting dynamite is recommended confidently as the best method of pret aring the soil."

HAWAII AGRICULTURAL FY STATION, Honolulu, Bulletin 38, on "The Uss : Lyramite in Farming." 


\section{EVIDENCE}

"I have used your farm Powder setting out trees and same has proved entirely satisfactory. Will use it this Fall to subsoil about five acres."

WM. S. LUXSTUN, Fredericksburg, Va.

"I can truthfully say I have gotten entirely satisfactory results from planting trees with Atlas Farm Powder."

V. G. HUMPHREY, Ocean Springs, Miss.

"We have used a considerable amount of Atlas Farm Powder in planting pecan trees and believe it to be indispensable. We will plant a large number of pecan trees this fall and expect to use Atlas to do the work."

BLACKLEDGE BROS., Muskogee, Okla.

"Relative to the condition of the fruit trees on our State Fair Demonstration Plot, which were planted with Atlas Farm Powder, wish to state that there is a very remarkable advantage in favor of the trees planted with dynamite."

JOSEPH W. EAKIN, Nashville, Tenn.

"After having used explosives in planting 800 fruit trees, and comparing results for the past three years with trees not dynamited, am so thoroughly convinced of the benefits, that I would not plant a tree of any kind without using the explosives. I have also reclaimed and rejuvenated three acres of hardpan, water leached spots in farm field that was absolutely worthless before blasting, and which now is producing good crops."

R. W. SMALL, Nowata, Okla.

"In the Spring of 1912 I set out 22 apple and-peach trees, six in spade-dug holes and sixteen in blasted beds, using Atlas Farm Powder. The first year I could see no difference in the growth of these trees, but at the end of the fourth year the trees set in the dynamited holes were fully one year ahead of those set in spade-dug holes. This convinces me that it pays to use dynamite in planting fruit trees."

RALPH A. GUTH, Wescosville, Pa.

"Two years ago we used Atlas dynamite in preparing ground for the setting of one thousand orange and grape fruit trees and the results so far are satisfactory. The trees are in fine shape and larger than any we have seen at any other point at the same age."

\section{J. A. CARR, Hattiesburg, Miss.}

"An orchard of about 75 trees which was planted in 1878 in a very tight soil had always been slow growth until last year, when I blasted around them, using a half stick on each side of the tree, placing them sometimes $3,4,5$ and 6 feet from the trees, depending on the size and roots of the tree. The larger trees would need shaking up more, so the charge was placed closer to them. It was astonishing how the trees took on new life and started to grow again, and they have grown more in the last year than they have in the five years previous."

W. J. PUETTE, Brevard, N. C.

"Holes were prepared for tree planting with dynamite. Experiments in 1905 proved to us that dynamite was the cheapest and most effective method of preparing the soil and opening the soil for the planting of fruit trees. Not only was the earth finely powdered, but the usually compact soil surrounding all spadedug holes was loosened up and softened and made good soil into which the finest roots could penetrate with ease. Strong root growth in a fine hole was made possible in a very short period of time."

H. B. FULLERTON, Director L. I. R. R. Exp. Station, Medford, N. Y.

"Your booklet 'Better Farming' was received and read with much interest. Two years ago I was employed to replant 5 acres of pecan trees that had died. Upon examining the ground I found it a very stiff clay and while a fair hole had been dug the clay was so hard the roots could not penetrate further than the loose dirt and the hole acted as a sort of a reservoir for water and many trees had died from too much moisture. I believe in giving a tree a fair chance and told the company I wouldn't replant till dynamite was furnished. I used $1 / 2$ stick for pecan and $1 / 4$ stick for orange trees and the newly planted trees show the benefit of the work. All trees started out and made a good growth and while the season was wet, no water stood around the trees. I have 20 acres to plant in December and will use dynamite in each hole. In clearing cut over land I used dynamite to cut off green pine trees and the results are very satisfactory, Any one planting trees in clay ground makes a mistake if dynamite is not used." 


\section{Cropping and Fertilizing Blasted Soil.}

To derive the maximum benefit from the deep breaking of blasting soils must have introduced into them an adequate supply of organic matter without delay. If they are plainly lacking in any element of plant food, as nitrogen, phosphorus or potash, that element should be supplied in one form or another. Should they need lime for any reason they should have it immediately-tree beds particularly.

Whenever it is possible-and it should be possible in almost every instance- - the ground to be blasted should be planted in a heavy-rooted crop at the time. Corn is good. A leguminous cover crop such as alfalfa, sweet, red, crimson or other clover, or some kind of peas or beans is better. Lacking these, rye, turnipsor even a heavy grow th of weeds is desirable. This crop should be planted in orchards as well as fields. The object of having the crop on the land at the time of blasting is that the roots will penetrate the loosened and crumbled ground to depths previously not attempted by them, and they will do it without loss of time, before any of the effect has been lost through puddling bound to follow heavy rains. If possible the entire crop should be plowed down not later than the following spring. In case a crop like corn is removed, it pays to sow turnips or other catch crops for turning down.

When there is no crop on the ground at the time of blasting (trees are not regarded as a crop in this sense) one should be planted as soon as possible. In an orchard the cover crop can be put in as early as the middle of June, and in the case of spring blasting this is highly desirable.

The more organic matter that is turned down and developed in roots during the seasons immediately following blasting, the longer the effect of the blasting will last and the greater will be the response in increased fertility, better tilth, and productiveness.

The Sod Mulch system of managing an orchard can be made much more effective if the soil is blasted occasionally. The characteristic compact "sad" condition of the under soil, due to lack of stirring and to tramping, can be changed to one of mellowness and openness. The blasting aerates it, lets roots down, and improves bacterial conditions, things which cannot be accomplished by any other means under the sod and among the roots of trees.

Shade Trees along streets, walks and on lawns and yards can be cultivated by blasting. The ground about them

gets compact, dry and sterile. The trees become stunted, yellow and ugly. Careful blasting reverses the soil processes and starts the tree beds to becoming more fertile. Moisture conditions also are improved

Roads and Paths through orchards, across fields and over lawns often are made carelessly. Even those intentionally made frequently have to be broken up. The under soil is much compacted and it can be crumbled and opened properly only by blasting. Without the use of powder years of plowing and cropping would not restore the original productiveness. With proper blasting, however, the soil can be made mellow in a season or two.

The holes usually are hard to make in such ground in dry condition. A good plan is to make them when the ground is wet and soft in the spring and leave them till midsummer, when they can be cleaned and the blasting done.

Terracing for the prevention of washing is largely unnecessary when ground is blasted properly, yet there are places in the heads of small hollows and elsewhere, toward which flood water gathers naturally, where terraces will provide additional insurance against gullying.

Powder can be used to advantage in making the terraces. Single furrows should be plowed across the slope where each terrace is to be made. Lines of light charges then can be loaded from the bottoms of these furrows. They should contain enough powder to blow out craters, but should be loaded no deeper than the bottom of the excavation for the terrace.

Hardpan and Shale in Spots. There are areas of soil where blasting is imperative; that is those underlaid with hardpan, slate, clay, etc. Trees or any other crops will not grow well without it. The point is to find out if your fields have such under-soil, and if so blast the soil. The blasting has to be done before trees will succeed as they should on such land Without blasting it is worthless; after blasting unexcelled. 


\section{How Long Will "Blasting" Last? The answer lies in} a description of what happens in blasted ground.

When the soil is crumbled, and each particle soon is surrounded by moisture, the several feet of loose ground hold more than enough water to grow big crops. The water is stored so it cannot escape in dry weather if the surface of the ground is shaded or cultivated. Roots can get it just as they want because it is in the form of moisture films, and because they can penetrate so easily.

This excellent supply of moisture is just what is needed to make the bacteria thrive and increase. They begin to work on organic matter and on the insoluble mineral plant food elements, and helped by the dissolving action of water and the oxidating action of the air, they release enormous quantities of potash and phosphorus which have been locked up since the beginning of time. Organic matter in the ground is broken down immediately by the combined action of bac. teria and water and air, and its food is made available.

In response to the abundance of water and food, plants take on new life, make heavy growth and fill the ground with roots. All this means new organic matter, more bacterial and more chemical action, more new nitrogen from the air, and additional potash and phosphorus from the mineral soil elements. The roots supply enormous quantities of organic matter or humus. Before blasting there is poorer growth because of a scarcity of plant food and water. After blasting there is heavy plant growth because of abundant food and water, and the abundance of these things is kept up.

With proper care and after-treatment blasted soil should get more mellow as the years go by.

\section{Why Soil Should Be Blasted}

Every implement or process on a farm or in an orchard has its place, and in many instances is almost indispensable. A plow, for illustration, is a necessity. It does certain work that must be done before crops can be grown to advantage, and we would have a hard time getting along without one, or trying to substitute another implement for it. A spring-tooth harrow is not so necessary, though it too has its distinct place in agricultural operations.

The intensive deep tillage to be secured by blasting of soil has its place, no less distinctly and surely than the work of a plow and of a spring-tooth harrow. In this book it is not enough to state that the blasting of soil will help to make bigger crops of fruit, grain and vegetables. Practical readers will want to know just what effects in the soil they can expect if they do blast it. When that is known they can judge for themselves what the effect will be on trees and plants. The specific place of soil blasting in modern farming and orcharding operations therefore shall be pointed out.

Erosion. To start with one of the most familiar features, proper blasting of soil will prevent erosion-which means not only the familiar washing and gullying common in every section of the world, but the less noticed loss of the best part of the top soil through its more or less even floating away in surplus water. Blasting prevents erosion by opening up the lower soil so rain-water sinks deep as fast as it falls. Instead of sinking only to plow depth, filling the top soil within a short time, and then tearing along the surface, the water strikes no bottom within several feet. There is enough loose ground to absorb it. During the hours and days that follow all the free water is allowed to seep and filter away, but it goes gently, carrying no fine soil or plant food as baggage. 
The value of this service will be appreciated by the man who has seen his corn or potato rows almost torn out by water, or who has seen the dirt washed away from the roots of his trees. It is not unusual for otherwise fine fields to be rendered almost worthless because they have washed. Even more often it is a side or corner of a field that washes, or a spot that slopes more than the rest of the land.
These areas of land which are subject to erosion should be blasted. Blasting will do more toward preventing the trouble than any other single treatment can. 'The use of cover crops is necessary in order to maintain the conditions established by blasting. In extreme cases terracing is needed to obtain full benefit from the blasting. The deep breaking with powder is the foundation.

\section{Root Penetration. Closely associated with the prevention} of erosion from the standpoint of condition of soil, is ease of root penetration. Roots have remarkable facility in penetrating hard soils. Sometimes we even find them growing through rocks. But let no one doubt but that such growth is made at great expense of growth above ground, or of yield of fruit or other crops. When the object is to obtain yields, it pays to make root growth easy.

On page 87 we picture two trees which show a contrast between easy and impossible conditions for root penetration. The subsoil is hardpan, but under the one tree this was broken. The other tree has not succeeded during the many years of its life in penetrating the hard subsoil, with the result that the entire tree has been lifted till the crown is above the surface of the ground.

While hardpan and rock naturally are primary causes of restricted root development, any poor or dry condition of soft soil may operate to the same end. In other words, stiff clay or other soil containing no organic matter and so compacted as to be impervious to moisture will not be penetrated by roots. The reason is that they have nothing to penetrate for. There is no available plant food below the looser top-soil.

The remedy for lack of root penetration, whether of trees of any age, or of a garden or field crop, is to break up the compacted condition, let in the air and organic matter, provide free drainage and a store of moisture in capillary form. When this is done roots will develop millions of small feeders and will reach out in a manner not known before.
Wind damage to trees with shallow roots is an important factor in many places. The trees blow over easily when not well anchored. Breaking up their beds previous to planting, or even later on if not done before, will enable them to send down anchor roots that will hold the trunk and top against any ordinary wind. Many orchardists go so far as to say that firmer root anchorage prevents a certain important proportion of the usual blowing off of fruit.

The depth of root penetration is important in dry weather. When the moisture is exhausted in the upper few feet of soil, shallow-rooted trees and plants are bound to suffer, but those with roots which penetrate to where the soil is always moist have a plentiful supply. Deep rooting also is important from a plant food standpoint as mentioned further along.

Drainage. Not only swampy ground should be blasted, but ground usually dry - as a guarantee against trouble during rainy periods or during wet seasons. After the water arrives the blasting cannot be done properly. When there is an impervious laver of clay, hardpan or other material, breaking through it may let the excess water escape below. Even where the layer is too thick to break through, the level of damaging water is lowered into the under soil. It does not stand on the surface. As a rule the blast- 
ing hastens the drying of ground after rains and in the spring, owing to the freer seepage conditions established.

Blasting, however, should not displace plans for underdrains except in pasture and timber land. Rather, it should be used to help the drains by breaking up the ground between the lines. If this is done they can be laid further apart. Instances are known

where the ground was so soggy and stiff that underdrains failed to carry off the water. It would not gather to the pipes. After the area between the lines was blasted, however, the ground dried off perfectly within a few days after every soaking.

Moisture Supply. The same breaking that helps drainage increases the supply of moisture for use in dry weather. The reason is explained on pages 108 and 109. A soil woll crumbled and deeply broken will hold ten times as much water for use in dry weather. as when it is compacted. Not only that, but the moisture is distributed better and is enabled to move upward toward the surface and in all directions toward roots. To improve moisture conditions is one of the most important reasons for blasting.

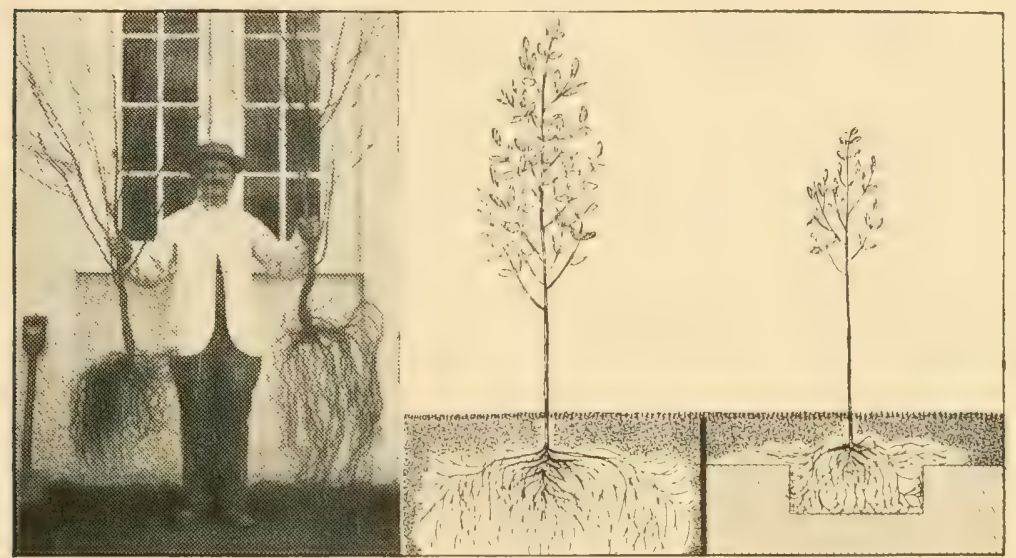

Photograph at left shows two trees, the one on your right washed out from blasted ground, the other from unblasted ground, at the New Jersey Experiment Station. Drawing shows, at left, how roots develop in blasted ground, and at right, how they are limited in spade-dug holes.

Plant Food and Fertility. Blasting helps to increase the amount of plant food that is available in a soil, to prevent its waste, and to secure distribution of available plant food throughout the entire feeding area of soil. By causing surplus water to filter and seep away slowly it prevents leaching and loss of plant food. Through various agencies it helps to release immense amounts of plant food naturally in the soil, but now in an insoluble or locked-up condition. By creating better conditions of tilth, largely on account of moisture and bacterial improvement, it prevents the reversion to insoluble forms of plant food already available or that may become so. For this reason it helps to make commercial fertilizers more effective. On blasted soil smaller applications are required to produce equal results. The deep intensive tillage helps to secure from the soil a supply of potash impossible to obtain in fertilizers to any effective extent at the present. 
Blasting, to sum up, helps to bring about the condition of soil that is necessary before plant food in it, native or commercial applied, can be maintained in an available condition. It helps to release potash and other insoluble food elements. It helps also to bring about an even distribution of plant food through the soil to a depth of several feet. When roots penetrate deeply and find good feeding conditions all the way down, the growth and production of the trees or plants is beyond comparison with any thing they do when shallow-rooted. They have a greater capacity to take up food.

Mellow Soil. The importance of a good physical condition of the soil is generally understood by everyone, and is discussed at length on later pages. Here we want to point out that the first step toward changing a harsh soil to a softer condition is to crumble it well. That is what blasting does. The granular condition then comes about naturally. And how else can the lower soil be crumbled or broken? It is the experience of everyone who blasts soil properly and follows the blasting with proper cover cropping and other care as advised here, that its cloddy nature tends to disappear and that it mellows well down into the subsoil.

Finally, blasting in all soils requiring it from a tillage standpoint usually saves considerable time, and more labor, in the actual planting of trees. It is no easy matter to dig holes for trees, and the troubles of the planter who tries to get workmen to dig them big enough are well known. When trees are to be planted right it pays to loosen the ground for shoveling with the proper subsoiling charge of powder.

Thrift and health of trees and plants mean better growth. The explanation of the bigger crops, bigger fruit, bigger trees, earlier bearing which usually follow the blasting of soil lies in the more abundant plant food, the better moisture conditions and the deeper rooting which blasting helps to bring.

\section{Factors of Modern Fertilization and Tillage}

The following brief outline of certain important factors in the relation of soil blasting to soil fertility and productiveness does not make a connected story. The subject is so large that only a series of views can be taken of it from various angles in such a brief space as this. The more or less mutually related points are discussed one by one, with the main object of showing what there is to learn rather than of exhausting present knowledge of the matter. It is easy enough to think of soil blasting as a means of breaking the ground so roots can penetrate easily, and that, unfortunately, has been a view widely taken as expressing the gist of the matter. It is hoped that these notes may give an idea of the real heart of the subject.

Objects of Tillage. Farmers of note have stated, after lifetimes of work and study, what in their opinions constitute the real objects of the tilling of the soil. One such statement is this: 
1. To secure uniform conditions all over the field so that growth will be equally good on every foot.

2. To develop and maintain a great effective depth of soil, so that there will be ample living room, an extensive feeding space, and large storage capacity for moisture and available plant foods. In other words, to increase the depth of the root zone and make of it all, to the very bottom, a sanitary living and feeding place for the roots of trees and plants and for soil organisms - adequately drained, perfectly ventilated, sufficiently warm.

3. To increase the humus of the soil through a deep and extensive incorporation of organic matter, so that there may be a strong growth of soil microorganisms and a high content of water-

\section{soluble plant food materials.}

4. To improve the tilth and maintain the best structural condition of the soil, so that the roots of trees and plants and the soil organisms may spread rapidly and widely to place themselves in closest contact with the largest amounts of food materials.

5. To control the amount, to regulate the movement, and to determine the availability of soil moisture, so that there never shall be an excess or deficiency.

6. To determine the amount, movement and availability of water-soluble plant food materials in the soil.

7. To reduce the waste and loss of plant food materials through washing, weed growth and other channels.

From Lucius L. Van Slyke, Chemist of the New York Agricultural Experiment Station, the following on the conditions needed in soil to promote plant growth, is interesting: food.

2. A physical structure which, first, combines mellowness and firmness, permitring roots to extend their growth freely; second, which enables the soil to receive water easily, distribute it promptly, hold it sufficiently well, and give it up as needed by roots; third, which permits some circulation of air, and, fourth, which makes the soil able to absorb heat and to maintain a degree of warmth suited to plant growth.

3. The presence of beneficial microorganisms and conditions favorable to their growth.

4. Absence of injurious amounts of substances poisonous to plants.

How Plants Feed. The one great fact that must be remembered is that roots can take up food from the soil only after it has been dissolved in water. The term "stone soup" has been used to characterize the solution.

Nor does the restriction end with the dissolving of the food elements. Roots of ordinary crops and trees cannot take up water in free form. That is, in water as we see it, they are helpless and may drown. Before they can use water it must be in thin films of moisture about soil particles. The hair-like feeding roots encounter the particles and even wrap their tendrils about them. 'The food solution, as the water carrying plant foods may be called, then is absorbed through the thin walls of the feeding roots.

It is to be seen from this that roots cannot feed in soil that is packed, even though such soil may have abundance of plant food in its composition. The number of particles is important as well as the presence of the right amount of water. But there are other checks, as will be explained.

Nature of Soil. Some soils naturally are more fertile than others. In studying why one produces more than another, the fact soon becomes plain that it is not so much the materials or composition that make the difference as the condition of the soil. Both the poor and the good soil may have the same composition, but in either one the elements are differently mixed or handled. 
A study of the agencies which have formed soil, and of how they work, is valuable, as it shows us how we may treat unproductive soils artificially to make them good.

Soil is composed of disintegrated, powdered and partially decomposed rocks, mixed with vegetable matter. Heat, cold, water, and growth of roots were some of the physical forces which helped to break down the original rock to its present stage as soil. Other forces, acting chemically, are air, acid, secretions of plants, and action of microorganisms, such as bacteria.

By inducing these same forces to continue their work, a soil can be broken further down, and more of the unavailable plant elements it carries can be lib- erated. The productiveness of a soil depends of course on its origin and kind, as that controls the actual amount of plant food elements it carries. But the productiveness depends to a far greater extent, in practice, on the fineness of the division of the particles, since the forces listed can act only when they can "get at" the soil in a large way. See the discussion of particles on page 103. It is for the purpose of subjecting the lower soil to the same changes that have made top-soil mellow and rich that blasting is recommended as a means of increasing the plant food supply. It lets in air and organic matter, regulates the moisture supply, and helps establish bacterial activity.

\section{Amount of Plant Foods Used by Crops. The} amount of plant food used by an average crop on one acre has been determined by some investigators to be about as follows:

\begin{tabular}{|c|c|c|c|c|}
\hline & & hosphori & & \\
\hline Crop. & Nitrogen. & Acid. & Potash & $\left(\mathrm{K}_{2} \mathrm{O}\right)$. \\
\hline Apples .................... & $16 \mathrm{lbs}$. & $16 \mathrm{lbs}$. & 19 & lbs. \\
\hline Beans . . . . . . & 75 " & 30 " & 30 & " \\
\hline Cabbage . . . . . & $198 \quad$ " & 70 & 270 & " \\
\hline$\ldots \ldots \ldots \ldots \ldots$ & 82 “ & 48 & -75 & “ \\
\hline$\ldots \ldots \ldots$ & 55 & 22 & 62 & * \\
\hline Onions $\ldots \ldots \ldots \ldots \ldots \ldots$ & 71 & 37 & 72 & “ \\
\hline 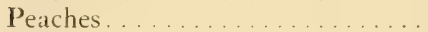 & 75 & 21 & 90 & ". \\
\hline Peas . . . . . . & 107 & 33 & 52 & “. \\
\hline Potatoes . . . . . . . . . . . & 46 & 21 & 74 & “ \\
\hline Tobacco .................... & 75 & 16 & 200 & “ \\
\hline 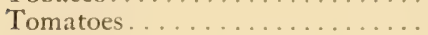 & 32 & 20 & 54 & “ \\
\hline Turnips . . . . . . . . . . . & 79 & 52 & 180 & “ \\
\hline Wheat.... & +2 & 16 & 21 & “ \\
\hline
\end{tabular}

In connection with the above table, the table of plant food elements in various crops, notably in legumes, to be found on page 110, while intended for another purpose, is also valuable here.
The application of commercial fertilizers should be based to a certain extent on the above figures, though of course the particular requirements of the soil to be fertilized will have a large bearing.

\section{Relation of Organic Matter and Plant Foods.}

By organic matter is meant anything of a vegetable nature that may be in the soil without life. Roots and stalks of plants are the most usual form, though sawdust would be so classified.

When organic matter decays, it gives off acids which act chemically on the unavailable plant food elements in a way that changes them to water-soluble forms. In this direct action organic matter is an important agency in keeping soil fertile. Bacteria "feed" on the organic matter. Bacteria and other beneficial micro-organisms 
cannot multiply without organic matter. Their enormous enriching effect is lost from the soil which does not have its full supply of decaying roots, leaves and stalks.

Organic matter is important also by reason of direct effect it has in loosening the soil, preventing it from compacting and in holding capillary moisture. A soil well supplied with organic matter will not dry out as quickly as one not well supplied.

It is not enough to have the top foot or so of soil filled with organic matter. The under soil must contain abundance of organic matter if its plant food is to be available or if a good condition of general tilth is to be maintained below plow depth. Blasting of soil opens up this lower soil to proper moisture, to air and to roots, with the result that it soon is penetrated thickly by roots which in turn die and furnish material to keep the soil in good condition and to attract other roots down below the usual depth. Potash, phosphorus and nitrogen all three are made available through the action of organic matter.

How Soils Gain Available Food. There are five chief ways in which a soil may gain in available plant food. The first and most obvious is the application of commercial fertilizer. A second, not often thought of, is the 4 to 8 pounds a year of nitrogen, besides smaller quantities of other materials, that are carried in to the soil of each acre in rain-water. Manure made from feed not grown on the land is still another source. Finally, there is the nitrogen added to the soil through the work of bacteria, of legumes and the phosphorus and potash mined by roots themselves in the subsoil.

Intensive deep tillage has a bearing on the application of commercial fertilizers, as explained on pages 120 and 121 , but a far more direct bearing on the plant food secured from the air and lower soil. When roots go deep in well broken subsoil they bring up new plant food. Such soil also gives up more and more of its native insoluble food elements through the oxidating action of air and the dissolving action of water. The upward and downward movement of moisture carries this released plant food to the roots. These things cannot happen, however, in a subsoil that is compact and impervious to moisture, or through which roots do not penetrate freely because of a lack of mellow physical condition plus the attraction of food.

\section{How Soils Lose Available Plant Food. It is not only} the plant food taken up by crops which is lost to soils. Every year some elements are lost through leaching, by changing into gas, which escapes into the air, and in other ways. If conditions in the soil are such that this loss is rapid no amount of care or fertilization will keep up the fertility.

In preventing the losses, the prime factor is fine particles, though organic matter both directly and indirectly is also of importance. When a soil is well crumbled, and is open and loose several feet down, water can neither wash away the surface soil nor leach away the plant food it dissolves. The particles absorb or pull to themselves the atoms of plant food in the water. Organic matter helps by holding larger quantities of moisture.
The deep breaking of soil first fines and opens it. Then roots penetrate it, and cause an accumulation of organic matter. As a consequence blasted soil will not lose plant food to nearly the same extent that an unblasted soil will.

Another form of loss, which consists of the reversion of available plant food to insoluble forms, is discussed in the paragraphs on Drainage, Moisture Supply and Plant Food on pages 102 and 103 and also on page 108. 
Micro-organisms including Bacteria. The importance of the minute plants and animals which live in the soil almost unknown to the average orchardist and farmer is now beginning to be rightly appreciated. Without them crops, plants and trees will not thrive, and in most places will not live long.

The most familiar bacteria are those that grow in the roots of clovers, peas and beans, and which act to cause an accumulation of nitrogen from the air on the roots. Others, however, are almost equally important. For instance, lime as ordinarily applied to the soil is not readily soluble or available for use of plants, but bacteria or other micro-organisms change it into soluble form. Native insoluble phosphorus likewise is acted on by bacteria.

It is not usually known that farm manures, ground rock, fish, tankage, green manures, and slag phosphate are not available to any large extent as applied, but are made available in the soil by the action of bacteria. Native insoluble potash is taken up by bacteria and transformed into chemical states in which roots can use it. In some instances, bacteria build plant food elements into their bodies as they grow, and then return them when the bodies decay. When bacteria are sufficiently numerous, they themselves constitute a source of organic matter.

It is only in a mellow, moist soil that bacteria will thrive however. Only after the soil has been well broken and crumbled, and has received a supply of organic matter, as well as lime if it is needed, will they take hold, multiply and spread. They require air. Too much water kills them.

They are numerous in the top-soil. The lower soil, however, is normally shut off from them because it is too compact, too uncertain and shifting in moisture supply, too lacking in vegetable matter. Blasting opens the lower soil to roots, air and proper moisture conditions, hence directly promotes bacterial development and activity.

Water in the Soil. The harmful effects of too much water are so plainly to be seen in every community that little needs to be said on the subject here.

Free water must be drained away or trees and plants will not grow. Roots cannot take up their food when free water is present, and in fact the food itself may revert to insoluble forms owing to lack of bacterial activity and to certain chemical reactions produced by the excess water. A point not always understood, however, is the line between free water and water which is useful to plants. The effects of a lack of water are equally plain, but just what happens in a soil and within plants when the moisture supply runs low is another point not universally known.

Water is necessary to plants because it furnishes two plant foods, hydrogen and oxygen, on which they feed heavily; it helps in the "digestion" of practically all other plant foods, after which it is passed in to the air in enormous amounts, in this process helping to maintain the proper temperature of the leaves, and it is one of the essentials for bacterial life and activity. Within the soil water dissolves plant food and serves as the base of the solution on which roots feed, acting as the carrier of food to the plants.

Any water in the soil in volumes like drops or larger is free water, and is harm108 ful to roots rather than beneficial.

The form in which water is useful is when it is held as thin films of moisture surrounding soil particles. The word "moisture" is a good one in this place, as it brings out the essential difference between useful and harmful forms of water. Capillarity is a force which causes water and other substances to cling to surfaces of solids. It is what makes a knife or stick or hand wet after it is dipped in water, and what makes a blotter take up ink, or a wick take up oil. Capillary moisture, then, is the moisture or dampness which clings to the surface of the particles or lumps after all the free water has drained away.

The amount of capillary water a soil will hold is determined by the amount of surface that can be covered by film. Right here is the nub of the whole matter. If a soil is compacted, as stiff clay sometimes is or as hardpan is, little surface area will be exposed. If it is broken up in a coarse manner, there will be many times more surface. In sand, where the particles are still smaller, the area exposed is perhaps a hundred times as great; in mellow loam or clay it is several hundredfold more. 
For illustration, one pumpkin big enough to fit snugly into a bushel measure will have about 800 square inches of surface. Half-inch potatoes filling the same measure will have more than 16,000 square inches of surface. The potatoes can hold 20 times as much capillary water as the pumpkin.

To bring home to ourselves the real meaning of these figures, and of the possibilities in water storage in soil under proper conditions, consider that each cubic foot of soil contains enough of surface to cover 1 to 3 acres if it could be spread out flat. The film moisture in an actual acre would cover the surface 3 to 7 inches deep.

But such capacity is possible only when the soil is in perfect tilth. The particles must not be puddled together. They must lie alone, or be held in the granules which permit space for the moisture films. Moisture capacity can easily be cut to half, to a fourth, even to a tenth of what it ought to be.

The necessity for maintaining all possible moisture against periods of dry weather requires emphasis. It is best given in the following table of the amount of water required by crops.

\begin{tabular}{|c|c|c|}
\hline $\begin{array}{l}1 \text { Ton Growth } \\
\text { (Weighed }\end{array}$ & $\begin{array}{l}\text { Requires } \\
\text { Water in }\end{array}$ & $\begin{array}{l}\text { In Inches } \\
\text { Deep Over }\end{array}$ \\
\hline When Dried). & Tons. & an Acre. \\
\hline Apples.... & 900 & 8 \\
\hline Clover hay... & 1500 & 14 \\
\hline Corn fodder. & 600 & 5 \\
\hline Oats...... & 1200 & 11 \\
\hline
\end{tabular}

These figures are subject to much variation on account of varying soils and seasons, and even of varieties. They serve to bring out the essential truths of the matter though, and to prove that deep rooting is absolutely essential. If the crop of clover hay should be 4 tons instead of one to the acre, water enough to make a layer 56 inches deep would be required. A bushel of apples weighs about 50 pcunds, and a 200-bushel crop perhaps is less than usual. To grow it takes 40 inches of water for the fruit alone, and likely 5 to 10 inches more for the leaves and new wood.

The problem therefore is simple. If 1 foot of soil will hold 3 , or 4 , or 5 inches of moisture (the inch depth is a convenient way of speaking of the amount required), how many feet of depth in the soil will be required to hold the essential 20 or 40 or 60 inches of water that the crops require. And if soil must be fine and loose to hold anything like its full capacity of capillary moisture, how can it be made so at depths below the reach of plows except by blasting followed by introduction of organic matter and other proper treatment?

As a matter of fact few soils are so fine and mellow below a few inches from the surface that they will hold their full moisture capacity, nor will blasting and subsequent workings make them do so. But it will crumble and break them up sufficiently to bring the holding capacity to half, two-thirds or even three-fourths of what it would be if perfect.

Little is said in the foregoing about capillary movement of water in soif. The same conditions of tilth which make for storage of moisture permit that moisture to move about freely - up and down, and in all directions - moving to the roots, and rising from many feet down in the ground during dry weather. In soil not open and fine, there can be little movement of water, even drainage of free water.

Air in Soil. What has been called the "first commandment of the tillage creed" is to let air into the soil. The processes that make soil fertile and plants grow cannot go on without air. The lack of air in some compacted soils is what makes them poor. Air helps to release native insoluble potash and phosphorus and helps to increase bacterial activity. Blasting introduces air in to the soil in quantities and to depths impossible of attainment by any other means.

These points serve to show what intricate details must be kept in mind. When soil is broken deeply by blasting the application of lime in proper form often will help to maintain the fine condition established, will help to liberate more insoluble plant food, and in general will make the effect of the blasting more complete. If applied to the surface at the time of blasting or before, the first heavy rain afterward will carry much of it down to the bottom of the broken soil.

By opening the soil so it can be penetrated blasting helps the distribution of lime to depths it could not possibly reach in unbroken soil. The lime is placed in touch with all the soil particles, and can act on them at once, without the usual delay of years. 


\section{EVIDENCE}

"My strawberry field is spring set, and is perhaps the best patch in Delaware. Before this land was blasted it was heavy and hard to work. Water stood on it. Since it was blasted it has been drained, and it is much lighter and more fertile."

O. A. NEWTON, Senator from Sussex County, Bridgeville, Delaware.

"It is with pleasure that I can testify to the beneficial results of Atlas Farm Powder on my farm in Hanover Co., Va. I used it last spring on a field that held the water most of the year and now it is dry and growing a fine field of wheat. Also on my garden which was wet and soggy, and as a result I had a fine garden all "summer."

IRA E. DAY, Hilldene Farms, Doswell, Va.

"My garden was in hard clay, with no top-soil. I subsoiled it with fifty-five charges of Atlas Powder, and had the finest vegetables last year of any one in the town. I also set all $\mathrm{my}$ trees, vines, etc., in blasted soil and they are doing fine. The use of Atlas Farm Powder pays handsome returns."

R. B. HENDERSON, New Albany, Miss.

"Success in farming depends to a large extent upon the maintenance of proper conditions for aëration and drainage. Otherwise it seems impossible to hold nitrogen in the soil in an available form or to bring about a suitable regulation of the water supply or of the distribution of air among the soil granules."

HAWAII AGRICULTURAL EXP. STATION, Honolulu, Bulletin 38 on "The Use of Dynamite in Farming."

"The plants on my subsoiled cotton patch reach up to my neck in most places. So far, by two pickings, I already have taken oft nearly two bales per acre. This subsoiled patch is far ahead of undynamited cotton. From it I will cut one-third to one-half bale per acre. My seven acres of sweet potatoes beat anything that is in this country for growth. They were subsoiled, and I am sure of 300 bushels per acre. My alfalfa is fine on dynamited land. I am just about to make the fourth cutting."

ARTHUR WILSON, Crosby, Texas.

"I subsoiled a piece of $\mathrm{my}$ land in March and that season it produced 102 bushels of corn to the acre. Previously it had been making 35 to 40 bushels to the acre with the same cultivation and fertilization. In November, that year, it was sowed to wheat and made 54 bushels to the acre, and immediately the wheat was harvested, the land was planted in corn and made 40 bushels to the acre. If I had time I would subsoil all my land with dynamite in the fall and let the ground hold the winter rains." A. J. PIRKLE, Buford, Ga.

"Mountain Creek, Ala., May 9-J. Sterling Moran, United States Government demonstrator at Thornsby, subsoiled land near here with dynamite to show conclusively the advantages of the subsoiling process. It was shown that last year a farmer near Brewton, Ala., doubled his yield on cotton, by blasting the subsoil. A farmer near Talladega increased his cotton crop so that he realized $\$ 45$ per acre more than he did the year before. A farmer near Marbury increased the yield of corn from twenty-five bushels the previous year to nearly one hundred bushels for 1913." NEWSPAPER DISPATCH.

"I am fully convinced of the economy and efficiency of farm blasting, and of Atlas Farm Powder. 'Too many farmers are prone to overlook the requisites of adequate root development in farm crops, and so unknowingly cut down the possible production of their land. This is particularly true in Oklahoma, where so much of the land is underlaid with stratas of heavy, tight subsoil, which tends to cement together. I have proven conclusively the great value of subsoiling with farm powder when the work is followed by the proper deep-rooted crops. The benefits extend over a long period of time. One field which would not grow enough corn to pay for harvesting was subsoiled. The first season afterwards it made a gross return of $\$ 39.40$ an acre. Adjoining land, similar in every respect but the blasting, gave only $\$ 21.55$ an acre with the aid of heavy fertilizing, while without any attention other than usual cultivation a third piece of the same land yielded five bushels of corn to the acre."

F. L. ROUNSEVELLE, County Agent, United States Dept. of Agriculture, Checotah, Okla. 


\section{EVIDENGE}

"We have used explosives considerably in digging tree holes and in the heavier clay subsoils always have found the results highly useful in underdraining and in holding moisture."

\section{T. J. W. TETIRICK, The C. V. Nurseries, Blackwell, Okla.}

"I used Atlas Farm Powder last spring in setting fruit trees, they certainly grew fine this summer, better than I expected. I also used dynamite for stumps and boulder blasting with results better than I expected. I find it good practice to have farm explosives on hand at all times."

PERCY H. SMITH, R. 3, Bound Brook, N. J.

"I thank you for the book 'Better Farming,' It is very interesting. I set 300 orange and grape fruit trees four years ago, at Largo, Fla. They were all set by sub-soil blasting. It is one of the best young groves anywhere around. I will set 300 more trees and will use your powder. I also expect to do some ditching with your powder this fall." E. J. PHELPS, New Haven, Conn.

"In the Spring four years ago I planted about 600 fruit trees using Atlas Farm Powder to blow the holes and break up the hard pan. I figure the cost of blowing the holes was much cheaper and quicker than by hand digging and the results are that nearly every tree planted is growing, having good roots and are a few feet larger than those planted without the use of Farm Powder. Would advise anyone planting trees to use it." H. B. HARDING, Breezeport, N. Y.

"It is a pleasure for me to testify to the splendid value and advantages your Farm Powder possesses in connection with the farm. I used 100 pounds in loosening up the dirt preparatory to planting an orchard and vineyard. To do this was a simple matter and the results were wonderful. I found that it enhanced the value of the vine and increased the growth of the tree to a very material extent. I am thoroughly convinced of the virtue of Farm Powder and recommend it to all farmers without hesitation." BARNEY HULET, Gowen, Okla.

"It is easy to observe from the cotton where I dynamited. The cotton grown on dynamited land has made 1775 pounds of seed cotton to the acre, and some yet to be gathered. The cotton raised on the same quality of land adjoining has made a yield of only 624 pounds to the acre. The stalks on the dynamited land are one-third taller, and the bolls are better developed and much larger. The dynamited ground had plenty of moisture all season, but the ground not dynamited, though it received the same cultivation as the dynamited ground, threw ff its forms in August."

LEE L. GALT, Ardmore, Okla.

"Last spring I set out about 250 shade and fruit trees and I used from one to one and a half sticks of $40 \%$ dynamite in each hole before planting these trees. We underwent a very severe drought during the summer, and I succeeded in saving all of the trees that I planted with the exception of about ten. The soil at this place was clay subsoil, with sand rock base, and it is my opinion that if I had not used this method of planting, I would have lost $80 \%$ of the entire number of trees planted, and the expense attached to dynamiting the holes was very nominal as compared with the results obtained. This spring I shall plant some more trees and use the same system." PRESS R. ALLEN, McAlester, Okla.

"Explosives properly used in many ways and for many purposes mean less labor, less invested capital, less time, more acreage cultivated, and an increased production per acre. . . . The use of explosives is not simply a benefit in case of hardpan, but is beneficial to all soils, and is necessary in any heavy, impervious soil. Its effect is to loosen, drain and aërate, and give additional feeding ground for the roots. It loosens up the structure of the deep material without bringing the subsoil to the surface. It fines the soil and increases the ease of root penetration. It establishes the best conditions for the storage of water, the rate and depth of percolation, increases the water capacity, and furnishes the growing plant with the right kind of water. It restores the so-called wornout soils to fertility and makes otherwise worthless acres produce record-breaking crops. The gases produced are mainly carbon dioxide, and compounds of oxygen, hydrogen and nitrogen, none of them injurious to plant growth, and most of them actually beneficial. Explosives destroy many forms of animal life, and some fungi and other undesirable forms of growth."

PROFESSOR GILBERT E. BAILEI, Uni. of S. California, Los Angeles, Bulletin 7, on "The Use of Explosives in Agriculture." 


\section{TILLAGE AND FERTILITY PRACTICES AND RULES}

In the management of orchard, field and garden soils, numerous facts should be on record close at hand for easy reference. Not all that are included here are related directly to the intensive deep tillage of soil by blasting, but all should be found useful at one time or another.

\section{GENERAL INFORMATION}

\section{NUMBER OF PLANTS, TREES OR HOLES TO THE ACRE.}

\begin{tabular}{|c|c|c|c|c|c|}
\hline Spacing. & To the Acre. & Spacing. & To the Acre. & Spacing. & To the Acre. \\
\hline $1^{\prime \prime} \times 2^{\prime \prime}$ & $3,136,320$ & $10^{\prime \prime} \times 60^{\prime \prime}$ & .. 10,454 & $13^{\prime} \times 13^{\prime}$ & $\ldots \ldots 258$ \\
\hline $1^{\prime \prime} \times 6^{\prime \prime}$ & $1,045,440$ & $12^{\prime \prime} \times 20^{\prime \prime}$ & 26,136 & $14^{\prime} \times 14^{\prime}$ & 222 \\
\hline $1^{\prime \prime} \times 12^{\prime \prime}$ & 522,720 & $15^{\prime \prime} \times 15^{\prime \prime}$ & 27,878 & $15^{\prime} \mathrm{x}$ & 193 \\
\hline $2^{\prime \prime} \times 2^{\prime \prime}$ & $1,568,160$ & $18^{\prime \prime} \times 18^{\prime \prime}$ & 19,360 & $16^{\prime} \mathrm{x}$ & 170 \\
\hline $2^{\prime \prime} \times 8^{\prime \prime}$ & 392,040 & $20^{\prime \prime} \times 20^{\prime \prime}$ & 15,681 & $17^{\prime} \mathrm{x}$ & 151 \\
\hline $2^{\prime \prime} \times 12^{\prime \prime}$ & 261,360 & $2^{\prime} \times 2^{\prime}$ & 10,890 & $18^{\prime} \mathrm{x}$ & 134 \\
\hline $3^{\prime \prime} \times 3^{\prime \prime}$ & 696,960 & $3^{\prime} \times 3^{\prime}$ & 4,840 & $20^{\prime} \mathrm{x}$ & 108 \\
\hline $3^{\prime \prime} \times 12^{\prime \prime}$ & 174,240 & $4^{\prime} \times 4^{\prime}$ & 2,722 & $24^{\prime} x$ & 75 \\
\hline $4^{\prime \prime} \times 12^{\prime \prime}$ & 130,680 & $5^{\prime} \times 5^{\prime}$ & 1,742 & $30^{\prime} \mathrm{x}$ & 48 \\
\hline $5^{\prime \prime} \times 12^{\prime \prime}$ & 104,544 & $6^{\prime} \times 6^{\prime}$ & 1,210 & $36^{\prime} \times$ & 33 \\
\hline $6^{\prime \prime} \times 12^{\prime \prime}$ & 87,120 & $7^{\prime} \times 7^{\prime}$ & 889 & $40^{\prime} \mathrm{x}$ & 27 \\
\hline $7^{\prime \prime} \times 12^{\prime \prime}$ & 74,674 & $8^{\prime} \times 8^{\prime}$ & 680 & $50^{\prime} \mathrm{x}$ & 17 \\
\hline $8^{\prime \prime} \times 12^{\prime}$ & 65,340 & $9^{\prime} \times 9^{\prime}$ & 537 & $60^{\prime} \mathrm{x}$ & 12 \\
\hline $9^{\prime \prime} \times 12^{\prime}$ & 58,080 & $10^{\prime} \times 10^{\prime}$ & 435 & $80^{\prime} \times 80$ & $\ldots$ \\
\hline${ }^{\prime \prime} \times 12^{\prime}$ & 52,272 & $11^{\prime} \times 11^{\prime}$ & 360 & $100^{\prime} \times 100^{\prime}$ & $\ldots \ldots$ \\
\hline & & $12^{\prime} \times 12^{\prime}$ & 302 & & \\
\hline
\end{tabular}

When the plants, trees or charges are located by the diagonal or staggard plan, instead of in squares, the number per acre increases about 10 per cent.

SPACING OF TREES AND PLANTS Apples.........20.20 to $40^{\prime}$ each way Apples, dwarf..... $8^{\prime}$ to $25^{\prime}$ each way Pears...........10 to $30^{\prime}$ each way Plums...........16 to $26^{\prime}$ each way Peaches.........16 to $26^{\prime}$ each way Cherries........ 16 to $26^{\prime}$ each way Apricots.........16 to $26^{\prime}$ each way Nectarines.......16 to $26^{\prime}$ each way Quinces......... $8^{\prime}$ to $14^{\prime}$ each way Figs..........2 $20^{\prime}$ to $25^{\prime}$ each way Mulberries......2.25' to $30^{\prime}$ each way Japanese Persim-

mons........25' to $30^{\prime}$ each way

Loquate..........15' to $25^{\prime}$ each way Pecans..........3 35' to $40^{\prime}$ each way Grapes.......... $8^{\prime}$ to $12^{\prime}$ each way Currants......... $4^{\prime}$ to $5^{\prime}$ each way Gooseberries....... 4' to $5^{\prime}$ each way Raspberries, biack. . $3^{\prime}$ by $6^{\prime}$

Raspberries, red.... 3 $3^{\prime}$ by $5^{\prime}$

Blackberries...... $4^{\prime}$ by $7^{\prime}$ to $6^{\prime}$ by $8^{\prime}$ Cranberries........ $1^{\prime}$ or $2^{\prime}$ apart each way
Strawberries....... 1' by $3^{\prime}$

Oranges and lem-

ons.........25' to $30^{\prime}$ each way Asparagus......... Rows $3^{\prime}$ to $4^{\prime}$ apart and $1^{\prime}$ to $2^{\prime}$ apart in row

Beans, bush.......1' in rows 2 to 3

Beans, pole.......3 to $4^{\prime}$ apart each way

Beet, early....... Drills $12^{\prime \prime}$ to $18^{\prime \prime}$ apart

Beet, late........ Dril!s $2^{\prime}$ to $3^{\prime}$ apart Cabbage, early.....16 $16^{\prime \prime}$ to $28^{\prime \prime}$ by $18^{\prime \prime}$ to $30^{\prime \prime}$

Cabbage, late......2 to $3^{\prime}$ to $2 \frac{1}{2}^{\prime}$ by $3 \frac{1}{2}^{\prime}$ Carrot............ In drills $1^{\prime}$ by $2^{\prime}$ apart

Celery........... Rows $3^{\prime}$ by $4^{\prime}$ apart and $6^{\prime \prime}$ by $9^{\prime \prime}$ apart in row

Corn, sweet....... Rows $3^{\prime}$ by $3 \frac{1}{2}$ apart, $9^{\prime \prime}$ to $2^{\prime}$ in row

Cucumber.......4.4 by $5^{\prime}$ each way

Egg-plant......... $3^{\prime}$ by $3^{\prime}$

Melons, water...... $7^{\prime}$ to $8^{\prime}$ each way

Melons, musk -..... $5^{\prime}$ to $6^{\prime}$ each way

Parsnips.......... In drills, $18^{\prime \prime}$ to $3^{\prime}$ apart 
Peas............ Early sorts, in double rows $8^{\prime \prime}$ apart

Late sorts, in single rows $2^{\prime}$ to $3^{\prime}$ apart

Potatoes........10.10 to $18^{\prime \prime}$ by $2 \frac{1}{2}^{\prime \prime}$ to $3^{\prime}$

Pumpkins........ $8^{\prime}$ to $10^{\prime}$ each way

Rhubarb......... 2' to $4^{\prime}$ by $4^{\prime}$

Squash, bush..... $3^{\prime}$ to $4^{\prime}$ by $4^{\prime}$

Squash, late...... 6. 6' to $8^{\prime}$ each way

Sweet potato..... 2. by $3^{\prime}$ to $4^{\prime}$

Tomato......... $4^{\prime}$ by $4^{\prime}$ to $5^{\prime}$

\section{SEEDS PER ACRE}

Including soiling, cover and catch crops useful when soil is blasted.

\section{Plant.}

Seed per Acre.

Alfalfa (broadcast)....20 to 25 pounds Alfalfa (drilled)........15 to 20 pounds Barley (heavy cover)... 2 to $2 \frac{1}{2}$ bushels

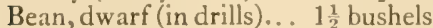

Bean, pole (in drills)....10 to 12 quarts Bean, field (small varie-

ties)............ 2 to 3 pecks

Bean, field (large varieties and for heavy

cover)........... 5 to 6 pecks

Beet............. 4 to 6 pounds

Blue-grass...........25 (pure)

Buckwheat (for heavy cover)........................

Cabbage.............. 1 pound

Celery............ 1 ounce for 2000 plants

Field-pea (small varieties)............ 3 to $3 \frac{1}{2}$ bushels

Field-pea (large varie-

ties)........... $1 \frac{1}{2}$ to 2 bushels

Grass, for lawns....... 3 to 5 bushels

Hemp (broadcast)..... $3_{2}^{1}$ to 4 pecks

Hungarian grass (hay). . 2 pecks

Johnson grass.......... $1 \frac{1}{2}$ to 1

Kafir (drills)........ 3 to 6 pounds

Kafir (for fodder)....... 10 to 12 pounds

Lupine............. 1 $1 \frac{1}{2}$ bushels

Melon, musk-(in hills).. 2 to 3 pounds

Melon, water- (in hills).. 4 to 5 pounds

Millet, pearl (for soil-

ing)...........4 4 pounds

Millet, pearl (for hay)... 8 to 10 pounds

Milo............. 5 pounds

Oats............ 2 to 3 bushels

Oats and peas........ 2 to $2 \frac{1}{2}$ bushel

Orchard grass........12 to 15 pounds

(pure) cuttings

Potato (Irish) average... 10 to 14 bushels

Potato recommended by

many for best yields. 15 to 30 bushels

Rape (broadcast)......4 to 8 pounds

Red-top (recleaned)....12 to 15 pounds
Rice............ 1 to 3 bushels Rye (late)..........6.6 to 8 pecks

Rye (forage and cover).. 3 to 4 bushels Rye-grass.......... 2 to 3 bushels Sorghum (forage, broad-

cast)........... 1 $1 \frac{1}{2}$ to 2 bushels Sorghum and peas..... 3 to 4 pecks each

Soybean (drills)....... 2 to 3 pecks

Soybean (broadcast).... 1 to $1 \frac{1}{2}$ bushels

Sunflower........... 10 to 15 pounds

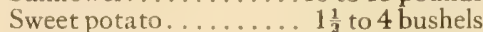

Timothy.............. 15 to 25 pounds

Timothy and clover....10 and 4 pounds

Tomato (to transplant). $\frac{1}{4}$ pound

Turnip (broadcast)..... 2 to 4 pounds

Velvet bean......... 1 to 4 pecks

Velvet, hairy (drilled)... 1 to $1 \frac{1}{2}$ bushel Vetch, hairy (broad-

cast)..........1 $1 \frac{1}{2}$ to 2 bushels

Vetch, spring.......10 pounds

Wheat........... 6 by 9 pecks

\section{TIME OF GROWTH}

Time from when seed or trees are planted till the fruit or crop is ripe. These figures become valuable when compared with the average date for last spring frosts in any locality. (Get such facts from the U. S. Weather Bureau), and with the condition of markets at various periods throughout the season. They also help in gauging the value of new varieties, when their maturing time can be learned for comparison. Good tillage and proper fertilization, especially drainage, will put land in shape for earlier planting, which, when frost permits, may increase the selling price of some crops, or permit growing earlier varieties.

Maturity.

Apple.......... 3 to 12 years

Blackberry........ 1 to 2 vears

Beans, shell......6 60 to 70 days

Beans, string. . . . . 40 to 60 days

Cabbage.................. 100 to 150 days

Corn........... 75 to 100 days

Currants........... 1 to 2 vears

Grapes. ......... 3 to 4 years

Lettuce. . . . . . . . 55 days

Muskmelons......120 to 140 days

Peach.......... 2 to 3 years

Pear........... 3 to 4 years

Plum.......... 2 to 5 years

()uince.......... 2 to 3 years

Raspberry.......... 1 to 2 years

Strawberry....... 4 to 12 months

Tomatoes................ 60 days

Turnips.........6 60 to 70 days

Oats...........110 days 
Some Nitrogen Facts. It pays to get the required supply of nitrogen from the air so far as possible, though fruit growers and farmers often are wise in applying some nitrate of soda, dried blood or manure in order to start the bacterial and other processes which gather it from the air, or to maintain them properly.

An ordinary leguminous crop derives about one-third of the nitrogen it uses from the soil, and two-thirds from the air. If it is cut the stubbles and roots usually contain as much nitrogen as the plants drew from the soil, leaving the fertility in this one respect as high as before the crop was grown. When the entire crop is turned under 50 to 150 pounds of actual nitrogen usually are gained on each acre. Soy beans, crimson clover and alsike clover are richest in nitrogen, field peas about 80 per cent. as rich and cowpeas 1 or 2 per cent. less. The money value of the nitrogen gained can be computed by comparing the number of pounds with the tables of values on page 123 .

Cover Crop Facts. The terms "cover crops," "soiling crops" and "catch crops" have been used indiscriminately by many farmers of this country, with some confusion resulting.

From the standpoint of this bookthat is, the soil blasting or deep tillage standpoint-any crop is a cover crop which fills the lower soil without delay with many roots and provides much folinge or stubble to be plowed down. The cover crop therefore primarily may or may not be planted for the purpose of improving the soil. It may or may not be a catch or soiling crop.

The purposes for which cover crops are planted are, first of all, as a source of organic matter and leavening. To this end they may be planted before the blasting is done (see page 88 ), or immediately afterward. The planting should not be delayed long after the blasting. If it is some of the effect of the blasting may be lost through puddling of the fined and loosened soil by hard rains.

In addition to being a big source of organic matter, cover crops help to prevent erosion, store up moisture and nitrogen (a valuable result in orchards, to force ripening of new wood before hard frosts), increase bacterial activity and prevent the waste of soluble plant foods of all kinds by taking them up into the roots, stalks and leaves, and holding them over winter. Leguminous crops also gather nitrogen from the air.

The crops that may be grown as cover crops are many in number and varied in nature. We shall tabulate them below in two classes:

Legumes.

Clover, red.

Clover, mammoth.

Clover, white.

Clover, alsike.

Clover, sweet.

Clover, crimson. 114
Clover, Japanese.

Alfalfa.

Cowpeas.

Field peas.

Soy-beans.

Field beans.

Velvet beans.

Horse beans.

Vetch, spring.

Vetch, hairy.

Peanuts.

Beggar-weed.

Lupine.

Lentil.

Sainfair.

The cover crop selected should be suited to the soil, to the particular purpose in view, to the climate and to the way in which it must be sowed. In respect to soil, certain crops will do well only on light, well drained types, while others will succeed even in wet, soggy ground. Some also demand a fine, mellow seed bed; others can be made to catch well on lumpy, sticky ground, or ground that is poor or run down. Where fall planting is necessary, quick, fast growth is essential, and this certain crops will give, while others will not. Some are killed by the first frost, others live over one winter, making a heavy growth in the spring, while others live two years, and a few many years. Those that live only till frost usually are the ones to plant in the spring, though many other factors enter into the matter.

If the intention is to turn down the entire grow th a different selection of ten will be wise from what should be made if hay is wanted. Green feed (the soiling system) throughout the summer demands careful selection and succession

Sorghum.

Oats.

kinds, including ragweed, wild carrot.
Kaffir.

Wheat.

Rye.

Corn.

Turnips.

Buckwheat.

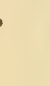

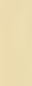


of crops, and silage something still different. Certain crops will not succeed in the North, but do well in the South. Some crops require careful planting in a well prepared, fertilized and limed seed bed, while others give satisfaction when put in with less work. Location and nature of soil determine your course.

The brief comments on individual crops in the following paragraphs are not intended to exhaust this subject. They merely aim to classify the crops so that those interested will have a basis for further study of them and for questioning proper authorities when the time comes to buy seed.

Sweet Clover is a large coarse plant which will gather nitrogen from the air. It grows fast, has heavy foliage, develops deep roots, and in general is one of the very best cover crop plants for use on blasted ground where the entire growth is to be turned down. Even where a cutting of hay is to be made it is excellent, though stock have to learn to eat it before they thrive on it as well as on alfalfa or red clover. It is a biennial.

Crimson Clover is an excellent nitrogen gatherer, and is a convenient cover crop plant on account of the way it keeps on growing late in the fall and during the early spring. It is an annual - that is, will live over one winter, then must be reseeded. It winterkills in the North. Just where it begins to fail depends on soil and elevation above sea level, and cannot be stated briefly. It is shallow-rooted, hence is not recommended for the first few crops after blasting of ground. Crimson clover is harder to seed than many other legumes. It requires a mellow seed bed. It always should be sowed in midsummer or fall, and usually is plowed down in April or May. A full crop will contribute 50 to 200 pounds of nitrogen to the soil it grows in. Even the fall growth should give 100 pounds of nitrogen. Each inch of growth of the plants, measured from the ground, is equal to a ton of ordinary manure in organic matter and nitrogen. (This same statement applies to other legumes.)

Alfalfa, a nitrogen gatherer, is hard to seed and slow to start growing, but roots very deeply and develops heavy foliage. It lives many years in mellow, well-drained soil, though two or three years will see it thin out unprofitably in soggy ground should a catch be secured there. It is valuable as a cover crop when one is to be left several years without cultivation.

Other Clovers, including red, mammoth and alsike, white, Japan and the like, sometimes are of advantage when for any reason more suitable cover crop plants will not thrive. Mammoth and alsike clovers, for instance, will grow well on ground too wet for some other legumes. White and alsike will stand more drought. Alsike and white clover, and sometimes red, often can be planted with vetch, peas or rye or wheat to advantage. All, however, start to grow slowly for cover crop purposes. Red clover is a biennial; the others mentioned in this paragraph perennial.

Field peas make excellent summer cover. In two months they often accumulate 130 pounds of nitrogen to the acre, and besides this, the roots, stalks and leaves mine or refine, and contain, 35 pounds of phosphorus and 120 pounds of potash. Field peas do well on ground too lumpy or lacking in organic matter to grow crimson clover. Warm weather is essential for their growth, hence they should be planted in the spring. They are killed by frost.

Cowpeas make big growth in short time, have deep roots, will catch and grow on poor, lumpy soil, will choke out weeds, and in general make one of the best cover crops where conditions are suitable. Some varieties are low and bushy, others tall and viney. While cowpeas usually are best suited for Southern planting, there are varieties which succeed as far north as Michigan. They of ten are sown with vetch, or with rye or oats. The first hard frost kills them, hence they must do all their growing before any freezing is due in any locality. When they can be planted in spring or early summer they make almost ideal cover, but they may be planted in mid-summer, particularly in more southerly localities.

Soy-beans are a little slower in growth than cowpeas, but are excellent. nitrogen gatherers, and when the crop is to be cut for hay are preferable on account of the finer stalks. They resemble cowpeas in almost every way, except that they are bothered more by weeds.

Vetch another good legume, will catch on poor and lumpy soil, and of ten is desirable to mix with cowpeas or oats. Its foliage is heavy though its roots do not go very deep. Frost seldom bothers it, even in the extreme North, hence 
when sown in the fall a good spring grow th may be expected. Velvet beans, on the other hand, are killed by frost, and are useful only in the South, though they make heavy growth of both roots and foliage.

Rye is a very useful plant for cover crop purposes, though it is a little too shallow-rooted for best results after blasting. Corn, kaffir and sorghum send down masses of deep-going roots, and are excellent for the purpose. The time of planting, however, often makes rye the better, since it will grow late in the fall, and again in the spring. Wheat can be used but is not as good as rye. Oats, though not deep rooted, are good, especially when used with peas. Buckwheat, sown thickly, is another good cover crop. It should have mixed with it some legume. Millet is excellent when weeds must be choked out and cowpeas for any reason are not desirable. Barley can be used as a nurse crop for some of the more tender legumes if desired. Turnips are not deep-rooted, but ac- cumulate much organic matter, with its potash, phosphorus and nitrogen, though they gather no nitrogen from the air.

In general, the non-leguminous cover crops should be used where legumes will not catch well owing to poor condition of soil, or to increase the amount of quick growth. For instance, a mixture of alsike or other clover and rye or oats or corn will make a bigger growth of organic matter to turn under than the clover alone, or will make excellent crops of hay. When it is desired to build up the fertility of a soil quickly, such a mixture, or cow peas alone, may be planted in the spring and turned down in July or August, then a second cover crop composed of rye and vetch or rye and crimson clover, can be sown for plowing down the next spring. Turnips and other such crops are advisable for cover purposes only where the soil is very poor and thin. They should be followed by legumes as soon as the soil mellows.

We recommend a liberal use of sweet clover, cowpeas or soy beans, together with corn, kaffir, sorghum and the like, to complete the work begun by blasting soil. If a crop can be sown in the spring, in anticipation of summer blasting, then turned down in August and another sown immediately, the effects will be all the better. However, regular field crops of corn or something else, followed by the fall cover crop, make good combinations.

Sowing of cover crops, it will be seen from the foregoing comments, should be done in the spring, or in late summer in time to permit good grow th before frost. The variety of plant used should be suited to the time of sowing.

One deep-rooted plant should be included in each combination. For instance, if crimson clover is sown on account of its nitrogen-gathering power, something else should have been included in the previous crop which would have dug deeper in to the subsoil.

Plowing Down of cover crops should be done at any time convenient, with a few limitations. Very heavy growth of foliage should be lightened by cutting for hay or fodder. If the ground is cold and wet, excess acidity is likely to be caused by turning down green stalks and leaves. On the other hand, dry and woody stalks decompose slowly and are less effective for the purpose intended. To turn down cover crops when the ground is hot and dry may cause the curing of the foliage instead of its decomposing. The ideal condition is when the ground is damp or wet and warm.
A little newly scattered and rotting manure turned down with the green stuff will hasten its decomposing.

Planting cover crops, to insure a good catch, requires more or less good preparation of seed bed, depending on the size of the seed that is used, and on its hardiness. Liming is essential for all legumes. If the soil lacks lime they will not grow well and may not grow at all. If the soil is very much lacking in nitrogen some should be applied in commercial form to give the plants a start. Phosphorus may be desirable in small quantities for the same purpose.

Inoculation of the seed or the ground is necessary for some legumes. Cowpeas seldom require it, though are benefited, and the same statement applies to sweet clover. Alfalfa always requires it, while field peas, alsike clover, red clover and other legumes are helped materially by inoculation.

Soil from another field that has grown the kind of plant you are going to put in is a good source of inoculating bacteria. It should be secured from 2 to 4 inches under the surface, applied in the 
evening and harrowed in immediately. The amount required is 200 to 500 pounds an acre. Direct sun will kill the bacteria. Sweet clover soil mayinoculate alfalfa successfully. Garden pea soil may inoculate field peas. Other methods are to soak the seed in water which has filtered slowly through the soil, or wet the seed in weak glue water and then sift on it the soil in a fine or powdered condition. Thorough mixing is important and the treated seed must be spread out to dry in deep shade or sown at once. Commercial cultures of bacteria are successful when applied according to the directions and with intelligence. They, however, must be fresh.

The following table gives the approximate quantities of plant food con- tained in an average crop of different plants. It must be remembered that most of this plant food is in an unavailable condition before the cover crop is sown, but it is left in an available condition after the plants are turned down and decomposed.

AMOUN'T OF PLANT FOOI) ELE MENTS IN AN AVERAGE CROP FROM ONE ACRE (IN POUNDS).

$\begin{array}{ccc}\text { Nitro- } & \begin{array}{c}\text { Phos- } \\ \text { phoric } \\ \text { Acid. }\end{array} & \text { Potash. } \\ \text { Corn (sowed)...45 } & 20 & 35 \\ \text { Beans....... } 100 & 30 & 75 \\ \text { Ragweed..... } 35 & 60 & 80 \\ \text { Turnips...... 50 } & 60 & 90\end{array}$

\section{Lime Facts. Lime is needed in soil as a corrective of acid} and other injurious conditions.

The ammonia test for need of lime consists in mixing together a large spoonful of soil, a half cup of water and a teaspoonful of ammonia water which has been diluted to one-fourth strength. If there are harmful soil acids present the mixture will turn brown in a few hours.

The litmus paper test requires strips of blue litmus paper of the best quality (get them at a drug store). Handle only with clean dry gloves or with pliers, and keep them in a large-mouthed bottle or jar with lid on. A strip can be applied directly to a ball of damp soil in the field, but this method is not very satisfactory except in the hands of an expert.

A better way is to put some litmus paper in the bottom of a water glass, then a disc of clean white blotting paper, and over' that a spoonful of soil. Pour on some water to cover the contents of the glass, cover the glass and stand aside for two hours. Another glass should be fitted with litmus paper, disc of blotting paper and water, without the soil, covered and permitted to stand. Do not disturb the contents of the glass when it is lifted to observe the result. In the glass with no soil, the blue litmus paper still should be blue; in the other glass it will be blue if the soil contains no acid, but red if acids are present. Should the glass containing no soil show red, then the test should be thrown away as useless, as the water or blotting paper apparently contains acid. A new test then can be made using different water.

It often is well to test soil with red litmus paper as well as with blue. If there is much acid, the paper will remain red; if plenty of lime is present, it will turn blue gradually.

Heavy soils that tend to puddle usually are lacking in lime and organic matter. Lime will help to mellow them. Stickiness of soil indicates a need of lime, though in most soils it is necessary to use every care when lime is applied without a corresponding amount of organic matter, that the soil is not damaged more than it is benefited.

The amount of lime to apply to the acre depends entirely on the soil. In terms of pulverized lump lime applications might be as follows: On muck and heavy clay and loam soil full of vegetable matter, particularly just after a heavy green crop is plowed down or after a heavy manuring, 1 to 2 tons to the acre may be used. On ordinary loam soils containing average amounts of stubble and roots 800 to 1500 pounds per acre is a good application. Sandy soils, particularly those that lack vegetable matter and are thin, cannot stand more than 500 to 1000 pounds per acre. These amounts may be applied once every six years.

Apply lime to the top of the ground after plowing. Be careful to get it distributed evenly. This is hard to do by' hand. A manure spreader or lime spreader should be used. 
The kind of lime to apply depends to some extent on the nature and needs of the soil, but to a much greater extent on the location of the land and the price at which the lime can be delivered to and spread over the ground.

The active or valuable element in the compound commercially known as "lime" is calcium. That form of lime is best which contains the largest percentage of calcium and at the same time delivers the calcium for the lowest cost per pound. There are differences in the solubility or what may be called availability of different forms of lime, and in their quickness of action, but since in nearly all forms the calcium is released satisfactorily when applications are proper, there is no use in the average man making a big feature of this point. The following table gives the figures of total content.

\section{CAICIUM IN DIFFERENT KINDS OF AVERAGE COMMERCIAL}

\section{LIME}

Quicklime or lump lime (calcium oxide)...... 70 Per Cent. Land plaster or gypsum (calcium sulphate)....22 Per Cent.

Ground limestone (calcium carbonate) ......4 40 Per Cent.

Water-slaked lime (calcium hyroxide)...... 54 Per Cent. Air-slaked lime....... Uncertain.

Air-slaked lime may be much like water-slaked, may be still larger in calcium content, or may be practically equivalent to ground limestone-all depending on the amount of moisture in the air and on the length of time it has been slaking. Ground limestone may be effective up to its full 40 per cent. of calcium if very finely divided, or may be less effective if coarser. Naturally all forms vary somewhat owing to the purity of the rock they are made from.

To find the equivalent effective amount of any one form of lime in another form, both may be reduced to their content of calcium, or the following equivalent may be used: An application of 100 pounds of lump lime equals 130 pounds of water-slaked lime, 180 pounds of ground limestone or 300 pounds of land plaster.

The comparative value of the differ. ent forms of lime in money is brought out strikingly in a table prepared by Van Slyke, of the New York Agricultural Experiment Station. It follows:

\section{COMPARISON OF PRICES FOR DIFFERENT CALCIUM COMPOUNDS}

When 1 ton of quicklime costs: $\$ 6$ 5 4 3
Other forms of lime should be bought for: Slaked Ground Land Lime. Stone. Plaster. $\$ 4.55 \$ 3.95 \$ \$ 1.95$ $\begin{array}{lll}3.80 & 2.80 & 1.65\end{array}$ $\begin{array}{lll}3.05 & 2.25 & 1.30\end{array}$

$\begin{array}{lll}2.30 & 1.70 \quad 1.00\end{array}$

The buyer must bear in mind that these figures must include all costs, not forgetting the cost of hauling from railroad station or wharf, and of spreading. It costs more to haul and spread 2 or 3 tons than 1 ton. The man who lives where transportation charges are low may be justified in using slaked lime or ground stone when another man living further away may not be.

\section{Manure Facts. The application of manure in the majority} of instances is made blindly, without any definite idea of the actual amounts of plant foods it carries or of its probable effect in the soil beyond the general thought that it may make crops better. There are many facts, however, on which more intelligent consideration of manure and its application to land can be based.

The composition of manure is one of them. It is sufficiently accurate to state that a ton of average mixed or cattle manure, protected from the weather, and which has lost little liquid, contains about 10 pounds of nitrogen $\left(\frac{1}{2}\right.$ of 1 per cent.), about 5 pounds of phosphoric acid ( $\frac{1}{4}$ of 1 per cent.) and 10 pounds of potash ( $\frac{1}{2}$ of 1 per cent.). Hog manure

$11 \mathcal{S}$ is not so good; horse and chicken manure are better.

Some feeds make richer manure than others. The table on the following page gives the plant food element constituents of several feeds.

If price and other factors are the same it pays to use the feed with the high manure value. 


\section{PLANT FOOD CONSTITUENTS OF VARIOUS FEEDS.}

\begin{tabular}{|c|c|c|c|c|}
\hline Feed. & $\begin{array}{c}\text { Nitrogen } \\
\text { in } \\
\text { Ton. }\end{array}$ & $\begin{array}{c}\text { Potash } \\
\text { in } \\
\text { Ton. }\end{array}$ & $\begin{array}{c}\text { Phosphoric } \\
\text { Acid in } \\
\text { Ton. }\end{array}$ & $\begin{array}{l}\text { Fertilizing value } \\
\text { from ton of feed. } \\
\text { (See table, page } \\
\text { 1 23.) }\end{array}$ \\
\hline meal & 140 lbs. & 60 lbs. & 35 lbs. & $\$ 20.40$ \\
\hline & 110 " & 36 " & 27 ، & 15.70 \\
\hline & 53 & 58 & 32 & 10.00 \\
\hline & 50 & 11 & 45 & 8.25 \\
\hline & 42 & 10 & 40 & 7.05 \\
\hline & 40 & 16 & 12 & 5.90 \\
\hline & 32 & 14 & 8 & 4.70 \\
\hline & 25 & 10 & 20 & 4.20 \\
\hline & 6 & 3 & “6 & 1.10 \\
\hline
\end{tabular}

The value of the manure produced by an animal for a year usually is more than is supposed. It varies directly with the weight of the animal. For instance, a horse, per 1000 pounds of his weight, usually produces about 150 pounds of nitrogen, 60 pounds of phosphoric acid and 140 pounds of potash. Equal quantities of the same elements in commercial fertilizers would cost about $\$ 100$ at normal prices. This value should not be overlooked when the cost of keeping horses and when fertility problems are considered. A horse will

average about 50 pounds of manure a day; a cow, about 80 pounds.

The money value of the plant food in manure averages on the same basis, about $\$ 2.50$ per ton (of manure) for horse manure, $\$ 2$ for cow and pig manure, $\$ 3$ for sheep manure and $\$ 4$ for chicken manure. These values, however, are that of manure which has not lost any of its elements through leaching or evaporation. It is probable that the average manure is not protected well enough to maintain quite so high an average.

Care of manure to prevent loss of its value is important. In addition to protecting it from the weather, it should be kept moist by throwing on water when it tends to dry out and get too warm, and it should be well compacted. If the new manure is thrown on a pile of old, the new will suffer less loss owing to the gases from below driving fresh air out of the pile above.

The use of absorbents and preservative materials is good practice in many instances. Land plaster has been used much in the past. Acid phosphate of low grade is as good as land plaster, and in addition combines with some of the plant food elements in the manure in a way that prevents their escape and makes them more readily available for roots. Plain ground rock phosphate absorbs the liquid parts of the manure, but has no chemical reaction to any of the mineral elements. Sulphuric acid sprinkled over the manure tends to prevent almost entirely any loss of nitrogen in ammonia. The amount of any of the absorbing materials to use will be about 100 pounds to the ton of manure, but should be limited by no set rule. Enough should be used to take up all the liquid manure.

Ten to 20 two-horse loads to the acre is a good application when the spreading is uniform. Twice to three times this much is profitable when other soil conditions are up to normal. It is a waste of manure or any other form of fertilizer to pile it in large amounts on a soil lacking in some one or more of the important links in the chain of fertility. We know of several farms where 100 loads to the acre often are used with big profit. The soil, however, is deeply broken and mellowed, well supplied with organic matter and lime, and is well tilled. The crops are immense. Manure is a help in building up poor soils, but farmers who use manure for that purpose must not expect immediate profit from heavy applications. The general conclusion, therefore, is that it pays to put manure lightly on thin soils, and heavily on rich soils.

To carry the same idea further, the manure should be applied to the crop which will yield the most profit. The crop that follows the application usually takes half the plant food in the manure. The other half is divided among several crops.

If the manure is applied on a lowpaying crop its greatest possible return cannot be realized. 
Fertilizer Facts. Every farmer and fruit grower is interested in commercial fertilizers. The man who blasts will do well to study the subject carefully, since intelligent selection of the particular food elements to apply, and of the form in which they are secured, will save money and will promote greater returns from the blasting and cultivation. Read pages 117 to 119.

An interesting comparison can be made of the term "ferti!'zer" with the term "clothing." To buy and use fertilizer without knowing the relation of its particular composition to the needs of the particular soil and crop is just about as sensible an action as to ask a storekeeper for clothing when it is gloves or shoes that are needed. Agriculturists should feed their soil with nitrogen, phosphorus and potash as needed, not just with "fertilizer."

The Elements. For the purpose of this book we take it for granted that readers are familiar with the fundamental facts of plant nutrition. We assume that everyone knows about or has heard of the dozen or more chemical elements that plants take from the soil and air as food, and that they understand about three of these elements sometimes run- ning low-or the soluble amount of them present in the soil getting low.

Nitrogen sometimes actually does become exhausted from the soil more or less completely. Phosphorus becomes exhausted less often, and potash, except in muck soils, seldom is lacking. Yet, as pointed out on page 100 , plants may starve to death with their roots in a veritable heap of all the elements, if the food is in a chemical condition in which it will not dissolve in water.

One of the chief results to be expected from proper blasting is the release of locked up native plant food unavailable up to that time. To hasten the natural processes which bring about such release the use of commercial plant food often is advisable, while to make good actual deficiencies is advisable always.

\section{PERCENTAGE OF THE THREE IMPORTANT PLANT FOOD ELE- MENTS IN VARIOUS COMMERCIAL MATERIALS}

$\begin{array}{ccccc}\text { Material. } & \text { Phosphoric } & \text { Phosphoric } & \text { Potash } & \text { Nitrogen, } \\ \text { Acid, Total } & \text { Acid } & \left(\mathrm{K}_{2} \mathrm{O}\right), & \text { Per } \\ \text { Per Cent. } & \text { Available } & \text { Per Cent. } & \text { Cent. }\end{array}$

Acid Phosphate..........

Ashes, Wood (unleached)..

Ashes, Wood (leached)....

Basic Slag. ................

Blood, Dried (high grade)..

Blood, Dried (low grade)..

Bone Meal...............

Bone (dissolved) ...........

Bone Black (dissolved) ....

Cotton-seed Meal..........

Cotton-seed.............

Castor Pomace. ......... .

Fish Scrap, dried.........

Garbage, City..........

Kainit..............

Meat Scraps...........

Muriate of Potash.......

Nitrate of Soda........... .

Phosphate Rock, ground...

Sulphate of Ammonia.....

Sulphate of Potash.......

Tankage.................

Tankage (concentrated)...
Tobacco Stems..........
13 to 19

1 to 2

1 to 1.5

10 to 18

3 to 5

20 to 25

15 to 17

17 to 19

1.5

6 to 8

0.1 to 1.5

-...

-..

-..

....

26 to 39

-...

…

8.5 to 14

1 to 2

0.5 to 1
12 to 16

$\begin{array}{ll}\ldots & 2 \text { to } 8 \\ \ldots & 1 \text { to } 2\end{array}$

\section{-...}

…

13 to 8

16 to 17

....

...

...

....

....

....

....

....

....

....

....

...

....

....
12 to 14.5

10 to 11

2.5 to 4.5

2 to 3

6.5 to 7.5
3 to 4
5 to 6
9.5 to 11
2 to 4

13 to 14

15 เo 16

19 to 22

48 to 52

5 to 9

11 to 12.5

2 to 3 
It will be seen from the table on the preceding page that nitrogen, potash and phosphorus can be secured from different sources. The wisdom of using one source of material in preference to another depends on the combination represented in the material in relation to the needs of your soil, on the market price per pound of the actual plant food contained, on the rate at which plant food becomes available, and on the indirect effects of the material on the soil. The details of all these characteristics make too long a story to tell here. They may be learned from the makers of fertilizers. Some materials help the soil to store and to hold capillary moisture; others mellow it, as lime does. The "filling" used in commercial fertilizers (often land plaster) may have some such effect, even if it contained no actual plant food whatever. Another point to bear in mind is that not all of the plant food in a material may be available. Some of it may remain insoluble for many years. Sometimes it is important to use materials in which the food elements are available immediately; elsewhere it may be of advantage to use materials which give up their food elements slowly, through months or years. A consideration of these factors leads directly to a study of the adaptation of fertilizers to different crops, and of tests that will tell what plant food a soil lacks.

Adaptation of Fertilizers to Crops. A deep-rooted tree should have a less quickly available fertilizer than a shallow-rooted plant. A crop which grows through a long season needs less quickly available fertilizer than one which makes its grow th in sixty to ninety days. Short and shallow roots also must be considered in connection with the necessity for having the plant food concentrated within their reach rather than distributed through several feet of soil. Crops which largely consist of green foliage, as garden crops, usually need nitrogen more than other food elements, but crops which must ripen large quantities of highly colored grain or fruit demand the other elements, especially toward the latter part of summer. Farmers and fruit growers should learn what the characteristics of the different materials are in respect to availability, and should select and use them so that the plant food they carry will be available soon or late as required.

\section{Tests to Determine What Plant Foods a Soil} Needs. It would be an easy solution of a difficult problem if a chemical analysis of a sample of soil would show what plant food elements it requires to make crops grow well. Unfortunately analysis will not show anything but the total content of each food, without giving any light on whether that content all is available, or is partly available, or is entirely insoluble and hence useless.

Pot or basket experiments will indicate what elements the soil will respond to, but to insure accurate and dependable results from them great care is necessary in controlling the moisture supply and in weighing out and applying the fertilizer materials. As a consequence the average man had better not attempt such experiments. It is too fine a job.

Field experiments on plots, on the other hand, can be made to yield practical information. They require care, of course, and often are delayed or interfered with by weather, but if conducted with intelligence and persisted in they will prove many points. They should be continued for five to ten years.

The best plan is to lay off 10 to 15 small plots where the soil is both uni. form and typical of large fields or areas within the farm or orchard. The plots should be well drained, preferably in a natural way, and should be located where they can be cared for with certainty and convenience. In size they may be anything from a rod square up to a quarter acre. Ten feet wide by 50 to 200 feet long is a popular size. Strips of unworked and unfertilized ground 2 or more feet wide should be left between the plots.

The two end or outside plots should have no fertilizer of any kind. Six of the plots should be devoted to applications of nitrate of soda, acid phosphate, muriate of potash (or some other form of potash), lime in some form, and manure, one material only to each plot. The remaining plots can be given combinations of two or more elements; one should receive nitrogen, potash and phosphorus. The amounts to apply should be in direct proportion to the usual amounts recommended per acre, but viell 
may be the maximum mentioned. As a guide, we may mention 1 to 2 pounds per square rod of nitrate of soda, and of potash material, 4 pounds of acid phosphate, 10 to 20 pounds of slaked lime and 150 pounds of manure.

The crop grown may be any that is usual in the locality. Wheat is good. A rotation should be practised, just as on land not under test.

We wish there was space to discuss the results and findings of such tests. All we can say, however, is that the greatest care is desirable not only in measuring with accuracy the actual differences in growth on different plots, but comparing the results on one plot to those on another. Any conclusions can be backed by coincident effects on two or more plots.

The results produced indirectly, as by lime in releasing insoluble potash and phosphorus, and as of the action of the deep tillage of blasting in connection with deep penetration of organic matter and lime, must be given equal attention and thought as given to the results produced directly by the food elements applied. One year's results seldom are conclusive, though they usually begin to show the main facts. The experiments should extend over several years. Wet seasons and dry seasons, or other out-of-theordinary conditions, often upset the findings, and their results should be disregarded.

Observations of field crops is another test that may help to tell what plant foods are lacking, especially when the observer knows fully the fertilizing that has been done during the past few years and is familiar with the kind of tillage and other practices carried on.

The presence of available nitrogen is denoted by bright color and deep green color in leaves, and to some extent by the size or amount of growth made. Lack of nitrogen usually causes pale green color, or yellow color, and may stunt the plants somewhat. The nitrogen may not be lacking in the soil, however, as it may merely be insoluble on account of continued cold and wet conditions, or there may not be enough moisture present to dissolve it. Too much nitrogen (rarely found) causes excess growth of stalks, leaves, at the expense of fruit or grain, or may show in soft, late-ripening fruit.

The presence of phosphorus in the soil is indicated by the plants or trees starting off to grow well, and by plump fruit or grain maturing in normal or shorter time. The lack of phosphorus usually shows up in slow growth of young plants or trees, and in slow maturing of fruit or grain.

The presence of potash in the soil is shown usually by good growth of corn, tomatoes, potatoes, and by fine flavor and texture in the fleshy part of fruits. A lack of potash usually shows itself in slimness of stalks and leaves, and in : general brittleness and weakness of stems and wood.

Because a plant food is present, however, does not mean that there may not be big profit in applying more of it. The main use of any test or observation is to point out what elements are limiting the crops, so that the limitation can be remedied, and that all links of the chain of plant foods may be made equally strong.

The Amount of Plant Foods to Apply should be just enough to bring the native soil supply up to the needs of the crop. The table on page 101 may be used as a guide to the total amount that must be within reach of the roots of trees or plants. There is no way of telling how much is available in the soil, except for the indirect knowledge that may be gained from the plot tests and in obser. vation of crops. In this connection, we will include a self-explanatory quotation from Lucius L. Van Slyke, of the
New York Experiment Station:

"The matter of soil fertilization is really more than the feeding of crops, since other conditions affect plant growth. When we apply plant food to soils, we not only place the material within reach of the growing plants, but the presence of the added material in the soil usually produces modifications of a physical, chemical and biological character in the soil itself, and these modifications influence plant growth to an extent we cannot easily measure."

\section{Fertilizer Materials and Formulae}

The expression of the percentage of nitrogen, phosphoric acid and potash in a commercial fertilizer analysis or guarantee often is made in figures only -thus: "2-8-2." The first figure usually refers to nitrogen, the second to available phosphoric acid and the third to potash. In the Southern 
States however the first figure often refers to phosphoric acid, the second to nitrogen and the last to potash. Thus, in the South the expression would be "8-2-2."

A word is advisable at this point about the chemical terms used in analysis. In spite of the fact that the actual plant foods meant are nitrogen, phosphorus and potassium, other terms for different chemical forms of the same element, such as ammonia for nitrogen, often are used, which lead to confusion and often to loss and disappointment.

The nitrogen in a fertilizer should be calculated in terms of nitrogen only, the phosphorus in terms of phosphoric acid only, and the potassium in terms of potash only. If the analysis or guaran- tee is in any other form, it should be translated in to these common terms according to the following table. Unless this is done a clear idea of the value of the fertilizer is hard to get, even by an expert.

It helps the man who is working carefully and intelligently if he knows the source of each element. It is important to know whether nitrogen comes from nitrate of soda, dried blood, cottonseed meal, or is in an ammonial form. Phosphoric acid in acid phosphateshould be stated as to percentage of water soluble and reverted. Potash may be in sulphate form or as muriate (chloride). The degree of availability and the effect on soil and crops can be estimated intelligently only when these points are known.

\section{RELATION OF CHEMICAL FORMS OF PLANT FOOD ELEMENTS}

One pound nitrogen equals

1.2 pound ammonia.

6.0 pounds nitrate of soda.

4.8 pounds sulphate of ammonia. 3.0 pounds calcium cyanamid.

One pound phosphoric acid equals ....... 0.44 pound phosphorus.

$\{2.2$ pounds "bone phosphate."

( 0.83 pound potassium.

One pound of potash $\left(\mathrm{K}_{2} \mathrm{O}\right)$ equals .........

( 1.85 pounds sulphate of potash.

The following table, largely from that excellent publication "The Farm and Garden Rule Book," is valuable as a basis of comparison with quoted market prices of fertilizers. It also may serve to help decide which one of two or more possible forms of any plant food element is the better buy. (This table is used because it was prepared before war conditions caused unprecedented rises in prices of some fertilizer materials. It should give the normal values.)

Trade values of plant food elements in raw materials and chemicals:

Nitrogen in ammonia salts and in nitrate.

Nitrogen in fine fish, meat, blood, mixed fertilizers, bone

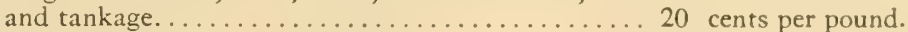

Nitrogen in coarse bone and tankage............. 15 cents per pound.

Phosphoric acid, water soluble.............. $4 \frac{1}{2}$ cents per pound.

Phosphoric acid in fish, bone, cottonseed meal and tankage. .

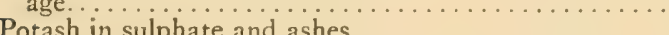

Potash in muriate. .

These figures give the market cost of the plant food elements, yet they do not signify what may be the crop value. If any one element is badly lacking, it may be cheap at ten times the prices named above. If the soil already contains enough of it it may be dear at the cost of hauling and applying it. The table, however, will serve a useful and instructive purpose if the actual market value of any fertilizer to be bought is computed by means of its figures in connection with the analysis or guarantee figures.

How to Do Your Fertilizer Figuring. Learn all possible about what foods
$3 \frac{1}{2}$ to 4 cents per pound. 5 cents per pound.

$4 \frac{1}{4}$ cents per pound.

soil and your crops require. Figure how many pounds of actual nitrogen, phosphoric acid and potash there are per ton in various materials and mixtures that can be bought. Multiply by the value per pound in the table above. Buy the food elements you need in the form in which they are cheapest and best balanced.

The war conditions have brought about marked increases in the quota. tions on certain plant food materials, notably on potash compounds. There is a limit to the price that may be paid with profit for any plant food element, 
though each farmer and fruit grower must set the limit for himself. Potash supplies in the soil may be drawn upon more largely than ever before by means of soil blasting and other tillage, and of lime applications. So long as excessively high prices prevail, more and more reliance must be placed on these other means of feeding plants.

Fertilizers That Should Not Be
Mixed. When lime (except ground limestone) is mixed with manure, there is a loss of nitrogen caused. Mixing acid phosphate and nitrate of soda also may result in loss of nitrogen, though a little lime added will prevent it. Acid phosphate also may lose some of its free phosphoric acid through the reversion to insoluble forms if mixed with lime of any kind or with wood ashes.

\section{GENERAL INFORMATION}

\section{How to Have an Experienced Man Do Your Blast-}

ing. If you do not want to do your own blasting, there are professional blasters who will do your work. If your operation is large, it will pay to get one of these men to superintend your work. He will save powder and get the work done quicker and better than an inexperienced man can do it. Write us for the name of the nearest blaster if you do not know one.

\section{Men Wanted to Learn Blasting. As the use of ex-} plosives becomes more common for subsoiling, orchard work, and ditching, as well as for removing stumps and stones, there is opportunity for hundreds of men to make money by becoming expert blasters.

Not everybody knows how to handle explosives. Some men do not care to learn. Many will pay good wages to an experienced blaster. Profitable contracts can be secured as soon as a blaster gets started. In fact, we help blasters to get such business.

If you are interested in learning agricultural blasting, we will be glad to take the matter up with you and tell you how you can get the training and experience.

How to Get Information. In the foregoing pages we have given detailed information on the action of explosives in all farm work, and have told how to prepare the charges and how to place and fire them to get the greatest results with least labor and expense.

If we have failed to make clear any points in connection with the benefits of using explosives for any purpose, or if we have not explained fully how to proceed with the work, we shall appreciate it if you will write us fully.

Tell us how many stumps or stones you have to remove, and also what are the soil conditions. If you want to make ditches, give us an idea of about how large and how long they should be and describe the soil conditions. If you are interested in subsoiling in orchard, field, garden, or lawn, give us details. After you have read this book, we would like to hear from you. Let us know whether or not you have any difficulty in any of your operations. 


\section{EVIDENCE}

"The Atlas Farm Powder that I have been getting the past few years has been used in clearing the larger stumps from 400 acres of land, and for blasting holes to plant about seven thousand pecan trees. For both purposes I have found it very satisfactory. I am especially enthusiastic in its use for tree planting."

V. G. HUMPHREY, Ocean Springs, Miss.

"We are very much pleased with the results obtained by using Atlas Farm Powder. We had about one acre of land which was covered with water most of the year, nothing at all would grow there, not even meadow grass. We dynamited this piece of land about the first of April and planted it in potatoes. At the present time they look even better than any other part of the 100 -acre field."

C. F. SEABROOK, Bridgeton, N. J.

"We used powder this spring to remove a lot of old trees about the College orchards. These trees varied from ten inches to fifteen or sixteen inches in diameter. The cost of removal was about twenty cents per tree for powder or dynamite, and about ten cents per tree for labor. The cost of removing the trees by digging varied from eighty cents to as high as two dollars per tree. Also used it to open up post holes in the rock, with marked success."

ALVIN KEYSER, Prof. of Agronomy, State Agri. College, Boulder, Colo.

"At the Garacove Farm we used a lot of Atlas Farm Powder, chiefly in tree planting, but also in stump blasting and draining of water holes. We planted more than 2200 apple trees in May, which is very late for this section, and all except one of them grew in spite of dry weather. No such success would have been possible without such soil treatment as the use of the Powder alone made possible. We blew out some big oak trees and caused the water to disappear at one very low spot in the field."

\section{GARACOVE FARM, Northeast, Md.}

"My husband and I talked about blasting stumps, but I didn't want him to do it until we got your book, 'Better Farming with Atlas Farm Powder.' We read the book together. The pictures and directions made everything so plain. The first stump we blasted came out whole, so we used a little more powder under the rest and split them up. 'This made it easy to handle them for burning. You surely are right in saying that using Atlas Farm Powder is the easy, quick and cheap way to get rid of stumps. It is so much easier than grubbing them out."

MRS. J. R. CRONISTER, Martha, Pa.

"We have been able to accomplish work by the use of explosives which otherwise never could have been done. Other work was done which, if it had not been for explosives, still would be in progress or unstarted. I know that we have made more than a mile of ditch this summer with explosives. For planting apple trees, an explosive is of a great deal of value. It saves men labor in digging holes, in clearing land, and it insures far better results in crops from the land. In blasting boulders we seldom drill, nearly always mudçap. This takes a little more dynamite, but saves more than its equivalent in time."

HORACE CHENERY, The Pastures, Belfast, Me.

"There is just one thing more I want to say about your Atlas Farm Powder, and that is its absolute safety. Like the majority of individuals, West Hatton folks had an exaggerated idea about the danger of handling explosives of this kind, and so when we finally decided to resort to blasting we employed an experienced man to come and do the work. After watching him handle the powder, it didn't take us long to realize that our ideas of the danger involved in handling Farm Powder were greatly exaggerated. We are doing our own blasting now, and we have found so many needs for powder in the every-day work about the Farm that we plan to keep a small supply on hand at all times. Seldom a week goes by that we don't have a little job about the farm where Atlas Farm Powder saves us a lot of work."

\section{F. M. REEDER, West Hatton Farm, Charles County, Md.}


Better Farming with Atlas Farit Powder

\section{A TLAS BLASTING MATERIALS MADE ESPECIALLY FOR FARM USE}

Atlas Farm Powder. This is put up in sticks $1 \frac{1}{4}$ inches in diameter by 8 inches long. Each stick weighs about $\frac{1}{2}$ pound. A 50-pound box contains 98 to 100 sticks. These sticks are packed in 25 - and 50-pound wooden boxes. See pages 5, 6, 25, 47, 66, 68 and 88 , covering work to which it is best adapted.

Atlas Powder 50 Per Cent. This is put up in sticks the same size and almost the same weight as Atlas Farm Powder. A 50 -pound box will contain from 95 to 100 sticks. See pages 5 and 6 , for purposes for which this powder is superior.

Atlas Blasting Caps. Made in two different strengths -No. 6 and No. 8. The No. 6 size is made strong enough to explode Atlas Farm Powder and Atlas Powders. All caps are copper tubes, $1 \frac{1}{2}$ to 2 inches long, open at one end. They contain an explosive sensitive to shock and heat and must be handled with the greatest care. Store them in a dry place. If caps are stored throughout the year, it is wise to buy No. 8 .

Fuse. This is put up in packages containing two 50-foot coils. Beaver Brand is right for ordinary dry and damp work. Where considerable water is encountered, Clover or Crescent Brand should be used. Keep in a dry cool place. Warm before unrolling if cold.

Electric Fuzes. An electric fuze is a specially prepared "cap" into which is fastened insulated wires, to carry an electric current. The wires come 4 to 30 feet long as ordered. Electric fuzes must be used instead of blasting caps and fuse for electric firing. They are made in the same strength as blasting caps with the same numbers. For use where charges are to be entirely under water for more than half an hour or so, get special waterproof electric fuzes. Electric fuzes are packed 25 and 50 in a box.

Atlas Electric Blasting Machine. An Atlas Electric Blasting Machine is shown on page 15. These machines are made in various sizes. The Atlas Little Giant blasting machine will fire 5 charges at once; the No. 2 U. S. standard machine, 10 charges; the No. 3 machine, 30 charges; larger sizes, up to 150 charges. See complete discussion of electric firing on page 13.

\section{Wire Needed for Electric Blasting. You will require} "Leading Wire" to connect the blasting machines with the fuze wires. This should be long enough for the blaster to stand at least 100 feet away for subsoil blasting, 300 feet away for stump blasting, and 450 feet away for stone blasting. With the Single Leading Wire you must use two wires to the charges. Duplex Leading Wire has two insulated wires bound together within another insulating coat, and is easier to handle. "Connecting Wire" is light single wire used to connect the end charges of series with Leading Wire and to connect fuze wires that are too far apart to reach each other. 


\section{General Information}

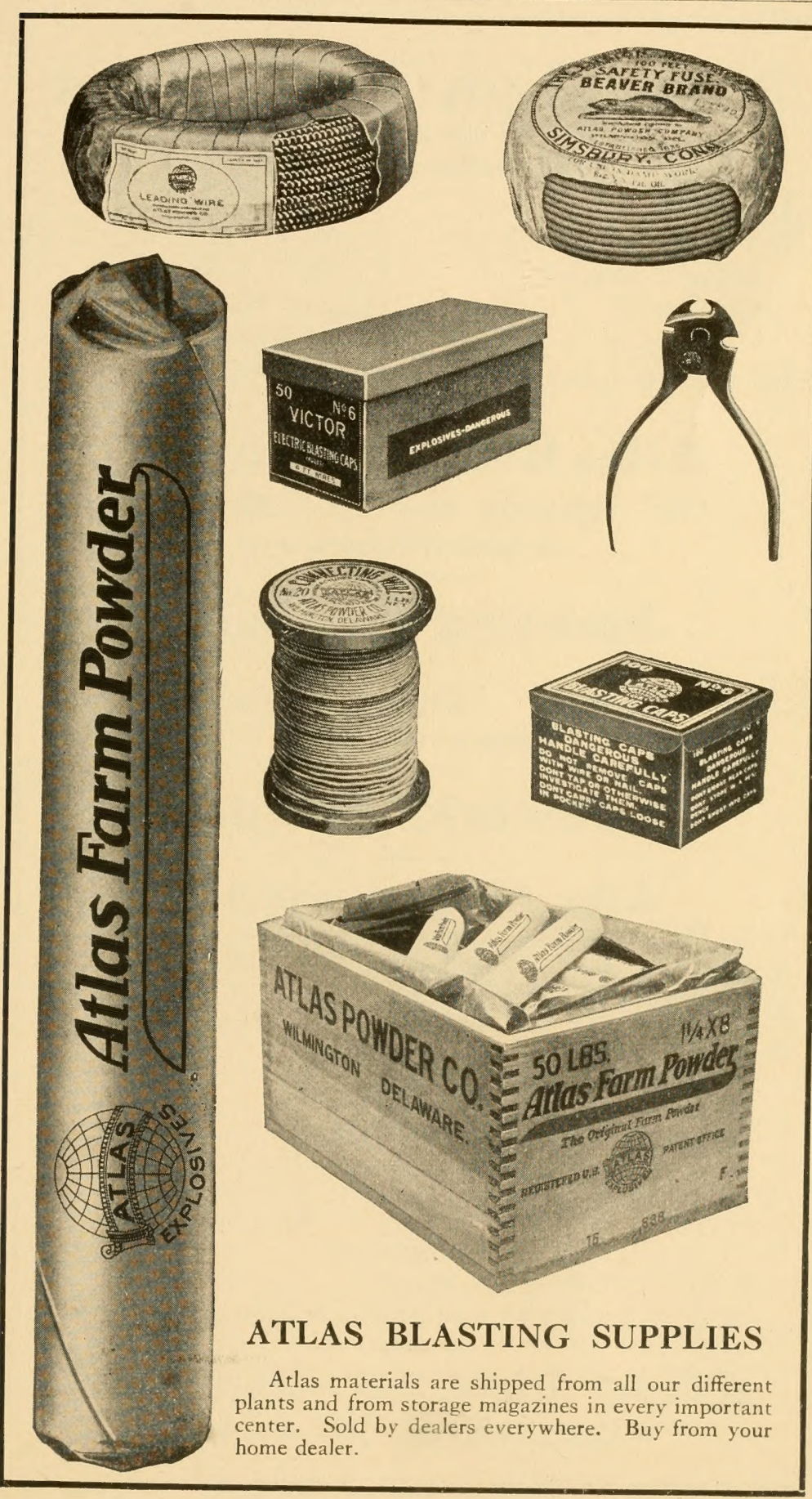




\section{Atlas High Explosives}

AN EXPLOSIVE FOR EVERY REQUIREMENT 100 Different Kinds

Dynamite

Permissible Explosives

Miners' Friend

Coalite

Vigorite

Gelatin Dynamite
Blasting Gelatin

Extra Dynamite

Oil Well Explosive

Quarry Powder

Farm Powder

Low Powders

\section{Atlas Blasting Powder} "A" Blasting and " $B$ " Blasting All Standard Granulations

\section{Sporting Powders}

for

Shotguns Rifles Revolvers

Smokeless and Black

\section{Fireworks Powder}

\section{Atlas Blasting Supplies}

Delay Electric Igniters Galvanometers Fuse

Electric Fuzes Rheostats Miners' Squibs

Delay Electric Fuzes Leading Wire Thawing Kettles

Electric Squibs Connecting Wire Tamping Bags

Blasting Machines Blasting Caps Cap Crimpers

Chemicals

Ammonium Nitrate

Sulphuric Acid

Nitric Acid
Mixed Acids

Nitrocellulose

Nitre Cake

\section{Lacquers}

Wood and Metal

Leather Cloth for Upholstering

\section{ATLAS POWDER GOMPANY WILMINGTON, DELAWARE}




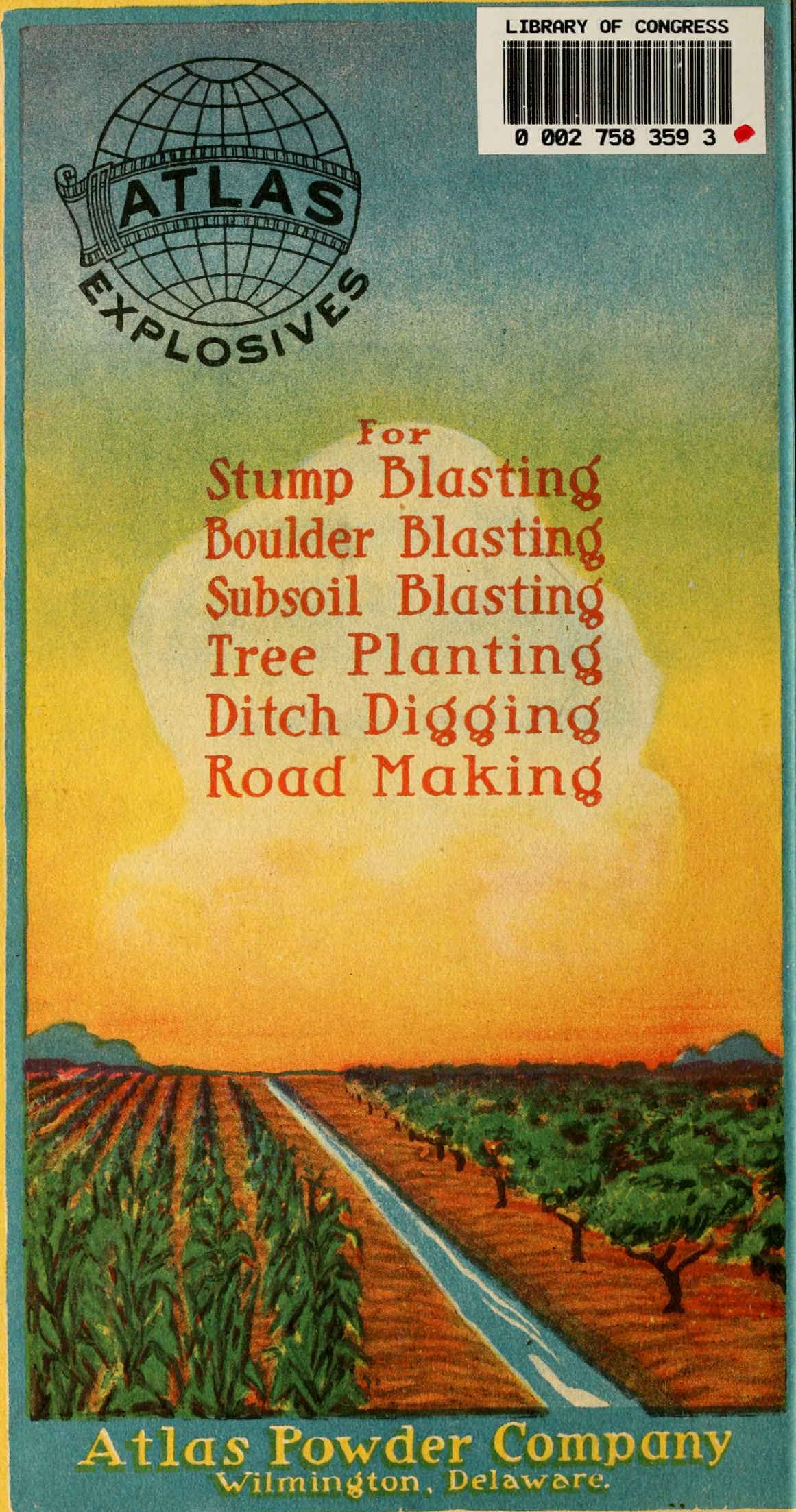

